DOC.20040827.0008

QA: QA

MDL-NBS-GS-000002 REV 02

August 2004

\title{
Geologic Framework Model (GFM2000)
}

Prepared for:

U.S. Department of Energy

Office of Civilian Radioactive Waste Management

Office of Repository Development

1551 Hillshire Drive

Las Vegas, Nevada 89134-6321

Prepared by:

Bechtel SAIC Company, LLC

1180 Town Center Drive

Las Vegas, Nevada 89144

Under Contract Number

DE-AC28-01RW12101 


\section{DISCLAIMER}

This report was prepared as an account of work sponsored by an agency of the United States Government. Neither the United States Government nor any agency thereof, nor any of their employees, nor any of their contractors, subcontractors or their employees, makes any warranty, express or implied, or assumes any legal liability or responsibility for the accuracy, completeness, or any third party's use or the results of such use of any information, apparatus, product, or process disclosed, or represents that its use would not infringe privately owned rights. Reference herein to any specific commercial product, process, or service by trade name, trademark, manufacturer, or otherwise, does not necessarily constitute or imply its endorsement, recommendation, or favoring by the United States Government or any agency thereof or its contractors or subcontractors. The views and opinions of authors expressed herein do not necessarily state or reflect those of the United States Government or any agency thereof. 
QA: QA

Geologic Framework Model (GFM2000)

MDL-NBS-GS-000002 REV 02

August 2004 


\begin{tabular}{|l|l|l|}
\hline \multirow{2}{*}{ OCRWM } & Model Signature Page/Change History & Page iii \\
\cline { 3 - 3 } & 1. Total Pages: 162 \\
\hline
\end{tabular}

\section{Type of Mathematical Model}

$\triangle$ Process Model

Abstraction Model

System Model

Describe Intended Use of Model

The intended use of the Geologic Framework Model is to provide a three-dimensional geologic representation of selected rock units and structures for the high-level radioactive waste repository and surrounding area.

3. Title

Geologic Framework Model (GFM2000)

4. DI (including Rev. No., if applicable):

MDL-NBS-GS-000002 REV 02

5. Total Appendices

Four (4)

\begin{tabular}{|c|c|c|c|}
\hline & Printed Name & Signature & Date \\
\hline 7. Originator & T.J. Vogt & & $8-26-04$ \\
\hline $\begin{array}{l}\text { 8. Independent Technical } \\
\text { Reviewer }\end{array}$ & R.W. Andrews & & $8 / 26 / 04$ \\
\hline 9. Checker & H.H. Liu & & $8 / 26 / 04$ \\
\hline 10. QER & K.O. Gilkerson & & \\
\hline 11. Responsible Manager/Lead & C.C. Lum & & $8 / 26 / 0 \%$ \\
\hline 12. Responsible Manager & M. Zhu & & $8 / 26 / 04$ \\
\hline
\end{tabular}

13. Remarks

Change History

\begin{tabular}{|l|l|}
\hline \multicolumn{1}{|c|}{ 14. Revision No. } & \multicolumn{1}{c|}{ Change History } \\
\hline REV 00 & Initial Issue \\
\hline REV 00 ICN 01 & ICN 01 text incorporates DOE comments and editorial changes \\
\hline
\end{tabular}




\begin{tabular}{|c|c|}
\hline REV 00 ICN 02 & $\begin{array}{l}\text { ICN } 02 \text { text incorporates the results of data qualification and verification activities. The } \\
\text { following data tracking numbers (DTNs) were replaced: } \\
\text { MO9811MWDGFM03.000 with MO0004Q GFMPICK.000 } \\
\text { MO9901MWDGFM31.000 filename "topography.2grd" with MO0002SPATOP00.001 } \\
\text { DTN: MO9906GPS98410.000 was verified }\end{array}$ \\
\hline REV 01 & $\begin{array}{l}\text { For REV 01, the model was revised to address possible alternative interpretation identified in } \\
\text { technical review comments of GFM3.1. A new fault was added to the model, and data from } \\
15 \text { additional boreholes were incorporated. The report incorporates a new estimation and } \\
\text { discussion of uncertainty. In addition, a new software version was used. References and } \\
\text { procedures were also updated. }\end{array}$ \\
\hline REV 01 Errata 001 & Errata in response to CR-1132 and CR-1152 \\
\hline REV 01 Errata 002 & Errata in response to CR-1138-004 \\
\hline REV 02 & $\begin{array}{l}\text { The document has been updated following the Regulatory Integration Team guidance and to } \\
\text { conform to procedural requirements of AP-SIII.10Q, Models and AP-3.15Q, Managing } \\
\text { Technical Product Inputs. } \\
\text { Side bars are not used because the changes were too extensive to use Step 5.8f)1) per AP- } \\
\text { SIII.10Q, REV 02, ICN 06. }\end{array}$ \\
\hline
\end{tabular}




\section{CONTENTS}

Page

ACRONYMS

xi

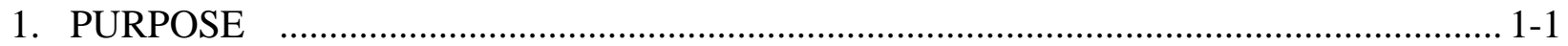

2. QUALITY ASSURANCE ............................................................................. 2-1

3. USE OF SOFTWARE ....................................................................................... $3-1$

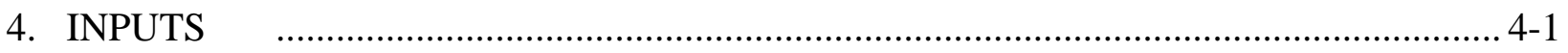

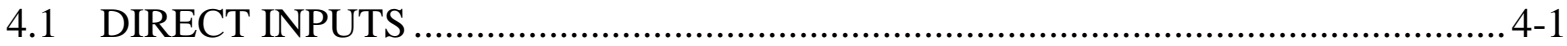

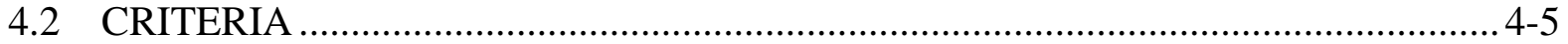

4.3 CODES , STANDARDS, AND REGULATIONS ............................................... 4-7

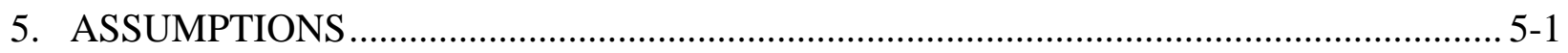

6. MODEL DISCUSSION ............................................................................................... $6-1$

6.1 IMPACTS OF CHANGES TO THE GEOLOGIC FRAMEWORK MODEL ........... 6-1

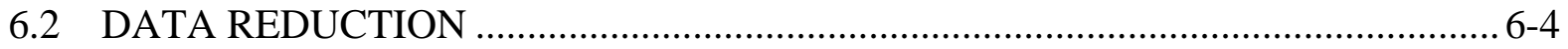

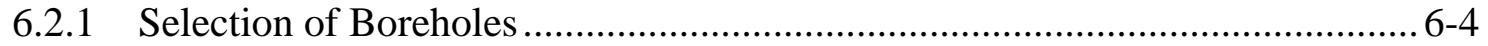

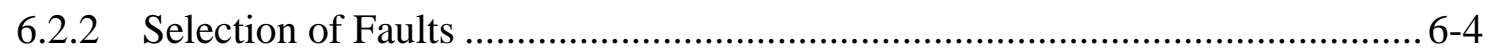

6.2.3 Selection of Topographic Data ................................................................. 6-6

6.3 MODEL DEVELOPMENT: GFM1.0 TO GFM2000 ….................................... 6-8

6.3.1 Changes From GFM1.0 to GFM2.0 …....................................................... 6-8

6.3.2 Changes From GFM2.0 to GFM3.0 ….................................................... 6-8

6.3.3 Changes From GFM3.0 to GFM3.1 …....................................................... 6-8

6.3.4 Changes From GFM3.1 to GFM2000 .................................................. 6-10

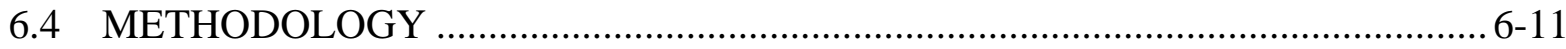

6.4.1 Geologic Framework Model Conceptual Models........................................ 6-18

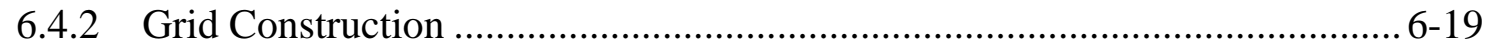

6.4.3 Interpretive Constraints.................................................................. 6-21

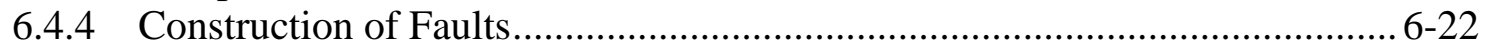

6.4.5 Construction of Reference Horizons and Model Isochores .......................... 6-22

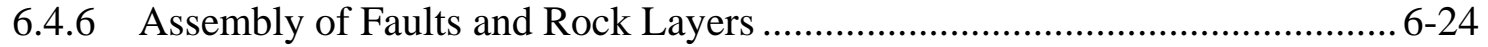

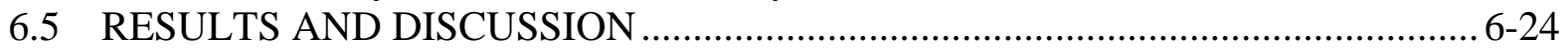

6.5.1 Interpretation of Rock Units ........................................................... 6-26

6.5.1.1 Alluvium and Post-Tiva Units.................................................. 6-26

6.5.1.2 Tiva Canyon Tuff (Tpc) ........................................................... 6-29

6.5.1.3 Paintbrush Nonwelded (PTn) Unit ..............................................6-29

6.5.1.4 Topopah Spring Tuff (Tpt) ........................................................ 6-32

6.5.1.5 Calico Hills Formation (Ta) ....................................................... 6-36

6.5.1.6 Prow Pass Tuff (Тсp) .......................................................... 6-41

6.5.1.7 Bullfrog Tuff (Tcb) ............................................................. 6-41

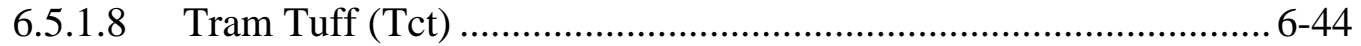

6.5.1.9 Older Tertiary Unit (Tund) .................................................. 6-47 


\section{CONTENTS (Continued)}

Page

6.5.1.10 Tertiary-Paleozoic Unconformity...........................................6-47

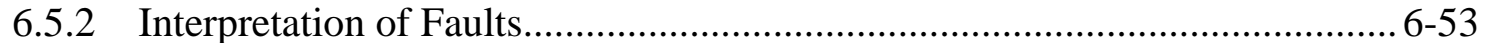

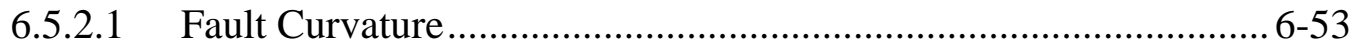

6.5.2.2 Fault Patterns ............................................................................ 6-53

6.5.2.3 Features of Individual Faults .................................................. 6-54

6.5.2.4 Faulting and Deposition ........................................................ 6-54

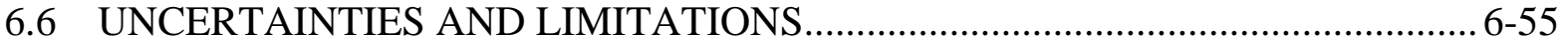

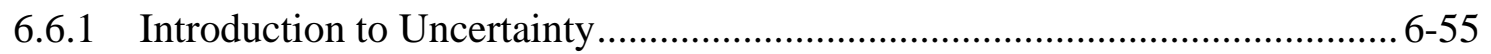

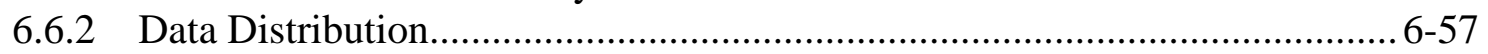

6.6.3 Uncertainty Estimates for Constrained Areas........................................... 6-58

6.6.4 Uncertainty Estimates for Less Constrained Areas ....................................... 6-63

6.6.5 Limitations and Alternative Interpretations......................................... 6-64

7. VALIDATION ....................................................................................................... $7-1$

7.1 CONFIDENCE BUILDING DURING MODEL DEVELOPMENT TO ESTABLISH SCIENTIFIC BASIS AND ACCURACY FOR INTENDED USE....... 7-1

7.2 CONFIDENCE BUILDING AFTER MODEL DEVELOPMENT TO SUPPORT THE SCIENTIFIC BASIS OF THE MODEL ….................................. 7-3

7.3 VALIDATION SUMMARY …........................................................................ 7-5

8. CONCLUSIONS....................................................................................................... 8-1

8.1 CONCLUSIONS FOR THE YUCCA MOUNTAIN REVIEW PLAN CRITERIA

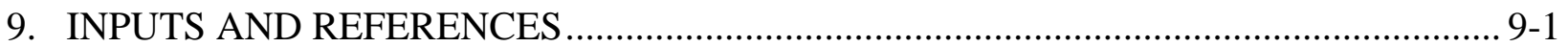

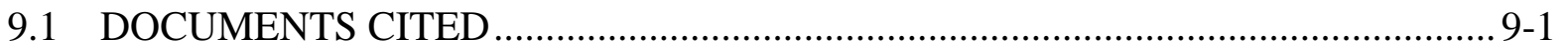

9.2 CODES, STANDARDS, REGULATIONS, AND PROCEDURES .........................9-5

9.3 SOURCE DATA, LISTED BY DATA TRACKING NUMBER ............................. 9-5

9.4 OUTPUT DATA, LISTED BY DATA TRACKING NUMBER ............................ 9-5

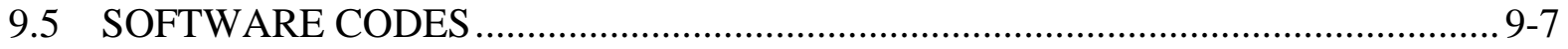

APPENDIX A JACK-KNIFE UNCERTAINTY ESTIMATION METHODOLOGY ............. A-1

APPENDIX B VALIDATED EARTHVISION MODULES ...............................................

APPENDIX C PREVIOUS MODEL VALIDATION -- CONFIDENCE BUILDING ACTIVITIES DURING DEVELOPMENT ....................................................

APPENDIX D INDEPENDENT TECHNICAL ASSESSMENT, YUCCA MOUNTAIN PROJECT, GEOLOGICAL FRAMEWORK MODEL: GFM2000

MAY 17-28, 2004. D-1 


\section{FIGURES}

1-1. Area of Integrated Site Model Showing Model Boundaries.

4-1. Locations of Measured Sections, Gravity Profiles, and Seismic Profiles......................... 4-4

6-1. Locations of Boreholes, Exploratory Studies Facility, and Cross-Block Drift................. 6-2

6-2. $\quad$ Surface Traces of Faults Modeled in Geologic Framework Model.................................. 6-3

6-3. Changes Between Geologic Framework Model Versions ................................................. 6-9

6-4. Isochore Method ........................................................................................... 6-16

6-5. Schematic Cross Section Showing the Relation of Partial Thickness to

Model Units ...................................................................................................... 6-18

6-6. Example of Interpretive Constraints …………...................................................... 6-23

6-7. Elevation Map of Basal Tiva Reference Horizon ...................................................... 6-25

6-8. Model Surficial Geology......................................................................................... 6-27

6-9. Perspective View of Model Showing Wedge of Post-Tiva Rocks in Solitario

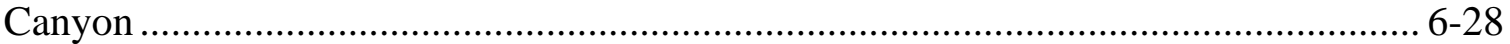

6-10. Model-Isochore Map of Alluvium .................................................................... 6-30

6-11. Model-Isochore Map of Tiva Canyon Tuff Crystal-Poor Member Vitric Zone

Densely Welded Subzone (Tpcpv3) ............................................................................ 6-31

6-12. Model-Isochore Map of Yucca Mountain Tuff (Tpy) ................................................... 6-33

6-13. Model-Isochore Map of Pah Canyon Tuff (Tpp)........................................................ 6-34

6-14. Model-Isochore Map of Paintbrush Nonwelded Unit (PTn) ........................................ 6-35

6-15. Model-Isochore Map of Topopah Spring Tuff (Tpt) .................................................... 6-37

6-16. Model-Isochore Map of Topopah Spring Tuff Crystal-Poor Member Vitric Zone

Densely Welded Subzone (Tptpv3) ........................................................................... 6-38

6-17. Model-Isochore Map of Topopah Spring Tuff Crystal-Poor Member Lithic-Rich Zone (Tptf).

6-18. Model-Isochore Map of Repository Host Horizon ............................................................ 6-40

6-19. Model-Isochore Map of Calico Hills Formation (Ta).................................................. 6-42

6-20. Model-Isochore Map of Prow Pass Tuff (Tcp) ……..................................................... 6-43

6-21. Model-Isochore Map of Bullfrog Tuff (Tcb) ……................................................... 6-45

6-22. Model-Isochore Map of Tram Tuff (Tct),.................................................................. 6-46

6-23. Elevation Map of Top of Older Tertiary Units (Tund) ................................................. 6-48

6-24. Elevation Map of Tertiary-Paleozoic Unconformity ........................................................ 6-50

6-25. Comparison of Geophysical and Geologic Framework Model Interpretations of Tertiary-Paleozoic Unconformity

6-26. Schematic Cross Section Showing the Relation Between Geologic Variability, Observed Variability, and Prediction Error .................................................................... 6-57

6-27. Maps of Constrained and Less Constrained Areas of GFM2000 for Selected Units .... 6-59

6-28. Map Showing the Study Area for Uncertainty Estimation ........................................... 6-61

A-1. Elevation Map of Top of Topopah Spring Tuff Lower Vitrophyre (Tptpv3).................. A-3

C-1. Comparison of Predicted Versus Actual Contact Depths in Borehole SD-6......................-6

C-2. Comparison of Predicted Versus Actual Contact Depths in Borehole WT-24..................-9 


\section{INTENTIONALLY LEFT BLANK}




\section{TABLES}

Page

3-1. Quality Assurance Information for Model Software ................................................ 3-1

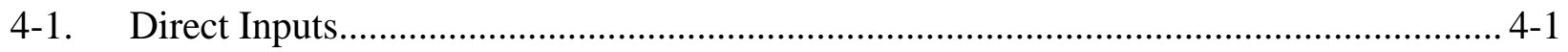

6-1. Differences Between Surveyed Borehole Collar Elevations and the USGS Digital Elevation Model Data ("DEM”) and Topographic Grid Used in the Geologic Framework Model (“Grid”), in Feet

6-2. Correlation Chart for Model Stratigraphy

6-3. Summary of Vertical Uncertainties (Elevation) Estimated by the Sequential and Cross-Correlation Jack-Knife Methods 6-62

6-4. Estimated Vertical Uncertainty (Elevation) from the Cross-Correlation Jack-Knife Method

A-1. Data Groups and Suites Used for Uncertainty Estimation........................................ A-1

A-2. $\quad$ Results of Sequential Jack-Knife Uncertainty Estimation ........................................ A-4

A-3. Statistics of Sequential Jack-Knife Uncertainty Estimation Results ............................ A-9

A-4. Summary of Sequential Jack-Knife Uncertainty Estimation Results ........................ A-10

A-5. Results of Cross-Correlation Jack-Knife Uncertainty Estimation .............................. A-11

A-6. Statistics of Cross-Correlation Jack-Knife Uncertainty Estimation Results................. A-13

A-7. Summary of Cross-Correlation Jack-Knife Uncertainty Estimation Results ............... A-13

A-8. Comparison of Sequential and Cross-Correlation Method Results ............................. A-15

C-1. Predicted Versus Actual Contacts (Tops) in Borehole SD-6 ............................................

C-2. Predicted Versus Actual Contacts (Tops) in Borehole WT-24.......................................7

C-3. Locations of Predicted and Actual Stratigraphic Contacts for the ECRB

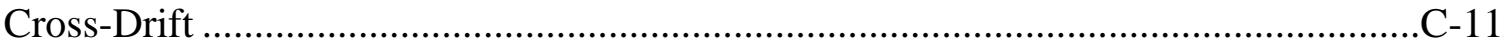

C-4. Match of GFM2000 Output Model Grids to Input Unit Contacts in Major Boreholes 


\section{INTENTIONALLY LEFT BLANK}




\section{ACRONYMS}

DTN data tracking number

ECRB Enhanced Characterization of the Repository Block

ESF Exploratory Studies Facility

GFM3.1 Geologic Framework Model, Version 3.1

GFM2000 Geologic Framework Model, Version 2000

NRC U.S. Nuclear Regulatory Commission

QA quality assurance

RHH Repository Host Horizon

STN software tracking number

SZ saturated zone

TSPA Total System Performance Assessment

TWP technical work plan

USGS U.S. Geological Survey

UZ unsaturated zone

YMRP Yucca Mountain Review Plan, Final Report

YMP Yucca Mountain Site Characterization Project 


\section{INTENTIONALLY LEFT BLANK}




\section{PURPOSE}

The purpose of this report is to document the geologic framework model, version GFM2000 with regard to input data, modeling methods, assumptions, uncertainties, limitations, and validation of the model results, and the differences between GFM2000 and previous versions. The version number of this model reflects the year during which the model was constructed. This model supersedes the previous model version, documented in Geologic Framework Model (GFM 3.1) (CRWMS M\&O 2000 [DIRS 138860]).

The geologic framework model represents a three-dimensional interpretation of the geology surrounding the location of the monitored geologic repository for spent nuclear fuel and high-level radioactive waste at Yucca Mountain. The geologic framework model encompasses and is limited to an area of 65 square miles (168 square kilometers) and a volume of 185 cubic miles (771 cubic kilometers). The boundaries of the geologic framework model (shown in Figure 1-1) were chosen to encompass the exploratory boreholes and to provide a geologic framework over the area of interest for hydrologic flow and radionuclide transport modeling through the unsaturated zone (UZ). The upper surface of the model is made up of the surface topography and the depth of the model is constrained by the inferred depth of the Tertiary-Paleozoic unconformity. The geologic framework model was constructed from geologic map and borehole data. Additional information from measured stratigraphic sections, gravity profiles, and seismic profiles was also considered.

The intended use of the geologic framework model is to provide a geologic framework over the area of interest consistent with the level of detailed needed for hydrologic flow and radionuclide transport modeling through the UZ and for repository design. The model is limited by the availability of data and relative amount of geologic complexity found in an area. The geologic framework model is inherently limited by scale and content. The grid spacing used in the geologic framework model (200 feet [61 meters]), discussed in Section 6.4.2, limits the size of features that can be resolved by the model but is appropriate for the distribution of data available and its intended use. Uncertainty and limitations are discussed in Section 6.6 and model validation is discussed in Section 7.

This revision of this report was conducted in accordance with Technical Work Plan for: The Integrated Site Model, TWP-NBS-GS-000003 REV 05 (BSC 2004 [DIRS 169635]). There are no features, events, and processes associated with this report.

The geologic framework model is one component of the integrated site model scope of work which has been developed to provide a consistent volumetric portrayal of the rock layers, rock properties, and mineralogy of the Yucca Mountain site. The integrated site model is also described in Yucca Mountain Site Description (BSC 2004 [DIRS 169734], Section 3.3.1). The integrated site model scope of work consists of three components:

- Geologic framework model

- Rock properties model

- Mineralogic model. 
Figure 1-1 shows the geographic boundaries of the geologic framework model and the other component models. Stratigraphic and structural contacts from the geologic framework model are used in the mineralogic model and rock properties model. The integrated site model scope of work merges the detailed project stratigraphy into model stratigraphic units that are most useful for the primary subsequent models and the repository design. The subsequent models include the hydrologic flow models and the radionuclide transport models.

The intended customers of the geologic framework model product output (GFM2000, DTN: MO0012MWDGFM02.002 [DIRS 153777]) are Design and Engineering, the UZ Flow and Transport Teams, and the Saturated Zone (SZ) Flow and Transport Team. Additional users include the Near Field Environment and Transport Team and the Seismic Team. The following documents, updated from the list found in Technical Work Plan for: The Integrated Site Model, TWP-NBS-GS-000003 REV 05 (BSC 2004 [DIRS 169635]), cite the geologic framework model as direct input.

Stratigraphic and structural relationships are important to Design and Engineering documents, for example: Underground Layout Configuration (BSC 2003 [DIRS 165572]). The requirements for accuracy and precision for Design and Engineering were established by users of the geologic framework model [Data Qualification Report: Borehole Stratigraphic Contacts, Revision 01 (CRWMS M\&O 2000 [DIRS 158094], p. 4)]. These requirements have been met by meeting the goals set forth within the discussion of uncertainty in Section 6.6.

The Unsaturated Flow Team's use of the geologic framework model output extends through several individual model reports primarily as defined by Development of Numerical Grids for UZ Flow and Transport Modeling (BSC 2004 [DIRS 169855], Section 4.1). The justification for use of the geologic framework model, as an appropriate input to the UZ numerical grids, is provided in BSC (2004 [DIRS 169855], Section 4.1).

The SZ model domain is a much larger area than that of the UZ model domain (Hydrogeologic Framework Model for the Saturated-Zone Site-Scale Flow and Transport Model (BSC 2004 [DIRS 170008], Figure 4-1). Consequently, the use of the geologic framework model output in the SZ demands less accuracy and precision than the geologic framework model output which is directly incorporated into BSC (2004 [DIRS 170008]). It should be noted that this report cites, as direct input, the previous version of the model GFM 3.1 (DTN: MO9901MWDGFM31.000 [DIRS 103769]). The justification for use of the geologic framework model, as an appropriate input to the SZ framework models, is provided in BSC (2004 [DIRS 170008], Section 4.1).

In addition, product output from the geologic framework model is used as direct input in the following seismic and thermal modeling analysis. Stratigraphic contacts are used in Thermal Conductivity of the Potential Repository Horizon Model Report (BSC 2004 [DIRS 169854]). 


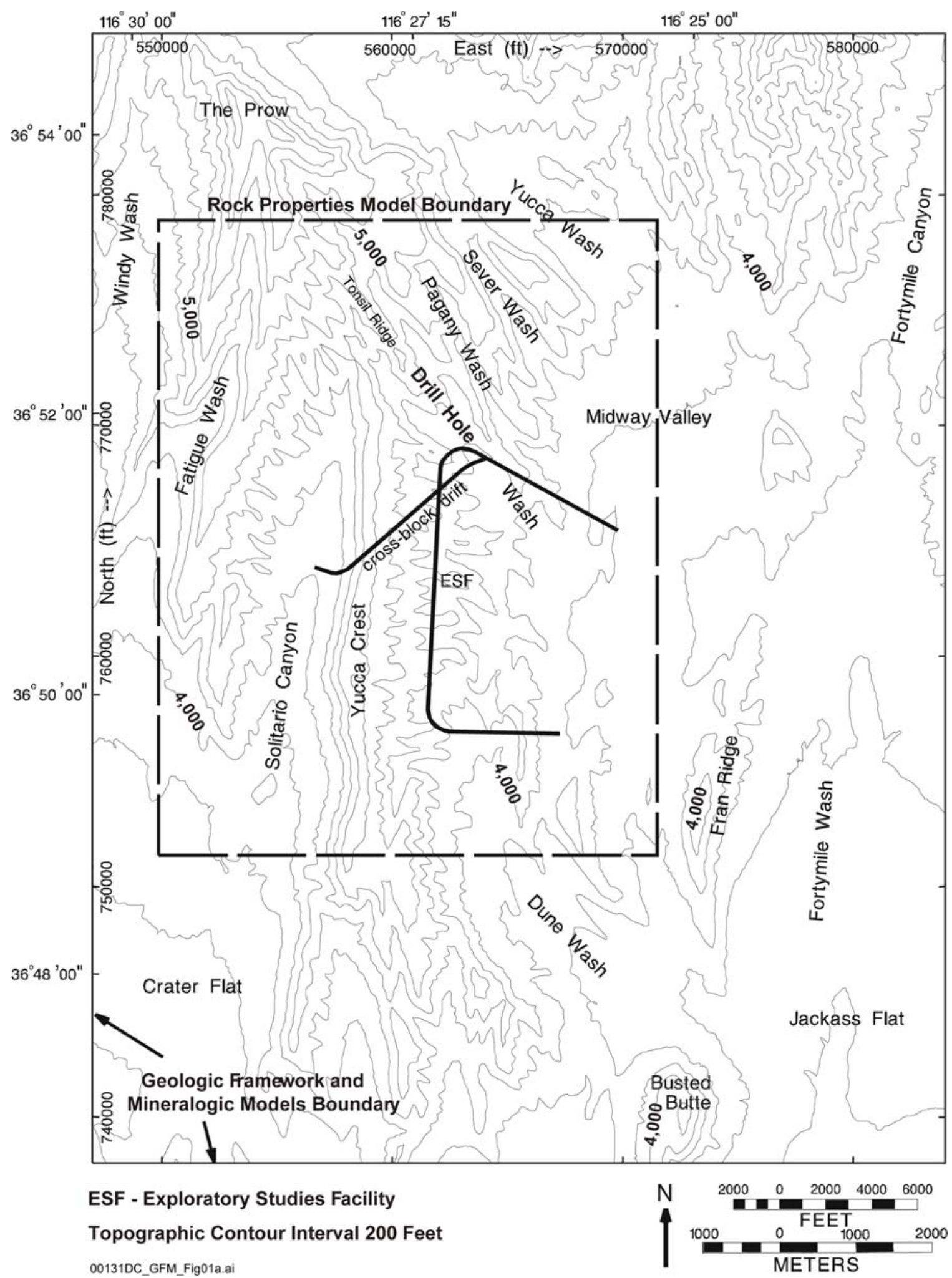

Source DTN: MO0002SPATOP00.01 Topography [DIRS 152643].

Figure 1-1. Area of Integrated Site Model Showing Model Boundaries 


\section{INTENTIONALLY LEFT BLANK}




\section{QUALITY ASSURANCE}

Development of this report and the supporting modeling activities have been determined to be subject to the Yucca Mountains Project's (YMP's) quality assurance (QA) program, as indicated in (BSC 2004 [DIRS 169635], Section 8.1, Work Package ARTM01). Approved QA procedures identified in the technical work plan (TWP) (BSC 2004 [DIRS 169635]) have been used to conduct and document the activities described in this report. The TWP also identifies the methods used to control the electronic management of data (BSC 2004 [DIRS 169635], Section 8.4, Work Package ARTM01) during the model documentation activities. The controls for the electronic management of data were implemented and are discussed in Clayton (2001 [DIRS 153713], p. 2).

This report provides a three-dimensional stratigraphic and structural representation of Yucca Mountain, including the repository block that is important to the demonstration of compliance with the postclosure performance objectives prescribed in 10 CFR 63.113 [DIRS 156605]. This report addresses part of the natural barrier Surface Topography, Soils and Bedrock, which is classified in the Q-List (BSC 2004 [DIRS 168361]) as Safety Category because it is important to waste isolation, as defined in AP-2.22Q, Classification Criteria and Maintenance of the Monitored Geologic Repository Q-List. The report contributes to the analysis and modeling data used to support performance assessment; the conclusions do not directly impact engineered features important to safety, as defined in AP-2.22Q. 


\section{INTENTIONALLY LEFT BLANK}




\section{USE OF SOFTWARE}

GFM2000 was constructed using Software Code: EARTHVISION Version 5.1 (Dynamic Graphics 2000 [DIRS 167994]), which is commercially available software designed for three-dimensional geologic modeling. The software was developed by Dynamic Graphics, Inc., Alameda, California. Use of EARTHVISION Version 5.1 is documented in EARTHVISION V5.1, Validation Test Report Rev 00 (CRWMS M\&O 2000 [DIRS 153526]). The software was obtained from Configuration Management, is appropriate for this application, and was used within the range of its validation. The software tracking number (STN) is 10174-5.1-00. Software and platform information is provided in Table 3-1. EARTHVISION Version 5.1 was used to construct the geologic framework model version GFM2000 using computer I.D. 700800 located in the YMP facility at Summerlin in Las Vegas, Nevada.

Table 3-1. Quality Assurance Information for Model Software

\begin{tabular}{|c|l|l|l|c|}
\hline Computer Type & \multicolumn{1}{|c|}{ Software Name } & \multicolumn{1}{|c|}{ Version } & $\begin{array}{c}\text { Platform/Operating } \\
\text { System }\end{array}$ & STN \\
\hline Silicon Graphics Octane & EARTHVISION & 5.1 & SGI/IRIX 6.5 & $10174-5.1-00$ \\
\hline
\end{tabular}

STN = software tracking number

Many commercial modeling software packages are available for three-dimensional modeling, but EARTHVISION software was selected because of its capability to model complex geology including large numbers of faults and to incorporate complex geostatistical models of properties conformable to geologic boundaries. The advantages of EARTHVISION software for modeling include short computation times, which allow more model refinement without compromising accuracy; true fault displacement, which creates realistic geometries; flexible and accurate three-dimensional visualization; and the ability to incorporate rock properties distributions conformable to rock layer boundaries. The software does not have limitations that affect the geologic framework model or integrated site model. There are no negative impacts of using EARTHVISION software on the geologic framework model and its users. Individual EARTHVISION modules that were validated and available for use in the construction of the geologic framework model are listed in Appendix B.

The electronic files for GFM2000 were submitted to the Technical Data Management System in EARTHVISION binary format or ASCII format, depending on the file type. Data files and instructions necessary to reconstruct GFM2000 are available in the Technical Data Management System (DTN: MO0012MWDGFM02.002 [DIRS 153777]). Reconstruction of GFM2000 or use of the EARTHVISION binary format files requires EARTHVISION software Version 5.1 or higher. Software-independent (ASCII) files containing all modeled horizons and faults are also provided in the Technical Data Management System under the same data tracking number (DTN) for input to other software used in subsequent modeling. The total size of the GFM2000 binary and ASCII files is approximately 1,200 megabytes. 


\section{INTENTIONALLY LEFT BLANK}




\section{INPUTS}

\subsection{DIRECT INPUTS}

Direct inputs for the geologic framework model include borehole lithostratigraphic contacts, maps of geology and topography, and measured stratigraphic sections (transects of stratigraphy measured at the earth's surface). In addition, interpretations from geophysical data were used to interpret structures beneath alluvium in Midway Valley. The sources of input data are listed in Table 4-1. The direct inputs for the GFM2000 are appropriate based on their qualification status, distribution within the modeled area, and because they provide parameters of interest as described in the following text.

With the exception of a fault modeled under Fortymile Wash (see Section 6.2.2), the fault traces and displacements modeled in the geologic framework model are based on the bedrock geologic map of the Yucca Mountain area (DTN: GS980608314221.002 [DIRS 107024]). A horst was interpreted from gravity and magnetic profiles beneath Midway Valley, with vertical displacements of 246 feet (75 meters) on the faults bounding the structure [Preliminary Gravity and Magnetic Models Across Midway Valley and Yucca Wash, Yucca Mountain, Nevada (Ponce and Langenheim 1994 [DIRS 102333], p. 6, Paragraph 3, Sentence 5). The supporting data are located in DTN: GS940908314212.007 [DIRS 107084]. The location of this feature was integrated with geologic map information and input to the bedrock geologic map of the Yucca Mountain area, which was then included in the geologic framework model.

Table 4-1. Direct Inputs

\begin{tabular}{|l|l|}
\hline Data Description & \multicolumn{1}{|c|}{ Data Tracking Number } \\
\hline Geologic Map & $\begin{array}{l}\text { GS980608314221.002 } \\
\text { [DIRS 107024] }\end{array}$ \\
\hline $\begin{array}{l}\text { Borehole } \\
\text { Lithostratigraphic } \\
\text { contacts }\end{array}$ & $\begin{array}{l}\text { MO0004QGFMPICK.000 } \\
\text { [DIRS 152554] }\end{array}$ \\
\hline SD-6 contacts & $\begin{array}{l}\text { SNF40060298001.001 } \\
\text { [DIRS 107372] }\end{array}$ \\
\hline $\begin{array}{l}\text { Topography } \\
\text { [DIRS 152643] }\end{array}$ \\
\hline $\begin{array}{l}\text { ESF North Ramp } \\
\text { geology }\end{array}$ & $\begin{array}{l}\text { GS960908314224.020 } \\
\text { [DIRS 106059] }\end{array}$ \\
\hline $\begin{array}{l}\text { ESF South Ramp } \\
\text { geology }\end{array}$ & $\begin{array}{l}\text { GS970808314224.016 } \\
\text { [DIRS 109061] }\end{array}$ \\
\hline $\begin{array}{l}\text { Tertiary/Paleozoic } \\
\text { unconformity }\end{array}$ & $\begin{array}{l}\text { LB980130123112.003 } \\
\text { [DIRS 109062] }\end{array}$ \\
\hline $\begin{array}{l}\text { Borehole locations, } \\
\text { collar elevations }\end{array}$ & $\begin{array}{l}\text { MO9906GPS98410.000 } \\
\text { [DIRS 109059] }\end{array}$ \\
\hline $\begin{array}{l}\text { RF\#3 contacts and } \\
\text { location }\end{array}$ & $\begin{array}{l}\text { GS931008314211.036 } \\
\text { [DIRS 150006] }\end{array}$ \\
\hline RF\#8 contacts & $\begin{array}{l}\text { GS931008314211.035 } \\
\text { [DIRS 150005] }\end{array}$ \\
\hline
\end{tabular}

\begin{tabular}{|c|c|}
\hline Data Description & Data Tracking Number \\
\hline $\begin{array}{l}\text { Measured section } \\
\text { SC\#1 }\end{array}$ & $\begin{array}{l}\text { GS940708314211.035 } \\
\text { [DIRS 109063] }\end{array}$ \\
\hline $\begin{array}{l}\text { Measured section } \\
\text { PTn\#1 }\end{array}$ & $\begin{array}{l}\text { GS950108314211.001 } \\
\text { [DIRS 109064] }\end{array}$ \\
\hline $\begin{array}{l}\text { Measured section } \\
\text { PTn\#2 }\end{array}$ & $\begin{array}{l}\text { GS950108314211.002 } \\
\text { [DIRS 109065] }\end{array}$ \\
\hline $\begin{array}{l}\text { Measured section } \\
\text { PTn\#3 }\end{array}$ & $\begin{array}{l}\text { GS950108314211.003 } \\
\text { [DIRS 109066] }\end{array}$ \\
\hline $\begin{array}{l}\text { Measured section } \\
\text { PTn\#4 }\end{array}$ & $\begin{array}{l}\text { GS950108314211.004 } \\
\text { [DIRS 109067] }\end{array}$ \\
\hline $\begin{array}{l}\text { Measured section } \\
\text { PTn\#5 }\end{array}$ & $\begin{array}{l}\text { GS950108314211.005 } \\
\text { [DIRS 109068] }\end{array}$ \\
\hline $\begin{array}{l}\text { Gravity and } \\
\text { magnetic models }\end{array}$ & $\begin{array}{l}\text { GS940908314212.007 } \\
\text { [DIRS 107084] }\end{array}$ \\
\hline $\begin{array}{l}\text { ECRB Cross-Drift } \\
\text { contacts }\end{array}$ & $\begin{array}{l}\text { GS981108314224.005 } \\
\text { [DIRS 109070] }\end{array}$ \\
\hline RF\#13 contacts & $\begin{array}{l}\text { MO0111GLOGRF13.001 } \\
\text { [DIRS 157305] }\end{array}$ \\
\hline
\end{tabular}

$\mathrm{ECRB}=$ Enhanced Characterization of the Repository Block; ESF = Exploratory Studies Facility 
All data from the 81 boreholes listed in DTN: MO0004QGFMPICK.000 [DIRS 152554] were evaluated. Sixty-seven boreholes from DTN: MO0004QGFMPICK.000 [DIRS 152554], and four others (SD-6, RF\#3, RF\#8, and RF\#13) from DTNs: SNF40060298001.001 [DIRS 107372], GS931008314211.036 [DIRS 150006], GS931008314211.035 [DIRS 150005], and MO0111GLOGRF13.001 [DIRS 157305] were used. The 14 boreholes not used from DTN: MO0004QGFMPICK.000 [DIRS 152554] contained no information that could be used due to limited penetration. Borehole collar location data (DTN: MO9906GPS98410.000 [DIRS 109059] and DTN: GS931008314211.036 [DIRS 109059]) were used to position the boreholes in the geologic framework model. No other borehole data for the modeled stratigraphic units are available in the modeled area.

Data from the Exploratory Studies Facility (ESF) (DTN: GS960908314224.020 [DIRS 106059]; GS970808314224.016 [DIRS 109061]) were used to constrain the elevations of the horizons in the geologic framework model.

Data from six measured stratigraphic sections have been incorporated into GFM2000 (Figure 4-1). Measured section PTn\#1 (DTN: GS950108314211.001 [DIRS 109064]) is located on the south face of Yucca Wash, north of the center of the ESF. Sections PTn\#2-5 and SC\#1 (DTN: GS950108314211.002 [DIRS 109065], DTN: GS950108314211.003 [DIRS 109066], DTN: GS950108314211.004 [DIRS 109067], DTN: GS950108314211.005 [DIRS 109068],

DTN: GS940708314211.035 [DIRS 109063]) are located on the Solitario Canyon face at Yucca Mountain, west of the ESF. The location and nature of this cross section information complimented other available data.

A group of 44 measured sections [Pre-1992 Measured Sections In the Vicinity of Yucca Mountain, Nevada (Spengler and Kornreich 2000 [DIRS 153782])] are located primarily in and north of Yucca Wash (Figure 4-1). These data were not used as input to the model for two primary reasons. First, the data are not needed due to their location away from the repository area and their partial redundancy with the revised bedrock geologic map (DTN: GS980608314221.002 [DIRS 107024]), which provides better areal coverage. Second, they are located in an area of rapid lithologic change, and most cannot be confidently correlated to the borehole data.

Because they cannot be confidently correlated to borehole data, using the 44 measured sections would add an unacceptable level of uncertainty to the model when compared to the value added. Because the measured sections are located away from the repository area and are in part redundant with the geologic map, they do not affect the critical characteristics or results of the geologic framework model, nor are the data directly relied upon to address safety and waste isolation issues. For these reasons, the 44 measured sections were not used in the geologic framework model.

For data to be used as input to a geospatial model, the data must include location in space (x-y coordinates and elevation), three-dimensional geometry, and identity of faults and stratigraphic units, which is not generally provided by the data obtainable from surface geophysical methods at Yucca Mountain because of the complex geologic setting. In general, although gravity, aeromagnetic, and seismic reflection and refraction data are available, they do 
not provide sufficient spatial information to be used as direct model input. These data are useful elsewhere in site characterization, including in the development of tectonic models. A summary of these data is presented in Major Results of Geophysical Investigations at Yucca Mountain and Vicinity, Southern Nevada (Oliver et al. 1995 [DIRS 106447]).

The seismic reflection method is also limited in its ability to provide spatially located model input data because of the inherent complexity and heterogeneity of rock properties in the volcanic rocks at Yucca Mountain. Seismic reflection profiles ["Implications of Seismic Reflection and Potential Field Geophysical Data on the Structural Framework of the Yucca Mountain-Crater Flat Region, Nevada,” (Brocher et al. 1998 [DIRS 100022], pp. 947 to 971)] were examined qualitatively to formulate three-dimensional fault geometries and interpret tilted strata; that is, they provide information on the orientations of faults and strata but not precise depths or identifications of reflections. The qualitative information is valuable to constructing the geologic framework model because it provides guidance for two-dimensional subsurface geometries that are not available from other sources.

Two potential sources of topographic data in the model area were evaluated for use in GFM2000. As discussed in Section 6.2.3, the topographic data from DTN: MO0002SPATOP00.001 [DIRS 152643] were used in the GFM2000 as the topographic surface of the model.

The depth to the top of Paleozoic strata (the Tertiary/Paleozoic unconformity) in the geologic framework model was obtained from a gravity inversion study (DTN: LB980130123112.003 [DIRS 109062]). Because the gravity data cannot resolve displacements on individual faults at depth, this surface had to be modified for incorporation into the geologic framework model to portray vertical displacement along the faults modeled in the geologic framework model. The modified surface has the same basic shape as the original, but is faulted to conform to the rest of the stratigraphic package modeled in the geologic framework model. This modification was necessary to produce reasonable results in the geologic framework model and would have only positive impact on the geologic framework model and its users. 


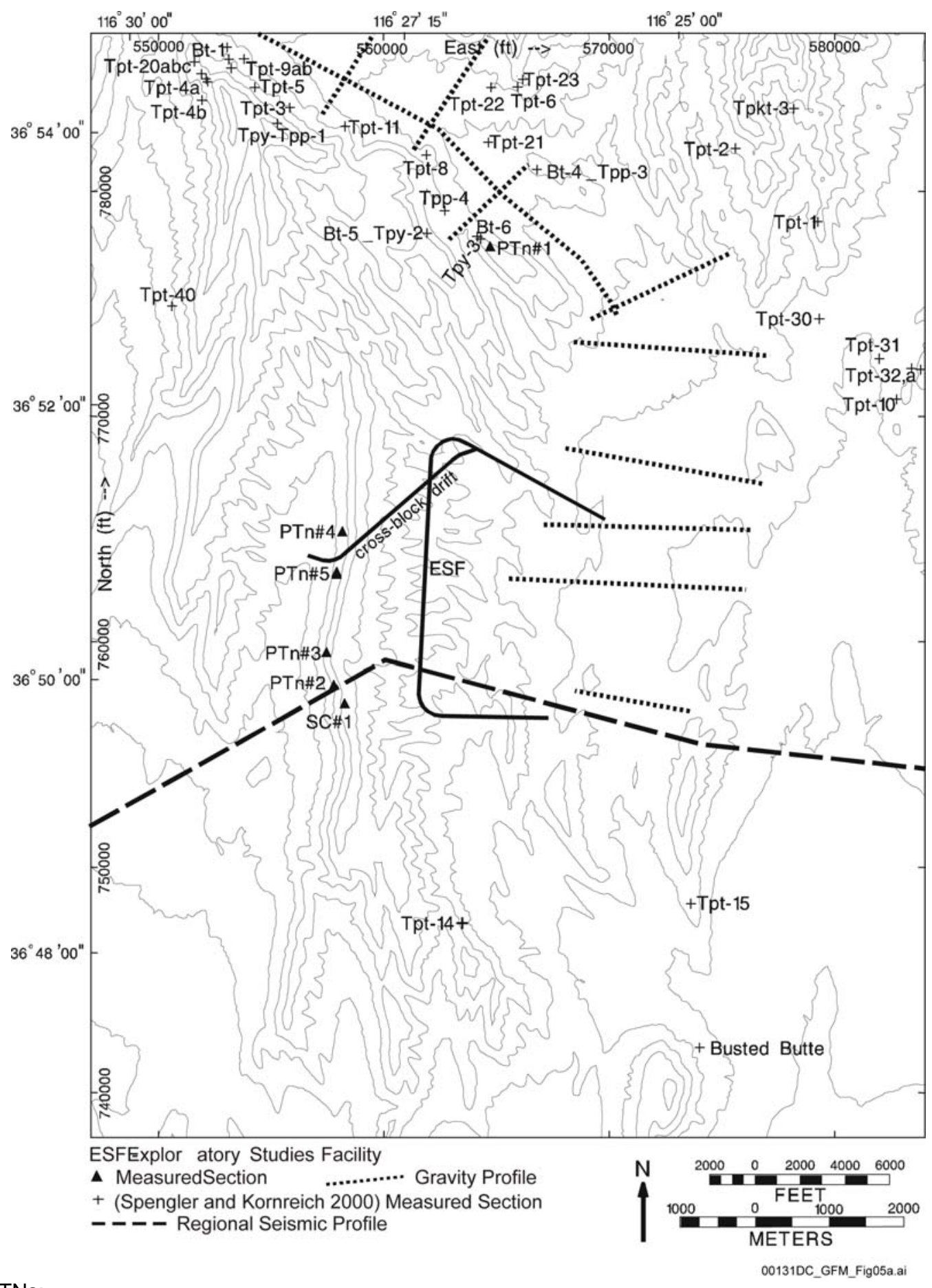

Source DTNs:

GS940708314211.035 Measured section SC\#1 [DIRS 109063]

GS950108314211.005 Measured section PTn\#5 [DIRS 109068] GS950108314211.001 Measured section PTn\#1 [DIRS 109064] GS950108314211.002 Measured section PTn\#2 [DIRS 109065] MO0002SPATOP00.001 Topography [DIRS 152643] GS940908314212.007 Gravity and magnetic models [DIRS 107084]

GS950108314211.003 Measured section PTn\# [DIRS 109066] GS960908314224.020 ESF North Ramp [DIRS 106059] GS950108314211.004 Measured section PTn\#4 [DIRS 109067] GS970808314224.016 ESF South Ramp [DIRS 109061]

Figure 4-1. Locations of Measured Sections, Gravity Profiles, and Seismic Profiles 


\subsection{CRITERIA}

The acceptance criteria that will be used by the U.S. Nuclear Regulatory Commission (NRC), to determine whether the technical requirements, have been met and are identified in the Yucca Mountain Review Plan, Final Report (YMRP) (YMRP; NRC 2003 [DIRS 163274]). An evaluation of acceptance criteria against the use of the information in this model showed that criteria other than those discussed in the TWP should be addressed. The identification of the technical users and their specific use of the product output, rather than the intended use of the product output, was basis for this re-examination of the acceptance criteria. Section 1.5.3 of the YMRP does not apply by its terms (i.e., description of site characterization). Section 2.1.1.1, of the YMRP, Acceptance Criterion 1 (1), does not apply because it refers to adequacy of the description of the site location; and 5 (1) does not apply because it pertains to preclosure safety analysis. Selected portions of Sections 2.2.3.6.3, 2.2.3.7.3, 2.2.3.8.3, and 2.2.3.9.3 apply to the extent that site geology affects flow and radionuclide transport. This document is intended to address the following YMRP Acceptance Criteria:

\subsection{Flow Paths in the Unsaturated Zone}

Acceptance Criterion 1: System Description and Model Integration Are Adequate.

(2) The aspects of geology, hydrology, geochemistry, physical phenomena, and couplings that may affect flow paths in the unsaturated zone are adequately considered. Conditions and assumptions in the abstraction of flow paths in the unsaturated zone are readily identified and consistent with the body of data presented in the description;

Acceptance Criterion 2: Data Are Sufficient for Model Justification.

(2) The data on the geology, hydrology, and geochemistry of the unsaturated zone, are collected using acceptable techniques;

\subsection{Radionuclide Transport in the Unsaturated Zone}

Acceptance Criterion 1: System Description and Model Integration Are Adequate.

(2) The description of the aspects of hydrology, geology, geochemistry, design features, physical phenomena, and couplings, that may affect radionuclide transport in the unsaturated zone, is adequate. For example, the description includes changes in transport properties in the unsaturated zone, from water-rock interaction. Conditions and assumptions in the total system performance assessment abstraction of radionuclide transport in the unsaturated zone are readily identified, and consistent with the body of data presented in the description;

Acceptance Criterion 2: Data Are Sufficient for Model Justification.

(3) Data on the geology, hydrology, and geochemistry of the unsaturated zone, including the influence of structural features, fracture distributions, fracture 
properties, and stratigraphy, used in the total system performance assessment abstraction are based on appropriate techniques. These techniques may include laboratory experiments, site-specific field measurements, natural analogue research, and process-level modeling studies. As appropriate, sensitivity or uncertainty analyses, used to support the U.S. Department of Energy total system performance assessment abstraction, are adequate to determine the possible need for additional data.

\subsection{Flow Paths in the Saturated Zone}

Acceptance Criterion 1: System Description and Model Integration Are Adequate.

(2) The description of the aspects of hydrology, geology, geochemistry, design features, physical phenomena, and couplings, that may affect flow paths in the saturated zone, is adequate. Conditions and assumptions in the abstraction of flow paths in the saturated zone are readily identified, and consistent with the body of data presented in the description;

Acceptance Criterion 2: Data Are Sufficient for Model Justification.

(3) Data on the geology, hydrology, and geochemistry of the saturated zone used in the total system performance assessment abstraction are based on appropriate techniques. These techniques may include laboratory experiments, site-specific field measurements, natural analogue research, and process-level modeling studies. As appropriate, sensitivity or uncertainty analyses, used to support the U.S. Department of Energy total system performance assessment abstraction, are adequate to determine the possible need for additional data;

\subsection{Radionuclide Transport in the Saturated Zone}

Acceptance Criterion 1: System Description and Model Integration Are Adequate.

(2) The description of the aspects of hydrology, geology, geochemistry, design features, physical phenomena, and couplings, that may affect radionuclide transport in the saturated zone, is adequate. For example, the description includes changes in transport properties in the saturated zone, from water-rock interaction. Conditions and assumptions in the abstraction of radionuclide transport in the saturated zone are readily identified, and consistent with the body of data presented in the description;

Acceptance Criterion 2: Data Are Sufficient for Model Justification.

(3) Data on the geology, hydrology, and geochemistry of the saturated zone, including the influence of structural features, fracture distributions, fracture properties, and stratigraphy, used in the total system performance assessment abstraction, are based on appropriate techniques. These techniques may include 
laboratory experiments, site-specific field measurements, natural analogue research, and process-level modeling studies. As appropriate, sensitivity or uncertainty analyses used to support the U.S. Department of Energy total system performance assessment abstraction are adequate to determine the possible need for additional data.

\subsection{CODES, STANDARDS, AND REGULATIONS}

No codes, standards, and regulations apply to this modeling activity, other than those identified in Section 4.2. 


\section{INTENTIONALLY LEFT BLANK}




\section{ASSUMPTIONS}

No assumptions were made with regard to a lack of input data, parameters or evidence for GFM2000. 


\section{INTENTIONALLY LEFT BLANK}




\section{MODEL DISCUSSION}

Yucca Mountain is located in the southwestern Nevada volcanic field and consists of tilted fault blocks composed of layered sequences of ash-flow, ash fall, and bedded tuffs of Miocene age ["Episodic Caldera Volcanism in the Miocene Southwestern Nevada Volcanic Field: Revised Stratigraphic Framework, ${ }^{40} \mathrm{Ar} /{ }^{39} \mathrm{Ar}$ Geochronology, and Implications for Magmatism and Extension” (Sawyer et al. 1994 [DIRS 100075], pp. 1304 to 1318)]. Additional information regarding the geologic setting of the Yucca Mountain site and model area is provided in (BSC 2004 [DIRS 169734], Chapter 3.3.1). The stratigraphic nomenclature used in this report is adapted from the YMP Reference Information Base (DTN: MO9510RIB00002.004 [DIRS 103801]).

This section describes the geologic framework model in terms of data reduction, model development, the modeling methodology, impacts of model changes on users, the model results, and the uncertainties and limitations of the model. Model validation is discussed in Section 7. The Nevada State Plane coordinates of the geologic framework model boundaries shown in Figure 1-1 are N738,000 to N787,000 feet (N224,943 to N239,878 meters) and E547,000 to E584,000 feet (E166,726 to E178,004 meters).

As described in Section 4.1, the geologic framework model is based primarily on the geologic map of the Yucca Mountain area and data from boreholes (Table 4-1). Borehole locations are shown in Figure 6-1. For brevity, the location identifiers (e.g., USW and UE-25) of boreholes are not used in this report. The faults included in the geologic framework model, shown in Figure 6-2, were input from the geologic map. Locations of geophysical data and measured sections, described in Section 4, are shown in Figure 4-1.

The geologic framework model, as described here, is appropriate for the intended use of providing a geologic framework, consistent with the level of detail needed, over the area of interest for unsaturated and saturated zone flow and radionuclide transport modeling and for repository design. The distribution of subsurface contacts is appropriately more dense in the areas of greatest interest, as discussed in Section 6.6. The model is limited by the availability of data and relative amount of geologic complexity found in an area. The grid spacing used in the geologic framework model (200 feet [61 meters]), discussed in Section 6.4.2, limits the size of features that can be resolved by the model.

\subsection{IMPACTS OF CHANGES TO THE GEOLOGIC FRAMEWORK MODEL}

This section provides an overview of the potential impacts of changes to the geologic framework model from GFM 3.0 to GFM2000 on subsequent users. The changes to methodology and interpretations described in the following sections have negligible impact on all users of the geologic framework model, except specific aspects of repository design modeling. The impacts are negligible because even in the central part of the modeled area where data are most abundant, uncertainty of the geologic system is greater than the potential impacts of changes to modeling methodology (including data reduction, gridding, fault selection, modeling methodology, and interpretive constraints). See Section 6.6.1 for a discussion of geologic variability within the context of uncertainty. When comparing various geologic framework models, changes to the rock layer elevations in the repository area are very small in magnitude, rarely as large as 25 feet. 
Changes are primarily in the corner areas of the model. Therefore, impacts of the modeling process on subsequent users of the geologic framework model are of secondary importance to the uncertainty associated with the natural system. The discussions of impact in the following sections are based on these concepts.

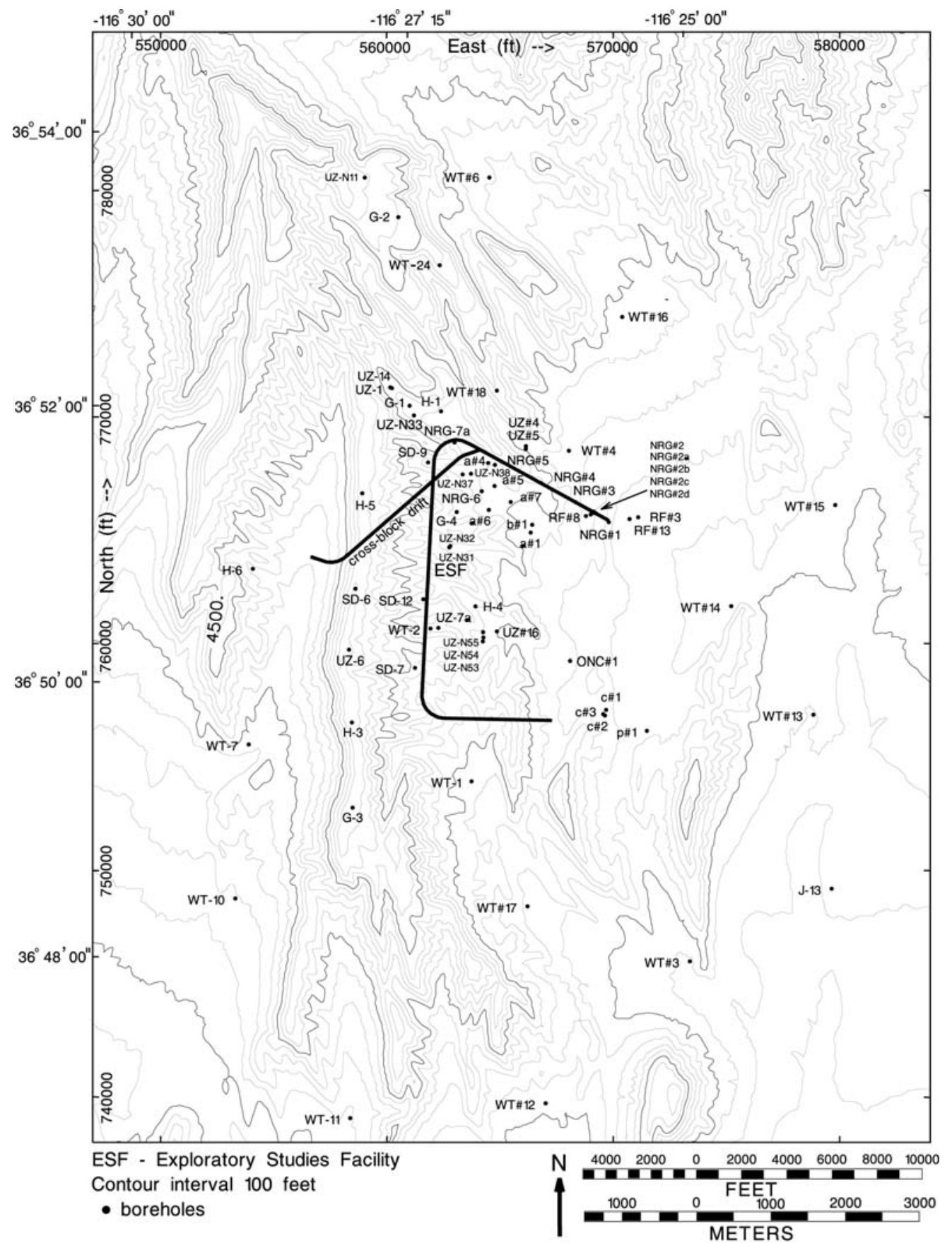

00131DC_GFM_Fig03b.ai

Source DTNs: MO0002SPATOP00.001 Topography [DIRS 152643]; MO9906GPS98410.000 Borehole locations [DIRS 109059]; GS931008314211.036 RF\#3 location [DIRS 150006].

Figure 6-1. Locations of Boreholes, Exploratory Studies Facility, and Cross-Block Drift 


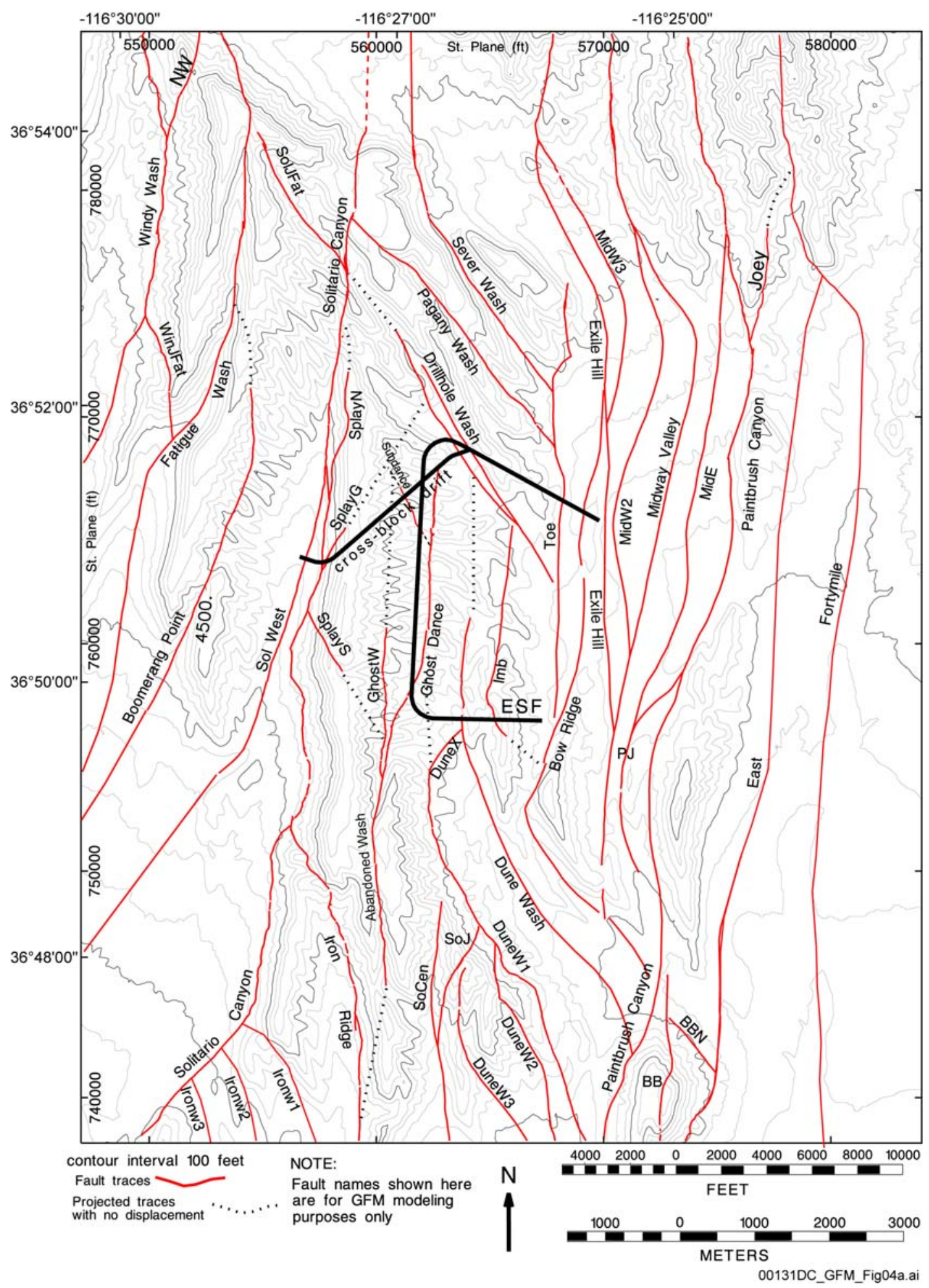

Source DTNs: MO0002SPATOP00.001 Topography [DIRS 152643], GS980608314221.002 Geologic Map [DIRS 107024].

Figure 6-2. Surface Traces of Faults Modeled in Geologic Framework Model 
All users of the geologic framework model, except repository design modeling, use a subsampling (abstraction) of the geologic framework model grids. The UZ and SZ model results are further abstracted for use in total system performance assessment (TSPA), so that impacts of changes to the geologic framework model on TSPA are further reduced. Therefore, impacts of nearly all aspects of the geologic framework model on its users are small except in repository design modeling. For repository design modeling, uncertainty (discussed in Section 6.6) is the overriding factor in assessing impact, and is estimated as the sum total of the effects of data, modeling methodology, interpretations, and heterogeneity of the natural system, and thereby encompasses and defines the potential maximum impact of the geologic framework model results.

\subsection{DATA REDUCTION}

\subsubsection{Selection of Boreholes}

The primary input data for the geologic framework are stratigraphic contacts from boreholes and the geologic map of the Yucca Mountain area (Table 4-1). All data from the 81 boreholes listed in DTN: MO0004QGFMPICK.000 [DIRS 152554] were evaluated. Figure 6-1 illustrates the locations of the 71 boreholes from which contact information was used. Sixty-seven of the boreholes are from DTN: MO0004QGFMPICK.000 [DIRS 152554], and four others (SD-6, RF\#3, RF\#8, and RF\#13) are from DTNs: SNF40060298001.001 [DIRS 107372], GS931008314211.036 [DIRS 150006], GS931008314211.035 [DIRS 150005], and MO0111GLOGRF13.001 [DIRS 157305]. The stratigraphic contact picks from DTN: MO0004QGFMPICK.000 [DIRS 152554] each met the acceptance criteria of \pm 5 to 15 feet [Data Qualification Report: Borehole Stratigraphic Contacts, Revision 01 (CRWMS M\&O 2000 [DIRS 158094], p. 4)]. The 14 boreholes not used from DTN: MO0004QGFMPICK.000 [DIRS 152554] contained no information that could be used due to limited penetration. Data from sources outside the model boundaries cannot be directly input to the model; however, model units were developed to allow reasonable extrapolation to them. The offsite data include boreholes VH-1 [Volcano-Tectonic History of Crater Flat, Southwestern Nevada, as Suggested by New Evidence from Drill Hole USW-VH-1 and Vicinity (Carr 1982 [DIRS 101519], Table 2)], VH-2 [Geology of Drill Hole USW VH-2, and Structure of Crater Flat, Southwestern Nevada (Carr and Parrish 1985 [DIRS 101093], Table 2)], JF\#3 [Hydrogeology of Rocks Penetrated by Test Well JF-3, Jackass Flats, Nye County, Nevada (Plume and La Camera 1996 [DIRS 141659], Table 2)], and J\#12 (Plume and La Camera 1996 [DIRS 141659], Table 1). Distances from the model boundaries to these boreholes ranges from 0.9 to 3.9 miles (1.4 to 6.3 kilometers).

\subsubsection{Selection of Faults}

Due to limited subsurface data, and the logistical complexity of modeling large numbers of fault blocks and stratigraphic units, all of the faults on the geologic map could not be modeled. Criteria were developed to determine which mapped faults would be included in the geologic framework model. Due to the large number of faults in the modeled area and limitations in modeling technology, guidelines are needed to select the faults that can realistically be modeled, consistent with the needs of the users of the outputs from this model. The fault selection guidelines presented herein were determined by a group of subject matter experts from the U.S. 
Geological Survey (USGS), M\&O, Sandia National Laboratories, and Lawrence Berkeley National Laboratory in an informal 1995 workshop. These experts determined the fault selection criteria needed to meet both the requirements of model users and provide a level of detail that was technically feasible to model while providing an adequate representation of the structure of Yucca Mountain. This workshop was informal, and as such was not documented. In general, if no downstream users needed a fault and omitting the fault did not adversely affect the geologic framework model, the fault was not modeled. In consideration of the impact that faults may have on repository design, more stringent criteria were developed for the repository area in the vicinity of the ESF. This iterative process involving early model results and YMP scientists was used to validate the criteria and ensure an adequate representation of the geology of Yucca Mountain.

Final selection criteria were developed for two different areas based on the nature and availability of stratigraphic data. The first area, generally bounded by the Solitario Canyon fault, the northward projection of the Dune Wash fault, and the westward projections of the ESF north and south ramps is identified as "in the vicinity of the ESF." The second modeled area is "outside the vicinity of the ESF."

In the vicinity of the ESF, the criteria are:

- The mapped trace length is at least 1 mile (1.6 kilometers) and the maximum vertical displacement is at least 100 feet (30 meters)

- The surface-mapped fault intersects the ESF or cross-block drift.

Outside the vicinity of the ESF, the criteria are:

- The mapped trace length is at least 2 miles (3.2 kilometers) and the maximum vertical displacement is at least 100 feet (30 meters)

- Omitting the fault would produce an unacceptable mismatch between the model and the geologic map.

As a result of the examination of early model constructions in the iterative process, an unmapped fault was added beneath Fortymile Wash, as shown on Figure 6-2, to account for geometric relations between outcrop data and boreholes WT\#13, WT\#15, and J-13. Location and extent of this fault have a high degree of uncertainty, which increases toward the south where data are sparsest. Interpretation of gravity and magnetic data in Fortymile Wash indicates that faults beneath the wash, if present, have vertical displacements that are small compared to the Paintbrush Canyon fault [Gravity and Magnetic Data of Fortymile Wash, Nevada Test Site, Nevada (Ponce et al. 1992 [DIRS 106561], pp. 6 to 7)]. This fault, as modeled in the geologic framework model, has a displacement of about 100 feet (30 meters), which is consistent with the above observations.

Using the final selection criteria, 43 faults were included in the geologic framework model. The locations of fault traces (Figure 6-2) were established by the geologic map of the site area (DTN: GS980608314221.002 [DIRS 107024]). Fault displacements were estimated from 
borehole data (Table 4-1) and the geologic map. Fault displacements and geometries were iterated during technical reviews of each model version to incorporate feedback from YMP scientists.

\subsubsection{Selection of Topographic Data}

Two potential sources of topographic data in the model area were evaluated for use in GFM2000: a topographic grid (DTN: MO0002SPATOP00.001 [DIRS 152643]) and a USGS digital elevation model (DTN: MO0010COV00124.001 [DIRS 153783]). Table 6-1 shows the differences between the surveyed borehole collar elevations (DTN: MO9906GPS98410.000 [DIRS 109059]) and surfaces generated from the topographic grid and the USGS digital elevation model data for 70 of the 71 boreholes. The results show that the topographic grid is in closer agreement with the borehole collar elevations (average difference: 0.4 feet [0.1 meters]) than the digital elevation model data (average difference: 8.5 feet [2.6 meters]). The topographic data from DTN: MO0002SPATOP00.001 [DIRS 152643] was therefore used in the GFM2000 as the topographic surface of the model. The largest errors in the grid occur on ridge tops and other places where abrupt elevation changes cannot be fully defined by the grid nodes (SD-9 and SD-12 [Table 6-1]; grid node spacing is 100 feet [30 meters]). The differences at borehole RF\#13 were caused by addition of material at the ESF North Portal pad, which post dates the topographic grid and the digital elevation model and pre-dates borehole RF\#13. Further analysis of the digital elevation model accuracy is not attempted here. The digital elevation model data were not used in modeling, but remain useful in geographic information systems applications and for plotting topographic maps where high precision is not required. Use of the topographic grid has negligible impact on the results of the geologic framework model because it is not used to constrain or define subsurface rock units; therefore, the differences between surveyed collar elevations and the topographic grid have no impact on the geologic framework model or its users. 
Table 6-1. Differences Between Surveyed Borehole Collar Elevations and the USGS Digital Elevation Model Data ("DEM") and Topographic Grid Used in the Geologic Framework Model ("Grid"), in Feet

\begin{tabular}{|c|c|c|c|c|c|}
\hline \multirow[b]{2}{*}{ Borehole } & \multicolumn{2}{|c|}{ Difference (feet) } & \multirow[b]{2}{*}{ Borehole } & \multicolumn{2}{|c|}{ Difference (feet) } \\
\hline & $\begin{array}{c}\text { Collar } \\
\text { minus } \\
\text { DEM }\end{array}$ & $\begin{array}{c}\text { Collar } \\
\text { minus } \\
\text { Grid }\end{array}$ & & $\begin{array}{c}\text { Collar } \\
\text { minus } \\
\text { DEM }\end{array}$ & $\begin{array}{c}\text { Collar } \\
\text { minus } \\
\text { Grid }\end{array}$ \\
\hline a\#1 & 6 & -2 & SD-7 & -3 & 4 \\
\hline$a \# 4$ & 10 & -3 & SD-9 & 22 & 9 \\
\hline$a \# 5$ & 17 & 3 & SD-12 & 20 & 11 \\
\hline$a \# 6$ & 14 & 1 & UZ-1 & 20 & 2 \\
\hline$a \# 7$ & 4 & -1 & UZ\#4 & 21 & -3 \\
\hline $\mathrm{b} \# 1$ & 6 & 1 & UZ\#5 & 8 & -5 \\
\hline $\mathrm{c \# 1}$ & -7 & -1 & UZ-6 & 10 & 1 \\
\hline $\mathrm{c \# 2}$ & -3 & 0 & UZ-7a & -1 & -5 \\
\hline $\mathrm{c} \# 3$ & -1 & 0 & UZ-14 & 16 & -1 \\
\hline G-1 & 15 & 3 & UZ\#16 & 11 & -3 \\
\hline G-2 & 14 & 0 & WT-1 & 3 & -5 \\
\hline G-3 & 20 & 2 & WT-2 & 4 & 2 \\
\hline G-4 & 12 & 0 & WT\#3 & -1 & -1 \\
\hline $\mathrm{H}-1$ & 7 & -2 & WT\#4 & 10 & -3 \\
\hline $\mathrm{H}-3$ & 0 & 0 & WT\#6 & 10 & 5 \\
\hline $\mathrm{H}-4$ & 21 & -1 & WT-7 & 11 & 2 \\
\hline $\mathrm{H}-5$ & 15 & 2 & WT-10 & 4 & -2 \\
\hline $\mathrm{H}-6$ & 19 & -8 & WT-11 & 0 & -3 \\
\hline $\mathrm{J}-13$ & 11 & -1 & WT\#12 & -4 & -6 \\
\hline NRG\#1 & 24 & -3 & WT\#13 & -1 & -1 \\
\hline NRG\#2a & 7 & 1 & WT\#14 & -1 & 0 \\
\hline NRG\#2b & -7 & -2 & WT\#15 & 6 & -1 \\
\hline NRG\#2C & -5 & 0 & WT\#16 & 5 & 4 \\
\hline NRG\#2d & -4 & 3 & WT\#17 & 11 & -2 \\
\hline NRG\#3 & 11 & -4 & WT\#18 & 21 & -4 \\
\hline NRG\#4 & 15 & -1 & WT-24 & 11 & -1 \\
\hline NRG\#5 & 2 & -5 & UZ-N11 & 18 & 6 \\
\hline NRG-6 & 10 & -6 & UZ-N31 & 12 & -4 \\
\hline NRG-7A & 20 & -8 & UZ-N32 & 3 & -2 \\
\hline ONC\#1 & 10 & 2 & UZ-N33 & 16 & 1 \\
\hline $\mathrm{p} \# 1$ & -17 & -2 & UZ-N37 & 14 & -2 \\
\hline $\mathrm{RF} \# 3$ & -2 & -2 & UZ-N38 & 10 & -1 \\
\hline $\mathrm{RF} \# 8$ & 16 & 2 & UZ-N53 & 16 & 2 \\
\hline RF\#13 & 10 & 11 & UZ-N54 & 7 & -1 \\
\hline SD-6 & 6 & -1 & UZ-N55 & 8 & 2 \\
\hline
\end{tabular}

Source for USGS DEM data: DTN: MO0010COV00124.001 [DIRS 153783]. Source for topographic grid: DTN: MO0002SPATOP00.001 [DIRS 152643]. Source for borehole collar elevations: DTN: MO9906GPS98410.000 [DIRS 109059]. 


\subsection{MODEL DEVELOPMENT: GFM1.0 TO GFM2000}

GFM2000 is the most current version of the geologic framework model. Each revision improved on the previous version and incorporated new data or was revised in accordance with technical review comments. Figure 6-3 summarizes the changes between model versions. The following sections describe the changes between versions.

\subsubsection{Changes From GFM1.0 to GFM2.0}

GFM1.0 (DTN: MO96071SM10MOD.001 [DIRS 109071]) provided an initial portrayal of the geologic framework, with simplified fault geometry for preliminary work. GFM2.0 (DTN: MO9807MWDGFM02.000 [DIRS 109074]) improved on GFM1.0 by including dipping faults and additional rock units.

\subsubsection{Changes From GFM2.0 to GFM3.0}

The primary difference between GFM3.0 (DTN: MO9804MWDGFM03.001 [DIRS 109050]) and its predecessor (GFM2.0) was use of the bedrock geologic map of the Yucca Mountain area (DTN: GS980608314221.002 [DIRS 107024]) and a set of correlated and standardized borehole lithostratigraphic data (DTN: MO9811MWDGFM03.000 [DIRS 109006]). The geologic map provided wider, more accurate data coverage than was previously available for the construction of faults, reference horizons, and model isochores. The number of rock layers modeled also increased to meet the needs of model users.

All model isochores and reference horizons were reconstructed on the basis of the new borehole and map data so that each rock layer in GFM3.0 was changed from that in GFM2.0. The Tertiary-Paleozoic unconformity (top of Paleozoic) was also changed using a new surface derived from gravity data (DTN: LB980130123112.003 [DIRS 109062]). Specific changes from GFM2.0 to GFM3.0 include improved gridding parameters, revised reference horizon selection, use of the geologic map data, and improved configuration of faults in accordance with geologic map data.

\subsubsection{Changes From GFM3.0 to GFM3.1}

Geologic Framework Model, Version 3.1 (GFM3.1) was constructed to incorporate new data from boreholes SD-6 (DTN: SNF40060298001.001 [DIRS 107372]) and WT-24 (DTN: SNF40060198001.001 [DIRS 107239]) and the cross-block drift excavated during the Enhanced Characterization of the Repository Block (ECRB) Cross-Drift (DTN: GS981108314224.005 [DIRS 109070]). Figure 6-1 shows the locations of boreholes SD-6 and WT-24 and the ECRB Cross-Drift. In addition, GFM3.1 included a new fault (from DTN: GS980608314221.002 [DIRS 107024]), which is located at the Prow (Figure 1-1) and is designated NW on Figure 6-2. The new fault was included to properly model the Calico Hills Formation and Prow Pass Tuff outcrops. 


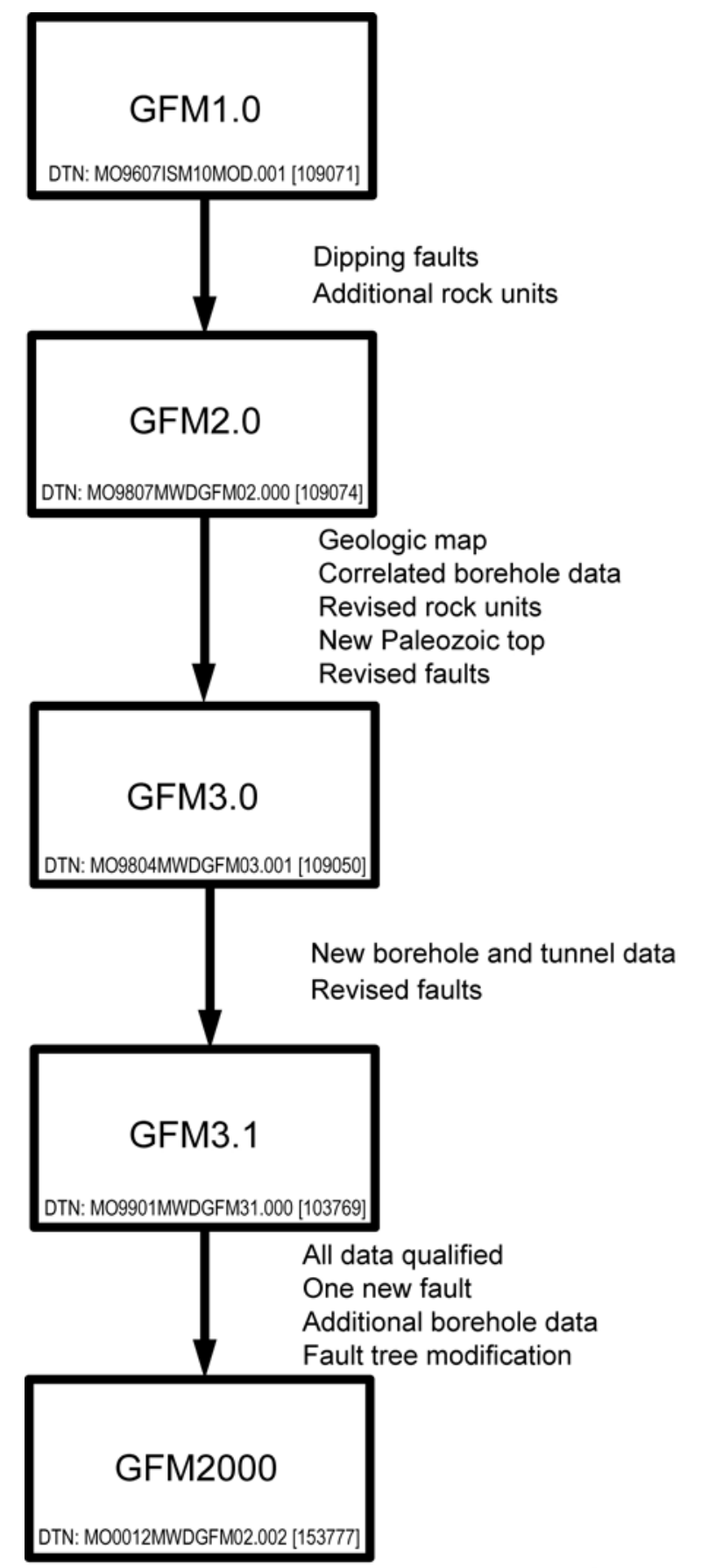

00131DC_GFM_Fig06d.ai

Source: For illustrative purpose only.

Figure 6-3. Changes Between Geologic Framework Model Versions 
GFM3.1 was constructed with more curvature on the dominant faults to be consistent with cross sections published with the bedrock geologic map of the Yucca Mountain area (DTN: GS980608314221.002 [DIRS 107024]) and to account for field relations showing rotated hanging wall strata BSC 2004 [DIRS 169734], Section 3.5.4). The revised geometries include a slight decrease in fault dip with depth, resulting in fault planes that are slightly concave-upward to account for field relations. Planes of minor faults are depicted as planar.

\subsubsection{Changes From GFM3.1 to GFM2000}

GFM2000 was developed after all input data were qualified and to address alternative interpretations suggested in technical review comments on GFM3.1. The comments that were addressed concern depositional models for the Crater Flat Group and Topopah Spring Tuff, thickness of model unit "RHHtop" in the northwestern corner of the model area, and existence of one anomalous grid flexure at the extreme northern edge of the model area. As a result, isochore grids for some units have changed. No impact is anticipated on users of the geologic framework model because the changes are primarily in the outlying areas away from the primary area of interest in the vicinity of the ESF. For SZ models that use the entire geologic framework model area, the changes would have minor impact because of the lower spatial resolution of those models and the lack of subsurface data in the affected areas.

GFM2000 also addresses review comments by NRC staff [Issue Resolution Status Report Key Technical Issue: Structural Deformation and Seismicity (NRC 1999 [DIRS 135621], p. E-2)], as follows:

- Mismatches between observed contact elevations and model grids have been reduced (they cannot be completely eliminated due to limitations in the gridding method).

- Inconsistent or incorrect fault displacements have been eliminated.

- The Ghost Dance fault has been modified to truncate at depth against the west-dipping normal faults.

- Relative amount of displacement between the Paleozoic and mid-Tertiary rock units was made more consistent and is discussed in Section 6.5.1.10.

- A fault has been added between the Fortymile and Paintbrush Canyon faults, and is named "Joey" in the digital files (because it is located on Joey Ridge). Although it does not meet the trace length and displacement criteria described in Section 6.2.2, this fault was added to provide a closer match to the geologic map (the last fault inclusion criterion).

- $\quad$ The input data are qualified.

The impact of these changes is to improve the accuracy of the geologic framework model and to provide more clear explanations of modeled features. Because the additional fault is located outside the boundaries of the models for repository design and UZ hydrologic flow, no impact is 
anticipated. The additional fault is unlikely to be included in the SZ models because of its limited areal extent and the large grid size of the SZ models, and so no impact is anticipated.

GFM2000 also incorporates currently qualified borehole data that were omitted from previous model versions. The boreholes were included in GFM2000 based on comments from geologic framework model users and technical reviewers and include contacts in the UZN boreholes and in boreholes c\#1, c\#3, a\#1, a\#7, and UZ-1. The impacts of using all boreholes are twofold: first, the geologic framework model more closely matches the boreholes that had previously been omitted, provided they are not near other boreholes; and second, the geologic framework model cannot exactly match disparate borehole data that are located within about 200 feet (61 meters) of each other ( 1 grid node space) because some averaging of the data is performed in the gridding process. The affected boreholes include UZ-1 and UZ-14, the C-holes complex, the "NRG\#2" holes, a\#1 and b\#1, UZ-N31, UZ-N32, and UZ-N53, UZ-N54, and UZ-N55. No negative impact is anticipated on the geologic framework model or its users because the averaging errors are smaller than the tolerances required by geologic framework model users (see Section 7.1). All borehole data listed in Table 4-1 were used as input. No other borehole data for the modeled stratigraphic units are available in the modeled area.

In addition, GFM2000 takes advantage of a modeling software enhancement in EARTHVISION Version 5.1 that improves the consistency of fault displacements with depth and calculates models in less time. This enhancement uses the same gridding algorithm but grids a horizon without the faults and then replaces the faults. As a result of these enhancements, the model is more accurate in its portrayal of fault displacements and more iterations were performed to produce a more accurate model.

GFM2000 portrays the steeply dipping Ghost Dance-Abandoned Wash faults as secondary features that are truncated at depth by the west-dipping normal faults. This portrayal is more consistent with the cross sections published with the geologic map and with the portrayal of other steeply dipping faults in the modeled area. The change was applied by modifying the "fault tree" in the parameter ("sequence") file, which defines the hierarchical relations between faults and determines which faults truncate which. No impact is anticipated on model users because the change occurs far below the repository level and far below the UZ and because this fault is too small to be used in the SZ models.

\subsection{METHODOLOGY}

The geologic framework model was constructed in the following general steps, which are discussed in detail in Scientific Notebook SN-M\&O-SCI-028-V1 [Geologic Framework Model (GFM2000) (Clayton 2001 [DIRS 153713], pp. 5 to 28)]:

1. Development of grid construction and contouring methodology

2. Construction of faults

3. Construction of reference horizons

4. Construction of model isochores

5. Assembly of faults and rock layers

6. Assessment, iteration, and quality control. 
Table 6-2 presents the correlation between the stratigraphic units modeled in the geologic framework model and the YMP stratigraphy (DTN: MO9510RIB00002.004 [DIRS 103801]). Most of the geologic framework model units correlate with the YMP stratigraphy; however, two nonstratigraphic units were included in the model because of their significance to geologic framework model users - a low-density zone (TpcLD) and the Repository Host Horizon (RHH). The TpcLD occurs above the Tiva Canyon Tuff lower vitric units (Tpcpv3 and Tpcpv2). The $\mathrm{RHH}$ is the body of rock in which the repository is proposed to be excavated [Determination of Available Volume for Repository Siting (CRWMS M\&O 1997 [DIRS 100223], pp. 43 to 50)], and it spans four lithostratigraphic zones (the lower part of the Tptpul, Tptpmn, Tptpll, and Tptpln). The model unit designated as RHHtop is within the lower part of the Topopah Spring Tuff upper lithophysal zone (Tptpul). This RHHtop unit is defined by a density log signature intermediate between the remainder of the upper lithophysal zone above and the middle nonlithophysal zone below. The RHH includes model units RHHtop, Tptpmn, Tptpll, and Tptpln.

Table 6-2. Correlation Chart for Model Stratigraphy

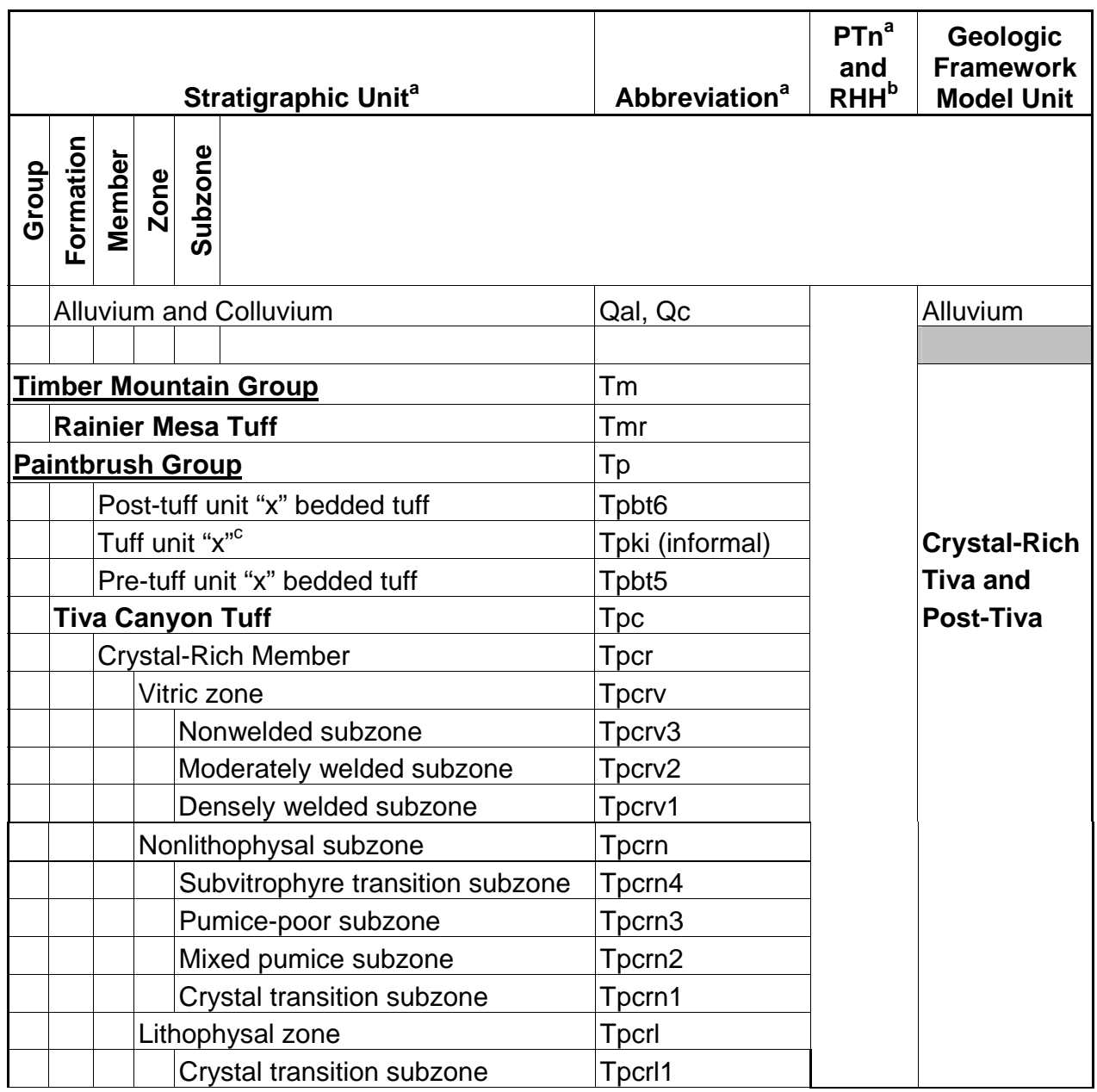


Table 6-2. Correlation Chart for Model Stratigraphy (Continued)

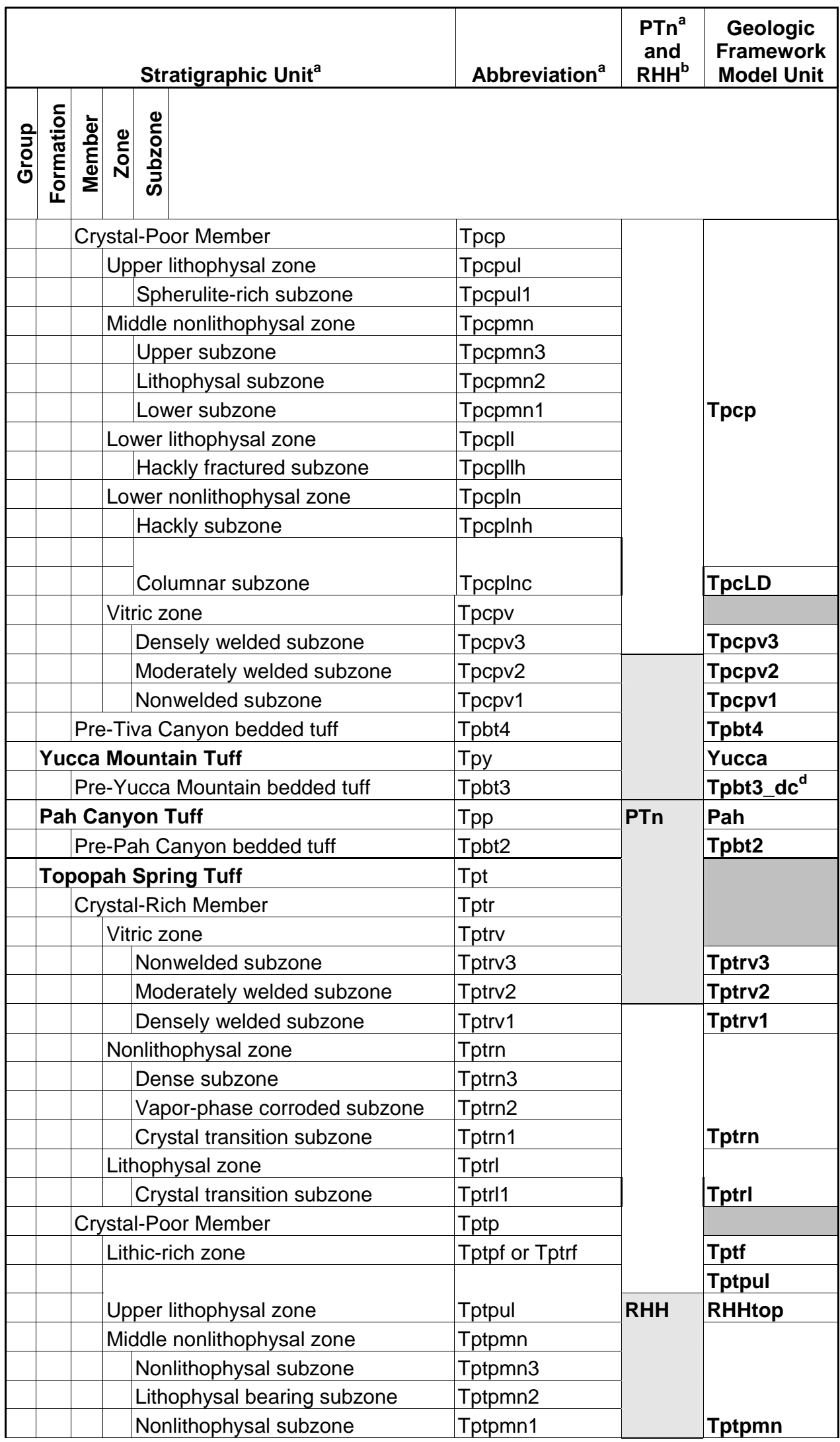


Table 6-2. Correlation Chart for Model Stratigraphy (Continued)

\begin{tabular}{|c|c|c|c|c|c|c|c|}
\hline & & & & ratigraphic Unit ${ }^{a}$ & Abbreviation $^{a}$ & $\begin{array}{l}\text { PTn }^{\mathrm{a}} \\
\text { and } \\
\mathrm{RHH}^{\mathrm{b}}\end{array}$ & $\begin{array}{c}\text { Geologic } \\
\text { Framework } \\
\text { Model Unit }\end{array}$ \\
\hline $\begin{array}{l}\frac{2}{3} \\
\frac{0}{0}\end{array}$ & 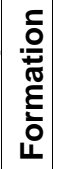 & $\begin{array}{l}\frac{\bar{d}}{\mathbf{0}} \\
\frac{\mathbf{c}}{\mathbf{D}} \\
\frac{0}{\Sigma}\end{array}$ & 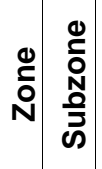 & & & & \\
\hline & & & Lower I & lithophysal zone & Tptpll & & Tptpll \\
\hline & & & Lower $r$ & nonlithophysal zone & Tptpln & & Tptpln \\
\hline & & & Vitric zc & one & Tptpv & & \\
\hline & & & Den & nsely welded subzone & Tptpv3 & & Tptpv3 \\
\hline & & & Mod & derately welded subzone & Tptpv2 & & Tptpv2 \\
\hline & & & Non & nwelded subzone & Tptpv1 & & Tptpv1 \\
\hline & & Pre- & -Topop & oah Spring bedded tuff & Tpbt1 & & Tpbt1 \\
\hline & Cal & ico & Hills F & Eormation & $\mathrm{Ta}$ & & Calico \\
\hline & & Bed & dded tuf & & Tacbt & & Calicobt \\
\hline Cra & ater & Flat & t Grour & & Tc & & \\
\hline & Pro & $\mathbf{W} \mathbf{P}$ & Pass Tu & uff & Tсp & & \\
\hline & & & $\begin{array}{l}\text { Prow P } \\
\text { nonwel }\end{array}$ & $\begin{array}{l}\text { ass Tuff upper vitric } \\
\text { Ided zone }\end{array}$ & $(\text { Tcpuv })^{\mathrm{e}}$ & & Prowuv \\
\hline & & & $\begin{array}{l}\text { Prow P } \\
\text { nonwel }\end{array}$ & $\begin{array}{l}\text { ass Tuff upper crystalline } \\
\text { Ided zone }\end{array}$ & $(\text { Tсрuc })^{\mathrm{e}}$ & & Prowuc \\
\hline & & & $\begin{array}{l}\text { Prow P } \\
\text { welded }\end{array}$ & $\begin{array}{l}\text { ass Tuff moderately densely } \\
\text { zone }\end{array}$ & $(T c p m d)^{\mathrm{e}}$ & & Prowmd \\
\hline & & & $\begin{array}{l}\text { Prow P } \\
\text { nonwel }\end{array}$ & $\begin{array}{l}\text { Pass Tuff lower crystalline } \\
\text { Ided zone }\end{array}$ & $(\text { Tcplc })^{\mathrm{e}}$ & & Prowlc \\
\hline & & & $\begin{array}{l}\text { Prow P } \\
\text { nonwel }\end{array}$ & $\begin{array}{l}\text { Pass Tuff lower vitric } \\
\text { Ided zone }\end{array}$ & $(\text { Tcplv })^{\mathrm{e}}$ & & Prowlv \\
\hline & & Pre- & -Prow $\mathrm{F}$ & Pass Tuff bedded tuff & $(T c p b t)^{e}$ & & Prowbt \\
\hline & Bul & Ifro & g Tuff & & Tcb & & \\
\hline & & & $\begin{array}{l}\text { Bullfrog } \\
\text { zone }\end{array}$ & g Tuff upper vitric nonwelded & $(\text { Tcbuv })^{\mathrm{e}}$ & & Bullfroguv \\
\hline & & & $\begin{array}{l}\text { Bullfrog } \\
\text { nonwel }\end{array}$ & $\begin{array}{l}\text { g Tuff upper crystalline } \\
\text { Ided zone }\end{array}$ & $(\text { Tcbuc })^{\mathrm{e}}$ & & Bullfroguc \\
\hline & & & Bullfrog & g Tuff welded zone & $(\text { Tcbmd })^{\mathrm{e}}$ & & Bullfrogmd \\
\hline & & & $\begin{array}{l}\text { Bullfrog } \\
\text { nonwel }\end{array}$ & $\begin{array}{l}\text { g Tuff lower crystalline } \\
\text { Ided zone }\end{array}$ & $(\text { Tcblc })^{\mathrm{e}}$ & & Bullfroglc \\
\hline & & & $\begin{array}{l}\text { Bullfrog } \\
\text { zone }\end{array}$ & g Tuff lower vitric nonwelded & $(\text { Tcblv })^{\mathrm{e}}$ & & Bullfroglv \\
\hline & & Pre- & -Bullfro & gg Tuff bedded tuff & $(T c b b t)^{\mathrm{e}}$ & & Bullfrogbt \\
\hline & Tra & $\mathbf{m} \mathbf{T}$ & Cuff & & Tct & & \\
\hline & & & $\begin{array}{l}\text { Tram T } \\
\text { zone }\end{array}$ & Tuff upper vitric nonwelded & $(T c t u v)^{e}$ & & Tramuv \\
\hline & & & $\begin{array}{l}\text { Tram T } \\
\text { nonwel }\end{array}$ & $\begin{array}{l}\text { Tuff upper crystalline } \\
\text { Ided zone }\end{array}$ & $(\text { Tctuc })^{\mathrm{e}}$ & & Tramuc \\
\hline & & & $\begin{array}{l}\text { Tram T } \\
\text { zone }\end{array}$ & Гuff moderately densely welded & $(\text { Tctmd })^{\mathrm{e}}$ & & Trammd \\
\hline & & & $\begin{array}{l}\text { Tram T } \\
\text { nonwel }\end{array}$ & $\begin{array}{l}\text { Tuff lower crystalline } \\
\text { Ided zone }\end{array}$ & $(T c t l c)^{\mathrm{e}}$ & & Tramlc \\
\hline & & & $\begin{array}{l}\text { Tram T } \\
\text { zone }\end{array}$ & Гuff lower vitric nonwelded & $(T c t l v)^{\mathrm{e}}$ & & Tramlv \\
\hline
\end{tabular}


Table 6-2. Correlation Chart for Model Stratigraphy (Continued)

\begin{tabular}{|c|c|c|c|c|c|c|c|}
\hline \multicolumn{5}{|r|}{ Stratigraphic Unit ${ }^{a}$} & Abbreviation $^{a}$ & $\begin{array}{l}\mathrm{PTn}^{\mathrm{a}} \\
\text { and } \\
\mathrm{RHH}^{\mathrm{b}}\end{array}$ & $\begin{array}{l}\text { Geologic } \\
\text { Framework } \\
\text { Model Unit }\end{array}$ \\
\hline \multirow[t]{4}{*}{$\begin{array}{l}\frac{0}{3} \\
\frac{0}{0}\end{array}$} & 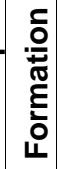 & $\begin{array}{l}\frac{1}{d} \\
\frac{0}{E} \\
\frac{0}{\Sigma}\end{array}$ & 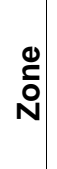 & $\begin{array}{l}0 \\
\stackrel{0}{0} \\
N \\
0 \\
\dot{J}\end{array}$ & & & \\
\hline & \multicolumn{4}{|c|}{ Pre-Tram Tuff bedded tuff } & $(\text { Tctbt })^{\mathrm{e}}$ & & Trambt \\
\hline & \multicolumn{4}{|c|}{ Lava and flow breccia (informal) } & TII & & \multirow{14}{*}{ Tund } \\
\hline & \multicolumn{4}{|c|}{ Bedded tuff } & Tllbt & & \\
\hline \multicolumn{5}{|c|}{ Lithic Ridge Tuff } & $\operatorname{Tr}$ & & \\
\hline & \multicolumn{4}{|c|}{\begin{tabular}{|l|} 
Bedded tuff \\
\end{tabular}} & Tlrbt & & \\
\hline & \multicolumn{4}{|c|}{ Lava and flow breccia (informal) } & TII2 & & \\
\hline & \multicolumn{4}{|c|}{ Bedded tuff } & Tllbt & & \\
\hline & \multicolumn{4}{|c|}{ Lava and flow breccia (informal) } & TII3 & & \\
\hline & \multicolumn{4}{|c|}{ Bedded tuff } & TIll3bt & & \\
\hline & \multicolumn{4}{|c|}{ Older tuffs (informal) } & $\mathrm{Tt}$ & & \\
\hline & \multicolumn{4}{|c|}{\begin{tabular}{|l} 
Unit a (informal) \\
\end{tabular}} & Tta & & \\
\hline & \multicolumn{4}{|c|}{ Unit b (informal) } & Ttb & & \\
\hline & & \multicolumn{3}{|c|}{ Unit c (informal) } & Ttc & & \\
\hline & \multicolumn{4}{|c|}{$\begin{array}{l}\text { Sedimentary rocks and calcified tuff } \\
\text { (informal) }\end{array}$} & Tca & & \\
\hline & \multicolumn{4}{|c|}{ Tuff of Yucca Flat (informal) } & Tyf & & \\
\hline \multicolumn{6}{|c|}{ Pre-Tertiary sedimentary rock } & & \\
\hline \multicolumn{5}{|c|}{ Lone Mountain Dolomite } & SIm & & \\
\hline \multicolumn{5}{|c|}{ Roberts Mountain Formation } & Srm & & Paleozoic \\
\hline
\end{tabular}

$\mathrm{RHH}=$ Repository Host Horizon

NOTE: Shaded rows indicate header lines for subdivided units.

aTN: MO9510RIB00002.004 [DIRS 103801].

${ }^{\mathrm{b}}$ CRWMS M\&O 1997 [DIRS 100223], pp. 43-50.

${ }^{\mathrm{C}}$ Correlated with the rhyolite of Comb Peak (Buesch et al. 1996 [DIRS 100106], Table 2).

d Includes rhyolite of Delirium Canyon north of Yucca Wash

(DTN: GS980608314221.002 [DIRS 107024]).

${ }^{\mathrm{e}}$ For the purposes of GFM2000, each formation in the Crater Flat Group was subdivided into six zones based on the requirements of the users of the geologic framework model. The subdivisions are upper vitric (uv), upper crystalline (uc), moderately to densely welded (md), lower crystalline (Ic), lower vitric (Iv), and bedded tuff (bt) (Buesch and Spengler 1999 [DIRS 107905], pp. 62-64). 
The geologic framework model stratigraphy was constructed by the thickness (or "isochore") method, which consists of adding or subtracting (as appropriate) thicknesses from one or more reference horizons as illustrated in Figure 6-4. An isochore is a map or grid that represents the thickness of a geologic unit measured in the vertical direction, regardless of dip. This contrasts with an isopach, which is thickness of a unit measured perpendicular to bedding. Because the structural dips at Yucca Mountain are low (generally less than $10^{\circ}$ ), an isochore is nearly identical to an isopach. This method was chosen for the following reasons:

- In volcanic units, thickness tends to be systematically distributed over large areas as a function of factors including magma type, eruptive processes, wind speed and direction, preexisting topography, and erosion. Thicknesses directly reflect these processes and can, therefore, be constructed with the use of those processes as guides.

- Because the volcanic strata at Yucca Mountain consist of many units that pinch out, are very thin, and/or have highly variable thicknesses (creating highly variable differences between the elevations of stratal tops and bottoms), the use of model isochores prevents the top and bottom grids from intersecting unintentionally.

- Construction of stratigraphy by model isochores results in fewer thickness anomalies than the construction of each surface as an elevation grid.

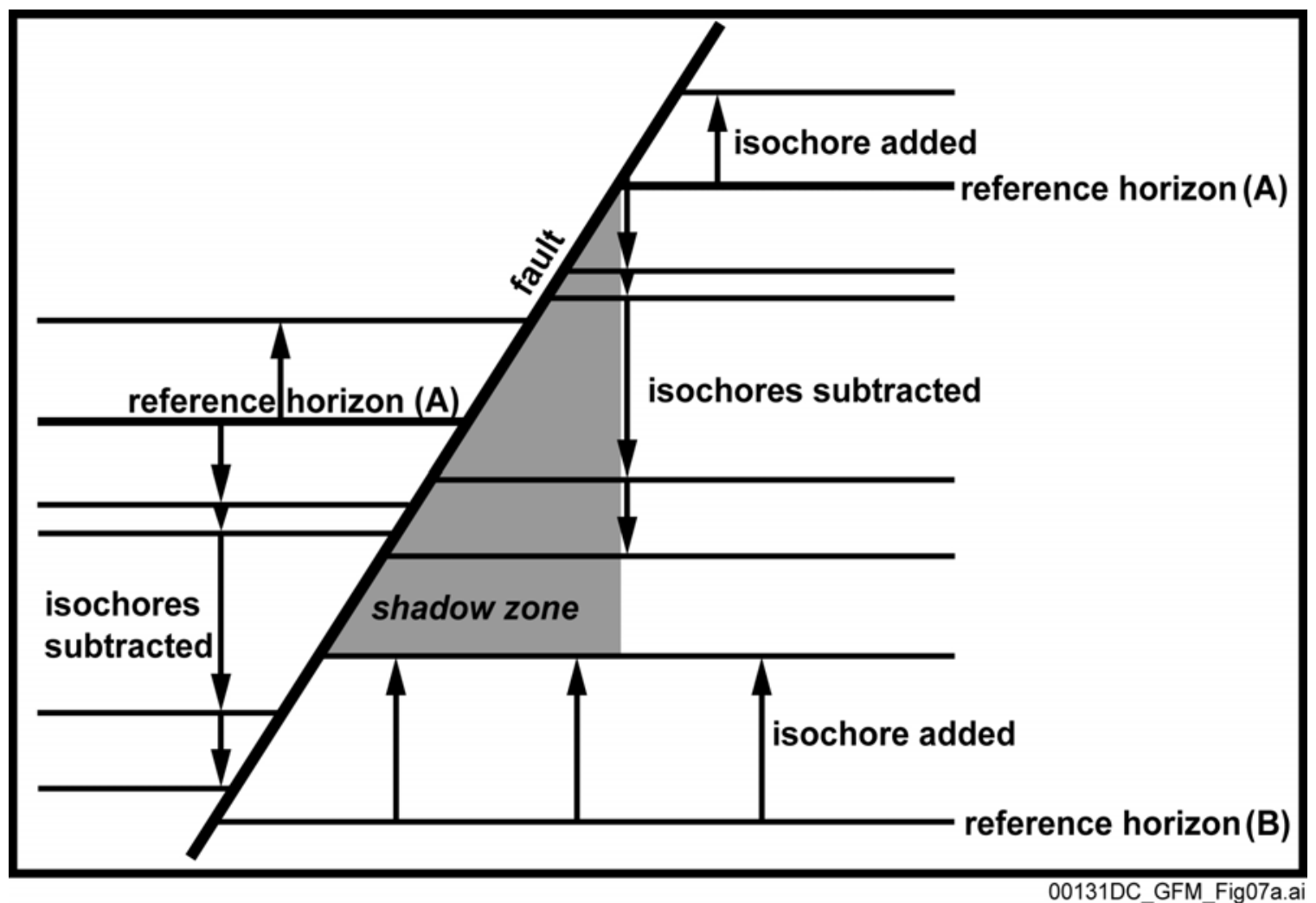

Source: For illustrative purpose only.

NOTE: Isochores are added or subtracted from reference horizons to assemble the rock units in the model. Because the process does not cross faults, a shadow zone develops beneath dipping faults.

Figure 6-4. Isochore Method 
The alternative to the isochore method is construction of each horizon as an elevation surface. The principal drawback of that method is difficulty in maintaining parallelism of the horizons and preventing horizons from overlapping. Because many of the 50 modeled units at Yucca Mountain are very thin or pinch out, constructing the model by elevation surfaces would be unlikely to produce adequate results without intersecting or overlapping surfaces. The benefits of using the isochore method are an improvement to the internal consistency of the model's representation of site geology and increased control by the geologist/modeler to produce results in accordance with the conceptual model. A potential drawback is decreased control over the details of isochores for composite units. For example, the thickness of the Topopah Spring Tuff is the cumulative thickness of 7 units, which were mapped individually, and the cumulative thickness map may contain abrupt contour changes. The abrupt contour changes may be visually unsatisfactory, but pose no technical impact on model results or subsequent model users because they are few in number and small in magnitude (much smaller than uncertainty). The impact of the isochore method on model results and model users is, therefore, positive in comparison to the alternative method.

The model isochore maps illustrated in the following sections may contain artifacts of the modeling process. For this reason, the maps and grids from which the maps are derived are referred to as "model isochores." Model isochores must include partial thicknesses caused by faulting in cases where the fault cannot be represented in the model. As illustrated in Figure 6-5, in a computer-based model around an unmodeled fault, a partial thickness is required during model construction to maintain true elevations of the units above and below. In general, a fault that cannot be mapped areally, cannot be modeled in three dimensions. In addition to the inclusion criteria, for a fault to be included in the model it must have a defined extent, strike, and dip. For a fault that intersects a borehole but is not mapped at the surface, extent, strike, and often dip are unknown. Where an unmapped, unmodeled fault displaces a unit in a borehole, resulting in a partial thickness in the borehole, the partial thickness must be used so that the remaining borehole data can be honored during model assembly (Figure 6-5). This result would be true for any modeling method used. The model isochore maps presented in this report are the maps used to construct the model, and therefore may contain artifacts of the modeling process like partial thicknesses as described in the preceding paragraph. In this regard, the model and its components including isochore maps, structure maps, and cross sections may differ from the results of traditional, two-dimensional field geology analyses in which the fit between data and surfaces is not rigorously defined in the third dimension (out of the plane of analysis). The three-dimensional model provides a more rigorous representation of subsurface geology than two-dimensional methods.

At each step of the modeling process, iterations were performed until the component or assembly provided an adequate representation in accordance with the conceptual model. Reasons for iterations included unacceptable shapes, a need for additional interpretive constraints or modification of those existing, modification to match the geologic map, or modification to produce more accurate fault displacements. The more iterations that are performed on the model or its components, the greater the accuracy of the results may become. The impact of using more iterations in GFM2000 than in previous model versions is increased accuracy of the model results. 


\subsubsection{Geologic Framework Model Conceptual Models}

As discussed in the following sections, interpretive constraints were used to guide the shapes of model isochores (thickness maps), which are the fundamental building blocks of the geologic framework model. The conceptual model described below was used to formulate the interpretive constraints based on the available data.

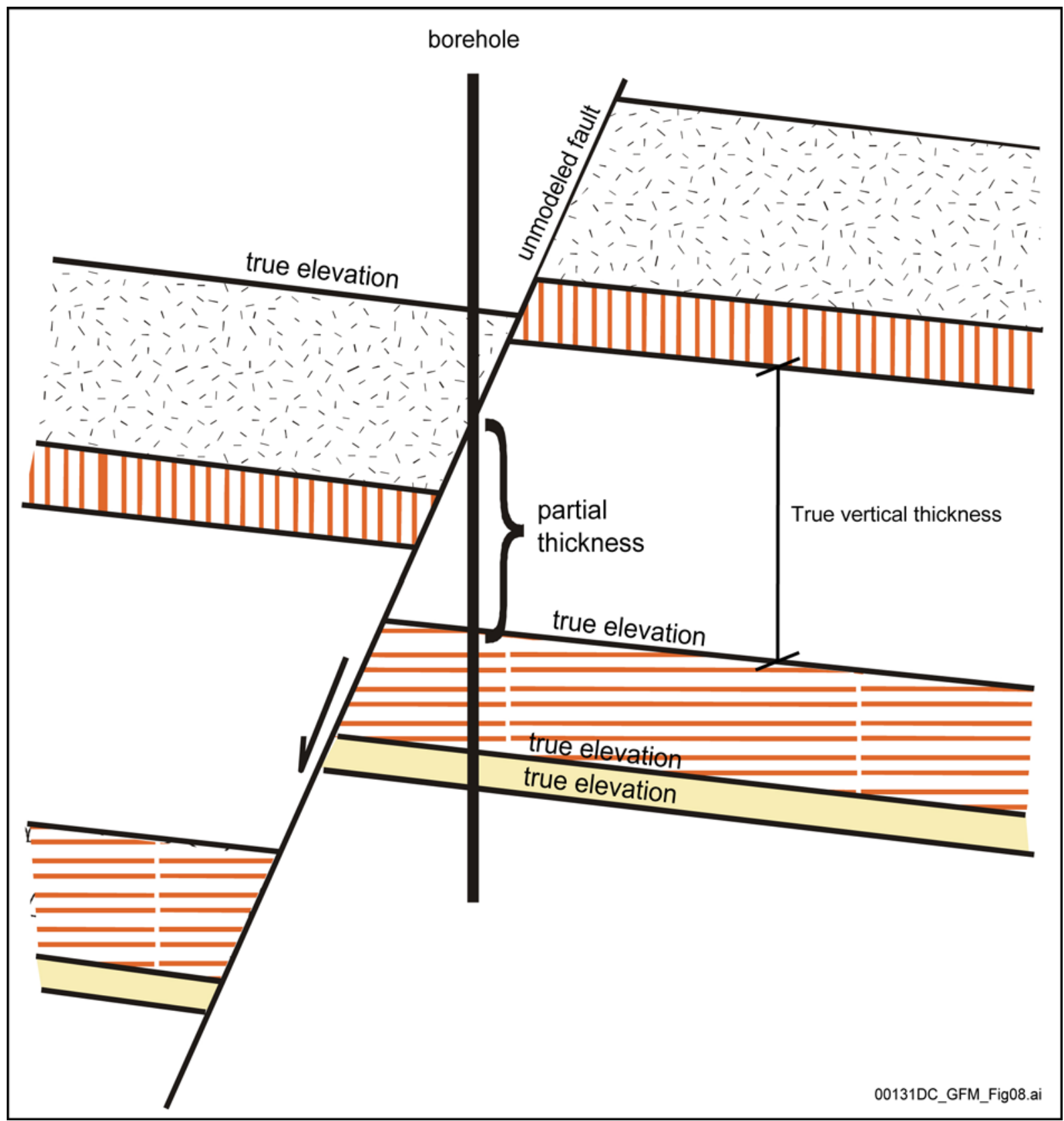

Source: For illustrative purpose only.

Figure 6-5. Schematic Cross Section Showing the Relation of Partial Thickness to Model Units 
The conceptual model used to construct the geologic framework model considers that Yucca Mountain is composed of volcanic rocks deposited from variously located calderas or vent sources (BSC 2004 [DIRS 169734], Section 2.3.5.1). The following geologic concepts were applied to construct the geologic framework model in accordance with the conceptual model:

- Volcanogenic rocks generally thin away from their sources.

- The major volcanic deposits at Yucca Mountain generally filled in preexisting topography (CRWMS M\&O 2000 [DIRS 151945], p. 4.3-9), so that the top of a formation may have been originally more planar than the base. (CRMS M\&O 2000 [DIRS 151945] has been cited here and elsewhere when BSC 2004 [DIRS 169734], with its more limited scope, does not include all previously cited information).

- The top of a formation may have eroded after deposition (erosion rates on bedrock ridges, (BSC 2004 [DIRS 169734], Section 2.3.5.1).

- The lower vitric zones of the Topopah Spring and Tiva Canyon Tuffs blanketed preexisting topography and began the process of filling in topographic lows.

- Topopah Spring Tuff lithophysal and nonlithophysal zones were produced by multiple processes (BSC 2004 [DIRS 169734], Section 3.3.4.7.1) and, although approximating a stratiform geometry (CRWMS M\&O 2000 [DIRS 151945], p. 4.5-4), these zones may have irregular thickness distributions.

No alternatives to the concepts listed above have been proposed. The conceptual model was applied to guide the shape of each model isochore between and away from the locations of input data (i.e., to interpolate and extrapolate). Alternative conceptual models that might affect the geologic framework model would differ only in details specific to particular units or locations. For example, an alternative (hypothetical) conceptual model might predict that the Tram Tuff thickens toward Crater Flat rather than thinning as conceived in the present geologic framework model. The impact of an alternative conceptual model like this would be to change the elevations and thicknesses of units in outlying areas where no data exist-few, if any, changes would occur in the vicinity of the ESF, which is the area of most interest to users of the geologic framework model, because the area is better constrained by borehole data. Uncertainty in the outlying areas is at least as great as the differences between potential alternative interpretations; therefore, the impacts of alternative conceptual models are unlikely to be significant to the geologic framework model or its users.

\subsubsection{Grid Construction}

The methodology for constructing GFM2000 included a combination of mathematical grid construction (gridding) and the application of interpretive constraints in accordance with the conceptual model. By using both, the model honors the measured data while allowing for interpretations in areas where data are sparse or where a grid generated by the model may initially conflict with the conceptual model or may be geologically unrealistic (that is, representing a feature in a way that is inconsistent with the way it is usually configured in nature). 
A grid is a systematic array of points, or nodes. In three dimensions, a grid forms a surface. Topography is an example of a surface that can be represented by a grid. Gridding is the process of creating a surface (grid) across an area based on widely and variably spaced input data. Many methods, both mathematical and interpretive, are available for use in creating surfaces in a model. Examples include triangulation, manual contouring, linear interpolation, geostatistical methods (including kriging), and various mathematical algorithms. The gridding method used in the geologic framework model is based on a minimum tension mathematical algorithm that calculates a surface passing through the input data and is an option in EARTHVISION. The minimum tension algorithm produces surfaces that have no abrupt flexures in the immediate vicinity of data, while still honoring all input data. Other gridding methods use other assumptions. Testing of the minimum tension algorithm during model construction and software qualification [Software Qualification Report (CRWMS M\&O 1998 [DIRS 138515], pp. 9 and 10)] indicated that it produces surfaces that are geologically realistic and closely honor the input data; it was selected for these reasons. The impact on the geologic framework model results of using other methods for creating grids or triangulated surfaces would be a slightly altered appearance of maps produced from the model and small differences in grid values at interpolated locations between data points. Significant differences would be unlikely, especially in the vicinity of the ESF where data are most abundant. The most significant differences produced by alternative methods would more likely be caused by interpretive differences rather than by the gridding algorithms, and would be restricted to outlying areas. Impacts of alternate gridding methods on geologic framework model users would be small compared to uncertainty; therefore, no practical impact would be anticipated.

For every grid in the geologic framework model, the minimum tension algorithm is constrained by field data (from boreholes, tunnels, measured sections, or the geologic map) and interpretive constraints in the form of contour segments (discussed in the next section). Grid node spacing for all grids except topography is 200 by 200 feet (61 by 61 meters). During the initial stages of earlier model versions, this node spacing was determined to be the largest that would adequately represent the input data without compromising computation time. The topographic grid spacing is 100 by 100 feet (30 by 30 meters) to accurately represent details of the ground surface (which is known in more detail than underground surfaces) and to produce more accurate surface maps and obtain more accurate surface information from the model.

In the geologic framework model, grids are the fundamental building blocks of the model. Grids were created to define fault planes, reference horizons, and model isochores. For fault planes and reference horizons, each node contains an elevation. For model isochores, each node contains a thickness value. The advantage of a grid over scattered data and manual forms of contouring and triangulation is that the grid can be operated on mathematically and can be used to apply mathematical or geological rules to interpolate a surface between data points or to extrapolate away from them.

Minimum tension gridding begins with an initial grid estimate in which data nearest each grid node are sampled to calculate a value for the grid node. In the estimate, only the data nearest to the node are sampled. At each grid node, the data values are averaged using an inverse-distance weighting function, with weighting also dependent on the angular distribution of the data. Weighting is necessary to produce a grid that transitions smoothly from one data point to another. The weighted average at each grid node is the initial estimate and takes into account all 
data provided for gridding (both field data and interpretive constraints, if provided). The initial estimated grid node values are then reevaluated by means of a biharmonic cubic spline function within EARTHVISION. This function distributes curvature across the surface rather than forming sharp flexures at data points - this is the primary characteristic of a minimum tension grid. The final step is refitting the grid to the field data (without the interpretive constraints) and a final distribution of curvature by the biharmonic cubic spline function.

\subsubsection{Interpretive Constraints}

As illustrated in Figure 6-6, interpretive constraints in the form of contour segments inserted into the model were used to control the shapes of grids in accordance with the conceptual model. The use of interpretive constraints results in a model that, in addition to honoring the data, applies basic geologic concepts to interpolate and extrapolate from the data. The interpretive constraints do not replace or alter data. The reference horizon, fault, and model isochore grids in the geologic framework model were calculated with the use of both field data and the interpretive constraints. None of the grids represent a purely mathematical representation of field data, but all were adjusted by interpretive constraints to produce results consistent with the geologic conceptual model. The impact of interpretive constraints is to produce a geologic framework model that more closely represents basic geologic concepts and the conceptual geologic model. The interpretive constraints may be found in the GFM2000 data submittal (DTN: MO0012MWDGFM02.002 [DIRS 153777]).

In the process of modeling, it was discovered that the minimum tension algorithm produces the most geologically reasonable and predictable results when the input data and interpretive contours are distributed more or less evenly across the model area. Therefore, interpretive contours were placed only in data gaps and never closer than about five grid nodes (1,000 feet [300 meters]) to input data. The wide distribution of interpretive contours also prevented unintended extrapolations. In this way, a balance was struck between the mathematical prediction of the gridding algorithm and geologic interpretation according to the conceptual model.

The process for creating grids for faults, reference horizons, and model isochores consisted of the following steps:

1. The field data were first gridded without any interpretive constraints. These results were analyzed to determine whether interpretive constraints were needed and to choose the most appropriate locations for their use.

2. The grid was then modified by introducing interpretive contours, and regridding.

3. The process was iterated until the grid adequately represented the conceptual model. 


\subsubsection{Construction of Faults}

Grids representing faults were constructed primarily with the use of data from the geologic map, boreholes, and tunnel intercepts. Interpretive contours were used to create the dip of the fault plane consistent with input data, and the grid was calculated using the data plus interpretive contours. The interpretive contours were then modified as needed to produce consistent results. Seismic profile data (Brocher et al. 1998 [DIRS 100022], pp. 947 to 971) were examined to confirm the geometries of the Paintbrush Canyon and Solitario Canyon faults by comparison of the seismic data to a cross section through the model at the same location. High-resolution seismic reflection data [Surface Geophysics. Volume I of Synthesis of Borehole and Surface Geophysical Studies at Yucca Mountain, Nevada and Vicinity (Majer et al. 1996 [DIRS 104685], maps)] were also examined to confirm stratal geometries.

\subsubsection{Construction of Reference Horizons and Model Isochores}

In geologic modeling, a reference horizon is an elevation grid that establishes the strike and dip of the rock layers and the displacement of rock layers along faults. Where the grid crosses a fault, the grid is displaced by the appropriate amount. The grid is constructed with the use of data from the geologic map, boreholes, and tunnels. Thicknesses (isochores) of other rock layers are then added to or subtracted from the reference horizon to create the other rock units in the model, as illustrated in Figure 6-4. The reference horizon and model isochore grids were constructed by the methods discussed in Section 6.4.

The reference horizon was constructed for the base of the Tiva Canyon Tuff (top of Tpbt4, the pre-Tiva bedded tuff). This horizon was chosen because it is well constrained by geologic map and borehole data. It is also a major lithologic break that is readily correlated from one data set to another; thus, the available data are both widespread and consistent. The reference horizon is illustrated in Figure 6-7 as output from the assembled geologic framework model, which includes the effects of erosion at the ground surface and at the base of alluvium (the noncontoured areas in Figure 6-7). When the model is first constructed, the reference horizon is not eroded so that it can provide elevation constraints at all locations. The effects of erosion are calculated during model assembly.

The Tertiary-Paleozoic unconformity and the topography (see Table 4-1 for DTNs) were provided as elevation grids and no model isochores were constructed. The Tpcr/Tpcp boundary was constructed as an elevation grid directly from abundant geologic map data because it is severely eroded in the area and few borehole data are available, making model isochore mapping impractical. 


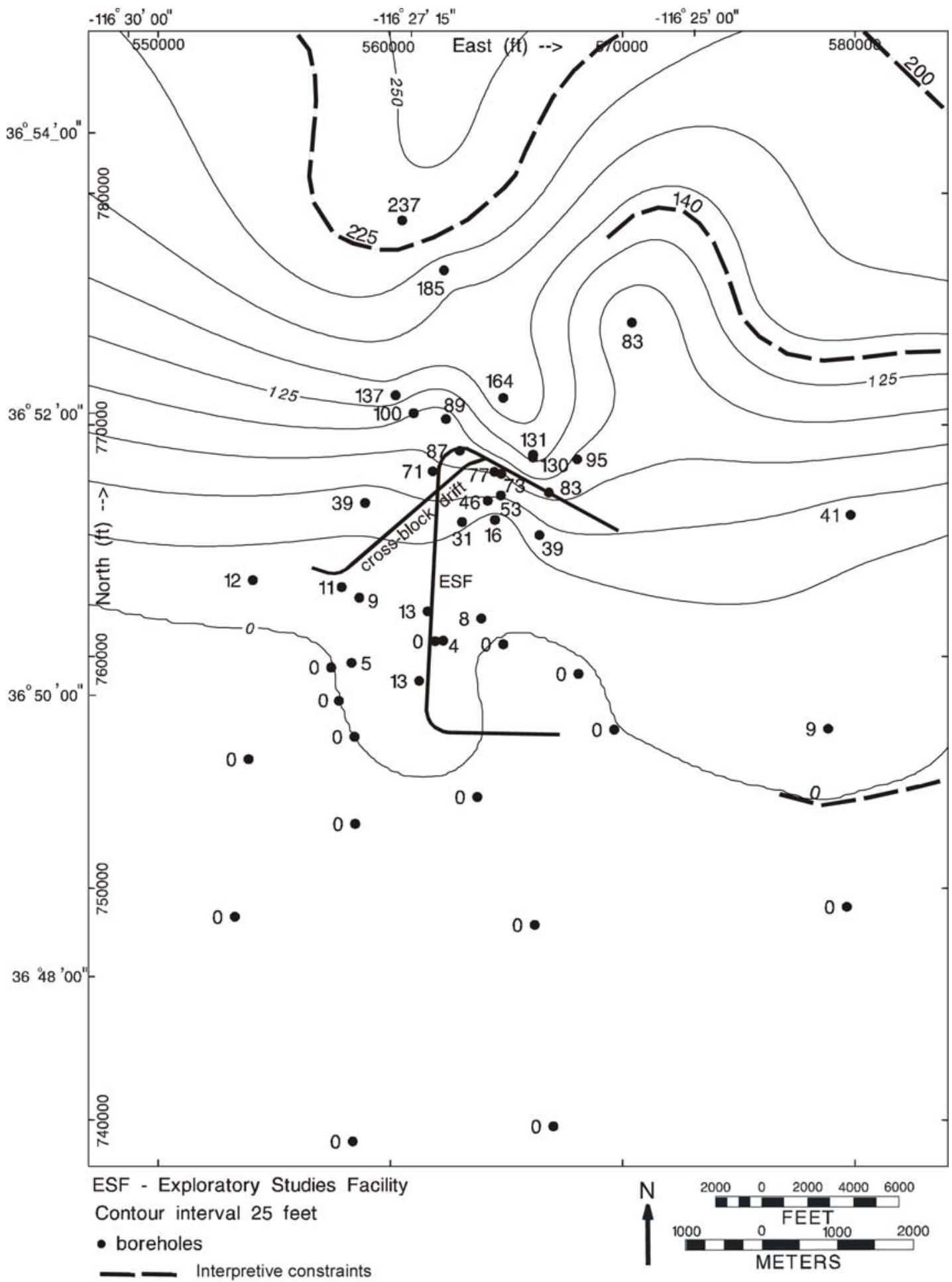

00131DC_GFM_Fig09.ai

Source: For illustrative purpose only.

NOTE: Obliterated text has no technical impact to the document.

Figure 6-6. Example of Interpretive Constraints 


\subsubsection{Assembly of Faults and Rock Layers}

The reference horizon grids, model isochore grids, and fault grids were combined to produce the final model. In the combination, calculations were performed within the EARTHVISION software to determine the intersections of faults and rock units, and this information was stored with each grid. The final model consists of a grid for each rock unit in each fault block (a fault block is the volume of rock between faults) and a grid for each fault. The total number of grids in GFM2000 is 2,287 (50 units $\times 44$ fault blocks +43 faults +44 isochores $=2,287$ grids).

Information about how all the grids fit together was recorded in a parameter file called a "sequence" file, which is in plain text format. The sequence file can be used for subsequent analyses or operations on the model; it is included in the GFM2000 data submittal (DTN: MO0012MWDGFM02.002 [DIRS 153777]) as the file named "GFM2000final.seq."

The grids of faults and horizons comprise the model, and are the output that is used by geologic framework model users. Besides this output, a graphical construction called a "faces" model was also created to allow visual examination of the model in three dimensions on the computer. The term "faces" is an analogy to crystal faces, which form multiple layers comprising an ordered three-dimensional volume. The faces model uses the grids of reference horizons and faults to create a three-dimensional model for display. In the display, rock layers and faults can be shown individually or in any combination. Examples of three-dimensional views of the faces models are provided in Figures 6-8 (a vertical view) and 6-9 (a perspective view). The faces model is used for quality control, assessment of results, and production of illustrations, and is not used as input to any subsequent models.

\subsection{RESULTS AND DISCUSSION}

The results of the geologic framework model provide a representation of the spatial position and geometry of rock units and faults. To fulfill the needs of users of the geologic framework model without the prohibitive length and repetition of explicitly discussing all 50 modeled units, this section discusses the model results in terms of rock units and faults that are important to other integrated site model component models (rock properties model and mineralogic model) and geologic framework model users. Some rock units are grouped into thermal-mechanical units, and others are discussed by depositional formation (Topopah Spring Tuff, Calico Hills Formation, etc.). The maximum and minimum thicknesses of rock units are discussed in terms of input borehole and geologic map data, not in terms of projected maxima and minima. On the thickness maps in this section, only boreholes that completely penetrate a unit and could be used as input are included-if a borehole is not shown on a map, it provided no input data for that map. The borehole thickness values were rounded to the nearest foot before subtraction to calculate the thickness value. As a result, subtraction using the decimals in the source data may differ from those on the map by 1 foot. This rounding was only performed during figure generation, and was not done in model construction. 


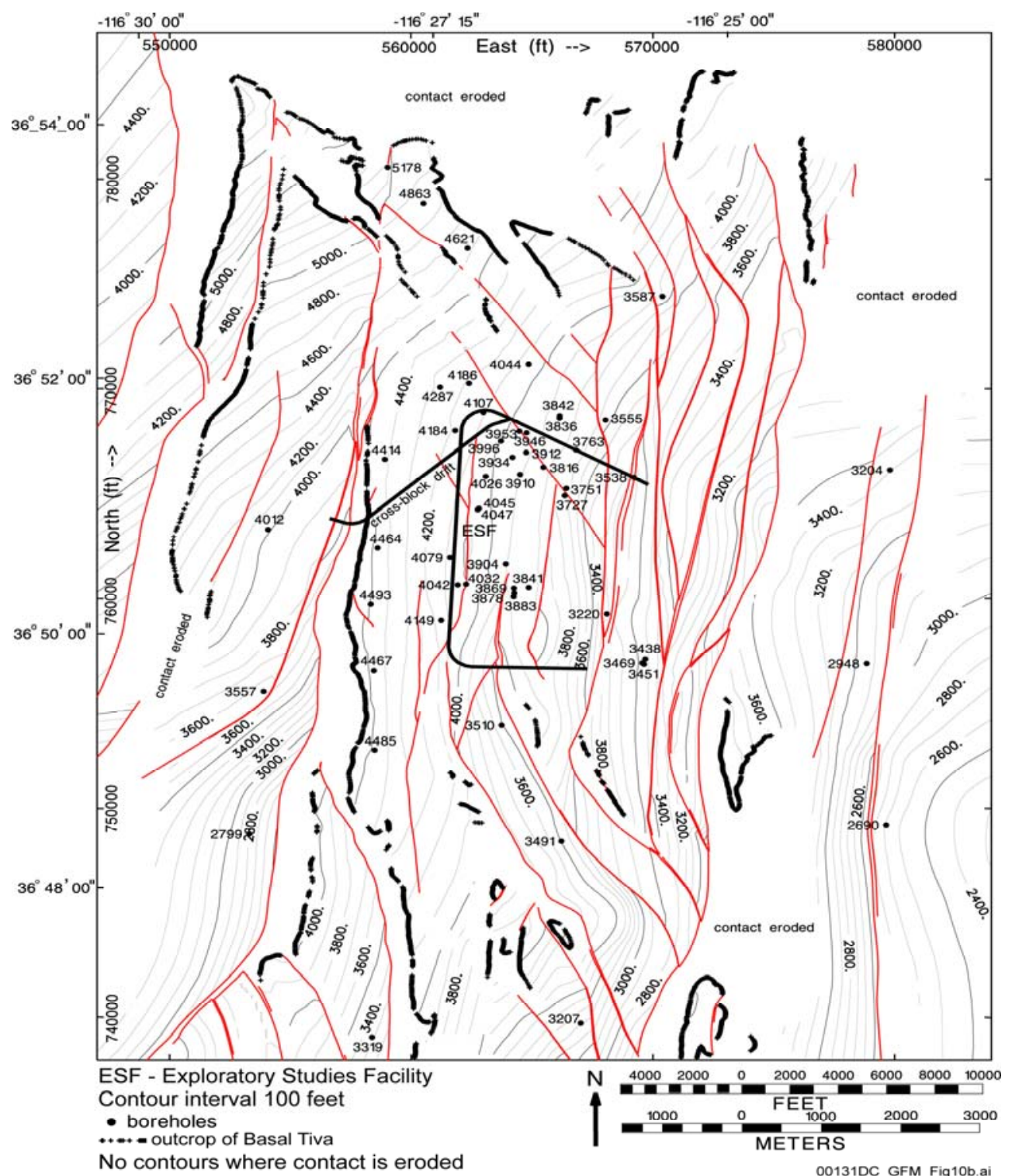

Source DTN: MO0012MWDGFM02.002 [DIRS 153777].

Figure 6-7. Elevation Map of Basal Tiva Reference Horizon 


\subsubsection{Interpretation of Rock Units}

This section describes the geometry and distribution of rock units in the geologic framework model that are important for the integrated site model, rock properties model, and mineralogic model, as well as the major direct and indirect users of the geologic framework model (repository design and hydrologic flow modeling through the UZ and the SZ). Each geologic formation is described, as well as the interval from the top of Tpcpv2 to the top of Tptrv1 (the Paintbrush nonwelded [PTn] unit), the undifferentiated older Tertiary unit (Tund), and the Tertiary-Paleozoic unconformity. Subunits of the formations that are particularly important for geologic framework model users are also described.

Regional stratigraphy and structure, deposition, origin, age, and lithology of the rock layers modeled in the geologic framework model are discussed in BSC (2004 [DIRS 169734], Sections 3.3.1 and 3.3.4).

\subsubsection{Alluvium and Post-Tiva Units}

Overview-The alluvium (Qal) and post-Tiva rock units (Table 6-2) in the geologic framework model account for a very small amount of the total model volume (much less than 1 percent), and they occur well above and outside the vicinity of the ESF.

Data Distribution and Unit Geometry-The distribution of modeled alluvium is illustrated in Figure 6-10. Alluvial thickness was interpreted with the use of the site area geologic map (DTN: GS980608314221.002 [DIRS 107024]) and available borehole lithologic log data (Table 4-1). Depth of alluvium in narrow washes was in part determined by projecting the bedrock slopes into the subsurface. This method produced good agreement with available borehole data. The areal extent of alluvium is well constrained by the geologic map, but borehole coverage is limited. 


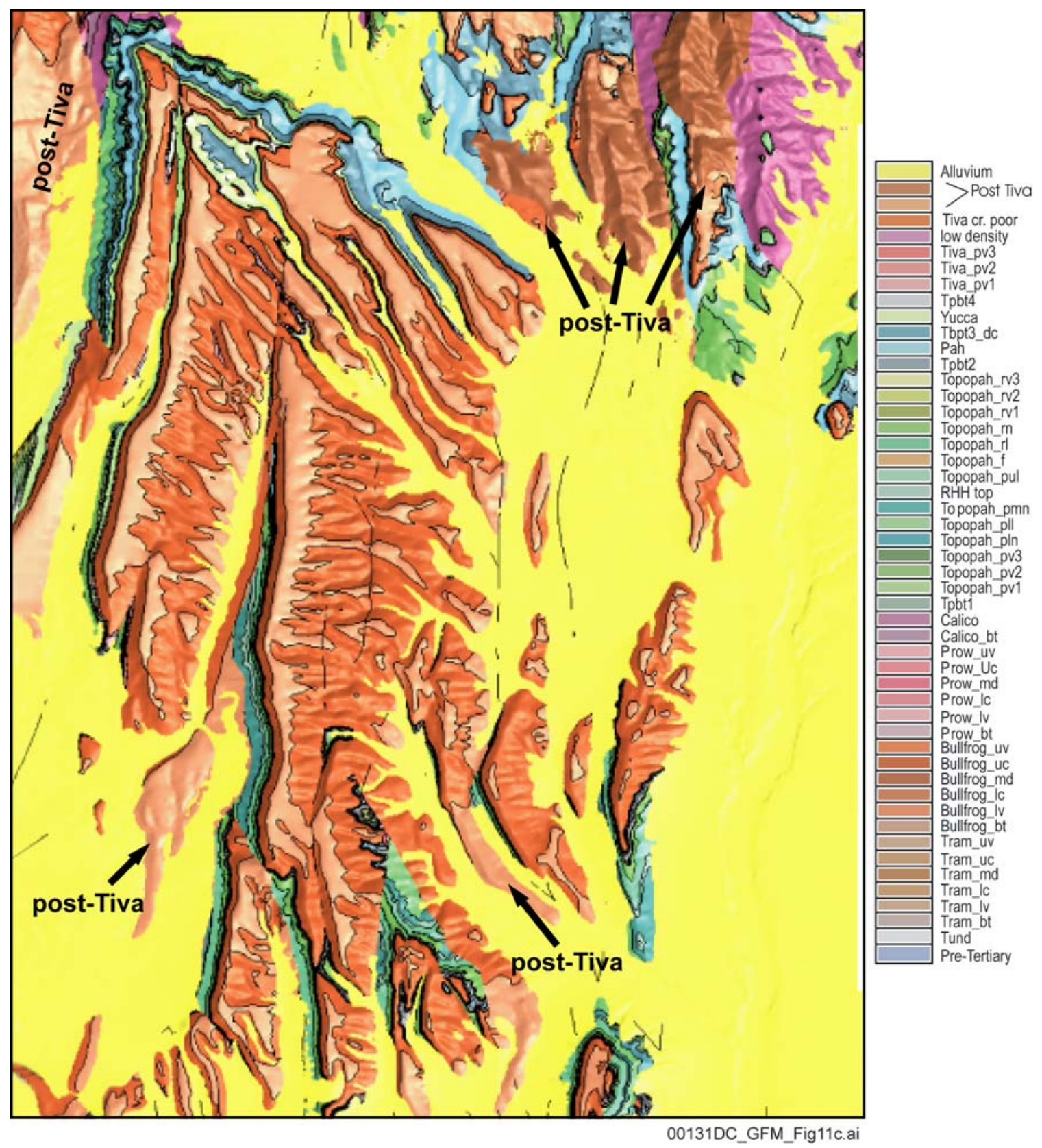

Source DTN: MO0012MWDGFM02.002 [DIRS 153777].

NOTE: Vertical View of GFM2000. (Same area as Figure 1-1.)

Figure 6-8. Model Surficial Geology 


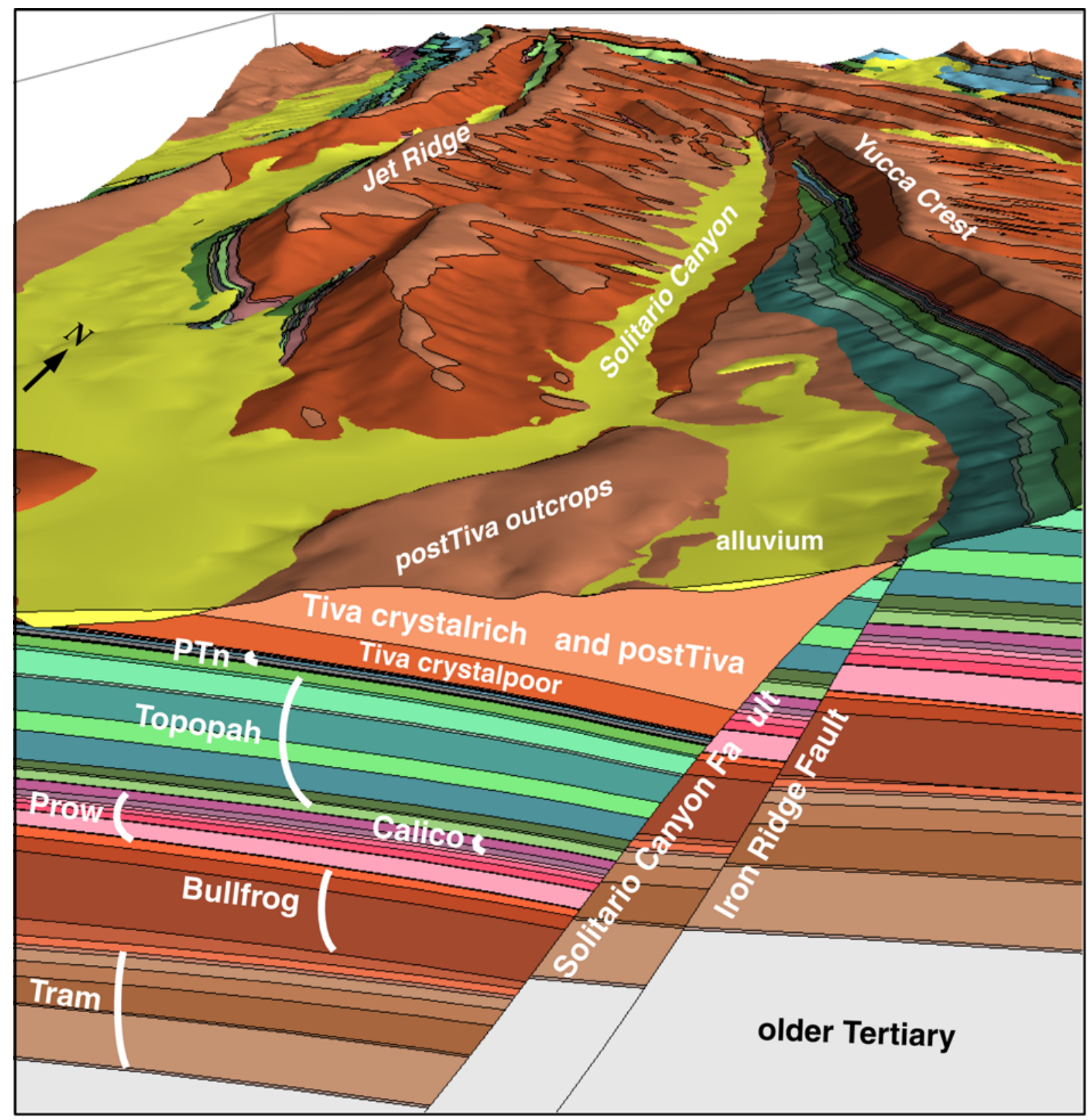

00131DC_GFM_Fig12a.ai

Source DTN: MO0012MWDGFM02.002 [DIRS 153777].

Figure 6-9. Perspective View of Model Showing Wedge of Post-Tiva Rocks in Solitario Canyon 
Because the base of alluvium is an unconformity and is therefore likely to have significant relief, the map in Figure 6-10 has a high level of uncertainty. This uncertainty is unlikely to have adverse impact on geologic framework model users because alluvium is only a significant feature in infiltration modeling, where alluvium is modeled in thickness groups with limits of 0.0, 1.6, 9.8, and 20 feet $(0.0,0.5,3.0$, and 6.0 meters) (BSC 2004 [DIRS 169734], Section 7.1.3.4). Only a small percentage of the modeled alluvium is less than 20 feet (6 meters) thick.

As shown in the map view (Figure 6-8), the post-Tiva rock units are only sparsely encountered in the modeled area. The distribution is based on the geologic map (DTN: GS980608314221.002 [DIRS 107024]) and borehole data (see Table 4-1). South of Yucca Wash, these units are typically preserved in wedges on the downthrown sides of faults. For example, in Figure 6-9, a wedge of the Tiva Canyon Tuff Crystal-Rich Member and post-Tiva unit is shown on the downthrown side of the Solitario Canyon fault.

\subsubsection{Tiva Canyon Tuff (Tpc)}

Overview-In the geologic framework model, the Tiva Canyon Tuff (Table 6-2) consists of the Crystal-Rich Member (Tpcr, grouped with post-Tiva rocks) and the Crystal-Poor Member (Трср), which is undivided in the geologic framework model except for the three basal vitric subzones (Tpcpv1, Tpcpv2, and Tpcpv3) and a low-density zone (TpcLD). The densely welded vitric subzone (Tpcpv3) is referred to as the "vitrophyre," which is a volcanic rock with a glassy groundmass. The Tiva Canyon Tuff makes up most of the exposed bedrock in the modeled area (Figure 6-8).

Because the Tiva Canyon Tuff makes up most of the exposed bedrock on Yucca Mountain, it is important in hydrologic infiltration modeling. The distribution of the lower vitrophyre (Tpcpv3) may be important in hydrologic modeling because, like the other vitrophyres, the lower vitrophyre is one of the layers in the mountain having low porosity (BSC 2004 [DIRS 169734], Section 7.2.1.2).

Data Distribution and Unit Geometry-Because the top of the Tiva Canyon Tuff is extensively eroded in the model area, none of the input boreholes penetrate the entire formation, and a true thickness map cannot be produced. The Tiva Canyon Tuff is thickest in the center of the modeled area and thins to the east, west, and south. The distribution and thickness of Tpcpv3 are illustrated in Figure 6-11. The model interpretation for this unit is based on borehole data (see Table 4-1) and abundant geologic map data (DTN: GS980608314221.002 [DIRS 107024]). The crystal-poor densely welded vitric subzone (Tpcpv3) is present only in the southwestern part of the area and appears to be distributed as pods or in a web-like pattern (Figure 6-11).

\subsubsection{Paintbrush Nonwelded (PTn) Unit}

Overview-The PTn unit is a grouping of rock layers that have similar physical properties, and is used in hydrologic and thermal-mechanical modeling. Stratigraphically, it consists of the rock units Tpcpv2, Tpcpv1, Tpbt4, Tpy, Tpbt3, Tpp, Tpbt2, Tptrv3, and Tptrv2 (Table 6-2). 


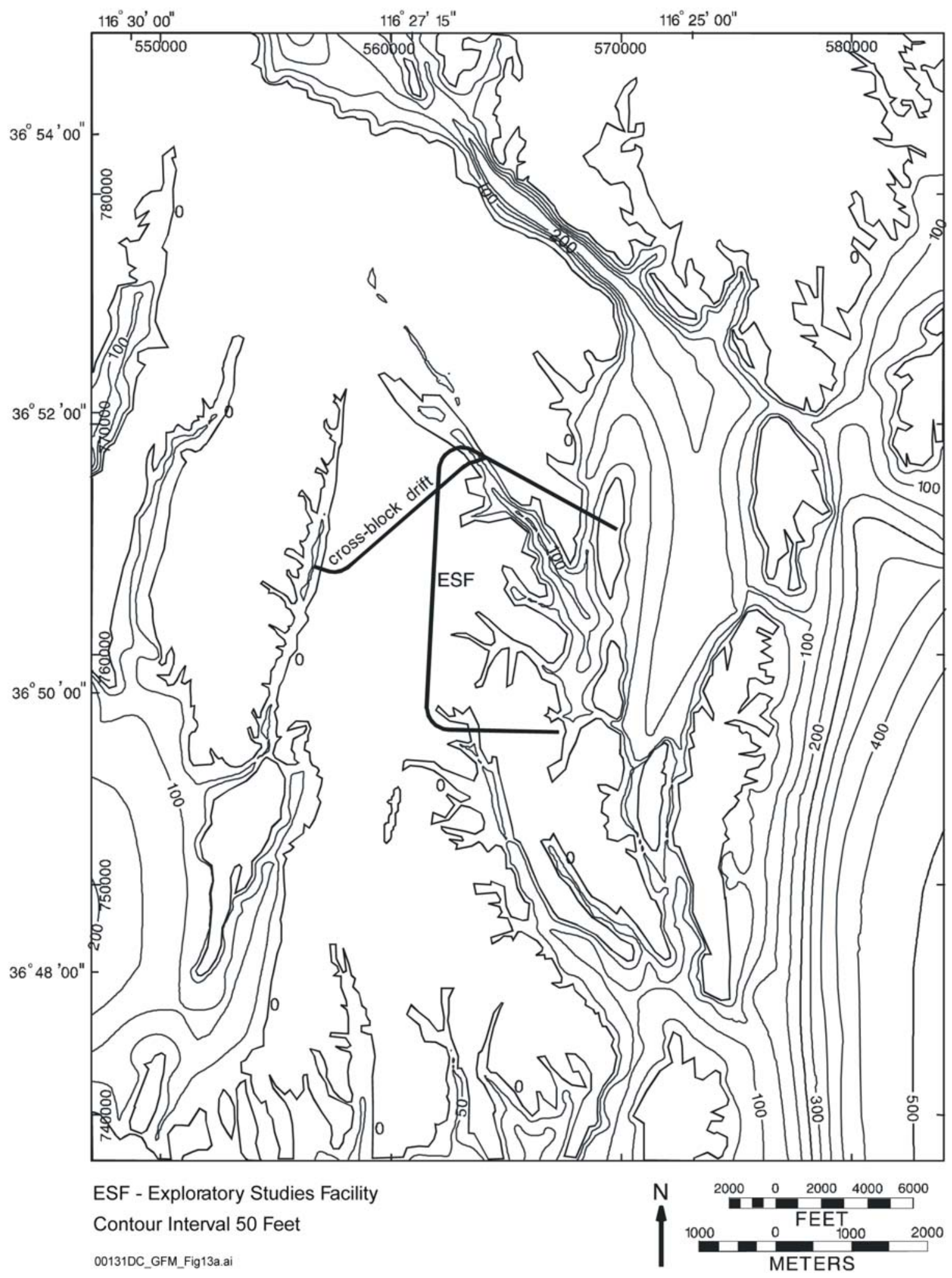

Source DTN: MO0012MWDGFM02.002 [DIRS 153777].

Figure 6-10. Model-Isochore Map of Alluvium 


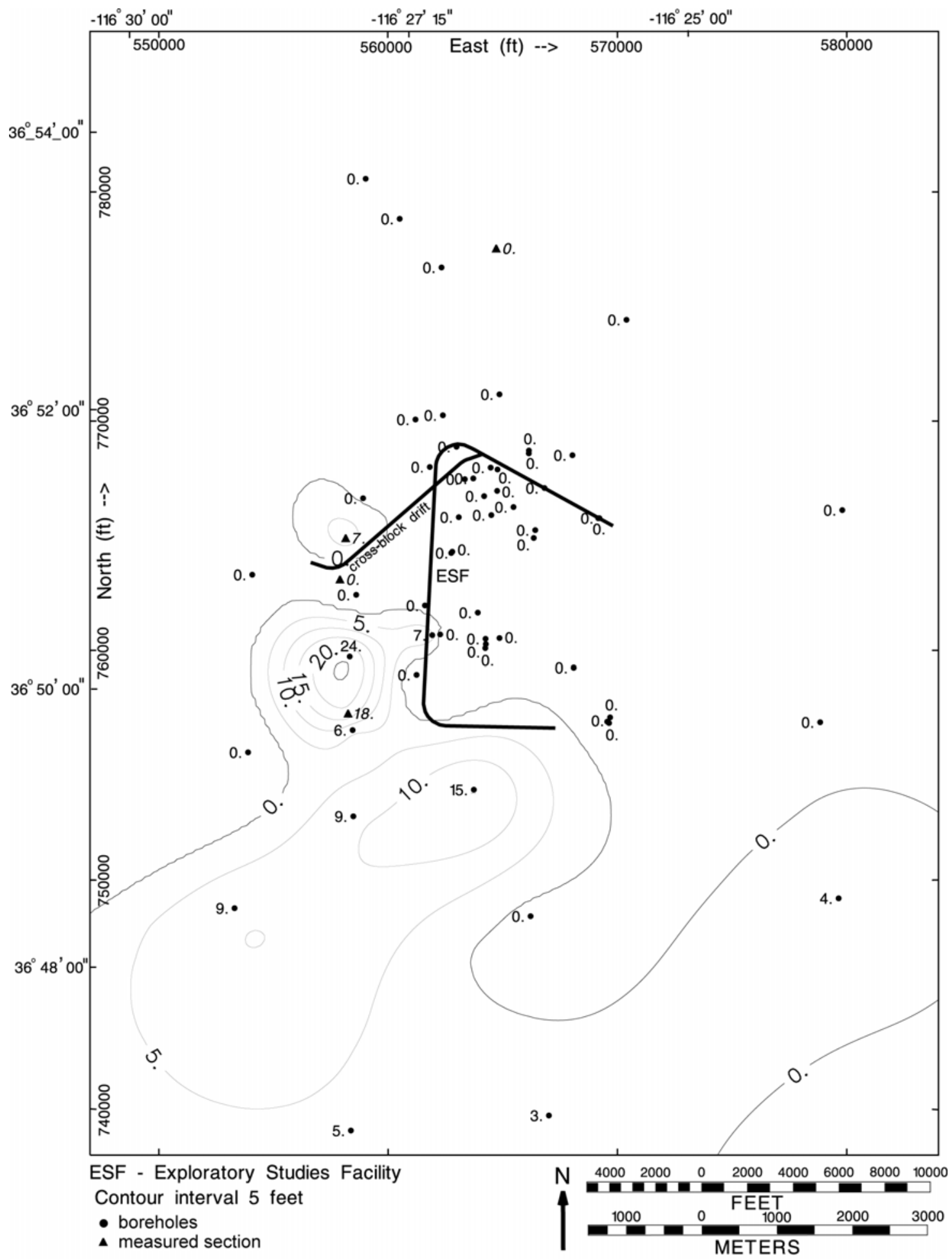

00131DC_GFM_Fig14b.ai

Source DTN: $\quad$ MO0012MWDGFM02.002 [DIRS 153777].

Figure 6-11. Model-Isochore Map of Tiva Canyon Tuff Crystal-Poor Member Vitric Zone Densely Welded Subzone (Tpcpv3) 
Because the mostly nonwelded rocks of the PTn unit are distinct from the welded rocks above and below, the distribution and thickness of the PTn unit are important in hydrologic modeling. The PTn unit has been hypothesized to cause lateral diversion of downward flow (BSC 2004 [DIRS 169734], Section 7.1.4.4). Modeling results support this hypothesis [FY 01 Supplemental Science and Performance Analyses, Volume 1: Scientific Bases and Analyses (BSC 2001 [DIRS 155950] Section 3.3.3)].

Data Distribution and Unit Geometry-The model interpretation for the PTn unit is based on input data from 51 boreholes that fully penetrate the unit (DTN: MO0004QGFMPICK.000 [DIRS 152554]), measured section PTn\#3 (DTN: GS950108314211.003 [DIRS 109066]), and abundant geologic map data (DTN: GS980608314221.002 [DIRS 107024]). Additional boreholes partially penetrate the PTn unit but do not provide information on total thickness. The major formations of the PTn unit, the Yucca Mountain Tuff (Tpy; Figure 6-12) and Pah Canyon Tuff (Tpp; Figure 6-13), both thicken dramatically to the north and northwest but are absent over the southern half of the modeled area. In the southern half of the modeled area, the PTn unit comprises bedded tuffs (Tpbt2, Tpbt3, and Tpbt4) and the vitric units of the lower Tiva Canyon Tuff (Tpcpv1 and Tpcpv2) and the upper Topopah Spring Tuff (Tptrv2 and Tptrv3). (Unit thickness data for Tpp in borehole UZ-N37 was inadvertently omitted in the preparation of the isochores illustrated in Figure 6-13. The difference between modeled thickness [63 feet] and borehole thickness [71 feet] is within the uncertainty for the model and results in no impact for users of the geologic framework model.) A model isochore map of the PTn unit is shown in Figure 6-14. In the vicinity of the ESF, the PTn unit is 67 to 387 feet (20.4 to 118.0 meters) thick and thickens rapidly to the north to 542 feet (165.2 meters) in borehole G-2.

\subsubsection{Topopah Spring Tuff (Tpt)}

Overview-The Topopah Spring Tuff encompasses the RHH (identified in Table 6-2) as well as lithologically distinct units used in modeling rock properties, mineralogy, and hydrologic flow. The Topopah Spring Tuff is exposed locally in the northern, western, and southeastern parts of the modeled area, as can be seen in Figure 6-8.

The Topopah Spring Tuff is important for the repository design because it encompasses the RHH. The distributions and thicknesses of the densely welded vitric subzones of the Topopah Spring Tuff are important for hydrologic modeling because their physical characteristics affect hydrologic flow (BSC 2004 [DIRS 169734], Section 7.1.3.3). In addition, the distribution of the Topopah lower densely welded vitric subzone (Tptpv3) is important because it bounds the bottom of the RHH. The lithic-rich unit (referred to in the geologic framework model as Tptf) is important for the geologic interpretation of the Topopah Spring Tuff because it provides information on the transition from crystal-poor to crystal-rich units.

Data Distribution and Unit Geometry-The model interpretation for this formation is based on input data from 34 boreholes that fully penetrate the formation (DTN: MO0004QGFMPICK.000 [DIRS 152554]), tunnel data (DTN: GS960908314224.020 [DIRS 106059]; GS970808314224.016 [DIRS 109061]), and abundant geologic map data (DTN: GS980608314221.002 [DIRS 107024]). Twenty-three additional input boreholes partially penetrate the formation but do not provide information on total thickness. North of Yucca Wash, the model was constructed using the geologic map data 
(DTN: GS980608314221.002 [DIRS 107024]) and the conceptual model discussed in Section 6.4.1. Based on the input data, the Topopah Spring Tuff reaches a maximum thickness of more than 1,200 feet (365 meters) along a northwest-southeast axis located across the vicinity of the ESF (Figure 6-15). The Topopah Spring Tuff thins rapidly toward the northeast and pinches out at the far northeastern corner of the modeled area (DTN: GS980608314221.002 [DIRS 107024]). To the southeast, the thickness diminishes to less than 750 feet (229 meters).

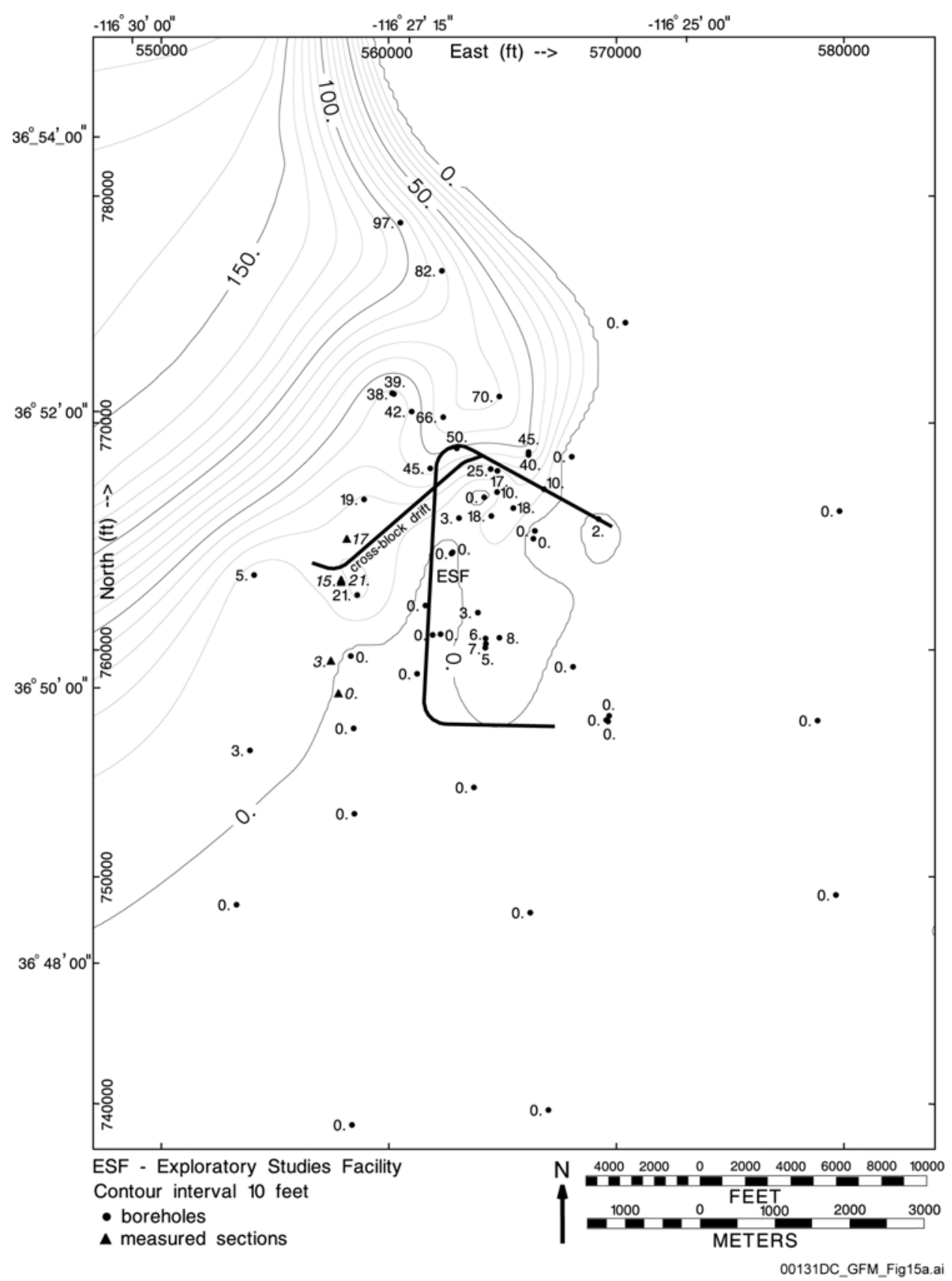

Source DTN: MO0012MWDGFM02.002 [DIRS 153777].

Figure 6-12. Model-Isochore Map of Yucca Mountain Tuff (Tpy) 


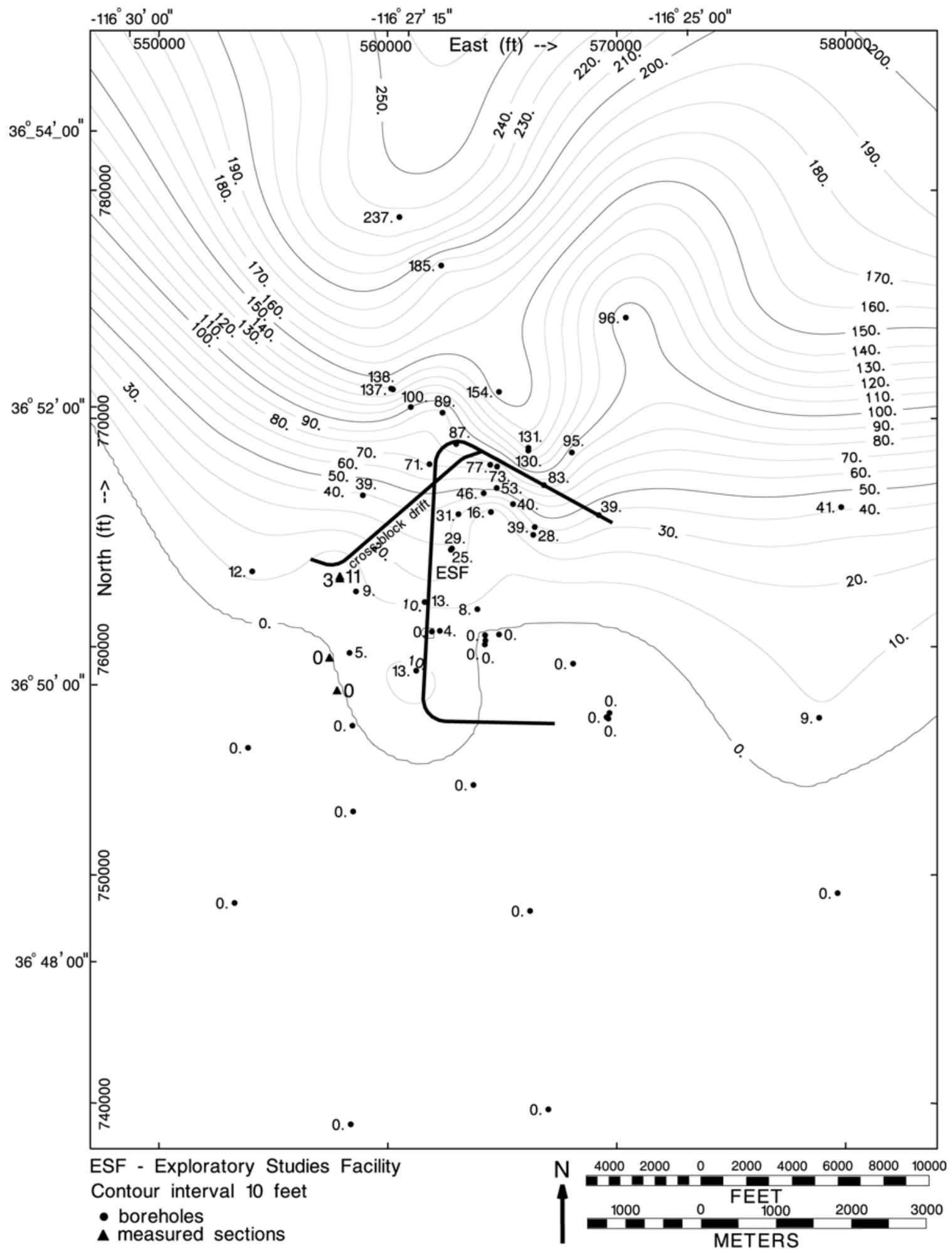

00131DC_GFM_Fig16a.ai

Source DTN: MO0012MWDGFM02.002 [DIRS 153777].

Figure 6-13. Model-Isochore Map of Pah Canyon Tuff (Tpp) 


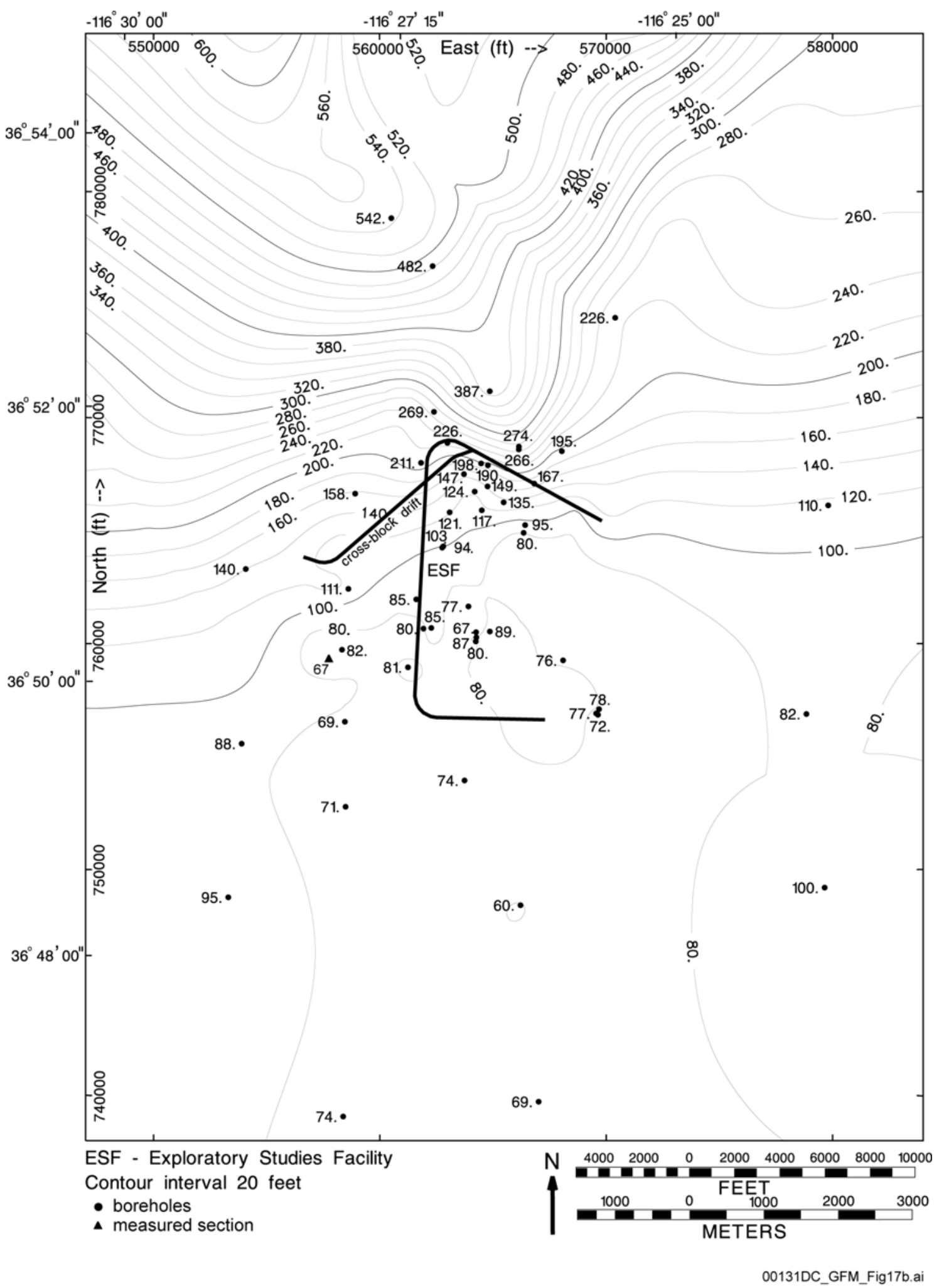

Source DTN: MO0012MWDGFM02.002 [DIRS 153777].

Figure 6-14. Model-Isochore Map of Paintbrush Nonwelded Unit (PTn) 
The crystal-rich densely welded vitric subzone (Tptrv1) near the top of the Topopah Spring Tuff is less than 10 feet (3 meters) thick over most of the modeled area, but is absent in a few isolated areas. The vitrophyre (densely welded vitric subzone) near the bottom of the formation (Tptpv3) is much thicker, ranging from 24 to 114 feet (7.3 to 34.7 meters) in the vicinity of the ESF and from 0 to 115 feet ( 0 to 35 meters) across the total modeled area (Figure 6-16). It pinches out only where the formation pinches out, in the northeastern corner of the modeled area. The thicknesses of both vitrophyre units vary by as much as 300 percent over distances as short as 2,000 feet (610 meters). The thickness of Tptpv3 in the southwestern corner of the modeled area is unconstrained, but was extrapolated to allow projection to the 155-foot (47-meter) thickness observed in borehole VH-2 in Crater Flat (Carr and Parrish 1985 [DIRS 101093], Table 2), approximately 4 miles (6 kilometers) west-southwest of the boundary of the modeled area.

The anomalously thin Tptpv3 in borehole WT-1 is due to faulting of the unit. The faulted thickness was used in the model so that all stratigraphic contacts could be honored; if a projected true thickness were used and no fault explicitly modeled at this rock layer, the model could not honor the rest of the stratigraphic contacts in the borehole. No fault was included at this rock layer because no spatial information about the fault is available.

A xenolithic unit (defined in the geologic framework model as Tptf) (Figure 6-17) straddles the Topopah Spring Tuff Crystal-Rich/Crystal-Poor Member boundary [Proposed Stratigraphic Nomenclature and Macroscopic Identification of Lithostratigraphic Units of the Paintbrush Group Exposed at Yucca Mountain, Nevada (Buesch et al. 1996 [DIRS 100106], p. 41)]. This unit is present only in the vicinity of Yucca Wash and northward and has not been observed in the vicinity of the ESF. It reaches a maximum known thickness of 68 feet (21 meters) in borehole G-2.

The RHH (identified in Table 6-2) includes model units RHHtop (representing the lower part of Tptpul), Tptpmn, Tptpll, and Tptpln within the Topopah Spring Tuff. The thickness of this unit mimics that of the total Topopah Spring Tuff-it reaches a maximum thickness of more than 750 feet (230 meters) along the same northwest-southeast axis (Figure 6-18). The thickness of the unit ranges from about 412 to 760 feet (126 to 232 meters) in the vicinity of the ESF and is modeled as decreasing to less than 200 feet (61 meters) to the southeast.

\subsubsection{Calico Hills Formation (Ta)}

Overview-The Calico Hills Formation crops out in the northern part of the modeled area, as well as at one isolated exposure at Busted Butte near the southern boundary of the modeled area.

The Calico Hills Formation is important for hydrologic and radionuclide transport modeling because it lies in the flow path between the repository and the water table (DTN: MO0106RIB00038.001 [DIRS 155631]). Over much of the modeled area, the formation has been altered to zeolites and clay minerals (BSC 2004 [DIRS 169734], Section 3.3.4.6), which may retard certain radionuclides (BSC 2004 [DIRS 169734], Section 7.9.2.3). 


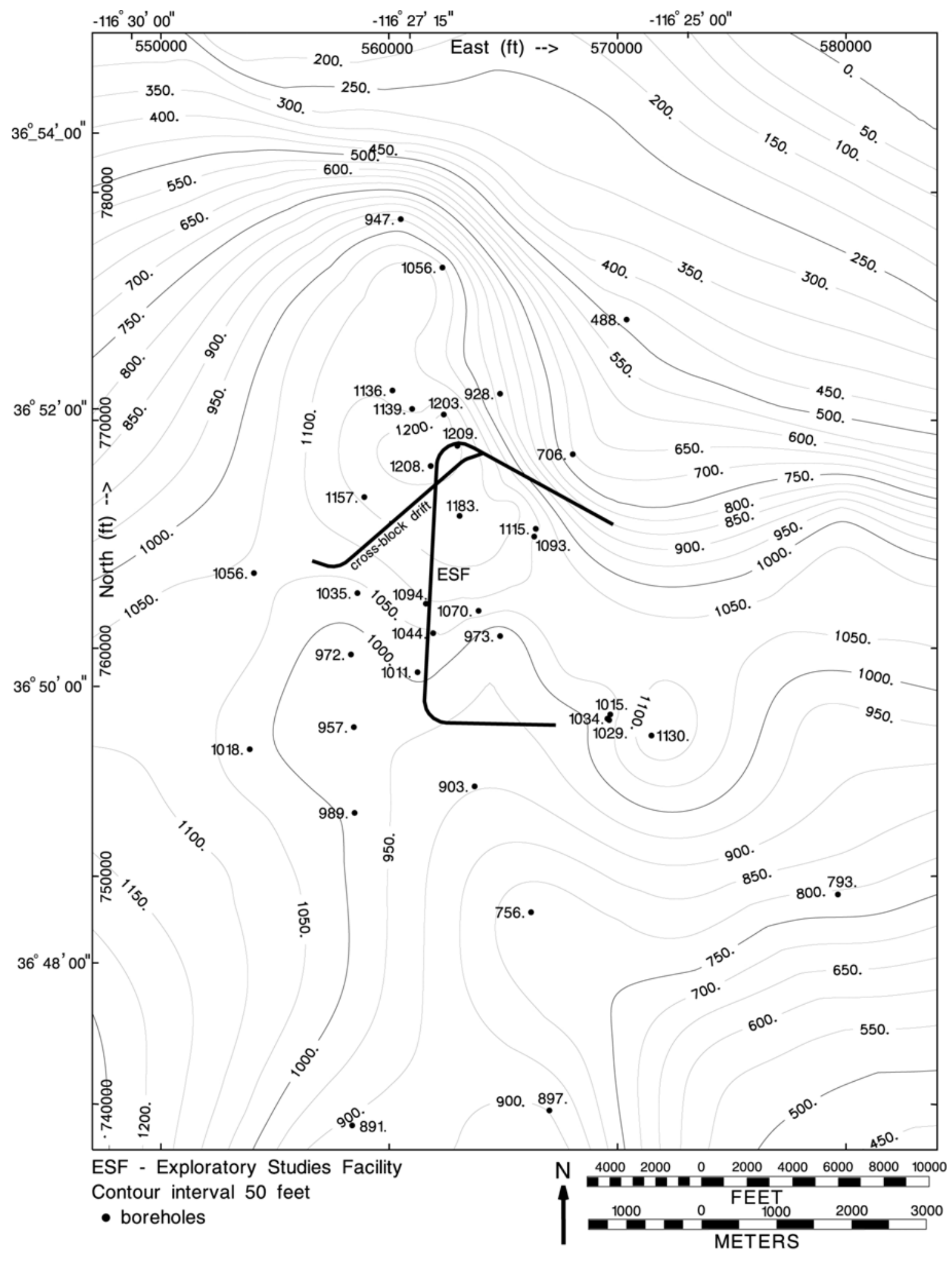

00131DC_GFM_Fig18a.ai

Source DTN: MO0012MWDGFM02.002 [DIRS 153777].

Figure 6-15. Model-Isochore Map of Topopah Spring Tuff (Tpt) 


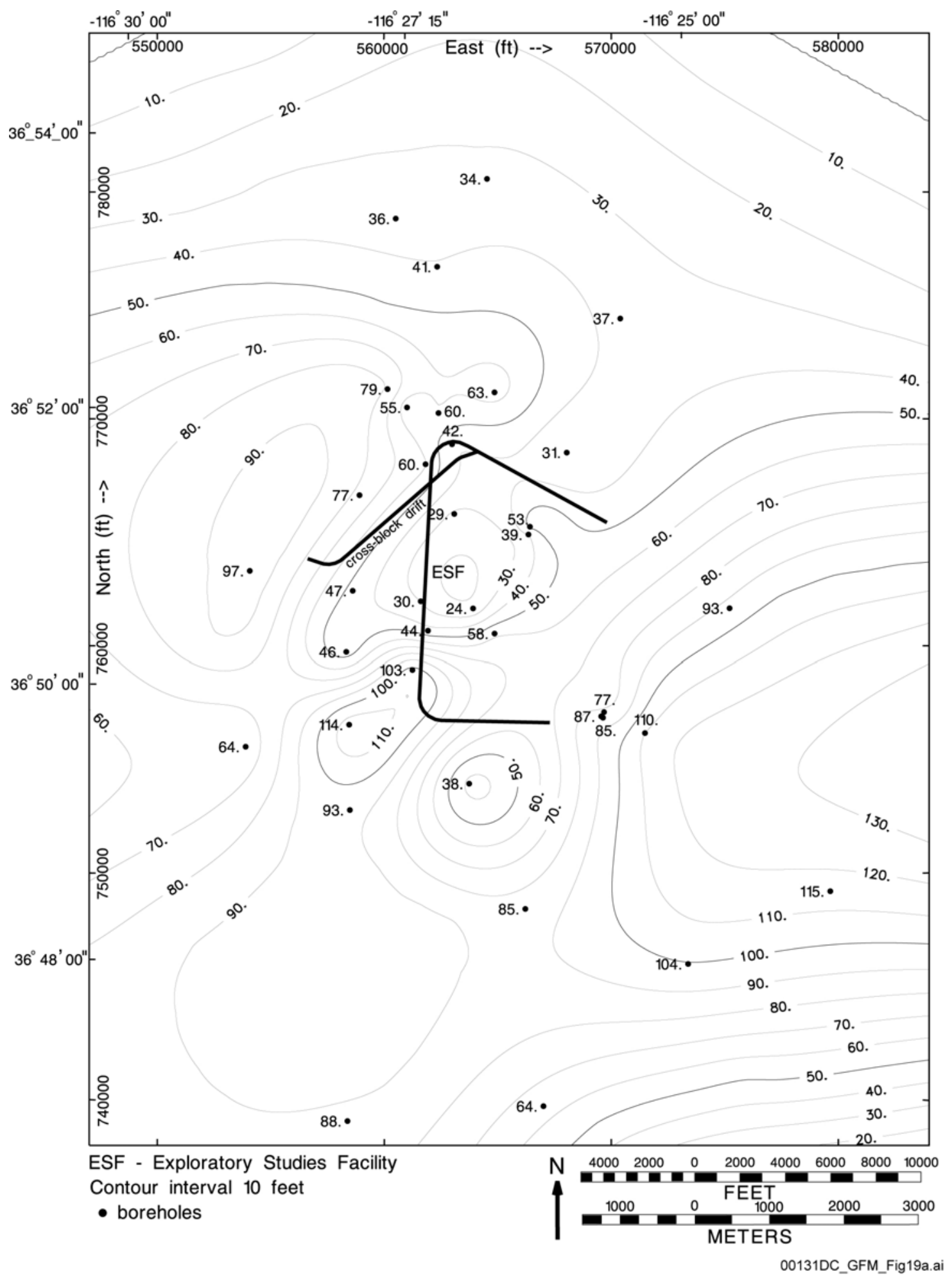

Source DTN: MO0012MWDGFM02.002 [DIRS 153777].

Figure 6-16. Model-Isochore Map of Topopah Spring Tuff Crystal-Poor Member Vitric Zone Densely Welded Subzone (Tptpv3) 


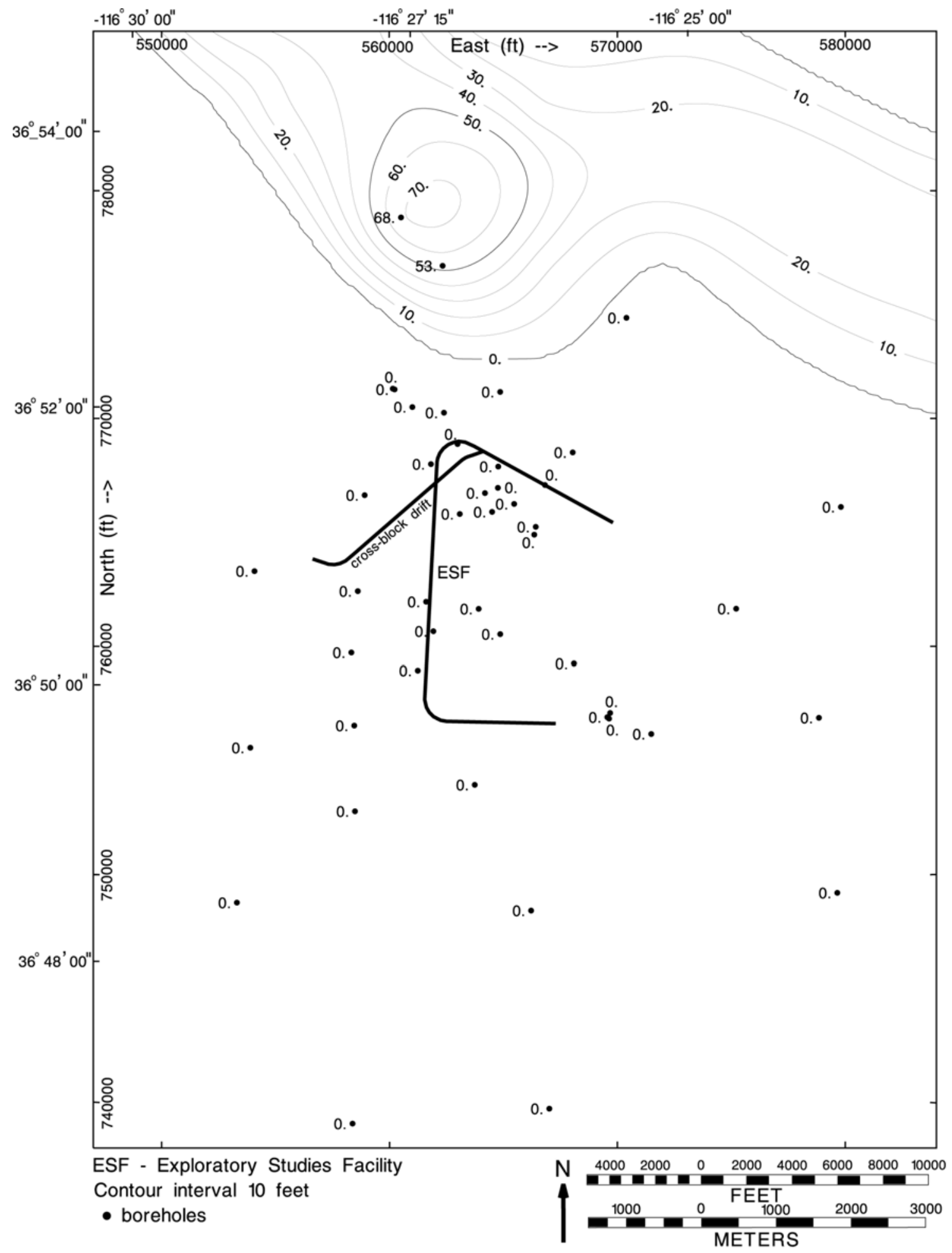

00131DC_GFM_Fig20a.ai

Source DTN: MO0012MWDGFM02.002 [DIRS 153777].

Figure 6-17. Model-Isochore Map of Topopah Spring Tuff Crystal-Poor Member Lithic-Rich Zone (Tptf) 


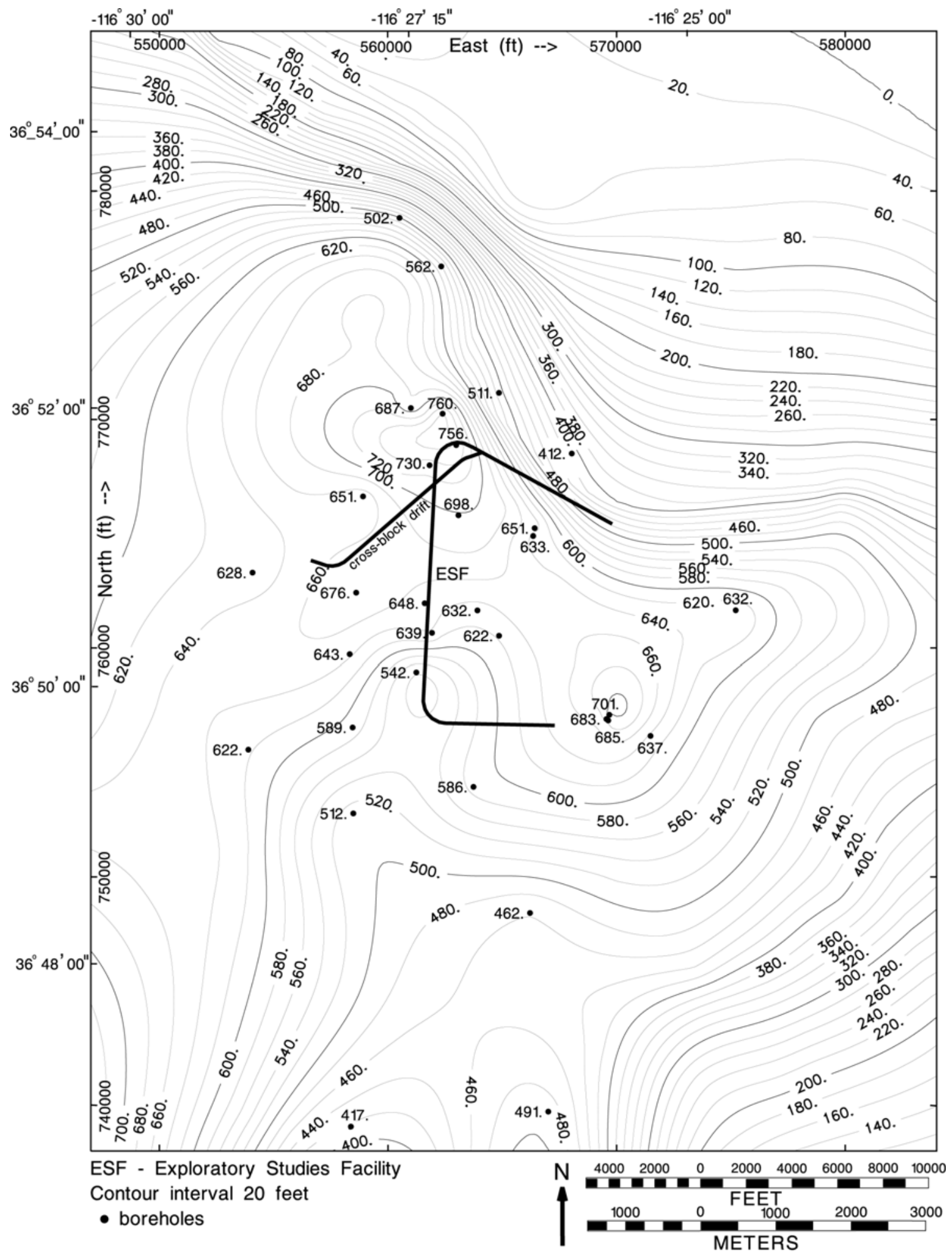

00131DC_GFM_Fig21a.ai

Source DTN: MO0012MWDGFM02.002 [DIRS 153777].

Figure 6-18. Model-Isochore Map of Repository Host Horizon 
Data Distribution and Unit Geometry-The model interpretation for this formation is based on input data from 28 boreholes that fully penetrate the formation (DTN: MO0004QGFMPICK.000 [DIRS 152554]) and geologic map data (DTN: GS980608314221.002 [DIRS 107024]). Ten additional input boreholes partially penetrate the formation but do not provide information on total thickness. The Calico Hills Formation ranges in thickness from as little as 37 feet (11.3 meters) in the south to more than 1,500 feet (450 meters) in the northeast (Figure 6-19). In the northeast, geologic map data provide only a minimum thickness because the base of the formation is not exposed. In the vicinity of the ESF, the formation thickness ranges from 37 feet (11.3 meters) to 460 feet (140.2 meters).

\subsubsection{Prow Pass Tuff (Tcp)}

Overview-The Prow Pass Tuff is present beneath the entire modeled area but is exposed at the surface in only one small outcrop in the northwestern corner of the modeled area.

The Prow Pass Tuff is important for hydrologic and radionuclide transport modeling because, like the Calico Hills Formation, it lies in the flow path between the repository and the water table (DTN: MO0106RIB00038.001 [DIRS 155631]) and has in part been altered to zeolites and clay minerals (BSC 2004 [DIRS 169734], Section 3.3.4.5.3), which may retard certain radionuclides (BSC 2004 [DIRS 169734], Section 7.9.2.3).

Data Distribution and Unit Geometry-The model interpretation for this formation is based on input data from 21 boreholes that fully penetrate the formation (DTN: MO0004QGFMPICK.000 [DIRS 152554]) and geologic map data for the lone outcrop in the modeled area (DTN: GS980608314221.002 [DIRS 107024]). Seven additional input boreholes partially penetrate the formation but do not provide information on total thickness. The formation is thickest along a north-south axis through the center of the modeled area, reaching a maximum observed thickness of 636 feet (193.9 meters) in borehole H-4 (Figure 6-20). In the vicinity of the ESF, the formation ranges in thickness from 295 feet (89.9 meters) to 636 feet (193.9 meters). The formation is not present several miles northeast of the modeled area according to geologic map data [Geologic Map of the Timber Mountain Caldera Area, Nye County, Nevada (Byers et al. 1976 [DIRS 103624])], which show the Calico Hills Formation depositionally overlying rocks of Devonian age. A regional interpretation [Stratigraphic and Volcano-Tectonic Relations of Crater Flat Tuff and Some Older Volcanic Units, Nye County, Nevada (Carr et al. 1986 [DIRS 104670], Figure 15)] shows the pinchout in a similar location. However, the exact location at which the Prow Pass Tuff pinches out is unknown.

\subsubsection{Bullfrog Tuff (Tcb)}

Overview-The Bullfrog Tuff is present beneath the entire modeled area and is the deepest stratigraphic unit exposed at the surface in the modeled area. It is exposed in only one small outcrop in the far northwestern corner of the modeled area.

The Bullfrog Tuff is important for hydrologic and radionuclide transport modeling because, like the Calico Hills Formation and the Prow Pass Tuff, it lies in the flow path between the repository and the water table (DTN: MO0106RIB00038.001 [DIRS 155631]). In addition, the Bullfrog Tuff has, in part, been altered to zeolites and clay minerals (BSC 2004 [DIRS 169734], 
Section 3.3.4.5.2), which may retard certain radionuclides (BSC 2004 [DIRS 169734], Section 7.9.2.3).

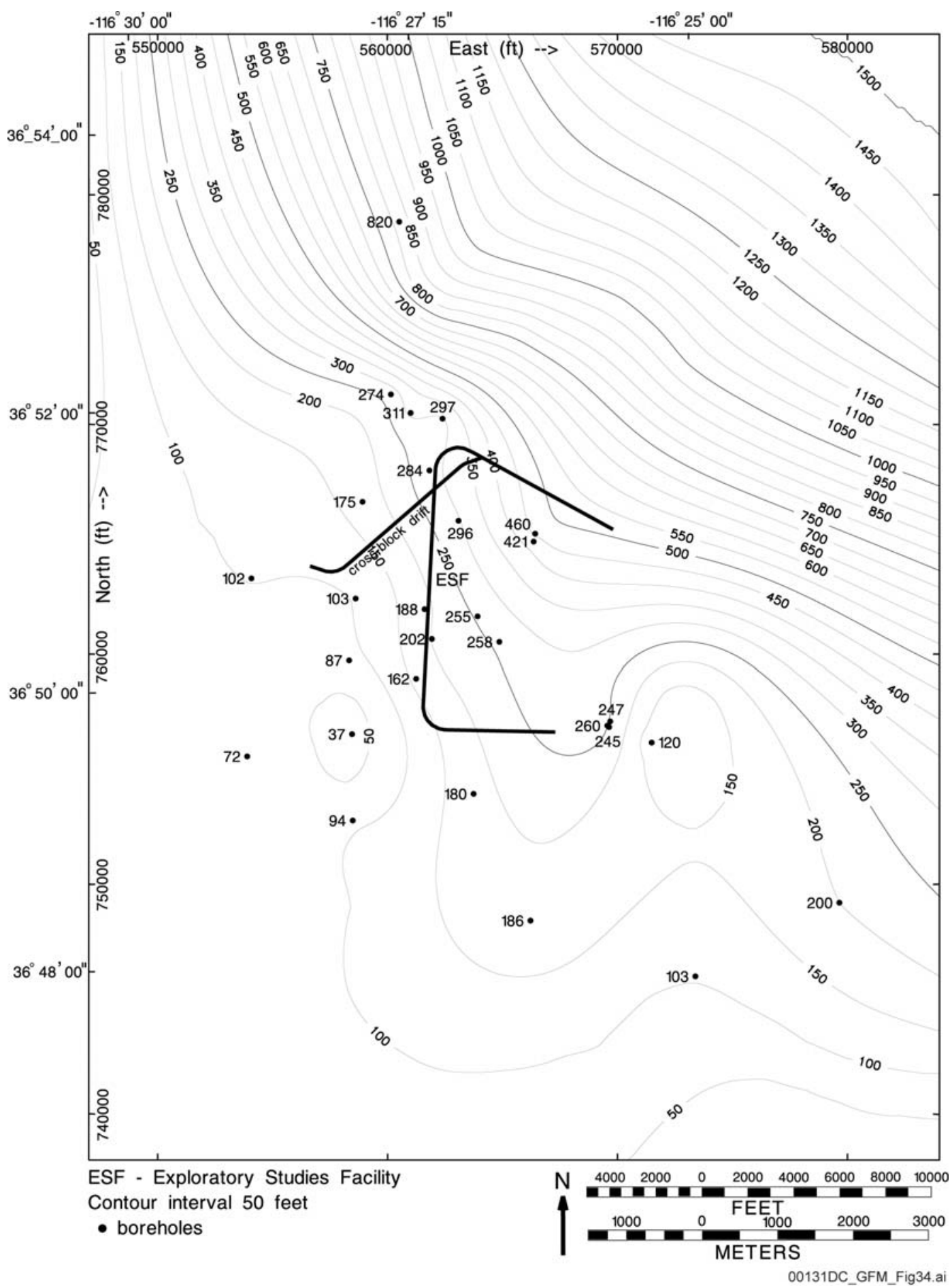

Source DTN: MO0012MWDGFM02.002 [DIRS 153777].

Figure 6-19. Model-Isochore Map of Calico Hills Formation (Ta) 


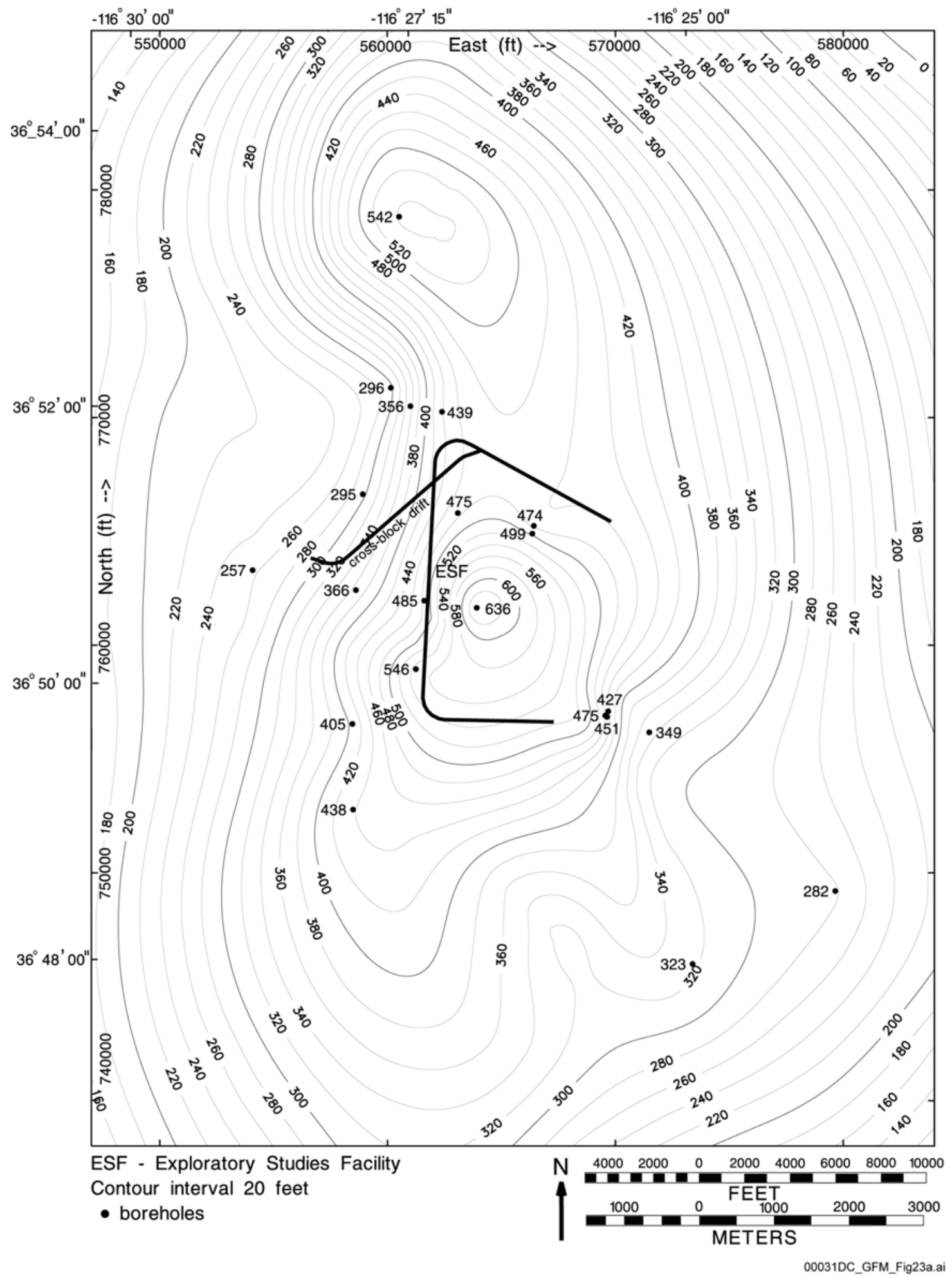

Source DTN: MO0012MWDGFM02.002 [DIRS 153777].

Figure 6-20. Model-Isochore Map of Prow Pass Tuff (Tcp) 
Data Distribution and Unit Geometry-The model interpretation for this unit is based on input data from 16 boreholes that fully penetrate the formation (DTN: MO0004QGFMPICK.000 [DIRS 152554]) and the lone outcrop data from the geologic map (DTN: GS980608314221.002 [DIRS 107024]). Six additional input boreholes partially penetrate the formation but do not provide information on total thickness. The Bullfrog Tuff model isochore is shown in Figure 6-21. The Bullfrog Tuff is thickest in the southwestern part of the central modeled area, reaching a maximum thickness of 618 feet (188.4 meters) in borehole G-3 (Figure 6-21). In the vicinity of the ESF, the formation ranges in thickness from 369 feet (112.5 meters) to 618 feet (188.4 meters). The formation is not present several miles northeast of the modeled area according to geologic map data (Byers et al. 1976 [DIRS 103624]). A regional interpretation (Carr et al. 1986 [DIRS 104670], Figure 6-12) shows the pinchout in a similar location. The exact location at which the Bullfrog Tuff pinches out is unknown. Units Tcblc and Tcblv in borehole J-13 are not present due to faulting. Therefore, the thickness of the Bullfrog Tuff at borehole J-13 (305 feet [93 meters]) shown in Figure 6-21 is not a true thickness, and the true (unfaulted) thickness of this unit in that area is not known. The increasing thickness in the southwestern corner of the model is based on a conceptual model in which the Bullfrog Tuff thickens into the Crater Flat basin, and is supported by data from offsite borehole VH-1 (Carr 1982 [DIRS 101519], Table 2) which indicates a minimum thickness of 464 feet (141 meters). Total thickness is not defined because VH-1 bottoms in the formation and does not fully penetrate it.

\subsubsection{Tram Tuff (Tct)}

Overview-The Tram Tuff is present beneath the entire modeled area but is not exposed in outcrop. The Tram Tuff is important for hydrologic and radionuclide transport modeling because, like the Calico Hills Formation, Prow Pass Tuff, and Bullfrog Tuff, it lies in the flow path between the repository and the water table (DTN: MO0106RIB00038.001 [DIRS 155631]). In addition, the Tram Tuff is, in part, altered to zeolitic clays (BSC 2004 [DIRS 169734], Section 3.3.4.5.1), which trap certain radionuclides (BSC 2004 [DIRS 169734], Section 7.9.2.3).

Data Distribution and Unit Geometry-The model interpretation for this unit is based on input data from 11 boreholes that fully penetrate the formation (DTN: MO0004QGFMPICK.000 [DIRS 152554]). Five additional input boreholes partially penetrate the formation but do not provide information on total thickness. In the geologic framework model, the Tram Tuff is the thickest of the formations in the Crater Flat Group. It is thickest in a north-northeasterly trending axis over the central part of the modeled area (Figure 6-22) with a maximum thickness of 1213 feet (369.7 meters) at borehole G-3. In the vicinity of the ESF, it ranges in thickness from 670 feet (204.2 meters) to 1213 feet (369.7 meters). The formation is not present several miles northeast of the modeled area according to geologic map data (Byers et al. 1976 [DIRS 103624]). A regional interpretation (Carr et al. 1986 [DIRS 104670], Figure 6-9) shows a thickness of more than 820 feet (250 meters) in northern Crater Flat northwest of the modeled area. In the northwestern part of the modeled area, thickness is constrained only by borehole G-2; however, this borehole may be located on a buried structural high and may not be representative of the regional trend. The thinning toward the southwest is based on the concept that the Tram Tuff is thickest along an axis trending northwest through borehole G-3, and is unconstrained by data. 


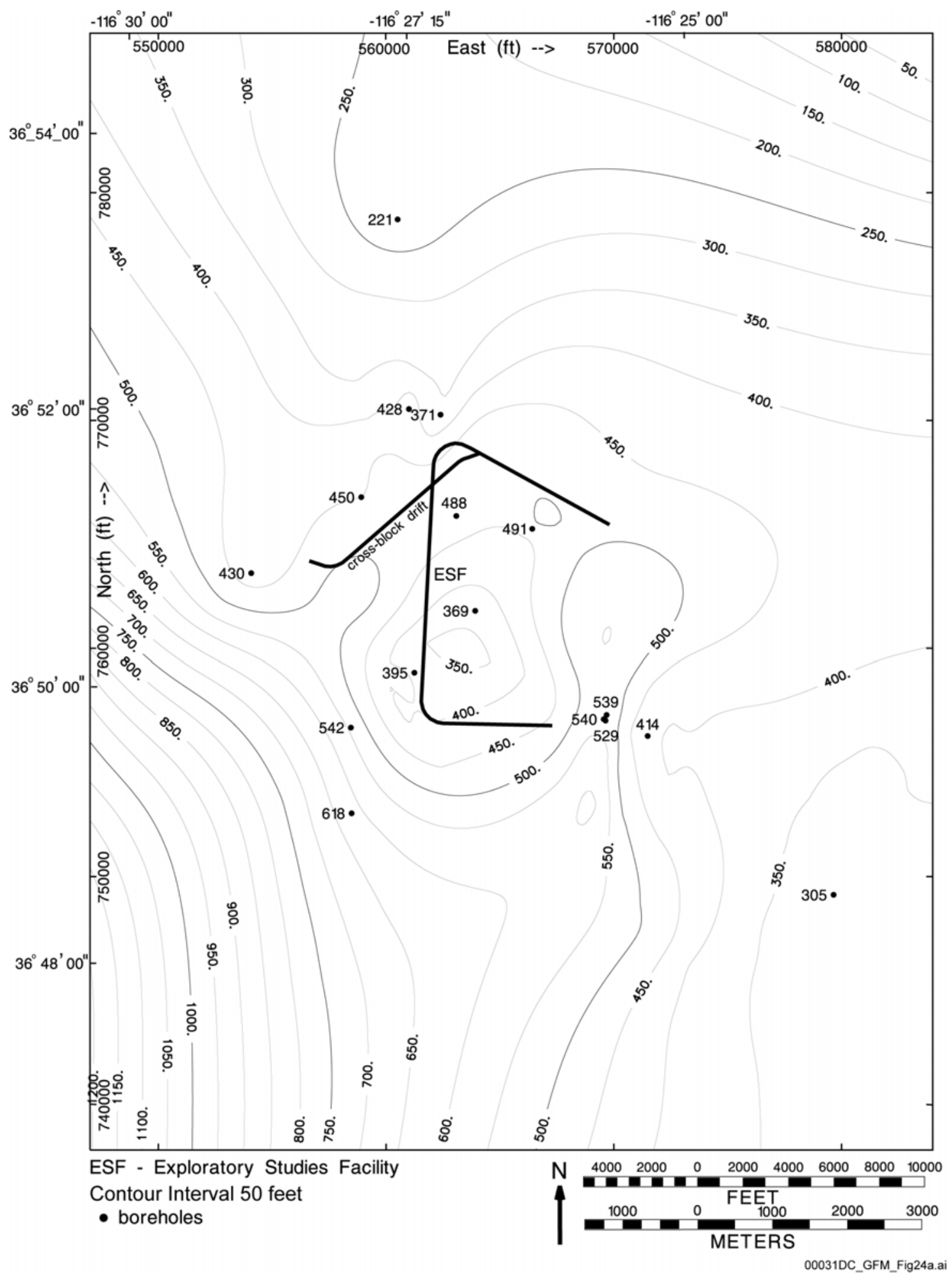

Source DTN: MO0012MWDGFM02.002 [DIRS 153777].

Figure 6-21. Model-Isochore Map of Bullfrog Tuff (Tcb) 


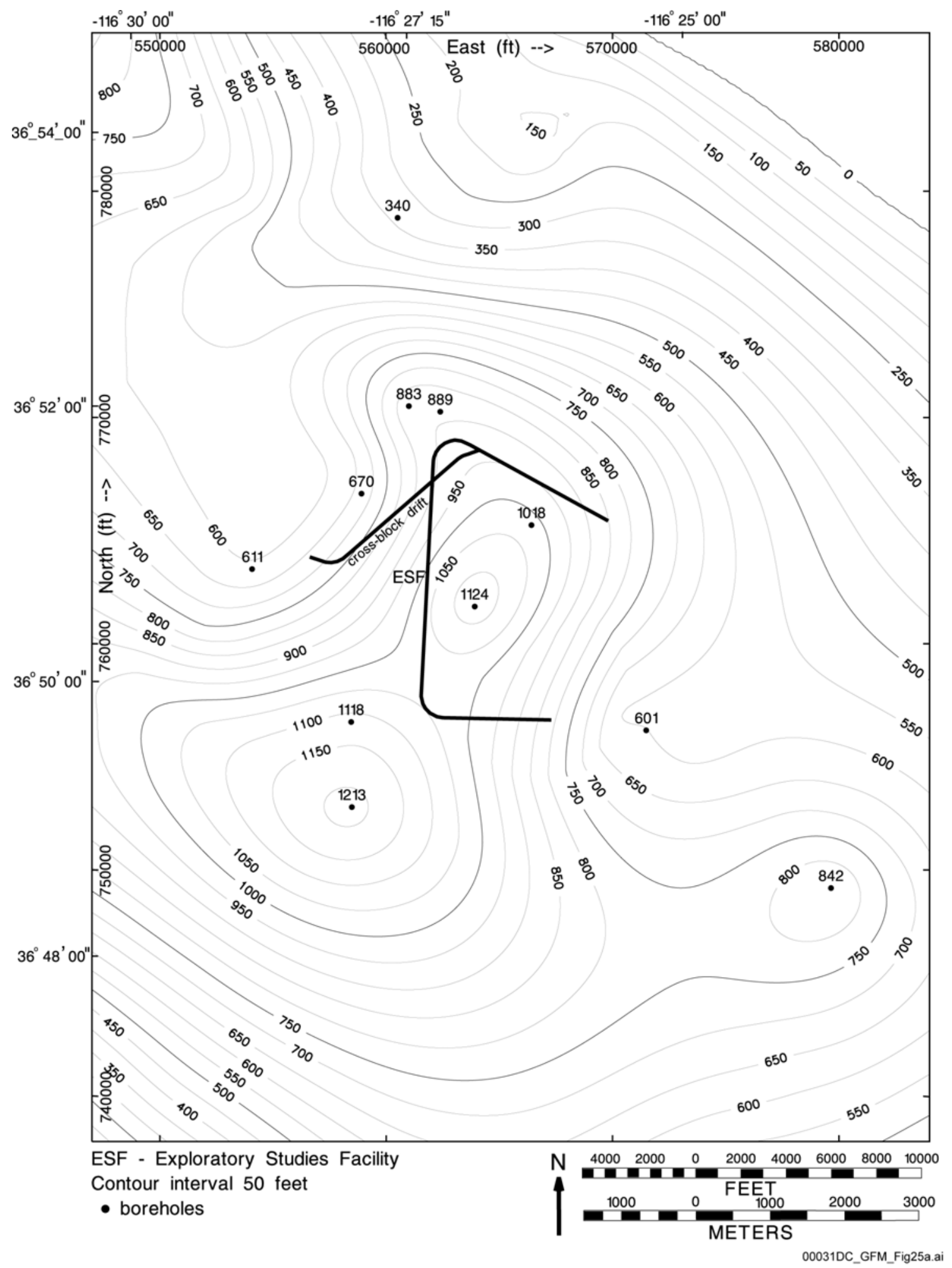

Source DTN: MO0012MWDGFM02.002 [DIRS 153777].

Figure 6-22. Model-Isochore Map of Tram Tuff (Tct) 
In Figure 6-22, the anomalously thin Tram Tuff at borehole p\#1 (601 feet, 183.2 meters) is interpreted in the model to be due to faulting. The faulted thickness had to be used in the model so that all stratigraphic contacts would be honored. This is true for any faulted contact, not just for $\mathrm{p} \# 1$. If a hypothetical true thickness were used for the Tram Tuff in borehole $\mathrm{p} \# 1$ and no fault explicitly modeled there, the model would not match the rest of the stratigraphic contacts in the borehole. The thickened Tram Tuff would have forced the other contacts to be out of place. (As described in Section 6.4, the model is built by thicknesses, not elevations.) No fault was included to intersect this unit because no spatial information about the fault is available. An alternative interpretation is that this fault is the Paintbrush Canyon fault and the Tertiary-Paleozoic contact in borehole p\#1 is not the Paintbrush Canyon fault.

\subsubsection{Older Tertiary Unit (Tund)}

Overview-The Tertiary rocks older than the pre-Tram Tuff bedded tuff (Tctbt) are labeled as Tertiary undifferentiated (Tund) in the geologic framework model. Although this unit represents the greatest share of the modeled volume, it is the least known of all the Tertiary units because few boreholes penetrate it.

The older Tertiary unit is important for hydrologic and radionuclide transport modeling because it lies in the flow path between the repository and the regional carbonate aquifer in the Paleozoic rocks below. It also makes up a large percentage of the SZ volume.

Data Distribution and Unit Geometry-The model interpretation for this unit is based on input data from 11 boreholes, only one of which fully penetrates the older Tertiary section (borehole p\#1, DTN: MO0004QGFMPICK.000 [DIRS 152554]). An elevation map of the top of this unit is provided as Figure 6-23. The unit thickness was not mapped because it is entirely dependent on the configuration of the Tertiary-Paleozoic unconformity derived from gravity data (DTN: LB980130123112.003 [DIRS 109062]).

\subsubsection{Tertiary-Paleozoic Unconformity}

Overview-The configuration of the unconformity between Tertiary and Paleozoic rocks is subject to several interpretations, as described in the following paragraphs. The nature of the geologic framework model is such that only one interpretation could be used, and the interpretation needed to cover the entire modeled area. These requirements limited the available sources to one, an interpretation of gravity data (DTN: LB980130123112.003 [DIRS 109062]), which is a recalculation of the Tertiary-Paleozoic unconformity that was initially used in GFM2.0. The interpretation incorporated in the geologic framework model also had to be consistent with the other data from boreholes and the geologic map, which further narrowed the options.

The elevation of the Tertiary-Paleozoic unconformity is used in hydrologic modeling because it forms the top of the regional carbonate aquifer (BSC 2004 [DIRS 169734], Section 8.2.2.1.5). Alternative interpretations are unlikely to be important because of the large vertical distance between the repository and the unconformity-according to the GFM2000 interpretation, the unconformity occurs 8,000 to 11,000 feet (2,400 to 3,350 meters) below the ESF. 


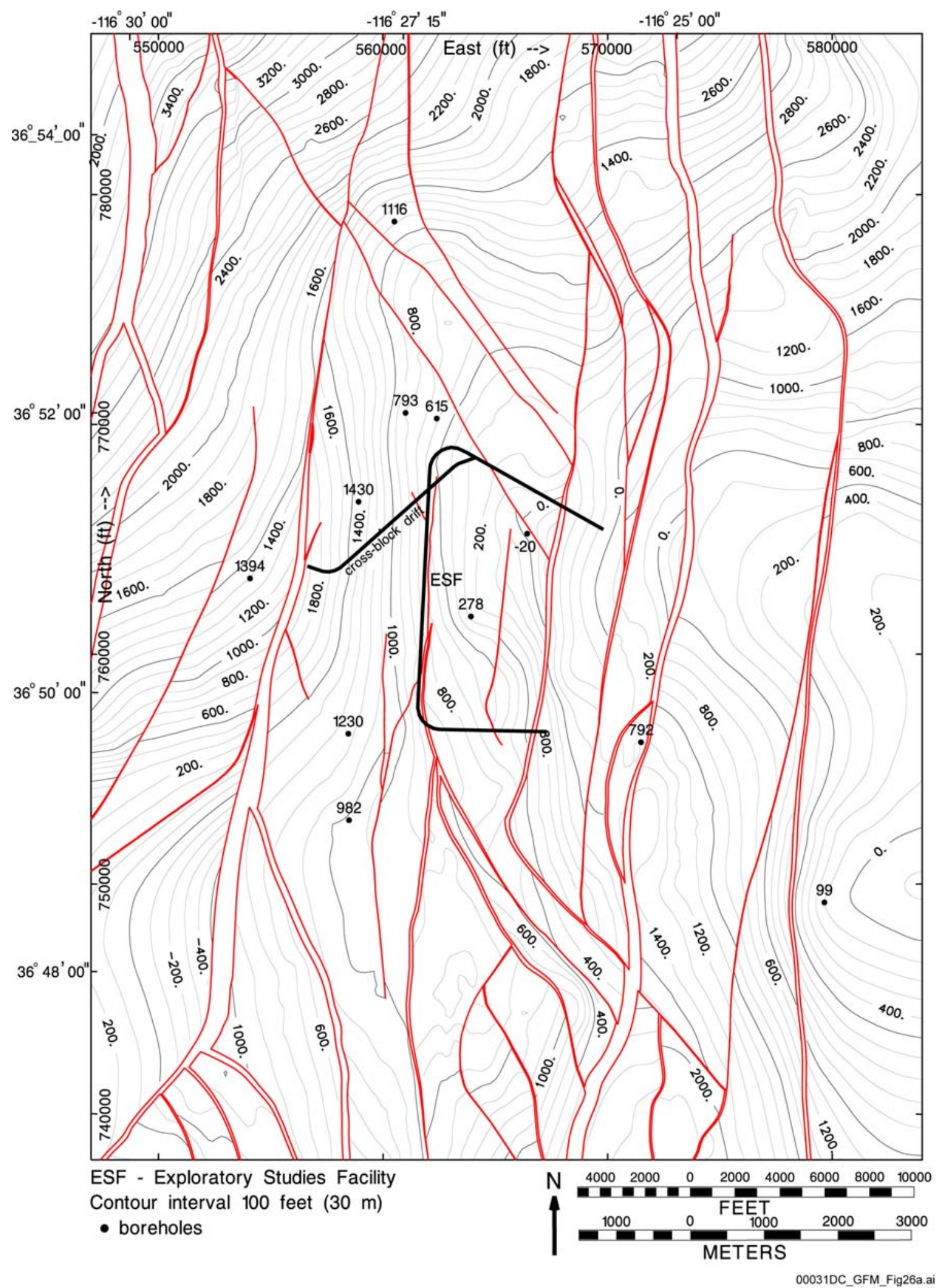

Source DTN: MO0012MWDGFM02.002 [DIRS 153777].

Figure 6-23. Elevation Map of Top of Older Tertiary Units (Tund) 
Data Distribution and Unit Geometry-The Tertiary-Paleozoic unconformity used in GFM2000, shown as an elevation map in Figure 6-24, is modified from an interpretation of gravity data (DTN: LB980130123112.003 [DIRS 109062]). The surface in the geologic framework model includes vertical displacements along the modeled faults, which were not included in the gravity interpretation. Fault displacements on the Tertiary-Paleozoic unconformity were constructed by matching the vertical displacements of the shallower modeled units and displacing the gravity interpretation. In the model area, only one borehole-p\#1penetrates the Paleozoic rocks which are encountered at an elevation of -425 feet (-130 meters) (DTN: MO0004QGFMPICK.000 [DIRS 152554]); therefore, the model relies primarily on the gravity interpretation.

The unconformity forms a high ridge beneath Busted Butte and Fran Ridge in the southeastern model area, falling away to deeper levels to the north and west. At its deepest point in the northwest, the unconformity is 13,000 feet (3,960 meters) below ground surface. At its shallowest point beneath Fran Ridge, it is 3,500 feet (1,070 meters) below ground surface. The deepening to the west can be explained by the combined down-to-the-west vertical displacement along several known north-trending Tertiary normal faults, but may also be enhanced by erosion and displacement on older, unknown faults. The deepening to the north may be a result of caldera deformation, deposition of the thick Tertiary volcanic pile, or prevolcanic deformation. Displacement of the unconformity along faults is generally depicted as equal to or greater than the displacement of the mid-Tertiary units to suggest multiple generations of faulting (CRWMS M\&O 2000 [DIRS 151945], p. 4.2-4).

Discussion of Alternative Interpretations-Several interpretations of the Tertiary-Paleozoic unconformity in the vicinity of borehole p\#1 have been made [DTN: LB980130123112.003 [DIRS 109062]; Brocher et al. 1998 [DIRS 100022], Figures 7, 8, and 14; Report: Results of VSP Analysis in P\#1 (Feighner et al. 1998 [DIRS 107428], Figure 7b)]. Although they are local interpretations, they coincide with part of the geologic framework model interpretation (Figure 6-25; adapted from DTN: LB980130123112.002 [DIRS 153784]). No definitive data, such as another borehole or conclusive geophysical data, are available to distinguish between the alternatives; available data permit a variety of interpretations. This section discusses the reasons for choosing the interpretations used in the geologic framework model over the others.

The geologic framework model was constructed with the interpretation that the Tertiary-Paleozoic contact in borehole p\#1 is the Paintbrush Canyon fault, as first interpreted in a USGS Open-File Report in which the fault was called the Fran Ridge fault [Geology of Drill Hole UE25p\#1: A Test Hole Into Pre-Tertiary Rocks Near Yucca Mountain, Southern Nevada (Carr et al. 1986 [DIRS 102046], p. 24, Figure 6-10)]. However, because the borehole data are inconclusive, other interpretations are possible, including an unfaulted unconformity at the Tertiary-Paleozoic contact, correlation of the fault at the contact to a fault other than the Paintbrush Canyon fault, or placement of the Paintbrush Canyon fault higher in the borehole.

On the other hand, an important observation is that the geologic map relations across the borehole p\#1 vicinity (DTN: GS980608314221.002 [DIRS 107024]) show approximately 700 feet (210 meters) of vertical displacement along the Paintbrush Canyon fault and 400 feet (120 meters) of vertical displacement on the splay (labeled "PJ" in Figure 6-2) that arcs west of the hill south of borehole p\#1. These relations require at least a 1,100-foot (330-meter) 
down-to-the-west vertical displacement in the immediate vicinity of borehole $\mathrm{p \# 1.} \mathrm{The}$ interpretation from the borehole report was accepted for the geologic framework model because it is consistent with the geologic map data and formed a reasonable interpretation in three dimensions. The conclusion that the Tertiary-Paleozoic contact in $\mathrm{p} \# 1$ is a fault rather than an unfaulted unconformity is strongly supported by the temperature log in p\#1, which shows a prominent high-temperature anomaly in the contact zone that may be due to upwelling of warm water along the fault zone (CRWMS M\&O 2000 [DIRS 151945] pp 9.3-46, 47).

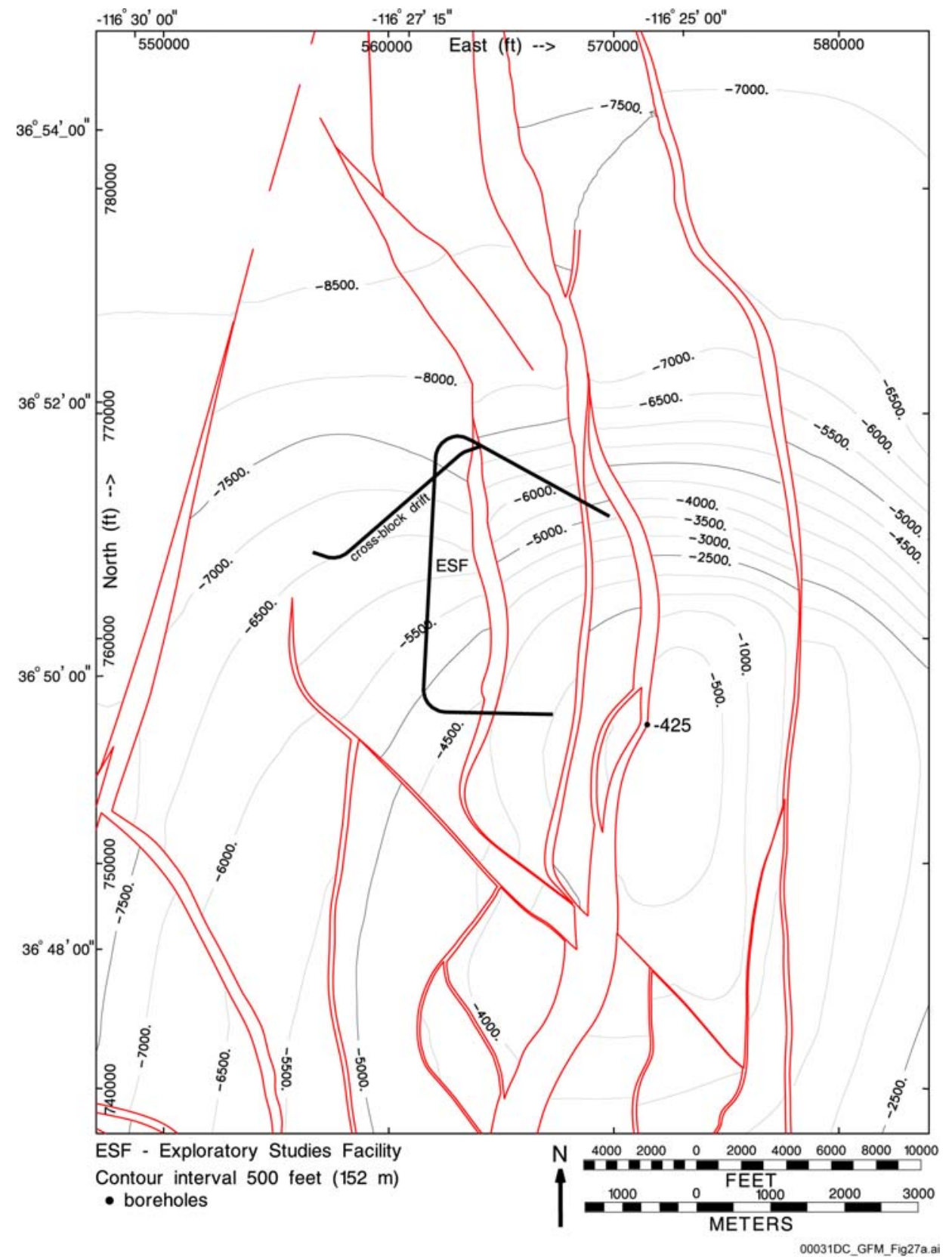

Source DTN: MO0012MWDGFM02.002 [DIRS 153777].

Figure 6-24. Elevation Map of Tertiary-Paleozoic Unconformity 
An alternative interpretation of borehole p\#1 data would be that the Paintbrush Canyon fault is intersected at the base of the Tram Tuff and there is no fault at the Tertiary-Paleozoic contact. This configuration is plausible if the Tertiary-Paleozoic contact in borehole p\#1 is interpreted as an erosional surface and not as a fault. The contact is represented as a fault in the geologic framework model because this interpretation is more consistent with published interpretations of the borehole data (Carr et al. 1986 [DIRS 102046], p. 16, Figure 6-10) and it provides a fault dip that is consistent with the geologic map.

The gravity and seismic interpretations summarized in Results of Gravity Modeling of the Paleozoic Basement (Majer et al. 1998 [DIRS 109472]) show the Tertiary-Paleozoic unconformity at shallow levels west of borehole p\#1 (shown in Figure 6-25 as the red, orange, and blue lines), conflicting with the geologic map relations discussed previously. The interpretations do not allow for 1,100-foot (330-meter) vertical displacement on normal faults in the vicinity of borehole p\#1. Because the geologic framework model could not be constructed with the use of the shallower interpretations and still be consistent with the data from the borehole and geologic map, the shallower interpretations were not used. To construct the Tertiary-Paleozoic unconformity in the geologic framework model, it was necessary to modify the gravity interpretation (DTN: LB980130123112.003 [DIRS 109062]) to be consistent with fault location, displacement, and orientation data from borehole data and the geologic map. The gravity interpretation is shown in Figure 6-25 as the blue line.

As shown in Figure 6-25, the geologic framework model interpretation is also consistent with the regional seismic profile (Brocher et al. 1998 [DIRS 100022], Figure 6-12) and closely resembles the deep seismic interpretation by extending the high-amplitude, subparallel reflections (interpreted here to represent lower Tertiary rocks) 2,000 feet (610 meters) farther east. Although available data do not provide a unique solution, the consistency of the geologic framework model interpretation with data from the borehole, geologic map, and seismic profile supports the interpretation.

Impacts of Alternative Interpretations-The alternative interpretations of the elevation of the Tertiary-Paleozoic unconformity show marked vertical differences 6,500 to 10,000 feet (2000 to 3000 meters) east of the ESF. The vertical differences between deep and shallow interpretations are on the order of 3,000 feet (900 meters) for a distance of 7,000 feet (2,133 meters) along the regional seismic profile west of borehole p\#1 (Figure 6-25). Despite the large differences, which could place the Paleozoic rocks approximately 2,000 feet (600 meters) closer than currently modeled, no impact greater than the uncertainty discussed above is anticipated on subsequent models. 

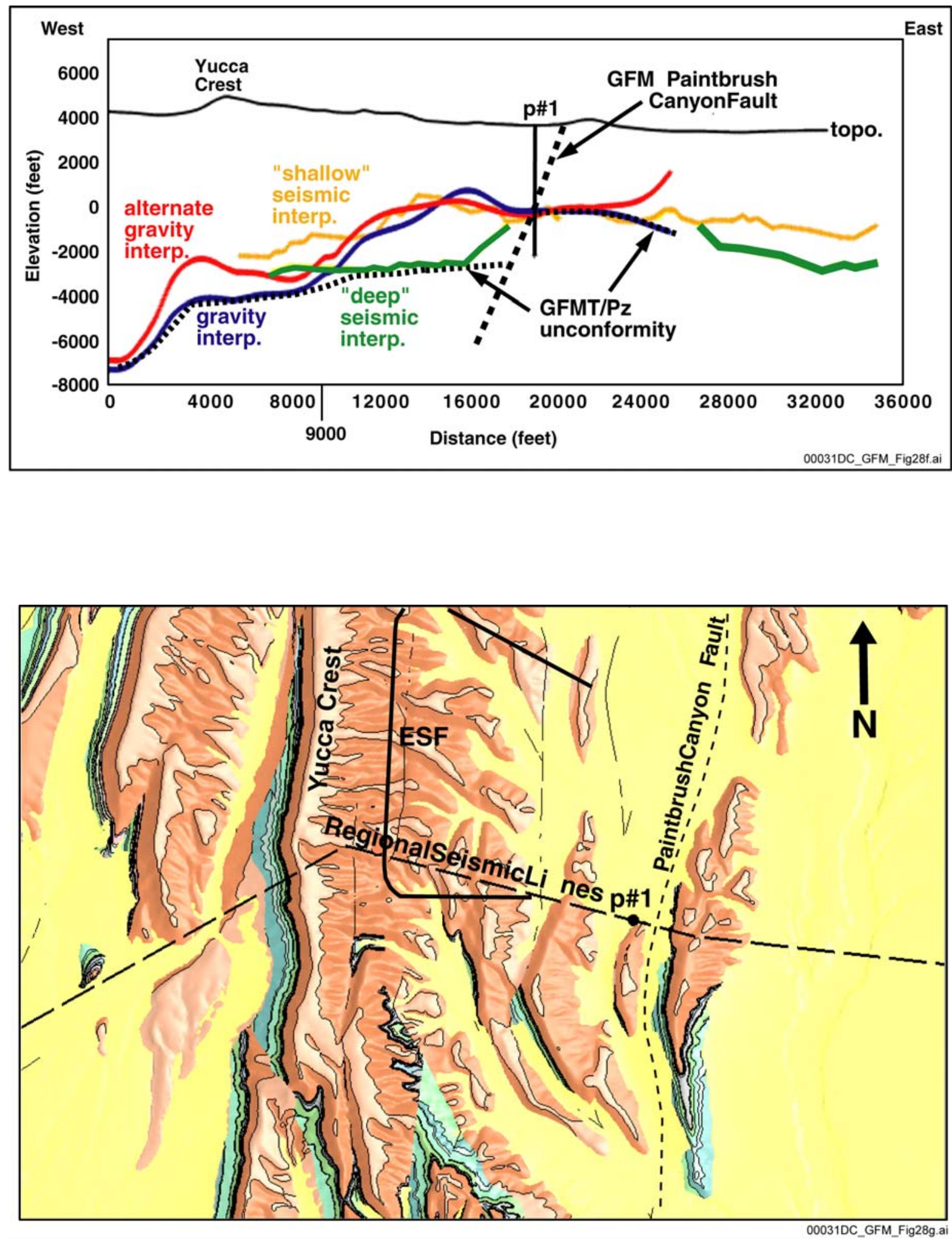

Source: DTN: LB980130123112.002; Majer et al. 1996 [DIRS 104685], Figure 1a.

Figure 6-25. Comparison of Geophysical and Geologic Framework Model Interpretations of Tertiary-Paleozoic Unconformity 


\subsubsection{Interpretation of Faults}

This section discusses the geometries of the faults depicted in the geologic framework model. The faults were constructed with the use of the criteria specified in Section 6.2.2 and the methodology described in Section 6.4.4, and were intended to be consistent with current YMP structural and tectonic models (BSC 2004 [DIRS 169734], Sections 3.5.3 and 3.5.11). The patterns of faulting, structural domains, and relative ages of the faults are discussed in previous documents (BSC 2004 [DIRS 169734], Section 3.5.3). The particular features of the faults modeled in the geologic framework model are discussed in the following sections. Except where specifically noted, data for the following discussions are from the geologic map (DTN: GS980608314221.002 [DIRS 107024]).

\subsubsection{Fault Curvature}

In the geologic framework model interpretation, the dominant faults were constructed as slightly curved (i.e., dip shallowing slightly with depth) in cross section to be consistent with data and cross sections from the geologic map. The faults could also have been depicted with greater or lesser curvature; however, in practical terms the uncertainty of fault geometries at depth is greater than the differences between geometric interpretations. There is, therefore, no practical impact of amount of fault curvature on subsequent users of the geologic framework model.

\subsubsection{Fault Patterns}

The north-trending fault system (Figure 6-2) dominates the model. The largest (approximate length times displacement) of these faults are the Solitario Canyon and Paintbrush Canyon faults, both of which displace strata down to the west by more than 1,400 feet (425 meters) (DTN: GS980608314221.002 [DIRS 107024]). The Windy Wash fault is as large but is present only in the far northwestern edge of the model. Other north-trending faults of note include the Fatigue Wash, Iron Ridge, and Bow Ridge faults, which form major topographic features in the modeled area. A system of faults beneath Midway Valley produces a series of small horst-graben bedrock structures now buried by alluvium (DTN: GS980608314221.002 [DIRS 107024]).

Prominent topographic features have also formed along northwest-trending faults in the site area. A series of northwest-trending faults is present in the prominent drainages (Drillhole, Pagany, and Sever Washes) in the north-central part of the area. The vertical displacements on these faults are small (less than 50 feet [15 meters]) (DTN: GS980608314221.002 [DIRS 107024], p. 11) and, therefore, are not significant in the model. In the southern part of the area, Dune Wash contains a complex pattern of intersecting north- and northwest-trending faults including the Dune Wash fault, which has a maximum vertical displacement of more than 200 feet (61 meters). The mapped pattern of faults in Dune Wash is complex, so much so that only a few of these faults could be included in the geologic framework model. The actual structure in Dune Wash is, therefore, more complex than represented in the geologic framework model. No impact is anticipated on geologic framework model users because Dune Wash is outside the repository design area, and details at this scale of complexity are not used in hydrologic modeling. 


\subsubsection{Features of Individual Faults}

The Paintbrush Canyon fault (Figure 6-2) is the longest of the faults in the geologic framework model and has the greatest Tertiary vertical displacement. The main strand of the fault passes along the west side of Fran Ridge. The report for borehole p\#1 called this the Fran Ridge fault (Carr et al. 1986 [DIRS 102046], Figure 6-10) and indicated that it intersects borehole p\#1 at the Tertiary-Paleozoic unconformity. This is the interpretation used to construct the Paintbrush Canyon fault in the geologic framework model. The Paintbrush Canyon fault reaches its maximum vertical displacement of approximately 1,400 feet (425 meters) in the model area at the mouth of Dune Wash, where several faults intersect the Paintbrush Canyon fault and increase the total vertical displacement.

The Solitario Canyon fault is a scissor fault that changes dip direction at Tonsil Ridge from west-dipping in the south to east-dipping in the north (DTN: GS980608314221.002 [DIRS 107024]). The location of Tonsil Ridge is indicated in Figure 1-1. This dip change was generalized in the geologic framework model as a single surface to prevent geometric anomalies at depth. Interpretations from the model from Tonsil Ridge northward should take this generalization into account. The uncertainties regarding fault dips and locations at great depth are expected to outweigh the potential impacts of the generalization in subsequent models.

The Bow Ridge fault (Figure 6-2) is also a scissor fault, with its hinge point covered by alluvium approximately at the mouth of Sever Wash. Outcrop and borehole data indicate that the fault passes between borehole WT\#16 and the outcrop to the west, and that the apparent displacement is down-to-the-east. North of the hinge point, the Bow Ridge fault is called the "Exile Hill" fault in the geologic framework model (Figure 6-2). In this case, the geometry of the Bow Ridge - exile Hill system allowed construction of two grids, which intersect at a bend in the fault.

Minor faults, such as the Ghost Dance, Abandoned Wash, and numerous faults around Dune Wash, appear to be secondary features that accommodated strain between the dominant faults. Their intersections with more dominant faults at depth are uncertain; however, the interpretation shown in the geologic framework model is that the Dune Wash, Bow Ridge, and Midway Valley faults intersect the Paintbrush Canyon fault at depth. The Ghost Dance and Abandoned Wash faults are truncated at depth by west-dipping normal faults.

\subsubsection{Faulting and Deposition}

In the geologic framework model, model isochore maps of the Paintbrush Group and older units do not show abrupt changes in thickness across faults, although some minor changes could be interpreted from the available data. Data distribution is too limited to allow systematic mapping of the thickness changes. Geologic map relations (DTN: GS980608314221.002 [DIRS 107024]) show that isolated thickness changes across faults in Solitario Canyon and elsewhere are associated with faulting that occurred during the time span of pre-Tiva Canyon Tuff Paintbrush Group deposition (CRWMS M\&O 2000 [DIRS 151945], pp. 4.6-12 to 4.6-13). The lateral extent of this faulting is obscured by deposition of the Tiva Canyon Tuff over most of the modeled area. The greatest fault displacement and tilting of the stratigraphic section occurred after the deposition of the Tiva Canyon Tuff (CRWMS M\&O 2000 [DIRS 151945], p. 4.6-13). Undetected thickness changes are accounted for in the geologic framework model by 
the estimation of uncertainty, and any that may be discovered by future data in the vicinity of the ESF are not anticipated to be of sufficient magnitude to impact geologic framework model users. Repository design would not be affected because the observed thickness changes do not occur in the RHH.

\subsection{UNCERTAINTIES AND LIMITATIONS}

The methods and results discussed in this section and Section 7 (Validation) present practical methods that are based on procedural definitions and that are appropriate for the unique geologic setting and data distribution at Yucca Mountain.

Because the geologic framework model exactly matches the measured lateral position of all input data (the $\mathrm{x}$ and $\mathrm{y}$ coordinates), and these are never altered or manipulated, the following discussion is limited to vertical uncertainty (elevation).

\subsubsection{Introduction to Uncertainty}

For the geologic framework model, uncertainty is an estimate of how closely the model matches the real world. In other words, uncertainty is an estimate of how well the subsurface is known. Uncertainty results from the interaction between geologic variability (heterogeneity), which is the variability of the natural system from place to place, and the ability of the modeling methodology to make accurate predictions based on available data.

The following terms are defined for the discussion of uncertainty:

Geologic variability-The actual change in the elevation or thickness of a rock layer from place to place. Geologic variability can only be sampled at point locations (boreholes or outcrops); it can never be completely known.

Observed variability-The change in the elevation or thickness of a rock layer as measured at sampled locations (i.e., at boreholes and outcrops). This is always less than or equal to geologic variability. The likelihood that observed variability is equal to geologic variability increases with the amount of data.

Figure 6-26 schematically illustrates the relations between data distribution, geologic variability, observed variability, and prediction error in the resulting model. The actual geologic surfaces are shown in black, and the modeled surfaces are shown in blue. Boreholes A through E represent the available borehole data. Based on the available data, the observed variability of each surface is labeled "OV," and the actual or geologic variability is labeled "GV." Observed variability is only equal to geologic variability when the distribution of data is adequate; otherwise, observed variability is always less than geologic variability. Borehole "New" represents a borehole drilled after construction of the model, and the difference between the elevations observed in the borehole and the predicted (modeled) elevations are the prediction error, "PE." The estimated uncertainty discussed in the following sections attempts to capture the complex relations between these factors. 
For the upper surface in Figure 6-26, the available data fortuitously provided adequate distribution to estimate the actual geologic variability (the observed variability is nearly equal to the geologic variability), but not to model the actual spatial distribution of the surface. For the middle surface, the available data indicated a very small-observed variability, and even though geologic variability is considerably greater than observed variability, the prediction error at the new borehole location is very small simply by virtue of its location relative to the subsurface geology (i.e., the prediction error was small, but fortuitously so). For the lower surface, the prediction error was much greater than the previously observed variability. In this case, the new borehole provided a unique new measure of geologic variability for the lower surface that was not known from the previous distribution of data. The results of the new borehole data for the lower surface are twofold: first, the borehole reduced uncertainty locally by providing new data; and second, because it provides a new measure of variability, the new borehole data improves the estimation of uncertainty for the lower surface.

As illustrated in Figure 6-26, evaluation of uncertainty is an assessment of the complex interaction between the variability of the geologic system, the modeling methodology, and the existing data. Uncertainty would be lowest in a site with little geologic variability and abundant data. Because geologic variability is high at Yucca Mountain (because of the geologic setting) and the available subsurface data are relatively sparse, the primary factor affecting the magnitude of uncertainty in the geologic framework model at any given location is distance from the data - the model matches the real world more closely in locations that are near the data, and matches progressively less with distance away from the data. Because borehole data are restricted in depth, uncertainty also increases with vertical distance below the bottoms of the boreholes as well as with horizontal distance away from them. Likewise, models of deeper rock units, for which there are fewer borehole penetrations, have greater uncertainty associated with them than do models of shallower rock units. Rock layers near the surface are constrained by observed variability portrayed on the geologic map, which provides extensive areal coverage and reduces uncertainty accordingly.

Because of faulting and tilting of the rock layers in the modeled area, geostatistical techniques could not be used to estimate uncertainty in the geologic framework model. The structural features introduce geometrical trends and discontinuities that would invalidate the technique. Instead, practical methods that examine the total modeling process (including data distribution) and model results were used to estimate the amount of uncertainty associated with the geologic framework model. A test of the model's ability to represent the real world would be acquisition of new data and a comparison to predictions from the model. Because new data are not available for this model revision, an alternative method was used to evaluate how well the modeling methodology predicts data that have been removed from the model. This is the "jack-knife" method described in Section 6.6.3. This method was chosen because it is a standard technique, it is appropriate to apply to the central part of Yucca Mountain, and it accounts for all sources of uncertainty and prediction errors. No alternative methods for estimating uncertainty in the geologic framework model have been proposed. Additional details of the jack-knife method, including tables and charts of results, are provided in Appendix A. 


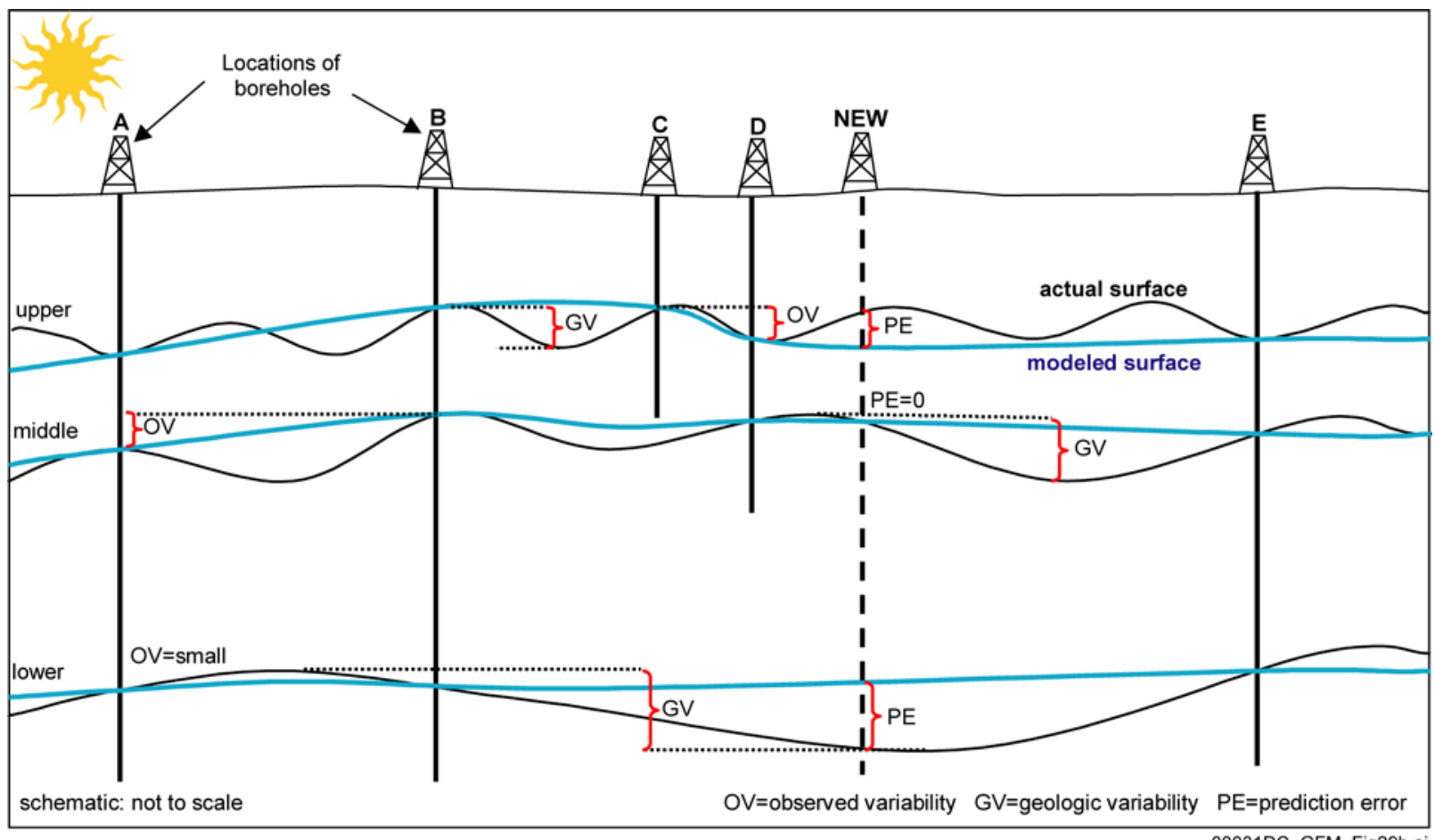

Source: For illustrative purpose only.

Figure 6-26. Schematic Cross Section Showing the Relation Between Geologic Variability, Observed Variability, and Prediction Error

Because uncertainty is an inherent part of a geologic model, users of the geologic framework model must take uncertainty into account when using the geologic framework model, and determine whether the uncertainty described in this section is appropriate to specific users. The only anticipated impact of uncertainty in the geologic framework model would be on the models related to repository design if uncertainty exceeds specific design constraints or assumptions. For other geologic framework model users, uncertainty is not expected to exceed requirements of the users.

\subsubsection{Data Distribution}

The modeled area is divided into constrained and less constrained areas for the purposes of estimating subsurface uncertainty (Figure 6-27). Constrained areas are those between at least two boreholes or exposure (interpolation), and less constrained areas are those outside borehole control or exposure (extrapolation) or which are influenced by geologic complexity. Because an interpolation is constrained on at least two sides, the related uncertainty is generally less than that of an extrapolation. Note that the boundaries of the constrained and less constrained areas vary by depth because borehole depths vary as illustrated in Figure 6-27. For example, 54 boreholes penetrate unit Tpy, but only 11 penetrate to the base of unit Tct. Dune Wash, described in Section 6.6.4 and labeled in Figure 6-27, is less constrained because of localized geologic complexity. The other less constrained areas described in Section 6.6.4 and labeled on Figure 6-27 are less constrained because of alluvial cover and/or lack of subsurface data. 
An inherent feature of all three-dimensional geologic models is that the subsurface is only partially known; in other words, it is uncertain because of limited information. Knowledge of the subsurface is defined by the number and distribution of boreholes and tunnels. The input boreholes in the total modeled area are relatively few in number and are concentrated in locations nearest the vicinity of the ESF (Figure 6-1) and at sites that were selected in part for reasons other than geologic modeling, such as accessibility. Many large sections of the modeled area and many fault blocks contain no subsurface data; in these areas, uncertainty is high. For the modeled area at Yucca Mountain, approximately 1 percent of the subsurface volume (limited to the depth of the deepest borehole, 6,000 feet [1,830 meters] below ground surface) is within 500 feet (150 meters) of a borehole or tunnel; therefore, uncertainty is pervasive in the geologic framework model.

\subsubsection{Uncertainty Estimates for Constrained Areas}

Uncertainty of subsurface rock layer elevations was estimated for the central part of Yucca Mountain in the vicinity of the ESF, which is a constrained area.

Uncertainty was estimated by two "jack-knife” methods ["A Leisurely Look at the Bootstrap, the Jackknife, and Cross-Validation." The American Statistician, 37 (Efron and Gong 1983 [DIRS 103967])], which are discussed in more detail in Appendix A. The essential concept of the "jack-knife" method is to use part of the input data to predict the remaining data. By dividing the data into groups and repeating this procedure for various combinations of the data groups, an estimate can be made of the model's ability to make accurate predictions (its ability to represent the real world). The estimated uncertainty is defined here as two standard deviations (95 percent confidence) above and below the mean of the prediction errors. The uncertainty represents a window above and below a modeled surface in which the actual surface is estimated to reside, based on a 95 percent level of confidence (i.e., the actual surface will occur within the uncertainty window 95 percent of the time). Statistics were calculated assuming normal distribution.

The study area shown in Figure 6-28 was chosen for the uncertainty analysis because it is the least faulted portion of the model (and therefore is best suited to statistical analysis), and because it is of greatest importance to geologic framework model users, particularly subsurface repository design. Three horizons were chosen to represent shallow, intermediate, and deep data: the tops of model units Tpy, Tptrv1, and Tptpv3. Unit Tpy was chosen because it is the shallowest unit that is present in all boreholes in the area of interest. Unit Tptrv1 was chosen because it is a significant lithologic break between less-welded and densely welded rocks. Unit Tptpv3 was chosen because it forms the bottom of the RHH, and knowledge of its elevation is important to repository design and construction. The 18 boreholes within the selected study area that contain all 3 units were used in the uncertainty analysis. The boreholes and groupings are listed in Appendix A. 

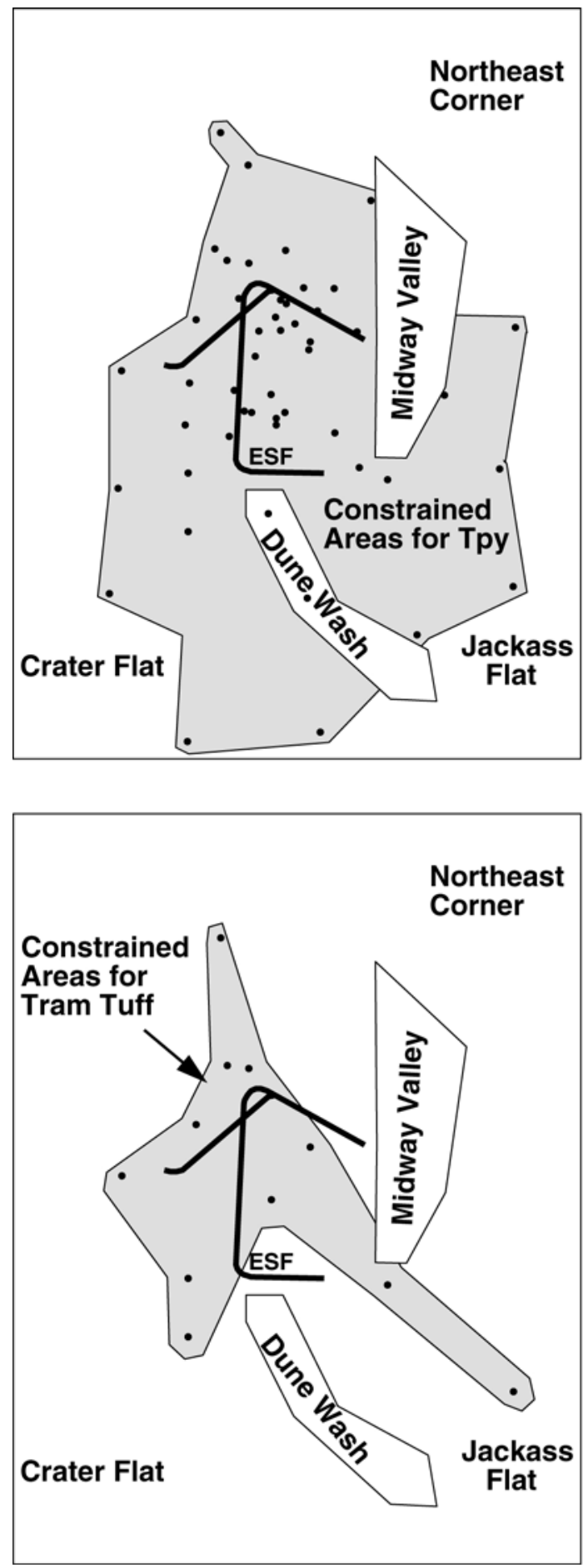

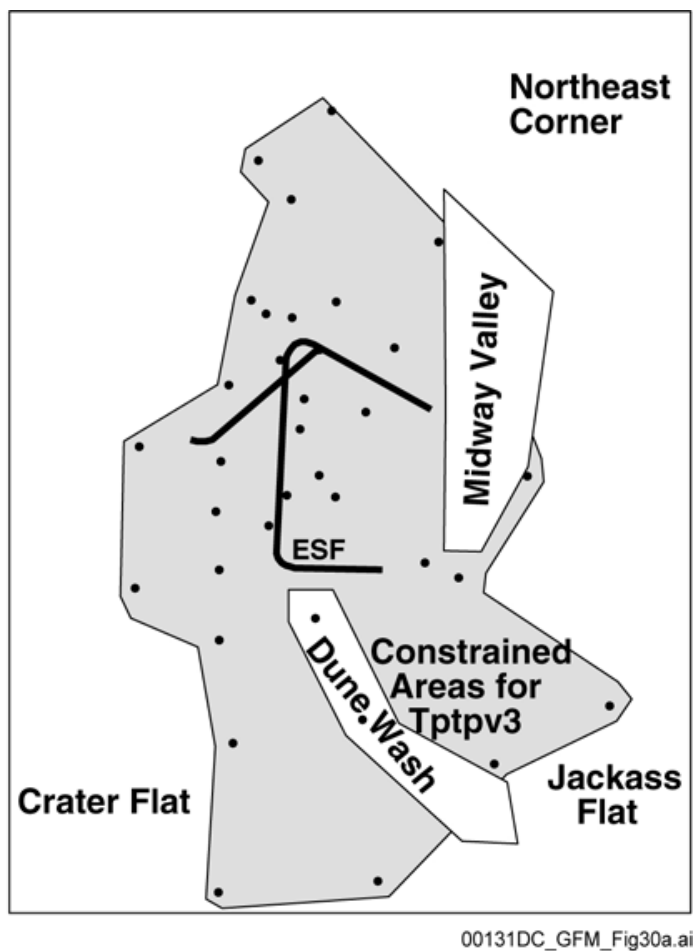

same area as Figure 1

ESF Exploratory Studies

Facility

\section{Less constrained area}

Constrained area

- Borehole

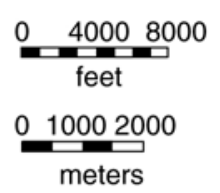

$\stackrel{\mathbf{N}}{1}$

Source: For illustrative purpose only.

Figure 6-27. Maps of Constrained and Less Constrained Areas of GFM2000 for Selected Units 
The borehole data were divided into 6 groups, each with 3 boreholes. The boreholes were grouped randomly. Three such random suites were created, resulting in 3 suites each containing 18 boreholes in 6 groups of 3 boreholes. A fourth suite of borehole data (also with 6 groups of 3 boreholes) was created by grouping the boreholes in order of date of drilling to evaluate the actual historical progression of predictions. Both of the methods discussed below were applied to each of the 4 suites.

Two types of "jack-knife" estimations were performed-sequential and cross-correlative. In the sequential method, the contacts from the first group of 3 boreholes was used to predict the contacts from second group and the errors were calculated. The first two groups were then combined to predict the third group, and so on until 5 groups predicted the sixth. This was repeated for all 4 suites. The prediction error was expected to decrease with the addition of each successive group to some minimum value that represents the ultimate ability of the model to predict the subsurface geology based on available data. Deviations from this trend can be interpreted to represent the effects of geologic variability.

In the cross-correlation method, each group of 3 boreholes was omitted in turn, and the prediction errors for each omitted group were calculated. This was expected to provide an estimate of prediction error ranges and averages, and is useful for evaluating the characteristics of individual borehole data. Errors caused by geologic variability associated with particular borehole locations would be expected to be repeated in all 4 suites.

Interpretive constraints were not used in the uncertainty estimations. The effects of interpretive constraints would be to reduce the initial prediction errors in the sequential method by limiting the poorly constrained grids (i.e., based on only 3 data points) to more realistic geometries. However, there is no a priori reason to assume that interpretive constraints would reduce prediction errors for the final sequential group or for the cross-correlative method, and so no adverse impact of this decision is anticipated.

The results of the sequential and cross-correlative methods are summarized in Table 6-3. The uncertainties estimated for the three surfaces by the two methods are similar. The similarity of results is expected because of the similarity of the final prediction in the sequential method and the cross-correlation method (both are based on 15 values predicting 3 values). Because the cross-correlation method produces a larger number of predictions, however, the results for this method provide a more accurate estimation of uncertainty and are the values used to summarize uncertainty in the geologic framework model.

As derived in Appendix A, the uncertainty estimations are dependent on the measured average spacing of the boreholes in the study area used in this analysis, which is typically 3280 feet (1000 meters); therefore, these values apply to locations at that distance from existing boreholes and tunnels. 


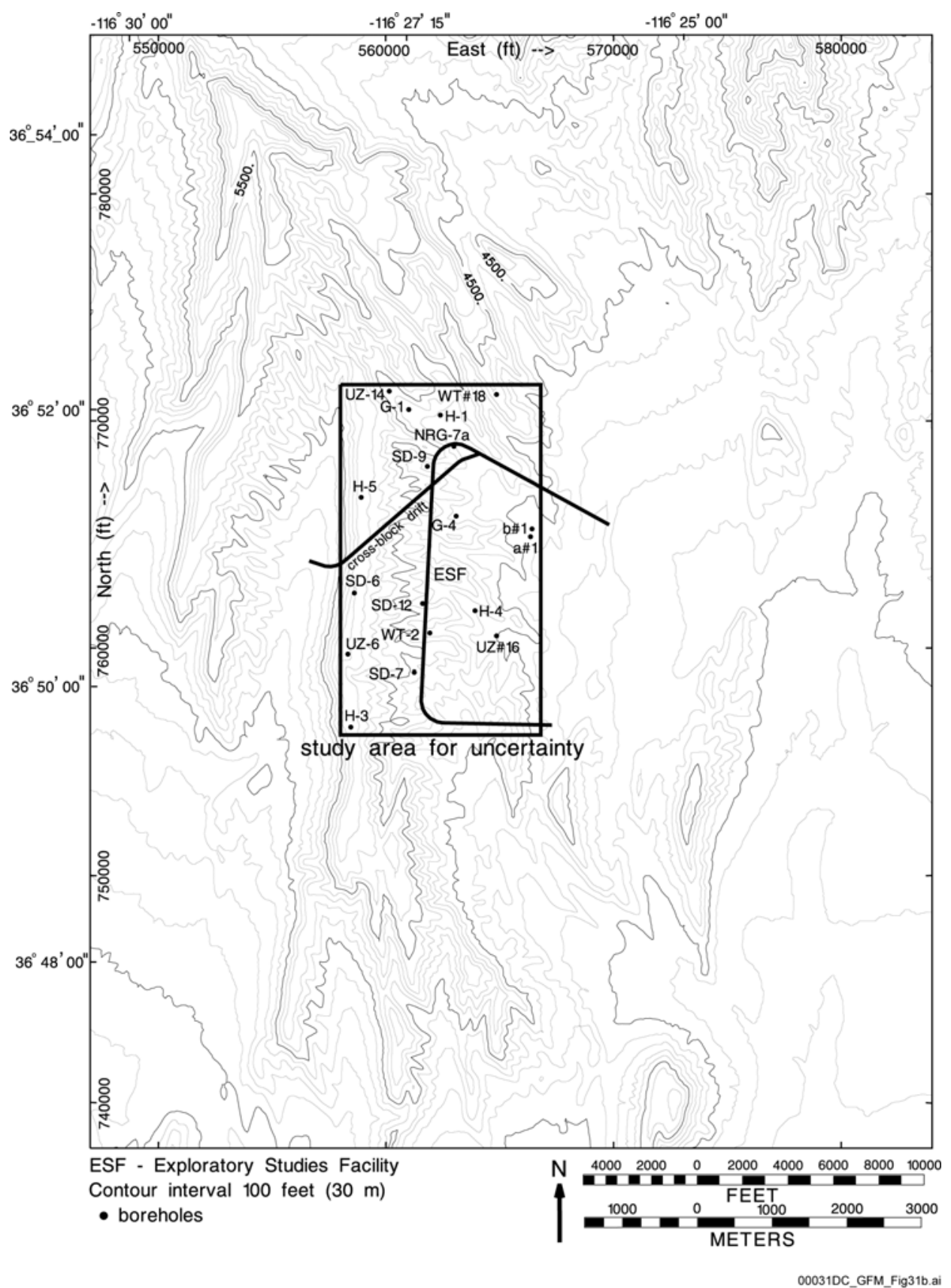

Source DTNs: MO0002SPATOP00.001 [DIRS 152643] Topography; MO9906GPS98410.000 [DIRS 109059 Borehole locations.

Figure 6-28. Map Showing the Study Area for Uncertainty Estimation 
Table 6-3. Summary of Vertical Uncertainties (Elevation) Estimated by the Sequential and Cross-Correlation Jack-Knife Methods

\begin{tabular}{|l|l|l|l|}
\hline \multicolumn{1}{|c|}{ Method } & \multicolumn{1}{|c|}{ Tpy } & \multicolumn{1}{c|}{ Tptrv1 } & \multicolumn{1}{c|}{ Tptpv3 w/o WT\#18a } \\
\hline Sequential & -34 to +45 feet & -38 to +48 feet & -75 to +79 feet \\
& $(-10.4$ to +13.7 meters $)$ & $(-11.6$ to +14.6 meters $)$ & $(-22.9$ to +24.1 meters $)$ \\
\hline Cross-Correlation & -42 to +58 feet & -49 to +55 feet & -76 to +80 feet \\
& $(-12.8$ to +17.7 meters $)$ & $(-14.9$ to +16.8 meters $)$ & $(-23.2$ to +24.4 meters $)$ \\
\hline
\end{tabular}

${ }^{a}$ For a complete discussion of this column see Sections A.2 and A.3 of Appendix A.

For the previous model version (GFM3.1), the 95 percent confidence limit was not used, but rather an average of absolute value errors (CRWMS M\&O 2000 [DIRS 138860], p. V-2). The higher uncertainty listed here represents a more conservative criterion. The variability represented by a 68 percent confidence interval (one standard deviation) would be half of the 95 percent confidence interval in Table 6-4, and would be close to the uncertainties calculated for GFM3.1.

The small decrease in uncertainty from unit Tpy to Tptrv1 shown on Table 6-4 (Table A-7) resulted from the large mean of prediction errors for unit Tpy (8 feet, 2.4 meters). Examination of the data indicates that the large mean was caused by the abrupt northward thickening (and resulting abrupt rise in the elevation of the top of the unit) of unit Tpy (Figure 6-12), which caused predictions to be low (positive errors). The Tpy uncertainty estimation illustrates that uncertainty is related to local geologic variability. Though the magnitude of the decrease is not significant, geologic framework model users should assess the uncertainty in relation to tolerances required in specific applications. No impact is anticipated on geologic framework model users because this unit occurs well above the $\mathrm{RHH}$, and the difference in uncertainties is small compared to user tolerances.

Table 6-4. Estimated Vertical Uncertainty (Elevation) from the Cross-Correlation Jack-Knife Method

\begin{tabular}{|c|c|c|c|}
\hline Unit & Mean of Difference & $\begin{array}{l}2 \text { Standard Deviation } \\
\text { (95\% conf.) of Difference }\end{array}$ & $\begin{array}{c}\text { Uncertainty }=\text { mean } \pm 2 \\
\text { Standard Deviation. }\end{array}$ \\
\hline Tpy & 8 feet (2.4 meters) & \pm 50 feet (15.2 meters) & $\begin{array}{l}-42 \text { to }+58 \text { feet } \\
(-12.8 \text { to }+17.7 \text { meters })\end{array}$ \\
\hline Tptrv1 & 3 feet (0.9 meters) & \pm 52 feet (16.0 meters) & $\begin{array}{l}-49 \text { to }+55 \text { feet } \\
(-14.9 \text { to }+16.8 \text { meters })\end{array}$ \\
\hline Tptpv3 & 2 feet ( 0.6 meters) & \pm 78 feet (23.8 meters) & $\begin{array}{l}-76 \text { to }+80 \text { feet } \\
(-23.2 \text { to }+24.4 \text { meters })\end{array}$ \\
\hline
\end{tabular}

Source: Table A-7.

Ninety-five percent confidence means that the model is expected to predict the elevation of a horizon within the uncertainty window 95 percent of the time in the study area. For the base of the $\mathrm{RHH}$, as an example, the estimated uncertainty is -76 to +80 feet $(-23.2$ to +24.4 meters $)$ at a distance of about 3,280 feet (1,000 meters) from a borehole or tunnel. Uncertainty is expected to decrease as the model approaches a data location. Beyond 3,280 feet (1,000 meters) from a data location, uncertainty is greater and is bounded only qualitatively by the geologic conceptual model. As illustrated in Figure 6-26, uncertainty estimates for a geologic model are made with the acknowledgement that new data may reveal that geologic variability in the subsurface locally exceeds the uncertainty that was previously estimated based on available data. This would more 
likely be true in the less constrained areas. Therefore, the uncertainty estimates described in this section apply only to relatively simple locations like the study area where faulting, tilting, and depositional complexities are minimal.

In summary, the uncertainty estimations provide confidence that the geologic framework model represents the geology of the central part of Yucca Mountain within the windows presented. The results indicate that uncertainty varies spatially; therefore, it can only be reduced by acquiring new data (drilling new boreholes or tunnels), and uncertainty is only reduced locally around the new data. Larger uncertainties (and larger prediction errors) could result if the geologic system is more variable than the available data can adequately define, as illustrated in Figure 6-26. These conclusions may affect decisions regarding future data acquisition if the uncertainties estimated in this report are large in relation to the tolerances required in users of the geologic framework model.

\subsubsection{Uncertainty Estimates for Less Constrained Areas}

In addition to distance from data, other factors contribute to uncertainty in some parts of the modeled area. The factors include uncertain amounts of fault displacements, fault blocks in which no subsurface data are available, and structural complexity buried by alluvium. Each of these factors contributes to lack of knowledge of the subsurface and increases uncertainty. Because fault displacements in the subsurface are rarely known precisely, elevation data from one side of a fault cannot be used to predict elevations on the other side of the fault, and the uncertainty values presented in the previous section are not applicable. In addition, faulting at Yucca Mountain is commonly accompanied by tilting of the rock strata, which further reduces the predictability of elevations from one side of a fault to the other. For these reasons, the relatively unfaulted area in the vicinity of the ESF was chosen for the uncertainty evaluations described in the previous section.

The less constrained areas are the northeastern corner of the modeled area, Midway Valley, Crater Flat, Jackass Flats, and the Dune Wash area (Figure 6-27). In addition, much of the subsurface in the corners of the model area is unconstrained by subsurface data and/or the bedrock is covered by alluvium. Collectively, these areas are called the less constrained areas because they are physically outside borehole control or because they are geologically complex and, therefore, highly variable. As illustrated in Figure 6-27, the extent of constrained area in the model decreases with depth as fewer boreholes penetrate the deeper horizons. Each of these areas is described below.

Northeastern Corner-The greatest uncertainty in the model is associated with the northeastern corner of the modeled area. Uncertainty is unquantifiable from the lower Calico Hills Formation and below because the base of the Calico Hills Formation is not exposed in the area and no subsurface data are available. The northeast corner is an area of long distance extrapolation.

Crater Flat, and Jackass Flats-Crater Flat and Jackass Flats are large areas covered by alluvium and are constrained only by widely scattered boreholes, so that structural details are not known with any degree of confidence. These are largely areas of long distance extrapolation. 
Midway Valley-Structure beneath Midway Valley is also covered by alluvium and qualitatively constrained only by geophysical profiles, which do not provide stratigraphic details or precise fault displacements.

Dune Wash-The uncertainty associated with the Dune Wash area is largely due to localized structural complexity, the details of which are buried by alluvium. Based on geologic mapping (DTN: GS980608314221.002 [DIRS 107024]), faults are likely to be present between boreholes WT-1 and WT\#17 (shown on Figure 6-2), and between the boreholes and outcrop; consequently, little detail can be interpolated from one location to another.

Older Tertiary and pre-Tertiary Units-Because of their great depth below ground surface and the minimal measured data available, the older Tertiary (Tund) and pre-Tertiary units have more uncertainty associated with them than the shallower Tertiary units (Figure 6-27). Therefore, these deeper units are also considered to be less constrained. The depth of the Tertiary-Paleozoic unconformity is constrained at only one datum (borehole p\#1) and is extrapolated across the modeled area by means of a gravity model (DTN: LB980130123112.003 [DIRS 109062], Figure $3 b)$. Because only the $\mathrm{p} \# 1$ borehole provides data on the physical properties of the older Tertiary (Tund) and pre-Tertiary units for gravity calculations, vertical uncertainty for the depth of the unconformity is more than 3,280 feet (1,000 meters), except in the vicinity of borehole $\mathrm{p} \# 1$.

Because they are areas of extrapolation and are not near boreholes, the minimum uncertainty in the less constrained areas is equal to or greater than the estimated uncertainty in the constrained areas. Uncertainty for the less constrained areas cannot be calculated - the jack-knife method could not be performed in an area of extrapolation, and the results would not be meaningful in an area that is structurally complex. Therefore, the maximum uncertainty in less constrained areas cannot be calculated, but can only be bounded qualitatively by the geologic conceptual model. Because the conceptual model constraints are not precise, nor are they quantifiable, no attempt is made here to bound maximum uncertainty in the less constrained areas.

The greater uncertainty in poorly constrained areas does not impact the geologic framework model and integrated site model, but acquisition of new data could reduce uncertainty locally. Because the less constrained areas are located outside the planned repository area, no impact is anticipated for repository design and UZ hydrology models. Because SZ models, including those used in TSPA, use large grid cells and large groupings of stratigraphic units, no impact is anticipated for these models.

\subsubsection{Limitations and Alternative Interpretations}

Because each reference horizon and model isochore in the geologic framework model is an interpretation (except where coincident with data), each is nonunique, and other viable interpretations are possible where no data are located. All interpretations and predictions made by the geologic framework model include an uncertainty window, as described in the previous sections, and it is explicitly recognized that alternative interpretations that reside within this window would also be considered valid. Changes to the geologic framework model within the estimated uncertainty based on alternative interpretations or methods would not, therefore, be considered significant. A significant change to the geologic framework model (or a significant 
alternative interpretation) would be one that exceeds the estimated uncertainty, which would be unlikely in the vicinity of the ESF where the model is most constrained by data. Because alternative interpretations within the uncertainty window would be equally valid, no impact of alternative interpretations is anticipated on the geologic framework model, integrated site model, or subsequent model users. Available alternative interpretations for specific model features in areas having no subsurface data are discussed below.

It is recognized that by inclusion of different interpretations based in part on boreholes outside of the model area (VH-1, VH-2, J\#12, and JF\#3) and regional data, the methodology described in this report could generate viable alternative interpretations that differ from the interpretations presented by GFM2000. This is especially true in the less constrained areas of the model (the model boundaries, corners, and deeper stratigraphic units) where few or no data are present. However, GFM2000 was constructed to be consistent with offsite data (which by definition cannot be input to the model) and interpretations derived from regional data so that if the geologic framework model boundaries were extended to include those data, no significant changes would be required inside the present boundaries. Selection of different modeling techniques (i.e., computer triangulation, hand contouring, or geostatistical methods) could also result in viable alternative interpretations. In the vicinity of the ESF, where the model is most constrained by data, differences due to alternative interpretations would be sufficiently small to be insignificant to geologic framework model users (less than the estimated uncertainty). Examples of alternative interpretations are discussed below.

The thickness of the Topopah Spring Tuff (Tpt) shown in Figure 6-15 could be alternatively interpreted using a conceptual model in which the thickness varies about some average between the vicinity of the ESF and Crater Flat as it was in GFM3.1 (DTN: MO9901MWDGFM31.000 [DIRS 103769], Figure 20). The thickness of the Topopah Spring Tuff lower vitrophyre (Tptpv3) shown in Figure 6-16 could also be shown to vary about an average value in the southwest part of the model area using the same conceptual model, or by using a different interpolation method to include borehole $\mathrm{VH}-2$, which is 3.9 miles (6.3 kilometers) outside the western edge of the model and penetrates a 155 -foot (47-meter) -thick vitrophyre as discussed in Section 6.5.1.4.

The thickness of the Tram Tuff (Tct) shown in Figure 6-22 could be interpreted differently in the vicinity of borehole G-2. This borehole appears to be located on a buried structural high because the Tram Tuff is dramatically thinner in this borehole than in the boreholes farther south. The orientation and extent of the structure is unknown. Using a different conceptual model for the structural high, the thickness in G-2 could be illustrated with closed contours instead of the axis of thinning shown. The orientation of the structural high could also be illustrated on this map by imparting a different trend to the contours based on a different structural conceptual model.

The model is limited by the availability of data and relative amount of geologic complexity found in an area. More data will yield less uncertainty and fewer limits (Section 6.6.2). Less geologic complexity will yield less uncertainty and fewer limits.

Finally, it should be noted that appropriate use of the geologic framework model is inherently limited by scale and content. The grid spacing used in the geologic framework model (200 feet [61 meters]), discussed in Section 6.4.2, limits the size of features that can be resolved by the 
model. Users of the geologic framework model must also consider the data reduction discussed in Section 6.2 to determine whether the geologic framework model is appropriate for specific applications. 


\section{VALIDATION}

The purpose of this section is to validate the geologic framework model by showing how the confidence building criteria were satisfied during and after model development for the geologic framework model. Section 7.1 shows how the model development process satisfied the criteria in the Technical Work Plan (BSC 2004 [DIRS 169635]) and AP-SIII.10Q. Section 7.2 provides a detailed discussion of the post-development validation of the geologic framework model in accordance with the applicable criteria.

The level of confidence required for the model validation activities for the geologic framework model has been determined from the guidelines in project procedure AP-2.27Q, Planning for Science Activities in Attachment 3, Levels of Model Importance, Validation, and Confidence, (BSC 2004 [DIRS 169635] Section 2.2.1), to be Level I for the following reasons. Because the geologic framework model does not provide direct input to the TSPA, its level of significance depends, in part, on its association with models which do provide input directly to the TSPA. The geologic framework model is used to support the development of Development of Numerical Grids for UZ Flow and Transport Models, BSC 2003 [DIRS 160109], Hydrologic Framework Model for the Saturated Zone Site Scale Flow and Transport Model USGS 2001 [DIRS 158608], and Repository Design. The hydrogeological framework model and the numerical grids for UZ flow and transport models are then used for UZ and SZ flow and transport studies. AP-2.27Q, Attachment 3 lists UZ flow models as requiring Level I validation. Accordingly, Level I validation is appropriate for the geologic framework model. In addition, the hydrogeological framework model and the UZ numerical grids developed from the geologic framework model are also used for UZ transport models and SZ flow and transport models as requiring Level II validation. However, the geologic framework model is a static model that represents the stratigraphy and structure of the site. The UZ transport models and SZ flow and transport models are insensitive to the geologic framework model grid when compared to the UZ and SZ models overall uncertainty. Therefore, validation Level I applies.

\subsection{CONFIDENCE BUILDING DURING MODEL DEVELOPMENT TO ESTABLISH SCIENTIFIC BASIS AND ACCURACY FOR INTENDED USE}

For Level I validation, Section 2.2.1 of Technical Work Plan for: The Integrated Site Model (BSC 2004 [DIRS 169635]) specifies the following steps for 'Confidence Building During Model Development': The development of the model should be documented in accordance with the requirements of Section 5.3.2(b) of AP-SIII.10Q. Attachment 3 of AP-2.27Q also provides model validation guidance that is documented in the TWP (BSC 2004 [DIRS 169635] Section 2.2.1). The development of the geologic framework model has been conducted according to all of the applicable criteria, as follows:

1. Selection of input parameters and/or input data, and a discussion of how the selection process builds confidence in the model. [AP-SIII.10Q 5.3.2(b) (1) and AP-2.27Q Attachment 3 Level I (a)]

The selection of input data builds confidence in the geologic framework model because all input data have been obtained from controlled sources and provide appropriate data for use in construction of the model (see Table 4-1, Section 4.1). For 
each type of input a discussion is provided that documents the data attributes and provides justification for their selection as model inputs. Explanations also are provided for the data sets that were excluded. All input data are qualified. Additional data reduction discussions related to the selection of boreholes, faults, and topographic data are found in Sections 6.2.1, 6.2.2, and 6.2.3, respectively

For these reasons, the process for selecting input data meets the applicable criteria and, thus, builds confidence in the model.

2. Description of calibration activities, and/or initial boundary condition runs, and/or run convergences, simulation conditions set up to span the range of intended use and avoid inconsistent outputs, and a discussion of how the activity or activities build confidence in the model. Inclusion of a discussion of impacts of any non-convergence runs [(AP-SIII.10Q 5.3.2(b)(2) and AP-2.27Q Attachment 3, Level I (e)].

Traditional calibration activities were not performed for this model. They were determined not to be necessary because the geologic framework model is static representational model. For the same reasons, no initial boundary condition runs, convergences, or simulation conditions were performed or deemed necessary. However, as described in detail in Section 6, a stepwise construction process based on generally accepted model construction techniques was applied to construct the geologic framework model consistent with available data. Section 6.4 describes the following model construction steps which provide confidence in the geologic framework model. These steps included the construction of geologic framework model stratigraphy by using the isochore method (Section 6.4), the use of interpretive constraints based on available data to guide the construction of the isochores (Section 6.4.1), the construction of a grid which honors the measured data while permitting the use of interpretations where data are sparse (Section 6.4.2), the construction of faults from the geologic map (Section 6.4.4), the construction of reference horizons and model isochores based on data from the geologic map, boreholes, and tunnels (Section 6.4.5), and finally, assembly of the faults and rock layers into a consistent model.

The geologic framework model does not provide "simulation conditions" because it is a static representational model (BSC 2004 [DIRS 169635], Section 2.2.1e).

These activities show how the model construction meets the applicable criteria and builds confidence in the model.

3. Discussion of the impacts of uncertainties to the model results including how the model results represent the range of possible outcomes consistent with important uncertainties. [(AP-SIII.10 Q 5.3.2(b)(3) and AP-2.27Q Attachment 3, Level 1 (d) and $(f)]$.

The impacts of uncertainties and limitations on model results are discussed in Section 6.6. Uncertainty concerns are limited to vertical locations (elevation) because the geologic framework model was constructed to exactly match the measured lateral 
positions of all input data. Uncertainty was evaluated by applying the recognized jack knife method. Uncertainty was characterized by demarcation of constrained and less constrained areas of the model (Figure 6.27). As illustrated by the figures and discussed in Sections 6.6.2, 6.6.3, and 6.6.4 the less constrained (areas of higher uncertainty) are in areas located away from the data sources. These areas of high uncertainty occur at the outer edge of the model, and in areas of the model segregated by faults. In addition, the predictive capability of the geologic framework model has been demonstrated by documenting the difference between predicted and measured stratigraphic contacts. Appendix $\mathrm{C}$ documents the confidence and uncertainty provided by the geologic framework model in constrained and less constratined areas and builds confidence in the model.

For these reasons, the impacts of model uncertainty on model results and the range of outcomes consistent with important uncertainties have been adequately addressed to meet the applicable criteria and build confidence in the model.

The geologic framework model does not provide model predictions (performance parameters) that incorporate a range of possible outcomes consistent with important uncertainties, because it is a static representational model (BSC 2004 [DIRS 169635], Section 2.2.1f).

4. Formulation of defensible assumptions and simplifications. [AP-2.27Q Attachment 3 Level I (b)].

Section 6.4.1 lists the generally accepted geologic concepts which were assumed to apply to the construction of the geologic framework model based on the data for the site. The demonstrated applicability of these concepts related to the deposition, erosion, and secondary processes for volcanogenic rocks builds confidence in the geologic framework model.

5. Consistency with physical principles, such as conservation of mass, energy, and momentum. [AP-2.27Q Attachment 3 Level I (c)]

The geologic framework model is consistent with physical principles. More importantly, the geologic framework model is consistent with geologic modeling principles as discussed in Section 6.4.1. The geologic framework model is a static representational model that provides a three-dimensional representation the structure and stratigraphy in the model volume. Therefore, principles governing transport phenomena such as the conservation of mass, energy, and momentum do not apply in this case.

\subsection{CONFIDENCE BUILDING AFTER MODEL DEVELOPMENT TO SUPPORT THE SCIENTIFIC BASIS OF THE MODEL}

Level I requires that a single method of post development validation be conducted to establish that the needed level of confidence has been met for the model. The previous version of this model report (BSC 2004 [DIRS 168029]) included a method of validation that demonstrated the adequacy of the geologic framework model in terms of matching available data and interpolating 
or predicting new data (i.e. corroboration). Some of the review activities preceding the current Regulatory Integration Team activities suggested that the previous model validation was unsatisfactory because it did not specify explicit validation criteria. A description of the previous model validation activities is provided in Appendix C. In order to improve the validation of the geologic framework model, the Technical Work Plan for: The Integrated Site Model (BSC 2004 [DIRS 169635]) directed that an independent technical review of the development, checking, and review of the model documentation be conducted. The independent technical review was completed and the results are discussed and summarized below. They show that the post-development activities build confidence in the geologic framework model.

The criteria for the independent technical review were to determine the adequacy, accuracy, and completeness of the geologic framework model and to determine that the decisions and methodology used in the construction of the model are reasonable and defensible and where applicable follow standard industry or best practices. The review was performed by Paul White, [Independent Technical Assessment, Yucca Mountain Project, Geologic Framework Model: GFM2000 (White 2004 [DIRS 170329])] and is included as Appendix D. Paul White is a manager with Digital Graphics Inc. and has over twenty years experience in the analysis, mapping and modeling of geologic information, and is an expert in EARTHVISION software.

The independent technical review was comprised of several elements.

- An examination of each component of the modeling methodology described in Section 6.4 was conducted. Each procedure of the component modeling process and of the final modeling assembly was reviewed to verify that the EARTHVISION software was used and applied in accordance with best and standard practice.

- The Scientific Notebook (SN-M\&O-SCI-028-V1) (Clayton 2001 [DIRS 153713]) and the previous version of the model report (BSC 2004 [DIRS 168029]) were examined to evaluate modeling methodology and use of the software in the estimation of uncertainty.

- Each of the geologic map fault trace data files were examined. Methods and scripts were examined to evaluate the projections of fault surfaces to depth. Fault surface contact data at depth and the fault gridding method and accuracy also were examined. The fault hierarchy that defines fault-to-fault relationships was examined. The 43 faults of the geologic framework model were found to be organized to accurately represent their truncation and age relationships. No faults were prematurely or incorrectly truncated by other intersecting faults.

- For each of the 50 rock units the input borehole data files, measured section data files, and geologic map stratigraphic contact data files were examined. The gridding parameters used in calculating reference horizons and intermediate isochores were examined. All aspects of data manipulation completed to control stratigraphic throw across faults were examined. The surface elevation (topographic) data were also examined. The integration of borehole, cross section, geologic section surface contact and elevation data along with the EARTHVISION isochore gridding algorithm to maintain rock layer thickness consistent throughout the model area is the industry standard method of calculating a model of this type with the software. 
- The model assembly procedure of the 43 faults and 50 horizons that create the final model, a three-dimensional representation of geology and structure, was examined to ensure compliance with industry standard practices and application of the software.

The conclusions of the independent technical review of the geologic framework model are found in White (2004 [DIRS 170329]). "The model was planned and built using best and standard practices in the application of the EARTHVISION 3D modeling software. Every aspect of the model building exercise was performed using EARTHVISION in a reasonable, credible, defensible, and repeatable manner. The output product, a static three-dimensional model representing the geologic framework of the specified area, is adequate for its intended use and is accurate for its intended use and parameter uncertainty. The model is appropriate for its intended use on the YMP, and there are no limits or restrictions on model use with stated and intended uses for the project." Thus, this post-development independent technical review supports confidence in the GFM.

Independent corroboration of this conclusion is provided in part by an NRC staff review of GFM 3.1, an earlier version of GFM 2000. (NRC 1999 [DIRS 135621], p. E-1). The NRC staff concluded that: (1) the level of detail and accuracy of the geologic framework model are adequate for the planned scope of the integrated site model and users of the geologic framework model; (2) the representation of faults is adequate for intended use (NRC 1999 [DIRS 135621], p. E-59); and (3) the representation of stratigraphy is adequate for intended use (NRC 1999 [DIRS 135621], pp. E-20 and E-21). Confidence in the geologic framework model is further supported by the NRC's statement that it will adapt a version of GFM3.1 for its own use in conducting three-dimensional analyses of the Yucca Mountain Site, including reviews of subsequent geologic framework model versions (NRC 1999 [DIRS 135621], p. E-3).

\subsection{VALIDATION SUMMARY}

The geologic framework model has been validated by applying acceptance criteria based on an evaluation of the model's relative importance to the potential performance of the repository system. Activities requirements for confidence building during model development have been satisfied (Section 7.1). Post development model validation criteria specified for this Level I model, as described in Technical Work Plan for: The Integrated Site Model (BSC 2004 [DIRS 169635] Section 2.2.1) and Section 5.3 of AP-SIII.10 Q, have been met as determined by the independent technical review. No future activities need to be accomplished for model validation. The independent technical review has determined that the geologic framework model is adequate and sufficiently accurate with no limits or restrictions on its use for the stated and intended purpose. The model development activities and the post-development validation activities prescribed establish the scientific bases for the geologic framework model. 


\section{INTENTIONALLY LEFT BLANK}




\section{CONCLUSIONS}

The geologic framework model is one component of the integrated site model, which also includes the rock properties model and the mineralogic model. The geologic framework model provides a baseline representation of the locations and distributions of 50 rock layers and 43 faults in the subsurface of the Yucca Mountain area for use in geoscientific modeling and repository design. The input data from geologic mapping and boreholes provide controls at the ground surface and to the total depths of the boreholes; however, most of the modeled volume is unsampled and uncertainty is high. The geologic framework model is an interpretative and predictive tool that provides a representation of reality within the estimated uncertainty. The computer files needed to reproduce the model results discussed in this report are compiled in DTN: MO0012MWDGFM02.002 [DIRS 153777].

Estimated vertical uncertainty in the geologic framework model increases with distance from the data and is also a function of heterogeneity, which results from geologic processes like deposition, faulting, alteration, and erosion. Uncertainty in the model is reduced by the application of established geologic principles.

The most uncertain areas in the model are the four corners, the less constrained areas, and the volume deeper than the borehole penetrations. For locations between boreholes in the central part of the model (the constrained areas), 95 percent of model predictions and acceptable alternative interpretations would be expected to lie within the uncertainty given in Table 6-4.

Uncertainty increases from zero at data locations and the ground surface to the values given in Table 6-4 at a horizontal distance of approximately 3,280 feet (1,000 meters) from the data locations. Uncertainty is greater for deeper stratigraphic units because geologic variability increases and fewer data are available. These estimated uncertainty values represent the sum of the mean and two standard deviations (95 percent confidence interval) of prediction errors based on sequential and cross-correlation jack-knife uncertainty estimations.

The geologic framework model portrays the distribution of rock layers that are of greatest interest to TSPA-related models and analyses, some of which are summarized here. The Paintbrush nonwelded (PTn) unit thickens dramatically to the northwest and thins southward throughout the vicinity of the ESF. The RHH is several hundred feet thick in the vicinity of the ESF. The Calico Hills Formation (Ta) thickens to an unknown maximum thickness toward the northeast. The Tertiary-Paleozoic unconformity, which is the top of the regional Paleozoic carbonate aquifer, is poorly constrained by data but appears to deepen dramatically from east to west in the vicinity of the ESF. This surface is between 8,000 and 11,000 feet $(2,400$ to 3,500 meters) below the ESF.

The independent technical review has determined that the geologic framework model is adequate and sufficiently accurate with no limits or restrictions on its use for the stated and intended purpose.

The geologic framework model is intended to be used in a variety of YMP studies and activities. Because the geologic framework model is an interactive three-dimensional database and volumetric representation of Yucca Mountain, it is a useful tool for geoscientific analyses of all 
types, including hydrologic modeling, confirmation test planning, site geotechnical analysis, uncertainty analysis, model integration, data analysis, and repository facilities design. However, users of the geologic framework model should consider the uncertainties and limitations of scale and content to determine whether the geologic framework model is appropriate to specific applications.

No confirmatory actions, such as compliance runs, additional sensitivity runs, or neutralization runs are addressed by this report.

\subsection{CONCLUSIONS FOR THE YUCCA MOUNTAIN REVIEW PLAN CRITERIA}

The following information describes how this analysis addresses the acceptance criteria in the Yucca Mountain Review Plan, Final Report (NRC 2003 [DIRS 163274], Sections 2.2.1.3.6.3, 2.2.1.3.7.3, 2.2.1.3.8.3, and 2.2.1.3.9.3). Only those acceptance criteria that are applicable to this report (see Section 4.2) are discussed.

Acceptance Criteria from Section 2.2.1.3.6.3, Flow Paths in the Unsaturated Zone

Acceptance Criterion 1, System Description and Model Integration Are Adequate.

Subcriterion (2): The geologic framework model provides a comprehensive model of the spatial position and geometry of rock units and faults at Yucca Mountain. This model is technically defensible and adequately considers geological aspects, physical phenomena, and geochemistry that may affect physical processes such as ground-water flow and radionuclide transport, both of which are inputs to safety analyses regarding repository performance and repository design as discussed in Section 6.1. The geologic framework model is a component of the integrated site model, which is used to develop a consistent volumetric portrayal of the spatial position and geometry of rock layers and faults at Yucca Mountain. Section 1 provides an overview of this process. The model development and evolution is described in Section 6.3 and shows why the descriptions of aspects of geology that may affect flow paths in the unsaturated zone are adequate. Section 6.4 discusses adequacy of the methodology used to construct the geologic framework model, which includes the development of grid construction and contouring methodology, construction of faults, construction of reference horizons and model isochores, assembly of faults and rock layers, and assessment, iteration, and quality control. It also presents a correlation between the stratigraphic units modeled in the geologic framework model and the YMP stratigraphy (Table 4), which supports model adequacy.

Acceptance Criterion 2, Data Are Sufficient for Model Justification.

Subcriterion (2): The Geologic Framework Model applies the data obtained from borehole samples, hydrostratigraphic contacts, maps of geology and topography, and measured stratigraphic sections that are discussed in Section 4.1 and listed in Table 2, Input Data. Acceptable 
techniques were used to collect the data and those techniques are described in more detail in the individual reports cited in Table 2. This model supports site characterization of the unsaturated zone by interpolating and converting that data to a three-dimensional interpretation of the geology at Yucca Mountain. Inputs to the model are also discussed in Section 6.2. Section 6.2 describes data reduction including selection of boreholes, faults, and topographic data and provides further evidence of data sufficiency.

Acceptance Criteria from Section 2.2.1.3.7.3, Radionuclide Transport in the Unsaturated Zone

Acceptance Criterion 1, System Description and Model Integration Are Adequate.

Subcriterion (2): The geologic framework model provides a comprehensive model of the spatial position and geometry of rock units and faults at Yucca Mountain. This model is technically defensible and adequately considers geological aspects, physical phenomena, and geochemistry that may affect physical processes such as ground-water flow and radionuclide transport, both of which are inputs to safety analyses regarding repository performance and repository design as discussed in Section 6.1. The geologic framework model is a component of the integrated site model, which is used to develop a consistent volumetric portrayal of the spatial position and geometry of rock layers and faults at Yucca Mountain. Section 1 provides an overview of this process. The model development and evolution is described in Section 6.3 and shows why the descriptions of aspects of geology that may affect flow paths in the unsaturated zone are adequate. Section 6.4 discusses adequacy of the methodology used to construct the geologic framework model, which includes the development of grid construction and contouring methodology, construction of faults, construction of reference horizons and model isochores, assembly of faults and rock layers, and assessment, iteration, and quality control. It also presents a correlation between the stratigraphic units modeled in the geologic framework model and the YMP stratigraphy (Table 4), which further supports model adequacy.

Acceptance Criterion 2, Data Are Sufficient for Model Justification.

Subcriterion (3): The Geologic Framework Model applies the data obtained from borehole samples, hydrostratigraphic contacts, maps of geology and topography, and measured stratigraphic sections that are discussed in Section 4.1 and listed in Table 2, Input Data. Acceptable techniques were used to collect the data and those techniques are described in more detail in the individual reports cited in Table 2. This model supports site characterization of the unsaturated zone by interpolating and converting that data to a three-dimensional interpretation 
of the geology at Yucca Mountain. Inputs to the model are also discussed in Section 6.2. Section 6.2 describes data reduction including selection of boreholes, faults, and topographic data and provides further evidence of data sufficiency.

Acceptance Criteria from Section 2.2.1.3.8.3, Flow Paths in the Saturated Zone

Acceptance Criterion 1, System Description and Model Integration Are Adequate.

Subcriterion (2): The geologic framework model provides a comprehensive model of the spatial position and geometry of rock units and faults at Yucca Mountain. This model is technically defensible and adequately considers geological aspects, physical phenomena, and geochemistry that may affect physical processes such as ground-water flow and radionuclide transport, both of which are inputs to safety analyses regarding repository performance and repository design as discussed in Section 6.1. The geologic framework model is a component of the integrated site model, which is used to develop a consistent volumetric portrayal of the spatial position and geometry of rock layers and faults at Yucca Mountain. Section 1 provides an overview of this process. The model development and evolution is described in Section 6.3 and shows why the descriptions of aspects of geology that may affect flow paths in the unsaturated zone are adequate. Section 6.4 discusses adequacy of the methodology used to construct the geologic framework model, which includes the development of grid construction and contouring methodology, construction of faults, construction of reference horizons and model isochores, assembly of faults and rock layers, and assessment, iteration, and quality control. It also presents a correlation between the stratigraphic units modeled in the geologic framework model and the YMP stratigraphy (Table 4), which supports model adequacy.

Acceptance Criterion 2, Data Are Sufficient for Model Justification.

Subcriterion (3): The Geologic Framework Model applies the data obtained from borehole samples, hydrostratigraphic contacts, maps of geology and topography, and measured stratigraphic sections that are discussed in Section 4.1 and listed in Table 2, Input Data. Acceptable techniques were used to collect the data and those techniques are described in more detail in the individual reports cited in Table 2. This model supports site characterization of the saturated zone by interpolating and converting that data to a three-dimensional interpretation of the geology at Yucca Mountain. Inputs to the model are also discussed in Section 6.2. Section 6.2 describes data reduction including selection of boreholes, faults, and topographic data and provides further evidence of data sufficiency. Acceptance Criteria from Section 2.2.1.3.9.3, Radionuclide Transport in the Saturated Zone 
Acceptance Criterion 1, System Description and Model Integration Are Adequate.

Subcriterion (2): The geologic framework model provides a comprehensive model of the spatial position and geometry of rock units and faults at Yucca Mountain. This model is technically defensible and adequately considers geological aspects, physical phenomena, and geochemistry that may affect physical processes such as ground-water flow and radionuclide transport, both of which are inputs to safety analyses regarding repository performance and repository design as discussed in Section 6.1. The geologic framework model is a component of the integrated site model, which is used to develop a consistent volumetric portrayal of the spatial position and geometry of rock layers and faults at Yucca Mountain. Section 1 provides an overview of this process. The model development and evolution is described in Section 6.3 and shows why the descriptions of aspects of geology that may affect flow paths in the unsaturated zone are adequate. Section 6.4 discusses adequacy of the methodology used to construct the geologic framework model, which includes the development of grid construction and contouring methodology, construction of faults, construction of reference horizons and model isochores, assembly of faults and rock layers, and assessment, iteration, and quality control. It also presents a correlation between the stratigraphic units modeled in the geologic framework model and the YMP stratigraphy (Table 4), which supports model adequacy.

Acceptance Criterion 2, Data Are Sufficient for Model Justification.

Subcriterion (3): The Geologic Framework Model applies the data obtained from borehole samples, hydrostratigraphic contacts, maps of geology and topography, and measured stratigraphic sections that are discussed in Section 4.1 and listed in Table 2, Input Data. Acceptable techniques were used to collect the data and those techniques are described in more detail in the individual reports cited in Table 2. This model supports site characterization of the saturated zone by interpolating and converting that data to a three-dimensional interpretation of the geology at Yucca Mountain. Inputs to the model are also discussed in Section 6.2. Section 6.2 describes data reduction including selection of boreholes, faults, and topographic data and provides further evidence of data sufficiency. 
INTENTIONALLY LEFT BLANK 


\section{INPUTS AND REFERENCES}

The following is a list of the references cited in this document. Column 2 represents the unique six digit DIRS number, which is placed in the text following the reference callout (e.g., CRWMS M\&O 2000 [DIRS 144054]). The purpose of these numbers is to assist the reader in locating a specific reference.

\subsection{DOCUMENTS CITED}

Brocher, T.M.; Hunter, W.C.; and Langenheim, V.E. 1998. "Implications of

100022

Seismic Reflection and Potential Field Geophysical Data on the Structural

Framework of the Yucca Mountain-Crater Flat Region, Nevada." Geological

Society of America Bulletin, 110, (8), 947-971. Boulder, Colorado: Geological

Society of America. TIC: 238643.

BSC (Bechtel SAIC Company) 2001. FY 01 Supplemental Science and

155950

Performance Analyses, Volume 1: Scientific Bases and Analyses. TDR-MGR-

MD-000007 REV 00 ICN 01. Las Vegas, Nevada: Bechtel SAIC Company.

ACC: MOL.20010801.0404; MOL.20010712.0062; MOL.20010815.0001.

BSC (Bechtel SAIC Company) 2003. Underground Layout Configuration. 800- 165572

P0C-MGR0-00100-000-00E. Las Vegas, Nevada: Bechtel SAIC Company. ACC:

ENG.20031002.0007.

BSC (Bechtel SAIC Company) 2004. Development of Numerical Grids for UZ 169855

Flow and Transport Modeling. ANL-NBS-HS-000015, Rev. 02. Las Vegas,

Nevada: Bechtel SAIC Company.

BSC (Bechtel SAIC Company) 2004. Geologic Framework Model (GFM2000), 168029 with errata. MDL-NBS-GS-000002 REV 01 [Errata 002]. Las Vegas, Nevada:

Bechtel SAIC Company. ACC: MOL.20020530.0078; DOC.20040128.0007;

DOC.20040211.0003.

BSC (Bechtel SAIC Company) 2004. Hydrogeologic Framework Model for the

170008

Saturated Zone Site Scale Flow and Transport Model. MDL-NBS-HS-000024,

Rev. 00. Las Vegas, Nevada: Bechtel SAIC Company.

BSC (Bechtel SAIC Company) 2004. Q-List. 000-30R-MGR0-00500-000-000

168361

REV 00. Las Vegas, Nevada: Bechtel SAIC Company. ACC:

ENG.20040721.0007.

BSC (Bechtel SAIC Company) 2004. Technical Work Plan for: The Integrated

169635

Site Model. TWP-NBS-GS-000003 REV 05. Las Vegas, Nevada: Bechtel SAIC

Company. ACC: DOC.20040601.0002. 
BSC (Bechtel SAIC Company) 2004. Thermal Conductivity of the Potential

169854 Repository Horizon. MDL-NBS-GS-000005, Rev. 01. Las Vegas, Nevada: Bechtel SAIC Company.

BSC (Bechtel SAIC Company) 2004. Yucca Mountain Site Description. TDR169734 CRW-GS-000001 REV 02 ICN 01. Two volumes. Las Vegas, Nevada: Bechtel SAIC Company. ACC: DOC.20040504.0008; Replacement for 168845.

Buesch, D.C. and Spengler, R.W. 1999. "Correlations of Lithostratigraphic 107905 Features with Hydrogeologic Properties, a Facies-Based Approach to Model Development in Volcanic Rocks at Yucca Mountain, Nevada." Proceedings of Conference on Status of Geologic Research and Mapping in Death Valley National Park, Las Vegas, Nevada, April 9-11, 1999. Slate, J.L., ed. Open-File Report 99-153. Pages 62-64. Denver, Colorado: U.S. Geological Survey. TIC: 245245.

Buesch, D.C.; Spengler, R.W.; Moyer, T.C.; and Geslin, J.K. 1996. Proposed 100106 Stratigraphic Nomenclature and Macroscopic Identification of Lithostratigraphic Units of the Paintbrush Group Exposed at Yucca Mountain, Nevada. Open-File Report 94-469. Denver, Colorado: U.S. Geological Survey. ACC: MOL.19970205.0061.

Byers, F.M., Jr.; Carr, W.J.; Christiansen, R.L.; Lipman, P.W.; Orkild, P.P.; and 103624 Quinlivan, W.D. 1976. Geologic Map of the Timber Mountain Caldera Area, Nye County, Nevada. Miscellaneous Investigations Series Map I-891. Denver, Colorado: U.S. Geological Survey. TIC: 204573.

Carr, M.D.; Waddell, S.J.; Vick, G.S.; Stock, J.M.; Monsen, S.A.; Harris, A.G.; 102046 Cork, B.W.; and Byers, F.M., Jr. 1986. Geology of Drill Hole UE25p\#1: A Test Hole Into Pre-Tertiary Rocks Near Yucca Mountain, Southern Nevada. Open-File Report 86-175. Menlo Park, California: U.S. Geological Survey. ACC: HQS.19880517.2633.

Carr, W.J. 1982. Volcano-Tectonic History of Crater Flat, Southwestern Nevada, 101519 as Suggested by New Evidence from Drill Hole USW-VH-1 and Vicinity. OpenFile Report 82-457. Denver, Colorado: U.S. Geological Survey. ACC: NNA.19870518.0057.

Carr, W.J. and Parrish, L.D. 1985. Geology of Drill Hole USW VH-2, and Structure of Crater Flat, Southwestern Nevada. Open-File Report 85-475. 101093 Denver, Colorado: U.S. Geological Survey. ACC: HQS.19880517.1918. 
Carr, W.J.; Byers, F.M., Jr.; and Orkild, P.P. 1986. Stratigraphic and Volcano104670 Tectonic Relations of Crater Flat Tuff and Some Older Volcanic Units, Nye County, Nevada. Professional Paper 1323. Denver, Colorado: U.S. Geological Survey. TIC: 216598.

Clayton, R.W. 2001. Geologic Framework Model (GFM2000). Scientific 153713 Notebook SN-M\&O-SCI-028-V1. ACC: MOL.20010108.0015.

CRWMS M\&O 1997. Determination of Available Volume for Repository Siting. 100223 BCA000000-01717-0200-00007 REV 00. Las Vegas, Nevada: CRWMS M\&O. ACC: MOL.19971009.0699.

CRWMS M\&O 2000. Data Qualification Report: Borehole Stratigraphic 158094 Contacts, Revision 01. TDR-NBS-GS-000007. Las Vegas, Nevada: CRWMS M\&O. ACC: MOL.20000424.0694.

CRWMS M\&O 2000. Geologic Framework Model (GFM3.1). MDL-NBS-GS138860 000002 REV 00 ICN 01. Las Vegas, Nevada: CRWMS M\&O. ACC: MOL.20000121.0115.

CRWMS M\&O 2000. Yucca Mountain Site Description. TDR-CRW-GS-000001 151945 REV 01 ICN 01. Las Vegas, Nevada: CRWMS M\&O. ACC:

MOL.20001003.0111.

CRWMS M\&O 2000. EARTHVISION V5.1, Validation Test Report Rev 00. STN: 10174-5.1-00. Las Vegas, Nevada: CRWMS M\&O.

ACC: MOL.20000927.0145

Efron, B. and Gong, G. 1983. "A Leisurely Look at the Bootstrap, the Jackknife, 103967 and Cross-Validation." The American Statistician, 37, (1), 36-48. Washington, D.C.: American Statistical Association. TIC: 245820.

Feighner, M.A.; Daley, T.M.; Gritto, R.; and Majer, E.L. 1998. Report: Results of 107428 VSP Analysis in P\#1. Milestone SP3B6AM4. Berkeley, California: Lawrence Berkeley National Laboratory. ACC: MOL.19980507.0948.

Majer, E.L.; Feighner, M.; Johnson, L.; Daley, T.; Karageorgi, E.; Lee, K.H.; 104685 Williams, K.; and McEvilly, T. 1996. Surface Geophysics. Volume I of Synthesis of Borehole and Surface Geophysical Studies at Yucca Mountain, Nevada and Vicinity. Milestone OB05M. Berkeley, California: Lawrence Berkeley National Laboratory. ACC: MOL.19970610.0150. 
Majer, E.L.; Johnson, L.R.; Vasco, D.W.; and Parker, P. 1998. Results of Gravity 109472 Modeling of the Paleozoic Basement. Milestone SP3B6DM4. Berkeley,

California: Lawrence Berkeley National Laboratory. ACC:

MOL.19980507.0940.

NRC (U.S. Nuclear Regulatory Commission) 1999. Issue Resolution Status

135621

Report Key Technical Issue: Structural Deformation and Seismicity. Rev. 2.

Washington, D.C.: U.S. Nuclear Regulatory Commission. ACC:

MOL.19991214.0623.

NRC (U.S. Nuclear Regulatory Commission) 2003. Yucca Mountain Review

163274

Plan, Final Report. NUREG-1804, Rev. 2. Washington, D.C.: U.S. Nuclear

Regulatory Commission, Office of Nuclear Material Safety and Safeguards. TIC:

254568.

Oliver, H.W.; Ponce, D.A.; and Hunter, W.C., eds. 1995. Major Results of

Geophysical Investigations at Yucca Mountain and Vicinity, Southern Nevada.

Open-File Report 95-74. Menlo Park, California: U.S. Geological Survey. ACC:

MOL.19980305.0122.

Plume, R.W. and La Camera, R.J. 1996. Hydrogeology of Rocks Penetrated by

141659

Test Well JF-3, Jackass Flats, Nye County, Nevada. Water-Resources

Investigations Report 95-4245. Carson City, Nevada: U.S. Geological Survey.

ACC: MOL.19970626.0500.

Ponce, D.A. and Langenheim, V.E. 1994. Preliminary Gravity and Magnetic

102333

Models Across Midway Valley and Yucca Wash, Yucca Mountain, Nevada. Open-

File Report 94-572. Menlo Park, California: U.S. Geological Survey. ACC:

MOL.19990406.0399.

Ponce, D.A.; Kohrn, S.B.; and Waddell, S. 1992. Gravity and Magnetic Data of

106561

Fortymile Wash, Nevada Test Site, Nevada. Open-File Report 92-343. Menlo

Park, California: U.S. Geological Survey. ACC: NNA.19920714.0032.

Sawyer, D.A.; Fleck, R.J.; Lanphere, M.A.; Warren, R.G.; Broxton, D.E.; and 100075

Hudson, M.R. 1994. "Episodic Caldera Volcanism in the Miocene Southwestern

Nevada Volcanic Field: Revised Stratigraphic Framework, ${ }^{40} \mathrm{Ar} /{ }^{39} \mathrm{Ar}$

Geochronology, and Implications for Magmatism and Extension." Geological

Society of America Bulletin, 106, (10), 1304-1318. Boulder, Colorado:

Geological Society of America. TIC: 222523.

Spengler, R.W. and Kornreich, S.K. 2000. Pre-1992 Measured Sections In the

153782

Vicinity of Yucca Mountain, Nevada. Denver, Colorado: U.S. Geological Survey. ACC: MOL.20001122.0097; MOL.19960123.0060. 
White, P.L. 2004. Independent Technical Assessment, Yucca Mountain Project, 170329 Geologic Framework Model: GFM2000, May 17-28, 2004. Alameda, California:

Dynamic Graphics. ACC: MOL.20040603.0242.

\subsection{CODES, STANDARDS, REGULATIONS, AND PROCEDURES}

10 CFR 63. Energy: Disposal of High-Level Radioactive Wastes in a Geologic 156605 Repository at Yucca Mountain, Nevada. Readily available.

AP-2.22Q, Rev. 1, ICN 0. Classification Criteria and Maintenance of the Monitored Geologic Repository Q-List. Washington, D.C.: U.S. Department of Energy, Office of Civilian Radioactive Waste Management. ACC: DOC.20030807.0002.

AP-3.15Q, Rev. 4, ICN 4. Managing Technical Product Inputs. Washington, D.C.: U.S. Department of Energy, Office of Civilian Radioactive Waste Management.

ACC: DOC.20040510.0004.

AP-SIII.10Q, Rev. 2, ICN 6. Models. Washington, D.C.: U.S. Department of Energy, Office of Civilian Radioactive Waste Management. DOC.20040805.0005.

AP-2.27Q, Rev. 1, ICN 4. Planning for Science Activities. Washington, D.C.: U.S. Department of Energy, Office of Civilian Radioactive Waste Management. ACC: DOC.20040610.0006.

\subsection{SOURCE DATA, LISTED BY DATA TRACKING NUMBER}

GS931008314211.035. Graphical Lithologic Log of Drill Hole RF-8 (UE-25 RF 150005 \#8). Submittal date: 10/07/1993.

GS931008314211.036. Graphical Lithologic Log of Borehole RF-3 (UE-25 150006 RF\#3), Version 1.0. Submittal date: 10/07/1993.

GS940708314211.035. Measured Stratigraphic Section on the East Side of 109063 Solitario Canyon (Section SC\#1). Submittal date: 07/19/1994.

GS940908314212.007. Preliminary Gravity and Magnetic Models Across 107084 Midway Valley and Yucca Wash, Yucca Mountain, Nevada. Submittal date: 09/23/1994.

GS950108314211.001. Measured Stratigraphic Section on Isolation Ridge (Section PTN\#1). Submittal date: 01/20/1995.

109064

GS950108314211.002. Measured Stratigraphic Section on the Eastern Side of 109065 Solitario Canyon (Section PTN\#2). Submittal date: 01/20/1995.

GS950108314211.003. Measured Stratigraphic Section on the Eastern Side of 109066 
Solitario Canyon (Section PTN\#3). Submittal date: 01/20/1995.

GS950108314211.004. Measured Stratigraphic Section on the Eastern Side of 109067 Solitario Canyon (Section PTN\#4). Submittal date: 01/27/1995.

GS950108314211.005. Measured Stratigraphic Section on the Eastern Side of 109068 Solitario Canyon (Section PTN\#5). Submittal date: 01/27/1995.

GS960908314224.020. Analysis Report: Geology of the North Ramp - Stations 106059 4+00 to 28+00 and Data: Detailed Line Survey and Full-Periphery Geotechnical Map - Alcoves 3 (UPCA) and 4 (LPCA), and Comparative Geologic Cross Section - Stations 0+60 to 28+00. Submittal date: 09/09/1996.

GS970808314224.016. Geology of the South Ramp - Station 55+00 to 78+77, 109061 Exploratory Studies Facility, Yucca Mountain Project, Yucca Mountain, Nevada. Submittal date: 08/27/1997.

GS980608314221.002. Revised Bedrock Geologic Map of the Yucca Mountain 107024 Area, Nye County, Nevada. Submittal date: 06/09/1998.

GS981108314224.005. Locations of Lithostratigraphic Contacts in the ECRB 109070 Cross Drift. Submittal date: 11/30/1998.

LB980130123112.002. Topography and Gravity Model Data; Comparison of 153784 Depth to Basement. Submittal date: 08/05/1998.

LB980130123112.003. Figure 3B of Report, "Results of Gravity Modeling of the 109062 Paleozoic Basement". Submittal date: 10/20/1999.

MO0002SPATOP00.001. Topographic Grid Data. Submittal date: 02/24/2000. 152643

MO0004QGFMPICK.000. Lithostratigraphic Contacts from 152554 MO9811MWDGFM03.000 to be Qualified Under the Data Qualification Plan, TDP-NBS-GS-000001. Submittal date: 04/04/2000.

MO0010COV00124.001. Coverage: YM24KFS2. Submittal date: 10/26/2000. 153783

MO0106RIB00038.001. Water-Level Data and the Potentiometric Surface. 155631 Submittal date: 06/22/2001.

MO0111GLOGRF13.001. Scientific Program Support Geologic Log for 157305 Borehole UE-25 RF\#13. Submittal date: 11/26/2001. 
MO9510RIB00002.004. RIB Item: Stratigraphic Characteristics:

Geologic/Lithologic Stratigraphy. Submittal date: 06/26/1996.

MO9607ISM10MOD.001. A 3-D Geologic Framework and Integrated Site

109071

Model of Yucca Mountain. Submittal date: 07/25/1996.

MO9804MWDGFM03.001. An Update to GFM 3.0; Corrected Horizon Grids for 109050 Four Fault Blocks. Submittal date: 04/14/1998.

MO9807MWDGFM02.000. ISM 2.0: A 3-D Geologic Framework and Integrated 109074 Site Model of Yucca Mountain. Submittal date: 04/03/1998.

MO9811MWDGFM03.000. Input Data to Geologic Framework Model GFM3.0. 109006 Submittal date: 11/30/1998.

MO9901MWDGFM31.000. Geologic Framework Model. Submittal date:

103769 01/06/1999.

MO9906GPS98410.000. Yucca Mountain Project (YMP) Borehole Locations. 109059 Submittal date: 06/23/1999.

SNF40060198001.001. Unsaturated Zone Lithostratigraphic Contacts in 107239 Borehole USW WT-24. Submittal date: 10/15/1998.

SNF40060298001.001. Unsaturated Zone Lithostratigraphic Contacts in 107372 Borehole USW SD-6. Submittal date: 10/15/1998.

\subsection{OUTPUT DATA, LISTED BY DATA TRACKING NUMBER}

MO0012MWDGFM02.002. Geologic Framework Model (GFM2000).

153777 Submittal date: 12/18/2000.

\subsection{SOFTWARE CODES}

Dynamic Graphics 2000. Software Code: EARTHVISION. V5.1. SGI/IRIX 6.5. 167994 10174-5.1-00. 


\section{INTENTIONALLY LEFT BLANK}


The purpose of this appendix is to provide additional details of the jack-knife (e.g., Efron and Gong 1983 [DIRS 103967]) uncertainty estimation methods and results discussed in Section 6.6. Impacts of the estimations are discussed in Section 6.6. The sequential jack-knife method is discussed in Section A.2, and the cross-correlation method is discussed in Section A.3.

The study area and boreholes used for this analysis are shown in Figure 6-28 (Section 6.6.3). Rationale for area and data selection are discussed in Section 6.6. The 18 boreholes were selected because they are the only ones in the area that contain data for all 3 selected horizons (Tpy, Tptrv1, and Tptpv3). The boreholes were divided into suites and groups as shown in Table A-1.

Table A-1. Data Groups and Suites Used for Uncertainty Estimation

\begin{tabular}{|l|l|l|l|l|l|l|}
\hline & \multicolumn{1}{|c|}{ Group 1 } & \multicolumn{1}{|c|}{ Group 2 } & \multicolumn{1}{|c|}{ Group 3 } & \multicolumn{1}{|c|}{ Group 4 } & \multicolumn{1}{|c|}{ Group 5 } & \multicolumn{1}{c|}{ Group 6 } \\
\hline Suite A & UZ\#16 & SD-6 UZ-6 & b\#1 UZ-14 & SD-9 SD-7 & H-4 H-5 & WT\#18 \\
& G-1 G-4 & SD-12 & NRG-7a & H-1 & WT-2 & H-3 a\#1 \\
\hline Suite B & a\#1 H-4 & UZ\#16 & SD-7 H-5 & G-1 G-4 & SD-6 SD-9 & SD-12 UZ-14 \\
& WT-2 & H-1 H-3 & UZ-6 & b\#1 & WT\#18 & NRG-7a \\
\hline Suite C & H-5 SD-6 & b\#1 H-4 & H-3 SD-7 & G-4 SD-12 & a\#1 H-1 & G-1 SD-9 \\
& WT\#18 & NRG-7a & UZ-14 & UZ-6 & WT-2 & UZ\#16 \\
\hline Suite D & a\#1 b\#1 & H-1 H-3 & H-5 G-4 & WT\#18 UZ-6 & UZ-14 & SD-12 SD-7 \\
& G-1 & H-4 & WT-2 & UZ\#16 & NRG-7a SD-9 & SD-6 \\
\hline
\end{tabular}

To select the data suites and groups, the borehole identifiers were written on slips of paper and drawn at random. The groupings in suite $\mathrm{D}$ were determined by date of drilling (oldest in Group 1, youngest in Group 6).

Surface and tunnel data were not used in this analysis because of the complexity of calculating a fully three-dimensional uncertainty analysis. Outcrop data introduce complex relations of projected dip, depth and configuration of erosion, line data with three dimensions (from outcrop), and faulting that would make the results of this analysis uninterpretable. The analysis was restricted to subsurface (borehole) data to reduce the problem to two dimensions, and was further simplified to remove the potential effects of faulting (by limiting the study area), which would introduce discontinuities that would invalidate the analysis. These simplifications are not anticipated to have any effect on uncertainty analysis in the repository area where the effects of faulting are minor and borehole data are relatively abundant, nor at RHH depths where outcrop data are not available in the study area.

The statistical calculations discussed here were performed assuming normal distribution. Uncertainty is defined here as two standard deviations (95 percent confidence) above and below the mean of the prediction errors. The mean is nonzero, and is used in the sum to account for the specific geometries of the units in the study area, which can cause biases in the mean. For example, Figure A-1 shows that in the study area, the top of unit Tptpv3 has the form of a gentle syncline with an axis trending northwest, located near the north end of the ESF. Depth predictions based on a subset of the data from one limb of the syncline would not be expected to produce accurate predictions for data located on the other limb of the syncline; in fact, they would be expected to show a bias toward being uniformly low, and the resulting histogram of 
prediction errors would be asymmetric. Including the mean in the estimation of uncertainty in part accounts for this asymmetry. The causes of asymmetry in the prediction error histograms are discussed case by case in the following sections.

The uncertainty estimates in the following sections are based on the spacing of boreholes in the study area. Uncertainty is minimal at data locations, and increases to the estimated value at 3,280 feet (1,000 meters). Uncertainties at greater distances are approximated by the results of the first 4 prediction groups in the sequential jack-knife method in which borehole spacings are greater, but specific results are not discussed here because they are not generally applicable to the vicinity of the ESF.

As discussed in Sections 6.6 and 7 and illustrated in Figure 6-26, in a geologic setting as complex as Yucca Mountain, new data could provide information that would affect these estimates. Therefore, when new subsurface data are acquired, the effects on uncertainty should be examined.

\section{A.2 SEQUENTIAL JACK-KNIFE UNCERTAINTY ESTIMATION}

The sequential jack-knife method simulates development of an exploratory (or site characterization) drilling program. Data from the first 3 boreholes were used to create a grid to predict the data from the second 3 boreholes. The prediction errors at the second 3 boreholes were calculated and tabulated. The data from all 6 boreholes were then combined to create another grid to predict the data from the third group of 3 boreholes. This process was repeated until data from the first 5 groups of boreholes were combined to create a grid to predict data from the final group. This method produces 5 groups of predictions in each of the 4 data suites for each unit ( 5 groups $\times 3$ boreholes $\times 4$ suites $\times 3$ units $=180$ total predictions). Only the final predictions, however (for the final 3 boreholes in each suite), are applicable to the model results because they represent the actual borehole spacing and distribution in the geologic framework model ( 3 boreholes $\times 4$ suites $=12$ predictions for each unit or 36 total predictions). Because of the small number of applicable prediction errors, only limited conclusions can be drawn from the results. The results of the sequential method are tabulated in Table A- 2 and associated statistics are shown in Table A-3.

As shown in Table A-2, in the final prediction group (Column Err5 in Table A-2), the largest error is associated with unit Tptpv3 in borehole WT\#18 in Suite A (293 feet [89 meters]). The problem is less for the other units. This borehole is located farthest toward the northeast, where the results of the geologic framework model show that stratigraphic complexity is increasing in the Topopah Spring Tuff (Section 6.5.1.4). 


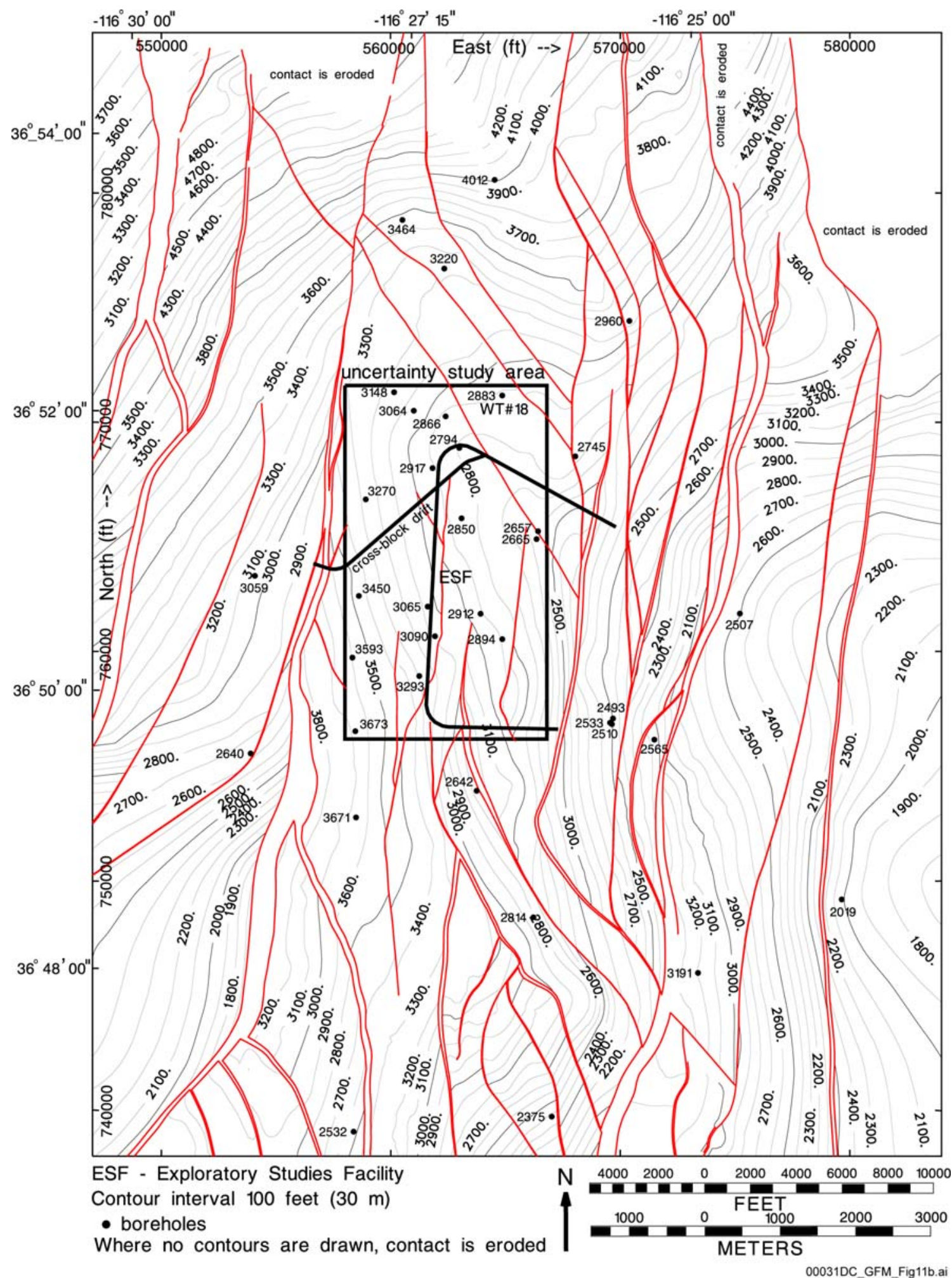

Source DTN: MO0012MWDGFM02.002 [DIRS 153777]

Figure A-1. Elevation Map of Top of Topopah Spring Tuff Lower Vitrophyre (Tptpv3) 
Table A-2. Results of Sequential Jack-Knife Uncertainty Estimation

\begin{tabular}{|c|c|c|c|c|c|c|}
\hline Group & Well ID & $\begin{array}{c}\text { Err1 } \\
\text { (feet) }\end{array}$ & $\begin{array}{c}\text { Err2 } \\
\text { (feet) }\end{array}$ & $\begin{array}{c}\text { Err3 } \\
\text { (feet) }\end{array}$ & $\begin{array}{c}\text { Err4 } \\
\text { (feet) }\end{array}$ & $\begin{array}{c}\text { Err5 } \\
\text { (feet) }\end{array}$ \\
\hline \multicolumn{7}{|c|}{ Unit Tpy } \\
\hline A1 & G-1 & & & & & \\
\hline A1 & G-4 & & & & & \\
\hline A1 & UZ\#16 & & & & & \\
\hline$A 2$ & SD-6 & 465 & & & & \\
\hline $\mathrm{A} 2$ & SD-12 & 150 & & & & \\
\hline $\mathrm{A} 2$ & UZ-6 & 579 & & & & \\
\hline A3 & $\mathrm{b} \# 1$ & -210 & 28 & & & \\
\hline A3 & NRG-7a & 65 & 25 & & & \\
\hline A3 & UZ-14 & -38 & 0.1 & & & \\
\hline A4 & $\mathrm{H}-1$ & -68 & 28 & 10 & & \\
\hline A4 & SD-7 & 306 & -12 & -8 & & \\
\hline A4 & SD-9 & 32 & 3 & -3 & & \\
\hline A5 & $\mathrm{H}-4$ & 20 & 3 & 2 & 2 & \\
\hline A5 & $\mathrm{H}-5$ & 264 & -28 & -19 & -10 & \\
\hline A5 & WT-2 & 157 & -26 & -25 & -22 & \\
\hline$A 6$ & $\mathrm{a} \# 1$ & -227 & -3 & -27 & -27 & -28 \\
\hline$A 6$ & $\mathrm{H}-3$ & 660 & -15 & -8 & 11 & -0.4 \\
\hline$A 6$ & WT\#18 & -215 & 104 & 44 & 21 & 23 \\
\hline B1 & a\#1 & & & & & \\
\hline B1 & $\mathrm{H}-4$ & & & & & \\
\hline B1 & WT-2 & & & & & \\
\hline B2 & $\mathrm{H}-1$ & 475 & & & & \\
\hline B2 & $\mathrm{H}-3$ & 189 & & & & \\
\hline B2 & UZ\#16 & -68 & & & & \\
\hline B3 & $\mathrm{H}-5$ & 483 & -13 & & & \\
\hline B3 & SD-7 & 28 & 27 & & & \\
\hline B3 & UZ-6 & 295 & 94 & & & \\
\hline B4 & $\mathrm{b} \# 1$ & 40 & 30 & 30 & & \\
\hline B4 & G-1 & 544 & -21 & -12 & & \\
\hline B4 & G-4 & 213 & -9 & -3 & & \\
\hline B5 & SD-6 & 367 & 89 & 49 & 49 & \\
\hline B5 & SD-9 & 391 & -10 & 2 & 2 & \\
\hline B5 & WT\#18 & 436 & 56 & 47 & 31 & \\
\hline B6 & SD-12 & 77 & -7 & -8 & -7 & -11 \\
\hline B6 & NRG-7a & 380 & 2 & 4 & 1 & -3 \\
\hline B6 & UZ-14 & 633 & -18 & -4 & 16 & 16 \\
\hline $\mathrm{C} 1$ & $\mathrm{H}-5$ & & & & & \\
\hline $\mathrm{C} 1$ & SD-6 & & & & & \\
\hline $\mathrm{C} 1$ & WT\#18 & & & & & \\
\hline $\mathrm{C} 2$ & $\mathrm{~b} \# 1$ & -431 & & & & \\
\hline $\mathrm{C} 2$ & $\mathrm{H}-4$ & -461 & & & & \\
\hline
\end{tabular}


Table A-2. Results of Sequential Jack-Knife Uncertainty Estimation (Continued)

\begin{tabular}{|c|c|c|c|c|c|c|}
\hline Group & Well ID & $\begin{array}{c}\text { Err1 } \\
\text { (feet) }\end{array}$ & $\begin{array}{c}\text { Err2 } \\
\text { (feet) }\end{array}$ & $\begin{array}{c}\text { Err3 } \\
\text { (feet) }\end{array}$ & $\begin{array}{c}\text { Err4 } \\
\text { (feet) }\end{array}$ & $\begin{array}{l}\text { Err5 } \\
\text { (feet) }\end{array}$ \\
\hline \multicolumn{7}{|c|}{ Unit Tpy (Continued) } \\
\hline $\mathrm{C} 2$ & NRG-7a & -75 & & & & \\
\hline C3 & $\mathrm{H}-3$ & -155 & 85 & & & \\
\hline C3 & SD-7 & -351 & 11 & & & \\
\hline C3 & UZ-14 & 176 & 5 & & & \\
\hline $\mathrm{C} 4$ & G-4 & -249 & -20 & -18 & & \\
\hline $\mathrm{C} 4$ & SD-12 & -334 & -57 & -54 & & \\
\hline $\mathrm{C} 4$ & UZ-6 & -39 & 37 & 16 & & \\
\hline $\mathrm{C} 5$ & $\mathrm{a} \# 1$ & -473 & -26 & -25 & -27 & \\
\hline $\mathrm{C} 5$ & $\mathrm{H}-1$ & 27 & -3 & -4 & -5 & \\
\hline $\mathrm{C} 5$ & WT-2 & -397 & -47 & -47 & -22 & \\
\hline C6 & G-1 & 89 & -7 & -9 & -10 & -7 \\
\hline C6 & SD-9 & -73 & -2 & -2 & 3 & 3 \\
\hline C6 & UZ\#16 & -535 & 38 & 29 & 15 & 18 \\
\hline D1 & $\mathrm{a} \# 1$ & & & & & \\
\hline D1 & $\mathrm{b} \# 1$ & & & & & \\
\hline D1 & G-1 & & & & & \\
\hline D2 & $\mathrm{H}-1$ & -25 & & & & \\
\hline D2 & $\mathrm{H}-3$ & 714 & & & & \\
\hline D2 & $\mathrm{H}-4$ & 207 & & & & \\
\hline D3 & $\mathrm{H}-5$ & 226 & -27 & & & \\
\hline D3 & G-4 & 82 & -28 & & & \\
\hline D3 & WT-2 & 286 & -68 & & & \\
\hline D4 & WT\#18 & -95 & 49 & 31 & & \\
\hline D4 & UZ-6 & 607 & 18 & 97 & & \\
\hline D4 & UZ\#16 & 235 & 31 & 22 & & \\
\hline D5 & UZ-14 & 9 & 21 & 16 & 15 & \\
\hline D5 & NRG-7a & -2 & -7 & 1 & -2 & \\
\hline D5 & SD-9 & 62 & -17 & 1 & 2 & \\
\hline D6 & SD-12 & 253 & -67 & -6 & -8 & -8 \\
\hline D6 & SD-7 & 428 & -37 & 28 & 17 & 17 \\
\hline D6 & SD-6 & 473 & 13 & 96 & 47 & 48 \\
\hline \multicolumn{7}{|c|}{ Unit Tptrv1 } \\
\hline A1 & G-1 & & & & & \\
\hline A1 & G-4 & & & & & \\
\hline A1 & UZ\#16 & & & & & \\
\hline $\mathrm{A} 2$ & SD-6 & 492 & & & & \\
\hline $\mathrm{A} 2$ & SD-12 & 174 & & & & \\
\hline $\mathrm{A} 2$ & UZ-6 & 612 & & & & \\
\hline A3 & $b \# 1$ & -214 & 32 & & & \\
\hline A3 & NRG-7a & -100 & -10 & & & \\
\hline A3 & UZ-14 & 31 & -6 & & & \\
\hline
\end{tabular}


Table A-2. Results of Sequential Jack-Knife Uncertainty Estimation (Continued)

\begin{tabular}{|c|c|c|c|c|c|c|}
\hline Group & Well ID & $\begin{array}{c}\text { Err1 } \\
\text { (feet) }\end{array}$ & $\begin{array}{c}\text { Err2 } \\
\text { (feet) }\end{array}$ & $\begin{array}{c}\text { Err3 } \\
\text { (feet) }\end{array}$ & $\begin{array}{c}\text { Err4 } \\
\text { (feet) }\end{array}$ & $\begin{array}{l}\text { Err5 } \\
\text { (feet) }\end{array}$ \\
\hline \multicolumn{7}{|c|}{ Unit Tptrv1 (Continued) } \\
\hline A4 & $\mathrm{H}-1$ & -112 & -15 & -15 & & \\
\hline A4 & SD-7 & 314 & -27 & -24 & & \\
\hline A4 & SD-9 & 5 & -27 & -15 & & \\
\hline A5 & $\mathrm{H}-4$ & 35 & 10 & 8 & 8 & \\
\hline A5 & $\mathrm{H}-5$ & 293 & -18 & -2 & 5 & \\
\hline A5 & WT-2 & 181 & -24 & -23 & -15 & \\
\hline A6 & $\mathrm{a} \# 1$ & -209 & 23 & -7 & -7 & -8 \\
\hline A6 & $\mathrm{H}-3$ & 673 & -35 & -29 & 10 & 1 \\
\hline$A 6$ & WT\#18 & -371 & -52 & -72 & -59 & -54 \\
\hline B1 & a\#1 & & & & & \\
\hline B1 & $\mathrm{H}-4$ & & & & & \\
\hline B1 & WT-2 & & & & & \\
\hline B2 & $\mathrm{H}-1$ & 299 & & & & \\
\hline B2 & $\mathrm{H}-3$ & 191 & & & & \\
\hline B2 & UZ\#16 & -76 & & & & \\
\hline B3 & $\mathrm{H}-5$ & 413 & 73 & & & \\
\hline B3 & SD-7 & 20 & 9 & & & \\
\hline B3 & UZ-6 & 288 & 115 & & & \\
\hline B4 & $\mathrm{b \# 1}$ & 16 & 8 & 9 & & \\
\hline B4 & G-1 & 392 & 31 & 18 & & \\
\hline B4 & G-4 & 176 & 26 & 10 & & \\
\hline B5 & SD-6 & 334 & 125 & 33 & 35 & \\
\hline B5 & SD-9 & 275 & 12 & -10 & -18 & \\
\hline B5 & WT\#18 & 149 & -77 & -56 & -46 & \\
\hline B6 & SD-12 & 70 & 7 & -9 & -10 & -14 \\
\hline B6 & NRG-7a & 248 & 8 & 2 & -1 & 12 \\
\hline B6 & UZ-14 & 448 & 32 & 15 & -17 & -19 \\
\hline $\mathrm{C} 1$ & $\mathrm{H}-5$ & & & & & \\
\hline $\mathrm{C} 1$ & SD-6 & & & & & \\
\hline $\mathrm{C} 1$ & WT\#18 & & & & & \\
\hline $\mathrm{C} 2$ & $\mathrm{b \# 1}$ & -257 & & & & \\
\hline $\mathrm{C} 2$ & $\mathrm{H}-4$ & -374 & & & & \\
\hline $\mathrm{C} 2$ & NRG-7a & -4 & & & & \\
\hline $\mathrm{C} 3$ & $\mathrm{H}-3$ & -215 & -10 & & & \\
\hline C3 & SD-7 & -348 & -43 & & & \\
\hline $\mathrm{C} 3$ & UZ-14 & 178 & 19 & & & \\
\hline $\mathrm{C} 4$ & G-4 & -138 & -3 & -3 & & \\
\hline $\mathrm{C} 4$ & SD-12 & -279 & -54 & -42 & & \\
\hline $\mathrm{C4}$ & UZ-6 & -55 & 12 & 31 & & \\
\hline $\mathrm{C5}$ & $a \# 1$ & -283 & -6 & -8 & -9 & \\
\hline $\mathrm{C} 5$ & $\mathrm{H}-1$ & 68 & 7 & 2 & 2 & \\
\hline
\end{tabular}


Table A-2. Results of Sequential Jack-Knife Uncertainty Estimation (Continued)

\begin{tabular}{|c|c|c|c|c|c|c|}
\hline Group & Well ID & $\begin{array}{c}\text { Err1 } \\
\text { (feet) }\end{array}$ & $\begin{array}{c}\text { Err2 } \\
\text { (feet) }\end{array}$ & $\begin{array}{c}\text { Err3 } \\
\text { (feet) }\end{array}$ & $\begin{array}{c}\text { Err4 } \\
\text { (feet) }\end{array}$ & $\begin{array}{l}\text { Err5 } \\
\text { (feet) }\end{array}$ \\
\hline \multicolumn{7}{|c|}{ Unit Tptrv1 (Continued) } \\
\hline C5 & WT-2 & -350 & -58 & -36 & -16 & \\
\hline C6 & G-1 & 127 & 21 & 10 & 10 & 9 \\
\hline $\mathrm{C} 6$ & SD-9 & -28 & -17 & -18 & -18 & -18 \\
\hline $\mathrm{C} 6$ & UZ\#16 & -462 & 6 & 7 & 1 & 1 \\
\hline D1 & $a \# 1$ & & & & & \\
\hline $\mathrm{D} 1$ & $\mathrm{b \# 1}$ & & & & & \\
\hline D1 & G-1 & & & & & \\
\hline $\mathrm{D} 2$ & $\mathrm{H}-1$ & -71 & & & & \\
\hline D2 & $\mathrm{H}-3$ & 747 & & & & \\
\hline D2 & $\mathrm{H}-4$ & 205 & & & & \\
\hline D3 & $\mathrm{H}-5$ & 286 & 25 & & & \\
\hline D3 & G-4 & 112 & 14 & & & \\
\hline D3 & WT-2 & 309 & -51 & & & \\
\hline D4 & WT\#18 & -272 & -53 & -46 & & \\
\hline D4 & UZ-6 & 663 & 58 & 103 & & \\
\hline D4 & UZ\#16 & 200 & -9 & -2 & & \\
\hline D5 & UZ-14 & -2 & -20 & -17 & -16 & \\
\hline D5 & NRG-7a & -26 & 5 & -2 & 3 & \\
\hline D5 & SD-9 & 57 & -6 & -19 & -18 & \\
\hline D6 & SD-12 & 286 & -34 & -3 & -11 & -10 \\
\hline D6 & SD-7 & 438 & -44 & 13 & 6 & 6 \\
\hline D6 & SD-6 & 526 & 64 & 91 & 35 & 34 \\
\hline \multicolumn{7}{|c|}{ Unit Tptpv3 } \\
\hline A1 & G-1 & & & & & \\
\hline A1 & G-4 & & & & & \\
\hline A1 & UZ\#16 & & & & & \\
\hline A2 & SD-6 & 525 & & & & \\
\hline A2 & SD-12 & 175 & & & & \\
\hline A2 & UZ-6 & 679 & & & & \\
\hline A3 & $\mathrm{b} \# 1$ & -194 & 91 & & & \\
\hline A3 & NRG-7a & -163 & -52 & & & \\
\hline$A 3$ & UZ-14 & 35 & -13 & & & \\
\hline A4 & $\mathrm{H}-1$ & -161 & -43 & -17 & & \\
\hline A4 & SD-7 & 400 & 21 & 24 & & \\
\hline A4 & SD-9 & -24 & -53 & -24 & & \\
\hline A5 & $\mathrm{H}-4$ & 28 & 8 & 3 & 3 & \\
\hline A5 & $\mathrm{H}-5$ & 302 & -26 & -29 & -8 & \\
\hline A5 & WT-2 & 197 & -18 & -16 & -26 & \\
\hline A6 & $\mathrm{a} \# 1$ & -186 & 82 & -3 & -2 & -3 \\
\hline A6 & $\mathrm{H}-3$ & 782 & -27 & -26 & -44 & -59 \\
\hline A6 & WT\#18 & -151 & 247 & 272 & 286 & 293 \\
\hline
\end{tabular}


Table A-2. Results of Sequential Jack-Knife Uncertainty Estimation (Continued)

\begin{tabular}{|c|c|c|c|c|c|c|}
\hline Group & Well ID & $\begin{array}{c}\text { Err1 } \\
\text { (feet) }\end{array}$ & $\begin{array}{c}\text { Err2 } \\
\text { (feet) }\end{array}$ & $\begin{array}{c}\text { Err3 } \\
\text { (feet) }\end{array}$ & $\begin{array}{c}\text { Err4 } \\
\text { (feet) }\end{array}$ & $\begin{array}{l}\text { Err5 } \\
\text { (feet) }\end{array}$ \\
\hline \multicolumn{7}{|c|}{ Unit Tptpv3 (Continued) } \\
\hline B1 & $a \# 1$ & & & & & \\
\hline B1 & $\mathrm{H}-4$ & & & & & \\
\hline B1 & WT-2 & & & & & \\
\hline B2 & $\mathrm{H}-1$ & 219 & & & & \\
\hline B2 & $\mathrm{H}-3$ & 272 & & & & \\
\hline B2 & UZ\#16 & -21 & & & & \\
\hline B3 & $\mathrm{H}-5$ & 324 & 44 & & & \\
\hline B3 & SD-7 & 101 & 60 & & & \\
\hline B3 & UZ-6 & 299 & 113 & & & \\
\hline B4 & $\mathrm{b \# 1}$ & 8 & 4 & 4 & & \\
\hline B4 & G-1 & 363 & 91 & 85 & & \\
\hline B4 & G-4 & 67 & -46 & -52 & & \\
\hline B5 & SD-6 & 288 & 104 & 35 & 50 & \\
\hline B5 & SD-9 & 160 & -42 & 53 & -35 & \\
\hline B5 & WT\#18 & 384 & 231 & 242 & 279 & \\
\hline B6 & SD-12 & 26 & -18 & -23 & -12 & -14 \\
\hline B6 & NRG-7a & 125 & -53 & -56 & -28 & -27 \\
\hline B6 & UZ-14 & 437 & 121 & 114 & -43 & -58 \\
\hline $\mathrm{C} 1$ & $\mathrm{H}-5$ & & & & & \\
\hline $\mathrm{C} 1$ & SD-6 & & & & & \\
\hline $\mathrm{C} 1$ & WT\#18 & & & & & \\
\hline $\mathrm{C} 2$ & $\mathrm{b \# 1}$ & -417 & & & & \\
\hline $\mathrm{C} 2$ & $\mathrm{H}-4$ & -398 & & & & \\
\hline $\mathrm{C} 2$ & NRG-7a & -248 & & & & \\
\hline $\mathrm{C3}$ & $\mathrm{H}-3$ & 1 & 139 & & & \\
\hline $\mathrm{C} 3$ & SD-7 & -205 & 72 & & & \\
\hline C3 & UZ-14 & 97 & 98 & & & \\
\hline $\mathrm{C} 4$ & G-4 & -314 & -9 & 1 & & \\
\hline $\mathrm{C} 4$ & SD-12 & -308 & -63 & -70 & & \\
\hline $\mathrm{C} 4$ & UZ-6 & 31 & 73 & 20 & & \\
\hline C5 & $\mathrm{a} \# 1$ & -426 & 1 & 3 & 1 & \\
\hline C5 & $\mathrm{H}-1$ & -144 & -12 & -36 & -35 & \\
\hline $\mathrm{C5}$ & WT-2 & -323 & -33 & -62 & -28 & \\
\hline $\mathrm{C} 6$ & G-1 & 14 & 84 & 29 & 29 & 51 \\
\hline $\mathrm{C6}$ & SD-9 & -201 & 11 & 9 & 9 & 11 \\
\hline $\mathrm{C6}$ & UZ\#16 & -430 & 47 & 29 & 10 & 8 \\
\hline $\mathrm{D} 1$ & $\mathrm{a} \# 1$ & & & & & \\
\hline D1 & $\mathrm{b} \# 1$ & & & & & \\
\hline D1 & G-1 & & & & & \\
\hline D2 & $\mathrm{H}-1$ & -136 & & & & \\
\hline $\mathrm{D} 2$ & $\mathrm{H}-3$ & 1000 & & & & \\
\hline
\end{tabular}


Table A-2. Results of Sequential Jack-Knife Uncertainty Estimation (Continued)

\begin{tabular}{|c|c|c|c|c|c|c|}
\hline Group & Well ID & $\begin{array}{c}\text { Err1 } \\
\text { (feet) }\end{array}$ & $\begin{array}{c}\text { Err2 } \\
\text { (feet) }\end{array}$ & $\begin{array}{c}\text { Err3 } \\
\text { (feet) }\end{array}$ & $\begin{array}{c}\text { Err4 } \\
\text { (feet) }\end{array}$ & $\begin{array}{l}\text { Err5 } \\
\text { (feet) }\end{array}$ \\
\hline \multicolumn{7}{|c|}{ Unit Tptpv3 (Continued) } \\
\hline D2 & $\mathrm{H}-4$ & 267 & & & & \\
\hline D3 & $\mathrm{H}-5$ & 280 & -65 & & & \\
\hline D3 & G-4 & 42 & -73 & & & \\
\hline D3 & WT-2 & 412 & -62 & & & \\
\hline D4 & WT\#18 & -58 & 298 & 278 & & \\
\hline D4 & $\mathrm{UZ}-6$ & 825 & 26 & 104 & & \\
\hline D4 & UZ\#16 & 315 & 37 & 20 & & \\
\hline D5 & UZ-14 & 21 & -30 & -44 & -51 & \\
\hline D5 & NRG-7a & -131 & -57 & -28 & -40 & \\
\hline D5 & SD-9 & -19 & -85 & -35 & -27 & \\
\hline D6 & SD-12 & 336 & -81 & -15 & -17 & -18 \\
\hline D6 & SD-7 & 643 & 2 & 61 & 48 & 48 \\
\hline D6 & SD-6 & 605 & 3 & 96 & 44 & 41 \\
\hline
\end{tabular}

NOTE: Shaded boxes not required for sequential method.

Table A-3. Statistics of Sequential Jack-Knife Uncertainty Estimation Results

\begin{tabular}{|c|c|c|c|c|c|c|c|c|c|}
\hline Unit & Group $^{a}$ & $\begin{array}{l}\text { Min. } \\
\text { (feet) }\end{array}$ & $\begin{array}{l}\text { Max. } \\
\text { (feet) }\end{array}$ & $\begin{array}{c}\text { Number of } \\
\text { values }\end{array}$ & $\begin{array}{l}\text { Mean } \\
\text { (feet) }\end{array}$ & $\begin{array}{c}\text { Median } \\
\text { (feet) }\end{array}$ & $\begin{array}{c}\text { Standard } \\
\text { Deviation } \\
\text { (feet) }\end{array}$ & $\begin{array}{c}\text { Mean - 2x } \\
\text { Standard } \\
\text { Deviation } \\
\text { (feet) }\end{array}$ & $\begin{array}{c}\text { Mean }+2 x \\
\text { Standard } \\
\text { Deviation } \\
\text { (feet) }\end{array}$ \\
\hline \multirow[t]{5}{*}{ Tpy } & 2 & -461 & 714 & 12 & 143 & 170 & 375 & -608 & 894 \\
\hline & 3 & -68 & 94 & 12 & 12 & 8 & 46 & -80 & 103 \\
\hline & 4 & -54 & 97 & 12 & 9 & 4 & 36 & -64 & 82 \\
\hline & 5 & -27 & 49 & 12 & 1 & 0 & 22 & -43 & 45 \\
\hline & 6 & -28 & 48 & 12 & 6 & 1 & 20 & -34 & 45 \\
\hline \multirow[t]{5}{*}{ Tptrv1 } & 2 & -374 & 747 & 12 & 162 & 183 & 341 & -520 & 843 \\
\hline & 3 & -51 & 115 & 12 & 14 & 12 & 46 & -78 & 106 \\
\hline & 4 & -46 & 103 & 12 & 2 & -3 & 39 & -76 & 80 \\
\hline & 5 & -46 & 35 & 12 & -7 & -12 & 20 & -47 & 32 \\
\hline & 6 & -54 & 34 & 12 & -5 & -4 & 21 & -48 & 38 \\
\hline \multirow[t]{5}{*}{ Tptpv3 } & 2 & -417 & 1000 & 12 & 160 & 197 & 433 & -707 & 1027 \\
\hline & 3 & -73 & 139 & 12 & 29 & 52 & 78 & -126 & 185 \\
\hline & 4 & -70 & 278 & 12 & 31 & 12 & 92 & -153 & 216 \\
\hline & 5 & -51 & 279 & 12 & 7 & -27 & 90 & -173 & 186 \\
\hline & 6 & -59 & 293 & 12 & 23 & 3 & 93 & -163 & 208 \\
\hline
\end{tabular}


Table A-3. Statistics of Sequential Jack-Knife Uncertainty Estimation Results (Continued)

\begin{tabular}{|c|c|c|c|c|c|c|c|c|c|}
\hline Unit & Group $^{a}$ & $\begin{array}{l}\text { Min. } \\
\text { (feet) }\end{array}$ & $\begin{array}{l}\text { Max. } \\
\text { (feet) }\end{array}$ & \begin{tabular}{|c|} 
Number of \\
values
\end{tabular} & $\begin{array}{l}\text { Mean } \\
\text { (feet) }\end{array}$ & $\begin{array}{c}\text { Median } \\
\text { (feet) }\end{array}$ & $\begin{array}{c}\text { Standard } \\
\text { Deviation } \\
\text { (feet) }\end{array}$ & $\begin{array}{c}\text { Mean - 2x } \\
\text { Standard } \\
\text { Deviation } \\
\text { (feet) }\end{array}$ & $\begin{array}{c}\text { Mean }+2 x \\
\text { Standard } \\
\text { Deviation } \\
\text { (feet) }\end{array}$ \\
\hline \multirow{5}{*}{$\begin{array}{l}\text { Tptpv3 w/o } \\
\text { WT\#18 }\end{array}$} & 2 & -417 & 1000 & 12 & 160 & 197 & 433 & -707 & 1027 \\
\hline & 3 & -73 & 139 & 12 & 29 & 52 & 78 & -126 & 185 \\
\hline & 4 & -70 & 104 & 11 & 9 & 4 & 52 & -95 & 113 \\
\hline & 5 & -51 & 50 & 11 & -18 & -27 & 28 & -74 & 38 \\
\hline & 6 & -59 & 51 & 11 & -2 & -3 & 39 & -79 & 75 \\
\hline
\end{tabular}

a Results of Suites A through D are combined.

Shaded boxes not required for sequential method.

As illustrated in Figure A-1, the strike and dip of the rock layers changes abruptly between borehole WT\#18 and the remaining boreholes, so that grids (surfaces) projected from the other boreholes are less likely to accurately predict the WT\#18 data. As shown in Table A-3 for sequential Group 6, without the anomalous borehole WT\#18 predictions, the mean prediction error (of all 4 suites) for unit Tptpv3 is reduced from 23 feet (7.0 meters) to -2 feet (-0.6 meters), and the standard deviation from 93 feet (28.3 meters) to 39 feet (11.9 meters). Because WT\#18 is relatively distant from the ESF, these smaller numbers are more appropriate for the vicinity of the ESF. Because WT\#18 is an actual part of the Yucca Mountain data, however, the larger numbers illustrate the degree to which uncertainty increases outside the study area.

The influence of borehole WT\#18 illustrates the limitation of these analyses to the geologically simplest part of the modeled area, where stratigraphic and structural complexities are fewest, and demonstrates that uncertainty increases significantly in other areas. This result also demonstrates the dependence of the sequential method results on the data groupings, in which one borehole can have a large influence.

The sequential jack-knife prediction errors, from Group 6 (Table A-3), are summarized in Table A-4.

Table A-4. Summary of Sequential Jack-Knife Uncertainty Estimation Results

\begin{tabular}{|l|l|l|l|}
\hline \multicolumn{1}{|c|}{ Unit } & \multicolumn{1}{c|}{ Mean } & \multicolumn{1}{c|}{$\begin{array}{c}\text { 2 Standard Deviation } \\
\text { (95\% conf.) }\end{array}$} & \multicolumn{1}{c|}{ Uncertainty } \\
\hline Tpy & 6 feet (1.8 meters) & 40 feet (12.2 meters) & $\begin{array}{l}-34 \text { to }+45 \text { feet } \\
(-10.4 \text { to }+13.7 \text { meters) }\end{array}$ \\
\hline Tptrv1 & -5 feet (-1.5 meters) & 43 feet (13.1 meters) & $\begin{array}{l}-38 \text { to }+48 \text { feet } \\
(-11.6 \text { to }+14.6 \text { meters })\end{array}$ \\
\hline Tptpv3 [w/ WT\#18] & 23 feet (7.0 meters) & 185 feet (56.4 meters) & $\begin{array}{l}-163 \text { to }+208 \text { feet } \\
(-49.7 \text { to }+63.4 \text { meters })\end{array}$ \\
\hline Tptpv3 [w/o WT\#18] & -2 feet (-0.6 meters) & 77 feet (23.5 meters) & $\begin{array}{l}-75 \text { to }+79 \text { feet } \\
(-22.9 \text { to }+24.1 \text { meters })\end{array}$ \\
\hline
\end{tabular}

NOTE: Uncertainty is Mean - 2 Standard Deviation to Mean + 2 Standard Deviation 
Because it is dependent on data groupings, the sequential jack-knife method is useful to evaluate actual exploratory drilling program results. As illustrated in Table A-2 (Suite D), the results for the data suite grouped by actual drilling date (the actual Yucca Mountain Site Characterization Project drilling program) are similar to the results for the other sample suites.

\section{A.3 CROSS-CORRELATION JACK-KNIFE UNCERTAINTY ESTIMATION}

In the cross-correlation jack-knife method, data from 15 boreholes are used to create a grid to predict the data from 3 boreholes that were omitted. Each group of 3 boreholes is omitted in turn, producing 6 groups of predictions for each of the 4 data suites for each unit (6 groups $\times 3$ boreholes $\times 4$ suites $\times 3$ units $=216$ total predictions). For example, the errors for unit Tpy in Table A-5 for the boreholes in Group A1 (G-1, G-4, and UZ\#16) are -7, -3, and 19 feet (-2.1, -0.9, and 5.8 meters), respectively. These were calculated by gridding the data in Groups A2 through A6 and calculating the difference between the grid and the actual elevations in boreholes G-1, G-4, and UZ\#16. The results of the cross-correlation method are tabulated in Table A-5 and associated statistics are shown in Table A-6. This method provides a larger number of relevant data for statistical analysis than the sequential method described above, and is less subject to the biases that can result from particular groupings of boreholes in the 4 data suites (in the sequential method, the final group has the largest influence).

Table A-5. Results of Cross-Correlation Jack-Knife Uncertainty Estimation

\begin{tabular}{|l|l|l|l|l|}
\hline Group & \multicolumn{1}{|c|}{ Well ID } & Tpy Err. (feet) & $\begin{array}{c}\text { Tptrv1 Err. } \\
\text { (feet) }\end{array}$ & \multicolumn{1}{|c|}{$\begin{array}{c}\text { Tptpv3 Err. } \\
\text { (feet) }\end{array}$} \\
\hline A1 & G-1 & -7 & 11 & 48 \\
\hline A1 & G-4 & -3 & 17 & 11 \\
\hline A1 & UZ\#16 & 19 & 0.4 & 9 \\
\hline A2 & SD-6 & 103 & 90 & 98 \\
\hline A2 & SD-12 & 1 & -2 & -5 \\
\hline A2 & UZ-6 & 99 & 100 & 96 \\
\hline A3 & b\#1 & 28 & 11 & -0.3 \\
\hline A3 & NRG-7a & -1 & 12 & -28 \\
\hline A3 & UZ-14 & 16 & -19 & -58 \\
\hline A4 & H-1 & 2 & -5 & -56 \\
\hline A4 & SD-7 & 15 & 5 & 46 \\
\hline A4 & SD-9 & 5 & -20 & 3 \\
\hline A5 & H-4 & 7 & 9 & 4 \\
\hline A5 & H-5 & -9 & 6 & -5 \\
\hline A5 & WT-2 & -22 & -15 & -27 \\
\hline A6 & a\#1 & -28 & -8 & -3 \\
\hline A6 & H-3 & -0.4 & 1 & -59 \\
\hline A6 & WT\#18 & 23 & -54 & 293 \\
\hline B1 & a\#1 & -27 & -9 & 1 \\
\hline B1 & H-4 & 3 & 7 & 4 \\
\hline B1 & WT-2 & -21 & -14 & -27 \\
\hline B2 & H-1 & 3 & -5 & -56 \\
\hline B2 & H-3 & -3 & 1 & -58 \\
\hline & & & & \\
\hline
\end{tabular}


Table A-5. Results of Cross-Correlation Jack-Knife Uncertainty Estimation (Continued)

\begin{tabular}{|c|c|c|c|c|}
\hline Group & Well ID & Tpy Err. (feet) & $\begin{array}{l}\text { Tptrv1 Err. } \\
\text { (feet) }\end{array}$ & $\begin{array}{c}\text { Tptpv3 Err. } \\
\text { (feet) }\end{array}$ \\
\hline B2 & UZ\#16 & 18 & 1 & 8 \\
\hline B3 & $\mathrm{H}-5$ & -14 & 1 & -12 \\
\hline B3 & SD-7 & 20 & 9 & 50 \\
\hline B3 & UZ-6 & 36 & 38 & 42 \\
\hline B4 & $b \# 1$ & 28 & 10 & 4 \\
\hline B4 & G-1 & -7 & 11 & 48 \\
\hline B4 & G-4 & 1 & 18 & 13 \\
\hline B5 & SD-6 & 59 & 45 & 64 \\
\hline B5 & SD-9 & 3 & -19 & -24 \\
\hline B5 & WT\#18 & 22 & -44 & 300 \\
\hline B6 & SD-12 & -11 & -14 & -14 \\
\hline B6 & NRG-7a & -3 & 12 & -27 \\
\hline B6 & UZ-14 & 16 & -19 & -58 \\
\hline C1 & $\mathrm{H}-5$ & 28 & 38 & 35 \\
\hline C1 & SD-6 & 68 & 58 & 78 \\
\hline C1 & WT\#18 & 17 & -58 & 287 \\
\hline $\mathrm{C} 2$ & $\mathrm{~b} \# 1$ & 27 & 11 & -1 \\
\hline $\mathrm{C} 2$ & $\mathrm{H}-4$ & 8 & 10 & 9 \\
\hline $\mathrm{C} 2$ & NRG-7a & -1 & 12 & -28 \\
\hline C3 & $\mathrm{H}-3$ & 6 & -15 & -4 \\
\hline C3 & SD-7 & 18 & 4 & 48 \\
\hline C3 & UZ-14 & 16 & -19 & -58 \\
\hline C4 & G-4 & -9 & 14 & 11 \\
\hline C4 & SD-12 & -13 & -11 & -15 \\
\hline $\mathrm{C} 4$ & UZ-6 & 31 & 36 & 33 \\
\hline C5 & $a \# 1$ & -27 & -9 & 0.2 \\
\hline C5 & $\mathrm{H}-1$ & 2 & -6 & -56 \\
\hline $\mathrm{C} 5$ & WT-2 & -22 & -16 & -28 \\
\hline C6 & G-1 & -7 & 9 & 51 \\
\hline C6 & SD-9 & 3 & -18 & 11 \\
\hline C6 & UZ\#16 & 18 & 1 & 8 \\
\hline D1 & $\mathrm{a} \# 1$ & -41 & -7 & 29 \\
\hline D1 & $\mathrm{b} \# 1$ & -14 & 2 & 32 \\
\hline D1 & G-1 & -7 & 11 & 49 \\
\hline D2 & $\mathrm{H}-1$ & 3 & -6 & -56 \\
\hline D2 & $\mathrm{H}-3$ & 0.2 & -0.4 & -57 \\
\hline D2 & $\mathrm{H}-4$ & 9 & 10 & 8 \\
\hline D3 & $\mathrm{H}-5$ & -8 & 4 & -3 \\
\hline D3 & G-4 & 0 & 22 & 23 \\
\hline D3 & WT-2 & -23 & -17 & -29 \\
\hline D4 & WT\#18 & 17 & -57 & 287 \\
\hline D4 & UZ-6 & 26 & 35 & 30 \\
\hline
\end{tabular}


Table A-5. Results of Cross-Correlation Jack-Knife Uncertainty Estimation (Continued)

\begin{tabular}{|l|l|l|l|l|}
\hline Group & \multicolumn{1}{|c|}{ Well ID } & Tpy Err. (feet) & $\begin{array}{c}\text { Tptrv1 Err. } \\
\text { (feet) }\end{array}$ & $\begin{array}{c}\text { Tptpv3 Err. } \\
\text { (feet) }\end{array}$ \\
\hline D4 & UZ\#16 & 17 & -1 & 6 \\
\hline D5 & UZ-14 & 15 & -16 & -52 \\
\hline D5 & NRG-7a & -2 & 3 & -42 \\
\hline D5 & SD-9 & 3 & -18 & -27 \\
\hline D6 & SD-12 & -8 & -10 & -18 \\
\hline D6 & SD-7 & 17 & 6 & 41 \\
\hline D6 & SD-6 & 48 & 34 & 48 \\
\hline
\end{tabular}

Table A-6. Statistics of Cross-Correlation Jack-Knife Uncertainty Estimation Results

\begin{tabular}{|c|c|c|c|c|c|c|c|c|}
\hline Unit & $\begin{array}{l}\text { Min. } \\
\text { (feet) }\end{array}$ & $\begin{array}{l}\text { Max. } \\
\text { (feet) }\end{array}$ & \begin{tabular}{|c|} 
Number of \\
values $^{\mathrm{a}}$
\end{tabular} & $\begin{array}{l}\text { Mean } \\
\text { (feet) }\end{array}$ & $\begin{array}{c}\text { Median } \\
\text { (feet) }\end{array}$ & $\begin{array}{c}\text { Standard } \\
\text { Deviation } \\
\text { (feet) }\end{array}$ & $\begin{array}{c}\text { Mean - 2x } \\
\text { Standard } \\
\text { Deviation } \\
\text { (feet) }\end{array}$ & $\begin{array}{c}\text { Mean }+2 x \\
\text { Standard } \\
\text { Deviation } \\
\text { (feet) }\end{array}$ \\
\hline Tpy & -41 & 103 & 72 & 8 & 3 & 25 & -42 & 58 \\
\hline Tptrv1 & -58 & 100 & 72 & 3 & 1 & 26 & -50 & 55 \\
\hline Tptpv3 & -59 & 300 & 72 & 18 & 4 & 77 & -136 & 172 \\
\hline Tptpv3 w/o WT\#18 & -59 & 98 & 68 & 2 & 2 & 39 & -77 & 80 \\
\hline
\end{tabular}

${ }^{\mathrm{a}}$ Results of Suites A through D are combined.

As discussed in the previous section, borehole WT\#18 is located in a slightly different geologic setting than the rest of the boreholes used in this analysis, which resulted in singularly large prediction errors that biased the results. Borehole WT\#18 is useful because it demonstrates that uncertainty increases outside of the immediate vicinity of the ESF, and that uncertainty varies from place to place in relation to the variability of the geologic system. Without borehole WT\#18, the results of the cross-correlation jack-knife method are those shown in Table A-7, which are more applicable to the vicinity of the ESF.

Table A-7. Summary of Cross-Correlation Jack-Knife Uncertainty Estimation Results

\begin{tabular}{|l|l|l|l|}
\hline \multicolumn{1}{|c|}{ Unit } & \multicolumn{1}{c|}{ Mean } & $\begin{array}{c}\text { 2 Standard Deviation } \\
\text { (95\% conf.) }\end{array}$ & \multicolumn{1}{c|}{ Uncertainty } \\
\hline Tpy & 8 feet (2.4 meters) & 50 feet (15.2 meters) & $\begin{array}{l}-42 \text { to }+58 \text { feet } \\
(-12.8 \text { to }+17.7 \text { meters) }\end{array}$ \\
\hline Tptrv1 & 3 feet (0.9 meters) & 52 feet (15.8 meters) & $\begin{array}{l}-49 \text { to }+55 \text { feet } \\
(-14.9 \text { to }+16.8 \text { meters) }\end{array}$ \\
\hline Tptpv3 & 2 feet (0.6 meters) & 78 feet (23.8 meters) & $\begin{array}{l}-76 \text { to }+80 \text { feet } \\
(-23.2 \text { to }+24.4 \text { meters) }\end{array}$ \\
\hline
\end{tabular}

NOTE: Tptpv3 values without WT\#18. 
The slight decrease in estimated uncertainty from unit Tpy to unit Tptrv1 is caused by the higher mean in unit Tpy. The higher mean is caused by the abrupt northward thickening of unit Tpy illustrated in Figure 6-12 (Section 6.5.1.3) and the resulting increase in the elevation of the top of the unit, which introduces a geometric bias into the data. The higher mean illustrates that uncertainty is related to local geologic variability. Although the magnitude of the decrease in uncertainty from unit Tpy to Tptrv1 is not significant, geologic framework model users should assess the uncertainty in relation to tolerances required in specific applications.

Careful examination of the prediction errors suggests that the other greatest prediction errors for unit Tptpv3 (the values clustered near -60 feet in Table A-6, without WT\#18) were caused by local variations in the geometry of the unit. The predictions were for boreholes $\mathrm{H}-1, \mathrm{H}-3$, and UZ-14 (Table A-5), which are located in the northwest and southwest corners of the study area. As illustrated in the central part of Figure A-1 near the ESF, a syncline in unit Tptpv3 is located between these boreholes, so that boreholes $\mathrm{H}-1, \mathrm{H}-3$, and UZ-14 are located on the limbs. This geometry caused projections made from one limb to the other to have a systematic error. These data were not excluded from the calculations because they are located in the immediate vicinity of the ESF and therefore represent an important component of the estimation of uncertainty in the area of interest.

\section{A.4 DISCUSSION OF RESULTS}

Table A-8 shows a comparison of the results using the sequential and cross-correlation methods.

It is significant to observe that the data distribution for all 3 horizons was identical. The observed increase in prediction errors for the deepest unit, Tptpv3, cannot be ascribed to a decrease in data density or to a difference in modeling methodology. The increase in prediction errors must be a result of an increase in the variability of the natural system (i.e., geologic variability) with depth-more precisely, with stratigraphic depth. Simple vertical distance from the current topographic surface could not alone account for increased prediction errors because no surficial data were used in this analysis, but rather the complexity of the geologic system must increase with depth. As stated in the conceptual model for Yucca Mountain (Section 6.4.1), the base of an eruptive formation is likely to be more irregular than the base of an interior unit of that same formation because the volcanic units at Yucca Mountain were deposited on preexisting topography and structure, and filled in topographic lows. Unit Tptrv1 is at the top of the Topopah Spring Tuff, and would therefore be more planar (with smaller prediction errors), and unit Tptpv3 is near the bottom, and would therefore be more irregular (with larger prediction errors) as observed. The conceptual model and uncertainty estimation results are in agreement. These results also suggest that uncertainty increases even further for deeper units (Calico Hills Formation and deeper) where geologic variability increases, unconformities occur, and data distribution is decreased. 
Table A-8. Comparison of Sequential and Cross-Correlation Method Results

\begin{tabular}{|l|l|l|}
\hline & \multicolumn{1}{|c|}{ Sequential } & \multicolumn{1}{|c|}{ Cross-Correlation } \\
\hline Tpy mean/median & $6 / 1$ feet (1.8/0.3 meters) & $8 / 3$ feet (2.4/0.9 meters) \\
\hline Tpy range & $\begin{array}{l}-28 \text { to } 48 \text { feet (-8.5 to } 14.6 \\
\text { meters) }\end{array}$ & -41 to 103 feet (-12.5 to 31.4 meters) \\
\hline Tpy standard deviation & 20 feet $(6.1$ meters) & 25 feet (7.6 meters) \\
\hline Tptrv1 mean/median & $-5 /-4$ feet (-1.5/-1.2 meters) & $3 / 1$ feet (0.9/0.3 meters) \\
\hline Tptrv1 range & $\begin{array}{l}-54 \text { to } 34 \text { feet (-16.5 to } 10.4 \\
\text { meters) }\end{array}$ & -58 to 100 feet (-17.7 to 30.5 meters) \\
\hline Tptrv1 standard deviation & 22 feet $(6.7$ meters) & 26 feet (7.9 meters) \\
\hline $\begin{array}{l}\text { Tptpv3 mean/median } \\
\text { without WT\#18 }\end{array}$ & $-2 /-3$ feet (-0.6/0.9 meters) & $2 / 2$ feet (0.6/0.6 meters) \\
\hline $\begin{array}{l}\text { Tptpv3 range without } \\
\text { WT\#18 }\end{array}$ & $\begin{array}{l}-59 \text { to } 51 \text { feet (-18.0 to } 15.5 \\
\text { meters) }\end{array}$ & -59 to 98 feet (-18.0 to 29.9 meters) \\
\hline $\begin{array}{l}\text { Tptpv3 standard deviation } \\
\text { with/without WT\#18 }\end{array}$ & $93 / 39$ feet (28.3/11.9 meters) & $77 / 39$ feet (23.5/11.9 meters) \\
\hline
\end{tabular}

The results of the sequential jack-knife method indicate that uncertainty is reduced by increasing the density of boreholes, but with notable exceptions. If the subsurface rock layers and faults at Yucca Mountain were simple and uniform, prediction errors would asymptotically approach a small, finite value in each data suite, and would have small variability in the predictions for the 5th (final) data groups. In several instances, mean prediction error increased when new data were added, particularly for units Tptrv1 and Tptpv3 whenever borehole WT\#18 was added. As discussed in the previous sections, borehole WT\#18 is located in a slightly more complex geologic setting than the other boreholes, and is more indicative of uncertainty outside the vicinity of the ESF. In other instances, however, prediction errors also increased when boreholes in the center of the area were added, including Suite D boreholes SD-6, SD-7, and SD-12 for unit Tptrv1, and Suite C boreholes G-1, SD-9, and UZ\#16 for unit Tptpv3. These instances illustrate the wide range of prediction errors that can be expected for future data acquisition, even in the vicinity of the ESF.

As shown in Table A-8, both methods resulted in similar estimates of uncertainty for the 3 stratigraphic units. The results of the cross-correlation jack-knife method (with borehole WT\#18 excluded) provide a larger sample population and statistics that are more meaningful for applications of the geologic framework model. For these reasons, the cross-correlation results are used as the final results for the estimation of uncertainty in the geologic framework model.

The major conclusions of this activity are that 1) uncertainty varies spatially, 2) uncertainty can only be reduced by acquiring new data (drilling new boreholes or tunnels), and 3) uncertainty is only reduced locally around the new data. Uncertainty and prediction errors result from the fact that the geologic system is variable and the available data are finite. These conclusions may impact decisions regarding future data acquisition if the uncertainties estimated in this report are large in relation to the tolerances required in users of the geologic framework model. 


\section{INTENTIONALLY LEFT BLANK}


APPENDIX B

VALIDATED EARTHVISION MODULES 
Appendix B consists of the list of EARTHVISION modules that were validated and available for use for the geologic framework model. This list of EARTHVISION modules is provided in response to CR-1132. Other EARTHVISION modules were used for graphics only or were not used.

The following EARTHVISION modules were validated and available for use in constructing GFM2000: ev_2grid, ev_2mindist, ev_2trend, ev_3grid, ev_3mindist, ev_3points, ev_3trend, ev_arrow, ev_backijk, ev_backpropijk, ev_decimate, ev_distribgrid, ev_export, ev_fbsort, ev_fbzonelabel, ev_fbzonesort, ev_field, ev_fill, ev_filter, ev_fpfp, ev_fromproj, ev_hg, ev_hgandev_hgmk, ev_hgmk, ev_ht2gd, ev_ht2sh, ev_import, ev_inter, ev_isochore, ev_krig, ev_makefaults, ev_modeler, ev_pick, ev_plybld, ev_plybop, ev_plyhull, ev_propgrid, ev_propmap, ev_recast, ev_res2face, ev_rescue, ev_runres, ev_sec, ev_seq2mk, ev_seq2wfp, ev_seqexport, ev_seqgrid, ev_seqprop, ev_seqvol, ev_seqxform, ev_slice, ev_smooth, ev_stat, ev_surfclip, ev_surfhide, ev_toproj, ev_tree, ev_truedip, ev_vario, ev_vect2grid, ev_volume, ev_wellpath, ev_wellstrc, ev_wellx, ev_x2face, ev_xformdata, ev_zonealign, evarc.

Not all modules that were validated and available for use were necessarily used. However, all validated modules are presented and documented for completeness. 


\section{INTENTIONALLY LEFT BLANK}




\section{APPENDIX C \\ PREVIOUS MODEL VALIDATION -- CONFIDENCE BUILDING ACTIVITIES DURING DEVELOPMENT}


The purpose of this section is to document the difference between the stratigraphic contacts predicted by the geologic framework model and those observed for the boreholes USW SD-6 and USW WT-24. As discussed in Section 6.3.3 inclusion of these boreholes was one of the primary changes from GFM 3.0 to 3.1. The following text was the model validation discussion from the previous version of this model report (BSC 2002 [DIRS 168029]). Although this comparison was presented without specifying explicit model validation criteria at that time, it is being retained as it documents the match between predicted and actual stratigraphic contacts for the constrained and less constrained areas of the model as discussed in Section 6.6.2 and 6.6.3. This comparison supports the evaluation of uncertainty and limitations that are inherent to the geologic framework model, and enhances model confidence during the model development.

As defined by procedure AP-SIII.10Q, Models, model validation is "a process used to establish confidence that a mathematical model and its underlying conceptual model adequately represent with sufficient accuracy the system, process, or phenomenon in question." Confidence for the geologic framework model is defined by the uncertainty discussed in Section 6.6. "Adequate" is defined in the context of validation to mean the geologic framework model represents the real world with the content needed for subsequent model users and to the degree of accuracy needed for subsequent model users. Content is discussed in Section 6.2, where it was stated that the geologic framework model contains all the units and faults needed in subsequent uses identified to date. The accuracy of the geologic framework model relative to available data is discussed in Section C.3. In addition, for the geologic framework model to be "adequate," it must be demonstrated to be a reasonable representation of the geology at Yucca Mountain. In this context, "reasonable" means "in accordance with well-known geologic principles." The discussion of validation that follows establishes the validity of the geologic framework model in terms of its adequacy.

As discussed in Section 6.6 and illustrated in Figure 6-26, when new data are acquired, the variability of the geologic system may be discovered to locally exceed the estimated uncertainty (which is based on observed variability in the previously available data). Under such conditions, no change to modeling methodology could have reduced the prediction errors; the geology was simply not predictable to a high degree of accuracy based on existing data (see for example the lowest horizon in Figure 6-26). In such a case, the model would be considered to be valid despite large prediction errors. For an individual prediction (and the model component on which it is based) to be invalid, two conditions must exist: first, the prediction falls outside the uncertainty window; and second, a reasonable change in the conceptual model and/or methodology would have resulted in the prediction falling within the uncertainty window. Uncertainty is mitigated in the geologic framework model by the application of established geologic principles in the modeling methodology to interpolate between the data and extrapolate into unknown areas; thus, if a better interpolation could reasonably be made during modeling to predict a stratigraphic contact in a borehole, then the model stands in need of improvement. Uncertainty can never be eliminated; it can only be reduced locally by additional data.

No known modeling methodology would have closely predicted each of the geologic (actual) surfaces in the schematic model illustrated in Figure 6-26, except fortuitously. The methodology that was applied was reasonable and adequate, given the available data, and yet did not closely predict the upper and lower surfaces. In the case of the upper surface, the prediction error was within the bounds of observed variability (which is used to estimate uncertainty), and so would 
be deemed acceptable. The prediction for the lower surface, however, was outside the bounds of observed variability (and estimated uncertainty) for that surface, and so the following questions must be answered:

- Was the prediction reasonable in the context of available data?

- Could the prediction error have been minimized by reasonable improvement to modeling methodology?

For the example, in Figure 28, the answer to the first question is "yes" and the answer to the second is "no." The model made reasonable predictions based on the available data-what the new borehole provided was new and unique information indicating that the geologic variability of the lower surface was greater than previously known. The modeling methodology successfully accounted for available data, and no reasonable alternative methodology would have prevented the prediction errors.

The definition of a valid geologic model, then, is one that:

- Adequately matches available data

- Applies reasonable methodology to interpolate between data (i.e., to make predictions).

For modeling methodology, "reasonable" means "in accordance with well-known geologic principles." These principles include observed geometries of volcanic deposition, geologic contouring principles, and established interpolation methods.

The geologic framework model was validated by predicting the subsurface geology for two boreholes and one tunnel using GFM3.0 (DTN: MO9804MWDGFM03.001 [DIRS 109050]), and comparing the predictions to the actual results in GFM3.1 (DTN: MO9901MWDGFM31.000 [DIRS 103769]). Because the same data and methods were used in GFM2000, the previous validation applies equally to the latest model revision. No new data are available to apply the same kind of validation directly to GFM2000; however, the jack-knife uncertainty estimates described previously provide a useful comparison to the model validation results and show similar results. GFM2000 was also evaluated for a match to available (input) data, and the results are discussed in Section C.3.

\section{C.1 VALIDATION CRITERIA}

To assess whether the geologic framework model provides an adequate representation of the geology of the site, the validation criteria were formulated as follows:

- The model would be considered valid if 95 percent of the prediction errors were less than the estimated uncertainty (as described in Section 6.6) and the model results adequately matched the available (input) data. An "adequate match" to input data was previously defined by the requirements of geologic framework model users, which is plus or minus 15 feet (5 meters) for contact elevations (CRWMS M\&O 2000 [DIRS 158094], Attachment II). 
- The model would be considered invalid if more than 5 percent of the prediction errors were greater than the estimated uncertainty and the causes of the errors were determined to be failure of the modeling methodology. For prediction errors greater than the estimated uncertainty, the results were analyzed for a cause. Where the cause was determined to be the inherent geologic variability of the natural system (i.e., the available data do not permit accurate definition of unit geometries), the results did not adversely affect the model validation because no reasonable modification of modeling methodology would have reduced the prediction error. Where the cause was determined to be a failure of the modeling methodology (i.e., an incorrect interpolation, conceptual model, or interpretive constraints), the faulty portion of the model would be deemed invalid.

Because the geologic framework model was constructed by combining rock layer thicknesses, thickness predictions were given the greatest weight in evaluating the validation results and causes of prediction errors.

Some anomalous (i.e., not accurately predicted) rock layer thicknesses, elevations, or structures were expected given the geologically complex setting of Yucca Mountain on the flank of a major caldera complex, where depositional patterns, erosion, alteration, and multiple generations of faulting have contributed to increase variability in the geologic system.

Model validation is closely related to the estimation of uncertainty, which is discussed in Section 6.6. Details of the uncertainty estimation methods are provided in Appendix A.

\section{C.2 PREDICTIONS FOR BOREHOLES SD-6 AND WT-24 AND THE ECRB CROSS-DRIFT}

Predictions were made from version GFM3.0, which was completed before boreholes SD-6 and WT-24 and the ECRB Cross-Drift were constructed (Figure 6-1). The model was then updated to incorporate the new data in versions GFM3.1 and GFM2000. The predictions for SD-6 and the ECRB Cross-Drift illustrate the predictive capability of the model and uncertainty in an area constrained by borehole data, whereas the predictions for WT-24 do so for a less constrained area.

\section{C.2.1 Predictions for Borehole SD-6}

Table C- 1 and Figure C- 1 show the predicted stratigraphy for borehole SD-6 and the actual results. Of 26 predicted contact depths, 25 (96 percent) were less than the estimated uncertainties for units Tpy, Tptrvl, and Tptpv3 as presented in Table 6-3 for the cross-correlation method. The prediction error for unit Tcp, the Prow Pass Tuff, is equal to the estimated uncertainty. Because this unit is deeper than unit Tptpv3, for which uncertainty was estimated, the uncertainty window for this unit is likely greater than -76 to +80 feet $(-23.2$ to +24.3 meters) due to increased natural variability and fewer available data with depth. The nearest borehole to SD-6 is approximately 2700 feet (823 meters) away; a total of 9 boreholes are within 5000 feet (1524 meters) of SD-6. For model validation purposes, however, the uncertainty window for unit Tptpv3 was used for unit Tcp. The source of the prediction error was errors in thickness predictions for two units above Tcp. As listed in Table C-1, model unit Tptpv1 was 22 feet (7 meters) thinner than predicted and unit $\mathrm{Ta}+\mathrm{Tacbt}$ was 24 feet (8 meters) thinner than 
predicted. These two thickness errors caused the subsequent elevation prediction errors; in other words, a thickness error in one unit results in cumulative errors in the units below (because the model is built downward from the base of the Tiva Canyon Tuff). In this case, the thickness predictions were inaccurate, causing the elevation prediction to be inaccurate, and the source of the errors must be determined. Because the magnitudes of several prediction errors were a significant fraction of the uncertainty, the causes of these errors are evaluated, beginning with the shallowest unit.

Table C-1. Predicted Versus Actual Contacts (Tops) in Borehole SD-6

\begin{tabular}{|c|c|c|c|c|c|c|}
\hline Unit & $\begin{array}{l}\text { Actual } \\
\text { Depth } \\
\text { (feet) }^{\text {a }}\end{array}$ & $\begin{array}{c}\text { GFM3.0 } \\
\text { Predicted } \\
\text { Depth } \\
\text { (feet) }^{\text {b }} \\
\end{array}$ & $\begin{array}{c}\text { Difference } \\
\text { in Depth } \\
\text { (Predicted } \\
\text { Minus } \\
\text { Actual) } \\
\text { (feet) } \\
\end{array}$ & $\begin{array}{c}\text { Actual } \\
\text { Unit } \\
\text { Thickness } \\
\text { (feet) }\end{array}$ & $\begin{array}{c}\text { GFM3.0 } \\
\text { Predicted } \\
\text { Thickness } \\
\text { (feet) }^{\mathrm{b}}\end{array}$ & $\begin{array}{c}\text { Difference } \\
\text { in Thickness } \\
\text { (Predicted } \\
\text { Minus } \\
\text { Actual) } \\
\text { (feet) }\end{array}$ \\
\hline Tpcpv3 & 415 & 414 & -1 & 0 & 0 & 0 \\
\hline Tpcpv2 & 415 & 414 & -1 & 14 & 15 & 1 \\
\hline Tpcpv1 & 429 & 429 & 0 & 13 & 8 & -5 \\
\hline Tpbt4 & 442 & 437 & -5 & 3 & 7 & 4 \\
\hline Tpy & 445 & 444 & -1 & 21 & 13 & -8 \\
\hline Tpbt3 & 466 & 457 & -9 & 14 & 22 & 8 \\
\hline Tpp & 480 & 479 & -1 & 9 & 11 & 2 \\
\hline Tpbt2 & 489 & 490 & 1 & 29 & 33 & 4 \\
\hline Tptrv3 & 517 & 523 & 6 & 3 & 13 & 10 \\
\hline Tptrv2 & 521 & 536 & 15 & 5 & 4 & -1 \\
\hline Tptrv1 & 526 & 540 & 14 & 2 & 3 & 1 \\
\hline Tptrn & 527 & 543 & 16 & 105 & 98 & -7 \\
\hline Tptrl & 632 & 641 & 9 & 14 & 44 & 30 \\
\hline Tptf & 646 & 685 & 39 & 0 & 0 & 0 \\
\hline Tptpul & 646 & 685 & 39 & 134 & 96 & -38 \\
\hline RHHtop & 780 & 781 & 1 & 73 & 106 & 33 \\
\hline Tptpmn & 853 & 887 & 34 & 142 & 118 & -24 \\
\hline Tptpll & 995 & 1,005 & 10 & 310 & 308 & -2 \\
\hline Tptpln & 1,305 & 1,313 & 8 & 151 & 164 & 13 \\
\hline Tptpv3 & 1,456 & 1,477 & 21 & 47 & 49 & 2 \\
\hline Tptpv2 & 1,503 & 1,526 & 23 & 17 & 26 & 9 \\
\hline Tptpv1 & 1,520 & 1,552 & 32 & 32 & 54 & 22 \\
\hline Tpbt1 & 1,552 & 1,606 & 54 & 9 & 11 & 2 \\
\hline Ta+Tacbt & 1,561 & 1,617 & 56 & 154 & 178 & 24 \\
\hline Tср & 1,715 & 1,795 & 80 & 388 & 379 & -9 \\
\hline $\mathrm{Tcb}$ & 2,103 & 2,174 & 71 & \multicolumn{3}{|c|}{ Not fully penetrated } \\
\hline
\end{tabular}

a DTN: SNF40060298001.001 [DIRS 107372].

b DTN: MO9804MWDGFM03.001 [DIRS 109050]. 
Cumulative error in predicted elevations was introduced by an error in the predicted thickness of unit Tptrl, which was 30 feet (9.1 meters) thinner than predicted. This error propagated to the units below, and other predicted thickness errors (right-side column of Table C-1) contributed to cumulative elevation errors. Because the model was constructed using thicknesses, the most accurate evaluation of the predictions is an assessment of the predicted thickness errors, 18 of which are 10 feet (3 meters) or less. The errors for units Tptrl, Tptpul, RHHtop, Tptpmn, and Tptpv1 were both positive and negative (too thick and too thin), as would be expected if the units formed in response to multiple postdepositional processes within the larger depositional unit (the Topopah Spring Tuff) as has been proposed (Buesch et al. 1996 [DIRS 100106], pp. 9 to 12). For each of these units, the geologic variability is therefore expected to be high relative to the available data distribution, similar to the upper surface in Figure 6-26. It is significant to note that the total Topopah Spring Tuff thickness prediction for SD-6 was within 5 percent of actual (1,035 feet (315 meters) actual versus 1,083 feet (330 meters) predicted), suggesting that the observed thickness variations of the subunits are indeed largely a function of depositional and postdepositional processes operating within the formation (i.e., one type of geologic variability).

As an example of the variability of units internal to the Topopah Spring Tuff, the thickness of Tptpv1 ranges from 71 feet (22 meters) at SD-12, which is 3,000 feet (914 meters) east of SD-6, to 28 feet (9 meters) at UZ-6, which is 2,800 feet (853 meters) to the south (data from DTN: MO0004QGFMPICK.000 [DIRS 152554]). The thicknesses of the other units are similarly variable. Therefore, the cause of the error in predicted thicknesses (and resultant elevation errors) for Tptpv1 and the other Topopah subunits in SD-6 is ascribed to geologic variability that could not have been mitigated by modification of the modeling methods.

Evaluation of the thickness of unit Ta + Tacbt produced similar results. The Calico Hills Formation was 24 feet (7.3 meters) thinner than expected (Figure 6-19), which indicates that geologic variability was the cause of the prediction error, not modeling methodology. Unit Ta ranges from 37 feet (11 meters) to 202 feet (62 meters) thick in the boreholes nearest SD-6.

The cumulative elevation error caused by the thickness predictions for Tptpv1 and Ta also affected the elevation prediction at the top of the Prow Pass Tuff, which was 80 feet (24.4 meters) higher than predicted. The Prow Pass Tuff was only 9 feet ( 2.7 meters) thicker than expected, suggesting that the borehole may be located on a structural high that formed after deposition of the Prow Pass Tuff but before deposition of the Calico Hills Formation. Again, this is an example of geologic variability that could not have been minimized by modifications of the modeling methodology because it could not be predicted on the basis of existing data. The Prow Pass Tuff thickness map is illustrated in Figure 6-20. The model shows no effect of possible pre-Calico structure on the RHH (Figure 6-18). 


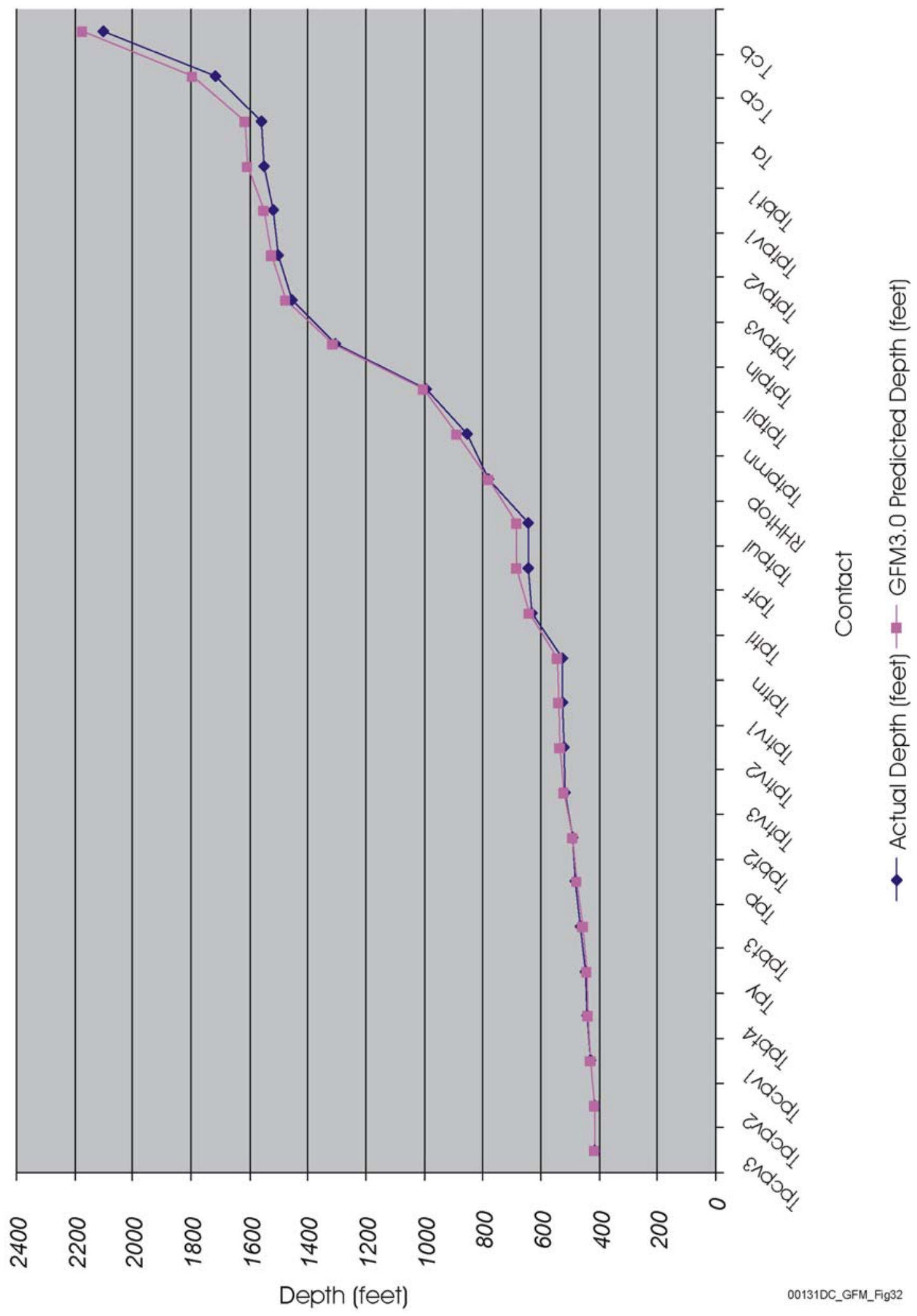

Source: Table C-1.

Figure C-1. Comparison of Predicted Versus Actual Contact Depths in Borehole SD-6 
In summary, the model meets all validation criteria for the SD-6 predictions; the model is validated with an acknowledgement that significant geologic variability exists in the vicinity of SD-6. Where prediction errors are greater than the estimated uncertainty, the causes are attributed to geologic variability and the cumulative error propagation associated with model contact elevation estimates. In view of the high-observed variability of these units, the prediction errors could not have been minimized by reasonable modifications to modeling methodology. Because it is relatively well constrained by surrounding boreholes, borehole SD-6 illustrates the predictive capabilities of the geologic framework model and the effects of geologic variability on model predictions in a constrained area.

\section{C.2.2 Predictions for Borehole WT-24}

Because borehole WT-24 was located on the fringes of the area constrained by boreholes when it was drilled, it provides an assessment of uncertainty for the geologic framework model in a less constrained area. In addition, WT-24 is located in an area that is more stratigraphically and structurally complex than borehole SD-6, so the predictions at WT-24 are expected to be less accurate (that is, the uncertainty is greater due to geologic complexity and lack of nearby subsurface data). The nearest borehole to WT-24 is approximately 3,200 feet (975 meters) away (borehole G-2; Figure 6-2) and no others are within 5,000 feet (1,500 meters). Even though prediction error is expected to be greater, for evaluation purposes the predictions were compared to the uncertainty for constrained areas discussed in Section 6.6.3.

Table C-2 and Figure C-2 show the predicted stratigraphy for borehole WT-24 and the actual results. Twenty-three of 24 elevation prediction errors (96 percent) were less than the estimated uncertainty given in Table 6-3 for the cross-correlation method for units Tpy, Tptrvl, and Tptpv3, and the model is considered valid; however, it is readily apparent from Table C-2 that significant prediction errors exist, and the causes must be understood.

Table C-2. Predicted Versus Actual Contacts (Tops) in Borehole WT-24

\begin{tabular}{|c|c|c|c|c|c|c|}
\hline Unit & \begin{tabular}{|l|} 
Actual \\
Depth \\
(feet) $^{\mathrm{a}}$ \\
\end{tabular} & \begin{tabular}{|c|} 
GFM3.0 \\
$\begin{array}{c}\text { Predicted } \\
\text { Depth } \\
\text { (feet) }\end{array}$ \\
\end{tabular} & $\begin{array}{c}\text { Difference } \\
\text { in Depth } \\
\text { (Predicted } \\
\text { Minus } \\
\text { Actual) } \\
\text { (feet) } \\
\end{array}$ & $\begin{array}{c}\text { Actual } \\
\text { Thickness } \\
\text { (feet) }\end{array}$ & $\begin{array}{c}\text { GFM3.0 } \\
\text { Predicted } \\
\text { Thickness } \\
{\text { (feet })^{\mathbf{b}}}\end{array}$ & $\begin{array}{c}\begin{array}{c}\text { Difference } \\
\text { in Thickness } \\
\text { (feet) }\end{array} \\
\end{array}$ \\
\hline Tpcpv3 & 215 & 241 & 26 & 0 & 0 & 0 \\
\hline Tpcpv2 & 215 & 241 & 26 & 40 & 5 & -35 \\
\hline Tpcpv1 & 255 & 246 & -9 & 24 & 17 & -7 \\
\hline Tpbt4 & 279 & 263 & -16 & 3 & 7 & 4 \\
\hline Tpy & 282 & 270 & -12 & 83 & 88 & 6 \\
\hline Tpbt3 & 365 & 358 & -7 & 110 & 129 & 20 \\
\hline Tpp & 474 & 487 & 13 & 185 & 212 & 27 \\
\hline Tpbt2 & 659 & 699 & 40 & 36 & 32 & -4 \\
\hline Tptrv3 & 695 & 731 & 36 & 0 & 7 & 7 \\
\hline Tptrv2 & 695 & 738 & 43 & 2 & 4 & 2 \\
\hline Tptrv1 & 697 & 742 & 45 & 0 & 2 & 2 \\
\hline Tptrn & 697 & 744 & 47 & 164 & 166 & 2 \\
\hline Tptrl & 861 & 910 & 49 & 24 & 5 & -19 \\
\hline
\end{tabular}


Table C-2. Predicted Versus Actual Contacts (Tops) in Borehole WT-24 (Continued)

\begin{tabular}{|l|l|l|l|l|l|l|}
\hline \multicolumn{1}{|c|}{ Unit } & \multicolumn{1}{|c|}{$\begin{array}{c}\text { Actual } \\
\text { Depth } \\
\text { ffeet) }^{\mathbf{a}}\end{array}$} & $\begin{array}{c}\text { Gredicted } \\
\text { Depth } \\
\text { (feet) }\end{array}$ & $\begin{array}{c}\text { Difference } \\
\text { in Depth } \\
\text { (Predicted } \\
\text { Minus } \\
\text { Actual) } \\
\text { (feet) }\end{array}$ & $\begin{array}{c}\text { Actual } \\
\text { Thickness } \\
\text { (feet) }\end{array}$ & $\begin{array}{c}\text { GFM3.0 } \\
\text { Predicted } \\
\text { Thickness } \\
\text { (feet) }\end{array}$ & $\begin{array}{c}\text { Difference } \\
\text { in Thickness } \\
\text { (feet) }\end{array}$ \\
\hline Tptf & 885 & 915 & 31 & 53 & 0 & -53 \\
\hline Tptpul & 937 & 915 & -22 & 181 & 28 & -153 \\
\hline RHHtop & 1,118 & 943 & -175 & 34 & 213 & 179 \\
\hline Tptpmn & 1,152 & 1,156 & 4 & 110 & 51 & -59 \\
\hline Tptpll & 1,262 & 1,207 & -55 & 363 & 398 & 35 \\
\hline Tptpln & 1,625 & 1,605 & -20 & 55 & 0 & -55 \\
\hline Tptpv3 & 1,680 & 1,605 & -75 & 41 & 44 & 3 \\
\hline Tptpv2 & 1,721 & 1,649 & -72 & 9 & 20 & 11 \\
\hline Tptpv1 & 1,730 & 1,669 & -61 & 22 & 26 & 4 \\
\hline Tptbt1 & 1,752 & 1,695 & -57 & 17 & 40 & 23 \\
\hline Ta & 1,769 & 1,735 & -34 & Not fully penetrated & \\
\hline
\end{tabular}

a DTN: SNF40060198001.001 [DIRS 107239].

${ }^{b}$ DTN: MO9804MWDGFM03.001 [DIRS 109050].

The prediction error for unit RHHtop was greater than the estimated uncertainties for unit Tptrvl above and unit Tptpv3 below, and was caused by an error in the predicted thickness for unit Tptpul. The mismatch for most units is the result of cumulative errors. The thicknesses of 3 model units (Tpcpv2, Tpbt3, and Tpp) caused errors in the depth predictions for 16 units below, and additional thickness variability in the internal Topopah Spring Tuff units (Tptrl through Tptpln) caused additional errors. The causes of error in the isochores (thickness predictions) are discussed below, beginning with the shallowest unit.

As illustrated in Figures 6-13 and 6-14, the PTn units, including the Pah Canyon Tuff (model unit Tpp), thicken rapidly toward the north in the area of WT-24. Without the constraint of WT-24, few data are available to constrain the thicknesses of these units in this area, and the thicknesses are not predictable to a high degree of accuracy. No reasonable conceptual model or known interpolation method could have been used to make an accurate prediction of Tpbt3 and Tpp thicknesses. In this context, the thickness prediction errors of only 20 feet (6 meters) and 27 feet (8 meters) are acceptable. 


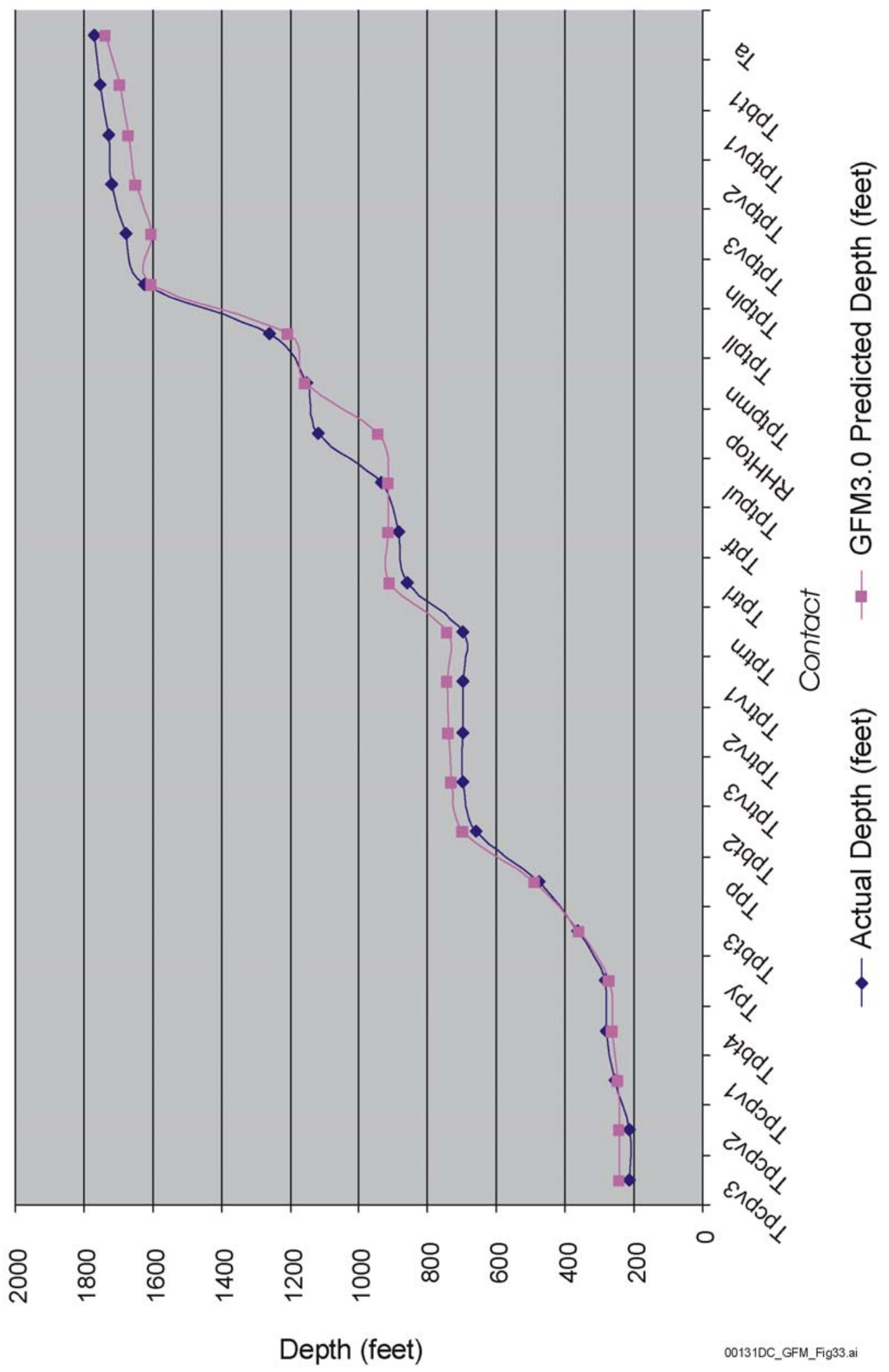

Source: Table C-2.

Figure C-2. Comparison of Predicted Versus Actual Contact Depths in Borehole WT-24 
As discussed for the borehole SD-6 predictions, units internal to the Topopah Spring Tuff (Tptf, Tptpul, RHHtop, Tptpmn, and Tptpln) and similar units in the Tiva Canyon Tuff (Tpcpv2) were formed by multiple depositional and postdepositional processes (Buesch et al. 1996 [DIRS 100106], pp. 9 to 12), which resulted in variable thicknesses that are not predictable to a high degree of accuracy based on the available data. This conclusion is supported by the observation that the predicted thicknesses for the units within the Topopah Spring Tuff and Tiva Canyon Tuff in WT-24 are both positive and negative (too thick and too thin) with a mean difference in thickness value of only -9 feet (-2.7 meters), suggesting that variability is internal to the larger formation. The model isochore map for the RHH (Figure 6-18), which includes units RHHtop, Tptpmn, Tptpll, and Tptpln shows that this interval changes thickness rapidly across the area of WT-24. The unit ranges in thickness from 502 feet (153 meters) to 760 feet (232 meters) in the nearest boreholes, and is constrained by geologic map data (DTN: GS980608314221.002 [DIRS 107024]) to pinch out at the northeast corner of the modeled area. In view of the steep thickness gradient and the variable nature of the subunits, it is concluded that the thickness prediction errors for these units and the elevation prediction for unit RHHtop could not have been minimized by reasonable modifications to modeling methodology.

It is important to note that the Topopah Spring Tuff is 93 feet (28 meters) thicker than predicted, and that most of the difference is contributed by the 55 feet ( 17 meters) of Tptpln and 53 feet (16 meters) of Tptf, which were both predicted to be absent in the borehole based on existing data. Without these units, the predicted thickness of the formation was close to actual $(1,057$ - $108=949$ feet (289 meters)) versus 964 feet (294 meters) predicted-a difference of only 15 feet (4.6 meters), or within about 1.6 percent-suggesting that the overall modeling methodology is appropriate for the geology of the modeled area. The thickness variabilities observed were most likely caused by singular combinations of depositional and postdepositional processes that affected individual rock layers (i.e., variability of the natural system) within the formation.

The bottom of the Calico Hills Formation (Ta) was not penetrated in borehole WT-24, even though drilling progressed to more than 300 feet (91 meters) below the predicted depth. No subsurface control exists for Ta thickness east of borehole G-2, and the bottom of Ta is not exposed anywhere to the northeast, so its maximum thickness is unknown. The poor subsurface constraints in the northern part of the modeled area do not permit definition of the maximum expected uncertainty for the thickness of the Calico Hills Formation in this area.

In summary, despite some large prediction errors, the model predictions based on existing data for this poorly constrained region were reasonable, and the model meets all validation criteria for the WT-24 predictions. Because the borehole is located in a less constrained area on the flank of a caldera complex, the large prediction errors are not surprising. For the one prediction error that was greater than the estimated uncertainty for the underlying unit Tptpv3, the cause is ascribed to geologic variability that was not well constrained by available data. For this unit, prediction errors could not have been lessened by reasonable modifications to modeling methodology. Because it is not well constrained by surrounding boreholes, borehole WT-24 illustrates the magnitude of geologic variability expected to be found in less constrained areas, especially in the northern part of the modeled area. 


\section{C.2.3 Predictions for Enhanced Characterization of the Repository Block Cross-Drift}

Table C-3 shows predicted and actual locations of stratigraphic contacts for the ECRB Cross-Drift. The vertical differences between predicted and actual stratigraphic contacts accounted for tunnel alignment and stratal tilt. All three prediction errors were less than the estimated uncertainty for these horizons at this location for the subjacent unit Tptpv3 (shown in Table 6-3), and the model is considered valid.

Table C-3. Locations of Predicted and Actual Stratigraphic Contacts for the ECRB Cross-Drift

\begin{tabular}{|c|c|c|c|}
\hline Contact & Predicted Station $^{\mathbf{a}}$ & Actual Station $^{\text {b }}$ & Vertical Difference \\
\hline Tptpmn (top) & $10+78$ meters & 10+15 meters & 23 feet ( 7 meters) \\
\hline Tptpll (top) & $15+21$ meters & $14+44$ meters & 26 feet ( 8 meters) \\
\hline Tptpln (top) & 24+10 meters & $23+26$ meters & 75.5 feet ( 23 meters) \\
\hline
\end{tabular}

In the west end of the drift, faults with vertical displacements of 10 feet to greater than 16 feet (3 meters to greater than 5 meters) (not included in GFM2000) appear to have caused most of the difference between predicted and actual elevations for the Tptpln contact. Although the faults in the west end of the tunnel were not evident at the surface, they were anticipated in concept because it was known beforehand that structural deformation increases in proximity to the Solitario Canyon fault and that small faults could be present there. In the ECRB Cross-Drift, the Tptpln contact is within 650 feet (200 meters) horizontally of the Solitario Canyon fault. Because it is so close, the prediction error for the Tptpln contact can be explained in terms of geologic variability and could not have been reasonably expected to be minimized by modifications to modeling methodology.

The predictions for the cross-block drift suggest that the geologic framework model will provide adequate predictions of subsurface stratigraphy for future repository tunneling, but that geologic variability is high on the western edge near the Solitario Canyon fault, and small faults like those in the cross-block drift could be encountered at other locations. In locations where uncertainty must be reduced for repository design or tunneling operations, the model validation results suggest that new boreholes would be required.

\section{C.3 MATCH TO AVAILABLE DATA}

Borehole contacts selected to provide a range of depths and because they are major lithologic horizons of interest to geologic framework model users were compared to the results of GFM2000, and the differences are tabulated in Table C-4. Existing EARTHVISION utilities were used to calculate the intersections between the borehole data and selected horizon grids from the model. Adequacy of the results was previously determined by the requirements of the geologic framework model users and is plus or minus 15 feet (5 meters) (CRWMS M\&O 2000 [DIRS 158094], Attachment II). As the results show, all contacts were matched within the uncertainty window. The large values at the C-holes complex were caused by the close spacing of these holes to one another relative to the grid node spacing (see Section 6.3.4). Other values greater than 2 feet ( 0.6 meters) are caused by proximity to faults or steep slopes. Borehole UZ-7a was not used in this analysis because it is located in the Ghost Dance fault zone, where 
multiple fault strands preclude an accurate match between the geologic framework model and all data from the borehole. UZN holes were not used because they provide few contacts.

Based on the match between available data and the geologic framework model results, the model is considered to be valid.

Table C-4. Match of GFM2000 Output Model Grids to Input Unit Contacts in Major Boreholes

\begin{tabular}{|c|c|c|c|c|c|c|c|c|c|}
\hline Borehole & Tpcpv2 & Tpbt4 & Tptrv3 & Tptpmn & Tptpv3 & $\mathrm{Ta}$ & Tcp & Tcb & Tct \\
\hline$a \# 1$ & -2 & -2 & -2 & -1 & 0 & 1 & 2 & ND & ND \\
\hline $\mathrm{b} \# 1$ & 2 & 2 & 2 & 2 & 1 & 1 & 1 & 1 & 1 \\
\hline $\mathrm{c \# 1}$ & -3 & 0 & -4 & -4 & 2 & 11 & 13 & 4 & ND \\
\hline $\mathrm{c \# 2}$ & -1 & 0 & -1 & -1 & 0 & 0 & -2 & 0 & ND \\
\hline $\mathrm{C \# 3}$ & 3 & 0 & 3 & 11 & 5 & -2 & -12 & -5 & ND \\
\hline G-1 & ND & ND & -1 & -1 & -1 & -1 & -2 & -3 & -3 \\
\hline G-2 & 0 & 0 & 0 & 0 & 0 & 0 & 0 & 0 & 0 \\
\hline G-3 & 0 & 0 & 0 & 0 & 0 & 0 & 0 & 0 & 0 \\
\hline G-4 & 0 & 0 & 0 & 0 & 0 & 0 & 0 & 0 & ND \\
\hline $\mathrm{H}-1$ & 0 & 0 & 0 & 0 & 0 & 0 & -1 & -1 & 0 \\
\hline $\mathrm{H}-3$ & -1 & 0 & -1 & -1 & -1 & -1 & -1 & -1 & -1 \\
\hline $\mathrm{H}-4$ & -1 & 0 & -1 & -1 & -1 & -1 & -1 & -1 & -1 \\
\hline $\mathrm{H}-5$ & 0 & 0 & 0 & 0 & 0 & 0 & 0 & 0 & 0 \\
\hline $\mathrm{H}-6$ & 0 & 0 & 0 & -1 & -1 & -1 & -1 & -1 & -1 \\
\hline ONC\#1 & -1 & -1 & -1 & 2 & ND & 4 & ND & ND & ND \\
\hline p\#1 & ND & ND & 3 & 3 & 3 & 2 & 3 & 3 & 3 \\
\hline SD-12 & 0 & 0 & 0 & 0 & 0 & 0 & 0 & ND & ND \\
\hline SD-6 & 0 & 0 & 0 & 0 & 0 & 0 & 0 & ND & ND \\
\hline SD-7 & 0 & 0 & 0 & 0 & 0 & 0 & 0 & 0 & ND \\
\hline SD-9 & 0 & 0 & 1 & 0 & 0 & 0 & ND & ND & ND \\
\hline UZ-14 & ND & ND & -2 & -2 & -2 & -2 & -1 & ND & ND \\
\hline UZ\#16 & 1 & 1 & 0 & 0 & 0 & 0 & ND & ND & ND \\
\hline UZ-1 & ND & ND & 1 & 2 & ND & ND & ND & ND & ND \\
\hline WT-10 & 0 & 0 & 0 & 0 & ND & ND & ND & ND & ND \\
\hline WT-11 & 0 & 0 & 0 & 0 & 0 & 0 & ND & ND & ND \\
\hline WT\#12 & 0 & 0 & 0 & 1 & 1 & 1 & ND & ND & ND \\
\hline WT\#13 & 1 & 1 & 0 & 2 & ND & ND & ND & ND & ND \\
\hline WT\#14 & ND & ND & ND & 0 & 0 & 0 & ND & ND & ND \\
\hline WT\#15 & -7 & 0 & 0 & 0 & ND & ND & ND & ND & ND \\
\hline WT\#16 & 0 & 0 & 0 & 0 & 0 & 0 & ND & ND & ND \\
\hline WT\#17 & 0 & 0 & 0 & 0 & 0 & 9 & ND & ND & ND \\
\hline WT\#18 & 0 & 0 & 0 & 0 & 0 & 0 & ND & ND & ND \\
\hline WT-1 & 0 & 0 & -1 & -1 & -1 & -1 & ND & ND & ND \\
\hline WT-24 & 0 & 0 & 0 & 0 & 0 & 0 & ND & ND & ND \\
\hline WT-2 & -1 & 0 & -1 & 1 & 0 & 0 & ND & ND & ND \\
\hline
\end{tabular}


Table C-4. Match of GFM2000 Output Model Grids to Input Unit Contacts in Major Boreholes (Continued)

\begin{tabular}{|l|l|l|l|l|l|l|l|l|l|}
\hline Borehole & Tpcpv2 & Tpbt4 & \multicolumn{1}{|c|}{ Tptrv3 } & \multicolumn{1}{|c|}{ Tptpmn } & \multicolumn{1}{|c|}{ Tptpv3 } & Ta & Tcp & Tcb & Tct \\
\hline WT\#3 & ND & ND & ND & ND & 0 & -4 & -4 & ND & ND \\
\hline WT\#4 & 1 & 1 & 1 & 1 & 1 & 1 & ND & ND & ND \\
\hline WT\#6 & ND & ND & ND & 1 & 1 & 1 & ND & ND & ND \\
\hline WT-7 & -1 & -1 & -1 & -1 & -1 & -1 & ND & ND & ND \\
\hline
\end{tabular}

$\mathrm{ND}=$ no data.

NOTES: Actual minus predicted elevations in feet.

Large values for C-holes complex are caused by close hole spacing (see Section 6.3.4).

\section{C.4 VALIDATION RESULTS}

The predictions of subsurface geology made from the geologic framework model (GFM3.0) for boreholes SD-6 and WT-24 and the ECRB Cross-Drift, and the match of the GFM2000 model results to available borehole data were used to validate the geologic framework model. While two prediction errors were greater than the estimated uncertainty, no prediction errors were found that were caused by a deficiency in the modeling methodology. The model was also shown to provide an adequate representation of selected data within a window of 15 feet (5 meters). Therefore, the results provide confidence that the geologic framework model satisfies all validation criteria. Nevertheless, the magnitudes of some prediction errors were a significant fraction of the estimated uncertainty, but in each case the errors were caused by geologic variability and not by incorrect modeling methodology. These results indicate that the geologic framework model should be used with caution in applications that require errors less than the estimated uncertainty. The results of the validation are considered to demonstrate that the geologic framework model provides an adequate representation of the geology of Yucca Mountain.

In addition, NRC staff performed an independent evaluation of GFM3.1 to 1) understand the main differences between model versions, 2) test and evaluate the adequacy of the geologic framework model for the U.S. Department of Energy's purposes of representing site stratigraphy and faults as a framework for its integrated site model, and 3) consider replacing the NRC's Geologic Site Model with an adapted version of the geologic framework model as NRC's three-dimensional model of the site for independent NRC analyses (NRC 1999 [DIRS 135621], p. E-1). The staff concluded that 1) GFM3.1 was an improved representation of the geologic features of the site, 2) GFM3.1 is an interpretation of the geologic framework of Yucca Mountain that will continue to evolve as new data or improved or alternative interpretations are developed, and 3) the NRC will adapt a version of GFM3.1 for NRC's use in conducting three-dimensional analyses of the Yucca Mountain Site, including reviews of subsequent geologic framework model versions (NRC 1999 [DIRS 135621], p. E-3). The staff further concluded that the level of detail and accuracy of the geologic framework model are adequate for the planned scope of the integrated site model and users of the geologic framework model, the representation of faults is adequate for intended use (NRC 1999 [DIRS 135621], p. E-59), and the representation of stratigraphy is adequate for intended use (NRC 1999 [DIRS 135621], pp. E-20 and E-21). 


\section{INTENTIONALLY LEFT BLANK}


APPENDIX D

INDEPENDENT TECHNICAL ASSESSMENT, YUCCA MOUNTAIN PROJECT, GEOLOGICAL FRAMEWORK MODEL: GFM2000 MAY 17-28, 2004 
MOL . 20040603.0242

Independent Technical Assessment

Yucca Mountain Project, Geologic Framework Model: GFM2000

May 17-28, 2004

Paul L. White PaulfH hs 28 -MAY-2004
Dynamic Graphics, Inc.

\section{Background}

I currently hold the title of Manager, EarthVision Solution Projects, for Dynamic Graphics, Inc., Alameda, CA. In this capacity I manage and direct Dynamic Graphics' services to clients in the application of EarthVision software using client data and specifications on oil and gas, mining and environmental projects. In addition to managing these services, I also work as a staff member, performing the tasks of using EarthVision on these types of projects.

I have more than 20 (twenty) years of experience in the analysis, mapping, and modeling of geoscientific information in support of the exploration and exploitation of hydrocarbon resources, 3D geologic modeling, and geoscientific research projects. I have been using the EarthVision software product since its inception in 1991. I am expert in the application of EarthVision to a wide range of earth science problems.

\section{Training}

I have completed sufficient training with BSC, and am familiar with the Yucca Mountain Project QA procedures as they relate to the completion of this Independent Technical Assessment.

\section{Scope of Work}

This is an Independent Technical Assessment (ITA) of the Geologic Framework Model DTN: MO0012MWDGFM02.002 [153777] as documented in Geologic Framework Model (GFM2000) (MDL-NBS-GS-000002 Rev 01 [168029]), as required by Section 5.3 of AP-SIII.10Q Rev 02 ICN 4, and planned in accordance with AP-2.27Q, Rev 01, ICN03, Section 2.2, and TWPNPB-GS-000003 REV 05, Section 2.2.1.

\section{General Activities}

For this ITA, I examined each component of the model, each procedure of the component modeling process and the final model assembly in order to verify that the EarthVision software was used and applied in accordance with best and standard practice. 


\section{Specific Activities}

1. I read the Scientific Notebook, SN-M\&O-SCI-028-V1, by Robert W.Clayton, Principal Modeler, CRWMS M\&O, Applied Research and Testing Programs, Site Integration Department, URS Corp. I did this to examine, evaluate, and understand the application and use of EarthVision software and modeling methodology for the Yucca Mountain geologic model, GFM2000, as described by the model author.

2. I read the Analysis Model Report (AMR), MDL-NBS-GS-000002 Rev 01. Technical Contact: Tim Vogt, Natural Systems, 702-295-5754, and Clinton Lum, Natural Systems, 702-295-5745. I did this to examine, evaluate and understand application and use of EarthVision software and modeling methodology for the Yucca Mountain geologic model, GFM2000, as well as the use of EarthVision software in uncertainty estimation for this model.

3. There are 43 geologic faults represented in the model. For each fault, I did the following:

- Examined the geologic map fault trace data files

- Examined the EarthVision scripts and methods used to project the fault surface contact data at depth

- Examined the fault surface contact data projected at depth

- Examined fault throw bounding polygon files

- Examined EarthVision fault gridding method and accuracy

I found, for example, that not all the faults were modeled with the same surface fitting algorithm. While this may seem unusual at first consideration, it is actually a best and standard practice to use the appropriate gridding algorithm which generates the best and most accurate fit for modeling a particular fault. The modeler would have been remiss and not used the EarthVision software in its full capacity had he not used different gridding methods for 4 of the 43 faults in the model.

4. With reference to the 43 geologic faults represented in the model and their fault throw bounding polygons, I thoroughly examined the "fault tree," or fault hierarchy, which defines the fault-to-fault relationships and forms the framework for fault blocks which subsequently contain the rock units.

I found that the faults were organized in such a manner as to accurately represent their truncation and age relationships, and that no faults were prematurely or incorrectly truncated by other intersecting faults. 
5. There are 50 rock units represented in the model. For each rock unit I did the following:

- Examined the input borehole data files

- Examined the input measured section data files

- Examined the geologic map stratigraphic contact data files

- Examined the surface elevation data (digital terrain model) file

- Examined the EarthVision gridding parameters used in calculating the reference horizons

- Examined the EarthVision gridding parameters used in calculating the intermediate isochores

- Examined all aspects of data manipulation done in EarthVision to control stratigraphic throw across faults and undesired surface flexures

The rock units, or stratigraphic layers, were modeled with the EarthVision horizon gridding algorithm. This model was constructed with the use of several reference horizons, together with isochores of intermediate horizons, and is a best and standard practice application of the EarthVision geologic structure builder.

The integration of borehole, cross section, geologic surface contact and digital elevation data, along with the use of the EarthVision isochore gridding algorithm to maintain rock layer thickness consistency throughout the model area is the industry standard method of calculating a model of this type with the EarthVision software.

6. For the final model, a three dimensional representation of geology and structure, I examined in detail the model assembly procedure of the 43 faults and 50 horizons to ensure compliance with industry standard practices and application of the EarthVision software.

\section{Conclusions}

The model was planned and built using best and standard practices in the application of the EarthVision 3D modeling software. Every aspect of the model building exercise was performed using EarthVision in a reasonable, credible, defensible, and repeatable manner. The output product, a static 3D model representing the geologic framework of the specified area, is adequate for its intended use and is accurate for its intended use and parameter uncertainty. The model is appropriate for its intended use on the Yucca Mountain Project, and there are no limits or restrictions on model use within stated and intended uses for the project. 


\section{INTENTIONALLY LEFT BLANK}

